UNIVERSITE DE LAUSANNE

FACULTE DES HAUTES ETUDES COMMERCIALES

\title{
STRUGGLES FOR MEANING AND STRUGGLES FOR CONTROL: THE DIFFUSION OF BANDWAGON TECHNOLOGY IN TWO INSTITUTIONAL ENVIRONMENTS
}

\author{
THÈSE \\ Présentée à la Faculté des HEC \\ de l'Université de Lausanne \\ par \\ Stéphane GUÉRARD \\ Bachelor Honours of Science in Psychology \\ from Université du Québec à Montréal \\ Master's Degree in Management Science \\ from HEC Montréal, Université de Montréal
}

Pour l'obtention du grade de

Docteur en Sciences Economiques mention « Management » 


\section{Unil}

UNIL | Université de Lausanne

HEC Lausanne

Le Doyen

Bâtiment Internef

$\mathrm{CH}-1015$ Lausanne

\section{M P R I M A T U R}

Sans se prononcer sur les opinions de l'auteur, le Conseil de la Faculté des hautes études commerciales de l'Université de Lausanne autorise l'impression de la thèse de Monsieur Stéphane GUÉRARD, titulaire d'un baccalauréat scientifique en psychologie de l'Université du Québec à Montréal et d'une maitrise ès sciences de la gestion de HEC Montréal, en vue de l'obtention du grade de docteur en Sciences économiques, mention « Management».

La thèse est intitulée:

\section{STRUGGLES FOR MEANING AND STRUGGLES FOR CONTROL: THE DIFFUSION OF BANDWAGON TECHNOLOGY IN TWO INSTITUTIONAL ENVIRONMENTS}

Lausanne, le 30 mars 2009

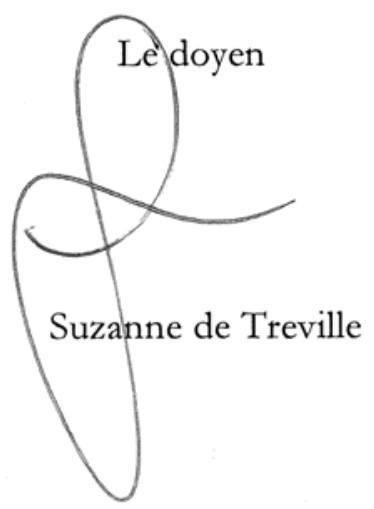



Jury Members

\author{
Alberto Holly \\ Full Professor \\ HEC Lausanne \\ Faculty of Business and Economics \\ University of Lausanne \\ Thesis Director \\ Ann Langley \\ Titular Professor \\ HEC Montréal \\ Affiliated to Université de Montréal \\ External Expert

\section{Jean-Philippe Bonardi} \\ Full Professor \\ HEC Lausanne \\ Faculty of Business and Economics \\ University of Lausanne \\ Internal Expert

\section{Guido Palazzo} \\ Full Professor \\ HEC Lausanne \\ Faculty of Business and Economics \\ University of Lausanne \\ Internal Expert
}


University of Lausanne

Faculty of Business and Economics

Doctorate in Management

I hereby certify that I have examined the doctoral thesis of

\section{Stéphane GUÉRARD}

and have found it to meet the requirements for a doctoral thesis.

All revisions that I or committee members

made during the doctoral colloquium

have been addressed to my entire satisfaction.

Signature: A. Hilly. Date: March 29,2009

Professor Alberto HOLLY

Thesis Director 
University of Lausanne

Faculty of Business and Economics

Doctorate in Management

I hereby certify that I have examined the doctoral thesis of

\section{Stéphane GUÉRARD}

and have found it to meet the requirements for a doctoral thesis.

All revisions that I or committee members

made during the doctoral colloquium

have been addressed to my entire satisfaction.

siganure: Ann hangley Date Le 23 mars 2009

Professor Ann LANGLEY

External member of the doctoral committee 
University of Lausanne

Faculty of Business and Economics

Doctorate in Management

I hereby certify that I have examined the doctoral thesis of

\section{Stéphane GUÉRARD}

and have found it to meet the requirements for a doctoral thesis.

All revisions that I or committee members

made during the doctoral colloquium

have been addressed to my entire satisfaction.

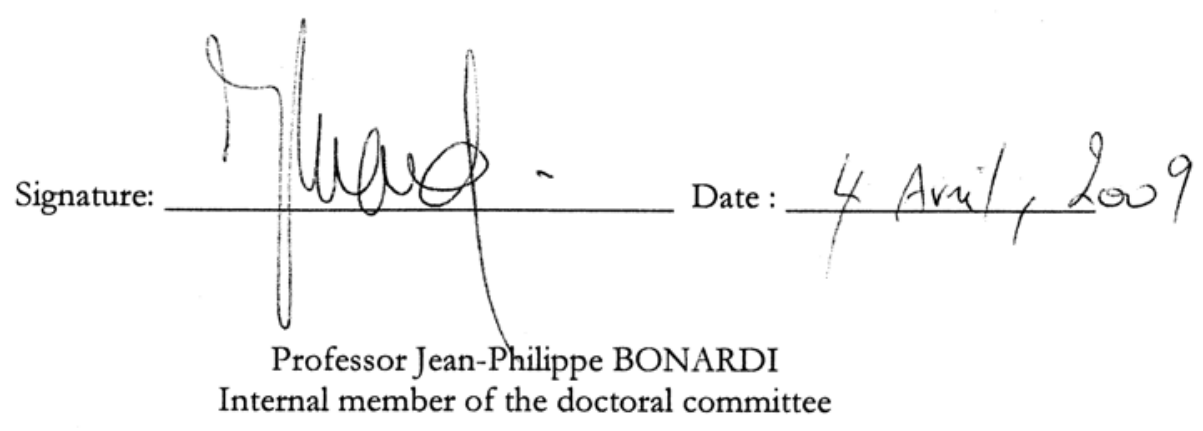


University of Lausanne

Faculty of Business and Economics

Doctorate in Management

I hereby certify that I have examined the doctoral thesis of

\section{Stéphane GUÉRARD}

and have found it to meet the requirements for a doctoral thesis.

All revisions that I or committee members

made during the doctoral colloquium

have been addressed to my entire satisfaction.

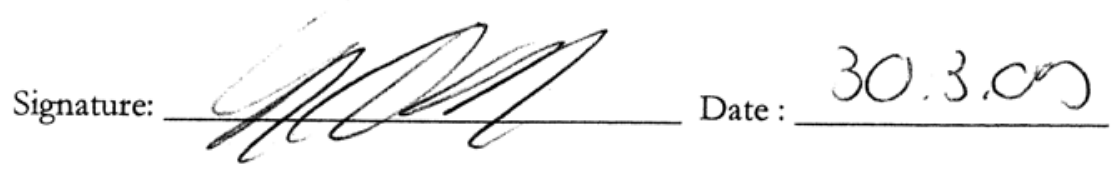

Professor Guido PALAZZO

Internal member of the doctoral committee 
The important thing is never to stop questioning

Albert Einstein 
CONTENTS

List of Figures and Tables $\quad$ xxv

Acronyms xxvii

Acknowledgments xxix

Abstract $\quad x x x i$

CHAPTER I INTRODUCTION 1

CHAPTER II THEORETICAL BACKGROUND 9

$\begin{array}{lll}2.1 & \text { Theoretical Perspectives } & 10\end{array}$

2.1.1 The Rational Perspectives 10

2.1.1.1 The Economic View - A Logic of Incentives 10

2.1.1.2 The Evidence-Based Medicine Movement - A Logic of Information13

2.1.2 The Relational-Network Perspective - A Logic of Interpersonal $\begin{array}{ll}\text { Communication } & 14\end{array}$

2.1.3 The Socio-political Perspective - A Logic of Power, Values \& Interests 17

2.1.4 The Neo-Institutional Perspective - A Logic of Legitimacy 20

2.2 Conceptual Framework 23

2.2.1 Innovation Attributes $\quad 25$

2.2.2 Adopters and Key Institutional Actors 26

2.2.3 Components of the institutional context 28

2.2.3.1 Governance Structures $\quad 29$

2.2.3.2 Institutional Logics 30

2.2.3.3 Theorization 32

CHAPTER III RESEARCH CONTEXT AND METHODOLOGY 35

3.1 Research Context 36

3.1.1 Two Institutional Environments 37

3.1.1.1 The Quebec Health Care System 38

3.1.1.2 The Swiss Health Care system 43 
3.2.1 Research Design and Data Collection 53

3.2.2 Data Analysis $\quad 54$

CHAPTER IV CASE STUDIES \& WITHIN CASES ANALYSIS

4.1 The PET Scanner as a Bandwagon Technology 59

4.2 The Diffusion of the PET Scanner in Quebec 63

4.2.1 Defining the PET scanner Technology 65

4.2.1.1 Region A: Developing the Machine THA2 - $1975 \quad 65$

4.2.1.2 Region B: Adopting a PET Scanner for Clinical Applications - 199865

4.2.1.3 Region C: Competing in Vain to Obtain a PET Scanner - 1988-2001

4.2.2 Analysis

4.2.3 The Health Technology Assessment Report and its Consequences: A Clash between two Factions $\quad 71$

4.2.3.1 Legitimizing the PET Scanner through a Report - October 200171

4.2.3.2 Reacting to the HTAA Report: Confronting two Institutional Logics73

4.2.4 Analysis 77

4.2.5 Local Strategic Actions in Region A 80

4.2.5.1 The First Deviant Adoption - January $2003 \quad 80$

4.2.5.2 Analysis 83

4.2.5.3 A Second Deviant Adoption - May 2004

4.2.5.4 Analysis 86

4.2.5.5 Private clinics adopt the PET-CT scanner - $2004 \& 2006 \quad 87$

4.2.5.6 Analysis 88

4.2.5.7 A Third Deviant Adoption - October 2004

4.2.5.8 Analysis 90

4.2.5.9 Disseminating PET Scanners in Teaching Hospitals 91

$\begin{array}{ll}\text { 4.2.5.10 Analysis } & 91\end{array}$

4.3 Within Case Analysis - Quebec $\quad 92$

4.3.1 Struggles for Control 92

4.3.2 Struggles for Meaning 93

4.3.3 Struggling for Control Through Institution Testing 94

4.4 The Diffusion of the PET Scanner in Switzerland 96

4.4.1 Developing the PET Scanner Technology 98

4.4.1.1 Canton V: Developing the Machine - $1971 \quad 98$

4.4.1.2 Canton U: Building a Quasi-Monopoly - 1993 / 1999

4.4.1.3 Analysis 100

4.4.2 The Challenge of Reimbursement: Colliding Logics at the Federal Level 101 4.4.2.1 Two logics for Reimbursement: Sensitivity versus Patient Management

$\begin{array}{lll}\text { 4.4.2.2 Analysis } & 105\end{array}$

4.4.2.3 Opening up Reimbursement 106

4.4.2.4 Analysis 112 
4.4.3 Local Strategic Actions to Obtain a PET Scanner 113

4.4.3.1 Canton T: A Fluid Adoption - May 2001

4.4.3.2 Analysis 114

4.4.3.3 Canton N: Setting up a Private Company - August 2001

4.4.3.4 Analysis 117

4.4.3.5 Canton D: Controversial Adoptions - November $2002 \quad 118$

4.4.3.6 Analysis 121

4.4.3.7 Canton R: Convincing Authorities for Adoption - September 2003122

4.4.3.8 Analysis 124

4.4.3.9 Canton V: Private Clinics Competing with Teaching Hospital THV125

4.4.3.10 Analysis 129

4.4.3.11 Canton G: A Tempting Opportunity - June 2004

4.4.3.12 Analysis 130

4.4.3.13 Canton U: Hindering Regional Competition 131

4.4.3.14 Analysis 131

4.4.3.15 Canton Z: Adopting a PET-CT Scanner - August 2005

4.4.3.16 Analysis 133

\section{$\begin{array}{lll}4.5 & \text { Within Case Analysis } & 134\end{array}$}

4.5.1 Struggles for Quality at the Federal Level 134

4.5.2 Struggles for Meaning: Efficiency versus Free Market Logics 135

4.5.2.1 Federal Level 135

4.5.2.2 Cantonal Level 136

4.5.3 Horizontal Struggles Between Hospitals in Different Cantons 138

4.5.4 Horizontal Struggles at the Cantonal Level 139

\section{CHAPTER V COMPARING DIFFUSION PROCESSES IN TWO} INSTITUTIONAL CONTEXTS 141

5.1 Comparative Analysis: How the Institutional Context Shapes the $\begin{array}{ll}\text { Diffusion Process } & 141\end{array}$

5.1.1 Institutional Logics \& Struggles for Meaning 143

5.1.2 Governance Structures and Struggles for Control 147

5.1.3 Institution Testing 150

5.1.3.1 When Institutional Logics Preempt Governance Structures $\quad 150$

5.2 Effectiveness in the Diffusion and Efficiency in the Use of the PET Scanner in Each Health Care System 153

5.2.1 Diffusion curves 153

5.2.2 The use of PET scanners $\quad 155$

CHAPTER VI DISCUSSION AND CONCLUSION 159

6.1 Multiple Institutional Logic $\quad 160$

6.2 Institutional Logics as Constraining Theorization and Enabling $\begin{array}{ll}\text { Legitimacy } & 162\end{array}$

6.3 Competing Theorizations Within the Same Institutional Logic 165

6.4 Coherence and Fragmentation of the Governance Structure $\quad 167$ 
6.5 Governance Structures and Institutional Logics Aligned through Institution Testing

6.6 Limitations, Directions for Future Research and Practical Implications

6.7 Conclusion 176

References 179

Appendix A Interview Guide for the Diffusion of the PET Scanner 189

Appendix B Consent Form 193

Appendix C Examples of Data Analysis 195 


\section{LIST OF FIGURES AND TABLES}

\section{FIGURES}

Figure 2.1: Conceptual Framework of the Innovation Diffusion Process 25

Figure 3.1: A PET Scanner and a Cyclotron 37

Figure 4.1: Diffusion of the PET scanner in Quebec and Switzerland 61

Figure 4.2: Visual Mapping of the Diffusion of the PET scanner in Quebec 64

Figure 4.3: Visual Mapping of the Diffusion of the PET scanner in Switzerland 97

Figure 5.1: Diffusion of the PET Scanner in Quebec and Switzerland with Main Events and Private-Public Status

\section{TABLES}

Table 3.1: Population, Life Expectancy at Birth for Men \& Women in 2003

Table 3.2: Number of Hospitals in both Jurisdictions 46

Table 3.3: Number of Doctors in both Jurisdictions 47

Table 3.4: Total Expenditure on Health, per Person, and as a Share of GDP in 200348

Table 3.5: Percentage of Public and Private Health Expenditure in 2003

Table 3.6: Number of CT-Scanners and MRI in Operation in both Jurisdictions in 2001

Table 3.7: Governance Structures of the Quebec and Swiss Health Care Systems 52

Table 3.8: Number of Interviews per Organization 54

Table 4.1: The PET Scanner as a Bandwagon Technology 60

Table 4.2: Adoption Dates of the PET Scanner in Quebec 62

Table 4.3: Adoption Dates of the PET Scanner in Switzerland 62

Table 4.4: Competing Quality-Based Theorizations in Region C 68

Table 4.5: Quality-Based Theorizations of the Health Technology Assessment Agency Report Providing Legitimacy to the PET scanner

Table 4.6: Competing Theorizations Emerging After the Publication of the HTAA Report 
Table 4.7: Competing Theorizations Related to Influencing Reimbursement Policy 109

Table 5.1: Theorizations \& Counter-Theorizations Influencing Diffusion in both Jurisdictions

Table 5.2: Causes \& Necessary Conditions for Institution Testing to Occur in each Jurisdiction

Table 5.3: Number of Examinations in Oncology per PET Scanner in Each Jurisdiction 
CSSS: $\quad$ Centre de santé et de services sociaux

Translated as « Health and Social Services Centre »

CT: $\quad$ Computed Tomography

DFI: Département fédéral de l'intérieur

Translated as «Federal Department of Internal Affairs »

FDG : Fluorodesoxyglucose

FMOQ: Federation des médecins omnipraticiens du Québec Translated as The Quebec Federation of General Practitioners

FMSQ: $\quad$ Federation des médecins spécialistes du Québec

Translated as The Quebec Federation of Specialist Doctors

GDP: $\quad$ Gross Domestic Product

GP: $\quad$ General Practitioner

HTAA: Health technology Assessment Agency

LAMal: Loi fédérale sur l'assurance-maladie

Translated as Federal Law on Health Insurance

MRI: Magnetic Resonance Imaging

NMA: Nuclear Medical Association

OFAS: Office fédérale de l'assurance sociale

Translated as Federal Office for Social insurance

OFSP: Office fédérale de la santé publique

Translated as Federal Office for Public Health

PET: Positron Emission Tomography

RAMQ: Régie de l'Assurance Maladie du Québec Translated as the Quebec Health Insurance Agency

USD: U.S. dollar 


\section{ACKNOWLEDGMENTS}

I am so grateful to Alberto Holly and Ann Langley who cleverly advised me in conducting this research. They were tremendously generous, granting me financial and institutional support. I am honoured to have had the opportunity to know and to work with them. Special thanks go to Ann for sharing her wisdom and understanding of human nature and dynamics. I am infinitely indebted to her.

Many thanks go to Jean-Philippe Bonardi who was always available to meet up with me and to provide me with precious advice to improve the quality of my work. I greatly appreciated the helpful comments of participants in the 2008 Academy of Management symposium on the Travel of Health Care Ideas: International Perspectives and in the 2007 European Group for Organizational Studies subtheme on Innovation and Institutions, especially of Peer Fiss, Robin Gustafson, Mariann Jelinek, John Meyer, Hayagreeva Rao, Richard Scott and Tammar Zilber. I also particularly appreciated the sympathy and generosity of Guido Palazzo, Mario Lessard and Dorothy Watson.

I am grateful to Pascal Paschoud and Tarik Yalcin for their confidence in entrusting the coordination of institutional projects to me. Meeting them was a highly fortunate event which allowed me to obtain an assistantship at the Institute of Health Economics and Management. I have also appreciated the institutional support of CHUV, HEC Lausanne, and University of Lausanne who granted me financial support via the Fondation du 450 anniversaire de l'Université de Lausanne.

I further need to address special thanks to the numerous participants in this research who anonymously dedicated much of their time to it. Without their kind participation and their confidence, this thesis would not be the same. I would also like to thank my colleagues from the Institute of Health Economics and Management, HEC Lausanne and CHUV for our numerous talks and coffees. Finally, I am especially grateful to my beloved wife who was remarkably patient and supportive during the whole process. 
ABSTRACT

In this thesis, I examine the diffusion process for a complex medical technology, the PET scanner, in two different health care systems, one of which is more marketoriented (Switzerland) and the other more centrally managed by a public agency (Quebec). The research draws on institutional and socio-political theories of the diffusion of innovations to examine how institutional contexts affect processes of diffusion. I find that diffusion proceeds more rapidly in Switzerland than in Quebec, but that processes in both jurisdictions are characterized by intense struggles among providers and between providers and public agencies. I show that the institutional environment influences these processes by determining the patterns of material resources and authority available to actors in their struggles to strategically control the technology, and by constituting the discursive resources or institutional logics on which actors may legitimately draw in their struggles to give meaning to the technology in line with their interests and values. This thesis illustrates how institutional structures and meanings manifest themselves in the context of specific decisions within an organizational field, and reveals the ways in which governance structures may be contested and realigned when they conflict with interests that are legitimized by dominant institutional logics. It is argued that this form of contestation and readjustment at the margins constitutes one mechanism by which institutional frameworks are tested, stretched and reproduced or redefined. 


\section{CHAPTER I}

\section{INTRODUCTION}

Although there is a vast literature on the subject of the diffusion of innovation (Rogers 2003; Ferlie, Fitzgerald et al. 2005; Greenhalgh, Robert et al. 2005) and although institutional theory has frequently been mobilized to explain the diffusion of managerial innovations and ideas (Meyer and Rowan 1977; DiMaggio and Powell 1983; Tolbert and Zucker 1983; Abrahamson 1991), there is surprisingly little work on the specific role that institutionalized structures and meaning systems may play in the process of diffusion of technological artifacts.

In this thesis, I address this issue by examining the diffusion process for a complex medical technology - positron emission tomography, or the PET scanner - in two institutional contexts, one of which is more market-oriented (Switzerland) and the other more centrally managed by a public agency (Quebec). Due to their structural similarities and differences, this comparison allows the role of the institutional environment in the diffusion process to be examined by maintaining the object of diffusion constant. The PET scanner is a particularly interesting technology for this study because it is complex, extremely expensive and was, initially at least, quite controversial, creating excitement in the medical community while engaging health care regulators in efforts to control its diffusion. Indeed, the PET scanner has all the characteristics of what I have called a bandwagon technology where the pressure to adopt would be intense. It is thus likely to engage multiple actors within the organizational 
field, providing an ideal case to address my key research question: How does the nature of the institutional environment influence the process of adoption of advanced technology within an institutional field?

Because they have multiple ramifications at economic, clinical, organizational and institutional levels (Gelijns and Rosenberg 1994; Gelijns, Brown et al. 2005), many health-care innovations are complex. This particularity may render innovation hard to diffuse (Fitzgerald, Ferlie et al. 2002; Ferlie, Fitzgerald et al. 2005). Indeed, the adoption of complex technology in health care is rarely an individual choice, but involves an array of stakeholders with different values, interests and interpretative schemes whose motives, roles and scope for action with regard to any particular innovation are structured at least in part by the institutional environment in which they evolve.

While there has been concern that some health care innovations have been adopted too slowly (Fitzgerald, Ferlie et al. 2002; Ferlie, Fitzgerald et al. 2005), there is evidence that others have over-diffused, resulting in excessive health care costs (Foote 1992). This phenomenon tends to occur for capital-intensive technologies (e.g., CT scans, magnetic resonance imaging, PET scanner) which are attractive to health care providers because of their prestige and potential economic and/or clinical benefits. The resulting quality competition, so-called medical arms race, is fuelled by a perception that early acquisition will provide competitive advantage by enhancing the reputation of the provider, as well as by capturing scarce resources such as patients, specialized doctors, and budgets to operate the technology. Moreover, to recoup the acquisition cost of capital-intensive technologies, supplier-induced demand may further enhance the overuse of the technology (James, Perry et al. 1991; Foote 1992).

Nonetheless, health care systems are highly regulated and institutionalized. Regulatory agencies, insurers and professions can intervene in an attempt to influence, control or manage the diffusion of costly innovations (Foote 1992). More generally, the particular institutional arrangements surrounding the health care systems of different countries or jurisdictions may structure adoption decisions in different ways through their influence on rules, on incentives and on local values and norms (Scott, Ruef et al. 2000; Alexander and D'Aunno 2003). While previous economic studies have suggested that more competitive environments tend to speed up diffusion (Rapoport 
1978; Vogt, Bhattacharya et al. 1995)1, there have been few comparative studies which have attempted to trace out in detail the processes of diffusion in different jurisdictions in order to examine how different contexts influence understanding of the technology and the patterns of adoption and diffusion over time.

This research mainly draws on the institutional and socio-political theories of the diffusion of innovations. While the former is relevant to my initial research question for its extensive treatment of institutional environments, the latter is particularly important for understanding the motivations for adoption within different institutional contexts. Combining these perspectives, institutional arrangements in each jurisdiction are viewed as structuring patterns of power, interests and values which will influence technology adoption in interaction with the characteristics of the technology itself (Denis, Hébert et al. 2002).

Since my inquiry is context-sensitive and involves investigating processes evolving over time, a comparative longitudinal case study is indicated (Yin 2003). Data was collected through 88 semi-structured interviews and through the analysis of internal and public documents. Each individual adoption or attempt at adoption in both Quebec and Switzerland was documented and analyzed in terms of three categories: the rationales used by adopters, their actions and their results. Visual mapping strategies as well as matrix displays (Miles and Huberman 1994) were used to synthesize the data (Langley 1999) and to compare the evolution of the processes across the two jurisdictions.

Findings. Based on the comparative longitudinal case study, I found that the processes of diffusion of the PET scanner in both Switzerland and Quebec were characterized by struggles between providers (horizontal struggles) and between providers and public authorities (vertical struggles) as providers pushed to acquire the technology faster than their rivals. These struggles manifested themselves in two distinct but interacting forms of action. First, they involved what I call struggles for control in which actors strategically mobilized power in the form of material resources and authority to orient adoption decisions according to their particular interests. At the same time, they also involved what I call struggles for meaning in which actors engaged in competing arguments or theorizations concerning what the technology is, how and why it should be used and who might legitimately acquire it. I show that the institutional environment influences these processes by determining the patterns of material

${ }^{1}$ This is the same reference as: Vogt, W. B., Bhattacharya, J., Kupor, S., Yoshikama, A., \& Nakahara, T. 1995. The role of diagnostic technology in competition among Japanese hospitals. International Journal of Technology Management (Special Issue 1): 93-105. 
resources and authority available to actors in their struggles for control, and by constituting the discursive resources or institutional logics on which actors may legitimately draw in their struggles for meaning.

My results also suggest that the fragmentation of the governance structure provides more opportunities for actors to influence decisions in ways that correspond to their interests than more coherent systems, at least in the short term. Fragmentation is defined as the lack of unity and coherence of the health care system, and is related in this thesis to the existence of public and private regimes and of two distinct governmental levels (federal and cantonal). It seems that while the number of PET scanners diffused is higher under the more fragmented governance structure, efficiency in the use of the technology is lower. Furthermore, the number of institutional actors also influences the intensity of struggles because each of these strives for the same set of limited resources.

I further show how institutional governance structures may be contested and realigned when they conflict with interests that are legitimized by dominant institutional logics. I suggest that this form of contestation, that I call institution testing, and adjustment constitute one mechanism by which institutional frameworks are stretched and reproduced or redefined. Finally, this study suggests that in order for institution testing to be successful, the normative legitimacy of the technology must outweigh the normative legitimacy of the regulation that hinders its diffusion.

Theoretical Contributions. These results make four contributions to the field of institutional theory and to knowledge about the diffusion of innovations. First, although scholars recognize the powerful effect of the institutional environment on the diffusion of innovations (Abrahamson 1991; Strang and Meyer 1993; Gelijns and Rosenberg 1994; Arndt 1995; Christensen, Bohmer et al. 2000; Rosenau 2000; Cetindamar 2001; Hutchison, Abelson et al. 2001; Gelijns, Brown et al. 2005) and despite a vast literature investigating the role of regulations and incentives on technological change (McClellan and Kessler 2002) or the outcome of diffusion (Rogers 2003; Greenhalgh, Robert et al. 2004), to my knowledge there is little work that scrutinizes further the process of diffusion and its interaction with the institutional environment. By documenting the struggles for control and the struggles for meaning, this thesis makes a detailed comparative analysis of the diffusion process of technological innovations. Since few studies have attempted to document how different institutional environments affect meaning-creation of technology and the patterns of adoption and diffusion over time, this constitutes an important empirical contribution to the literature. 
Second, by showing how institutional logics are mobilized in competing theorizations and how these logics may be differentially interpreted according to actors' interests, this thesis shows that the iron cage which constrains an actor's rhetorical repertoire is composed of a given limited set of elements i.e. institutional logics that actors can actually mobilize in their struggles for meaning. By instrumentally selecting institutional logics which best suit their interests and values, actors gain legitimacy for their claims and provide legitimacy to the artifact. This instrumentalization of institutional logics shows that actors are aware, knowledgeable and active agents who have a deep understanding of institutions and know how to manipulate them. While many studies in the tradition of institutional theory have exploited the constraining nature of institutions (see Scott 2008), I answer the call of scholars for more studies on how institutions can be enabling (Barley and Tolbert 1997). Furthermore, by focusing on the socio-political dimension of the diffusion of innovation, this study incorporates politics and interest into institutional dynamics as called for by DiMaggio (1988) and Oliver (1991). This thesis also shows that theorization can legitimize both would-be adopters and the technology by grounding them in institutional logics. This provides an explicit analysis of legitimation which are still considered to be scarce (Suchman 1995; Vaara, Tienari et al. 2006).

Third, institutional maintenance is highly relevant for institutional theory and was neglected by scholars until recently (Lawrence and Suddaby 2006; Zilber 2008). My work suggests that institution testing, a form of contestation, with readjustment at the margins of governance structure constitutes one mechanism that maintains institutions. My results also show how institution testing might eventually challenge institutional frameworks and even disrupt them. At the same time, they illustrate the reciprocal role of institutionalized governance structures in constituting the political context within which meanings are mobilized (Scott 2008). I further show that institution testing is successful when the normative and cultural-cognitive legitimacy of the position defended is grounded in dominant institutional logics and is higher than the legitimacy of a regulation.

Fourth, while several authors have discussed the coexistence of multiple institutional logics (e.g., Friedland and Alford 1991; Boltanski and Thévenot 1999; Zilber 2006), to my knowledge this study constitute the first to document their impact on the diffusion of a medical technology.

Besides theoretical contributions, this thesis may have practical implications. Technological change is believed to account for more than $50 \%$ of increasing medical expenditures (Newhouse 1992), which makes it a major cost-driver in the health care 
sector (Gelijns and Rosenberg 1994; Fuchs 1996; McClellan and Kessler 2002; Cutler and Huckman 2003). Given that rising expenditures in health care is putting increasing financial pressure on governments, better policies need to be designed in order to make better use of resources and to allocate these equitably. For example, instead of using a top-down approach, government can call for proposals and evaluate which hospital should have the technology; extends regulations to both private and public sectors; decrease the fragmentation of the decision-making system; and apply sanctions. Clearly, understanding the diffusion process of innovations in health care is important for policy makers, governments, and all citizens.

Structure of the Chapters. The organization of the chapters closely follows recommendations by Eisenhardt (1989) on the case study approach to research. After defining the questions, researchers must become acquainted with the relevant literature. Accordingly, chapter II presents four theoretical perspectives which provide an overview of knowledge about the diffusion of innovations. The economics, evidence-based medicine, institutional theory, relational-network and the sociopolitical literatures are reviewed because they offer potential for unraveling fundamental concepts and associations between the institutional environment and the diffusion of innovations. Then, drawing more specifically on two selected bodies of literature, I present the conceptual model which I used as a guideline for collecting data.

Chapter III provides an overview of the research contexts which are the health care systems of Quebec and Switzerland, and explains why such a comparison is relevant for my research questions. I then detail the comparative qualitative approach used to answer the initial research question which is: "How does the institutional environment affect the diffusion of innovations?" Data was organized using visual mapping (Langley 1999) and matrix displays in order to explore, analyze and display results (Miles and Huberman 1994).

This is followed, in chapter IV, by a chronological presentation of the two cases, drawing particular attention to the struggles inherent in the diffusion process and to the institutional logics mobilized by actors as they interpret the role of the technology, as well as to how actors challenge existing institutions. To preserve the anonymity of participants and organizations involved in this research, all names of individuals and organizations were removed from the narratives as were the positions of interviewees. The presentation of each case study is followed by a synthetic within-case analysis. 
In chapter $\mathrm{V}$, a detailed comparative analysis of the two cases leads to a series of six propositions for further research. Finally, some discussions of the implications of this study for the understanding of institutions and the diffusion of innovations constitute the heart of chapter VI. Limitations, directions for future research and practical implications, as well as a general conclusion close this chapter. 


\section{CHAPTER II}

\section{THEORETICAL BACKGROUND}

The diffusion of innovations has been the object of many research traditions and there have many attempts to review and classify these literatures (Damanpour 1991; Wolfe 1994; Rogers 2003; Greenhalgh, Robert et al. 2005). In order to have a better understanding of how the institutional environment may influence the diffusion of innovations, I selected four traditions which appeared to offer the highest potential to explain and provide me with an overview of this phenomenon.

Assuming the rationality of actors, the economic perspective is reviewed here because it is concerned with the role of incentives and regulations in the environment, and with the impact of competition on the diffusion processes. This approach is contrasted with the relational-network approach which argues that diffusion is ensured neither by rational information nor by benefits per se; but arises through the influence of interpersonal communication and the social network. In turn, this approach is criticized by the neo-institutional standpoint which suggests that there are forces in the environment that colour the content of interpersonal communications. Consequently, this perspective extends the conception of the institutional environment beyond regulations by considering how norms and cultural-cognitive elements affect the diffusion of innovations. The socio-political view focus more 
specifically on the motivation to adopt an innovation to consider that adoption is a matter of congruence between, on the one hand, values, interests and power distribution of the adopting system, and on the other hand, the risks and benefits of an innovation in an environment composed of various adopters having different interests, values and power.

Thus, the first part of this chapter provides an overview of these four complementary theoretical perspectives. Then, the four perspectives are mobilized to establish the conceptual framework which forms the backdrop of the analysis of the case studies and the guidelines for data collection.

\subsection{Theoretical Perspectives}

\subsubsection{The Rational Perspectives}

The rational-economic perspective assumes that organizational actors will adopt innovations based on the best choice, under prevailing context, which help them achieve their objectives. As such, actors try to maximize their benefits and minimize their costs by comparing different course of action. For some proponents of this approach, competition is assumed to be a mechanism that would insure a rational diffusion of innovation i.e., innovations bringing clear benefits are going to be chosen by organizations. A contrasting view is taken by other economists who examine how to overcome market failure through the enforcement of regulations and the use of financial incentives to orient organizations according to policy objectives. The following section reviews the role of competition between health care providers in the diffusion of innovation and strives to shed light on the impact of regulatory mechanisms and financial incentives on the diffusion of innovations. Besides reviewing economic theories, this section briefly presents the evidence-based medicine movement, a rational perspective which assumes that availability of information and knowledge may change actor behaviours.

\subsubsection{The Economic View - A Logic of Incentives}

Competition is believed to be a powerful force moulding the diffusion of innovations (Schumpeter 1944; Nelson, Peck et al. 1967; Rapoport 1978; Christensen, Bohmer et al. 2000). Schumpeter (1944) was the first to propose that competition is the fundamental motor of innovation understood as invention, and that it increases with market concentration. This hypothesis has been under relentless scrutiny ever since, 
but studies have shown inconclusive results (Cohen and Levin 1989). However, Schumpeter's idea that competition stimulates innovation has been taken up by scholars and applied to the health care industry in relation not to invention, but to the diffusion of existing innovations. In this respect, most of the studies in this sector support the hypothesis that a competitive environment increases the speed of diffusion of innovation.

It must be noted that competition takes on a particular form in this sector; because of third-party payer mechanisms and universal coverage, hospitals do not always compete on price to attract patients but on quality and status which are measured by having highly specialized equipment and personnel, and by offering a wide range of services. Consequently, the better equipped a hospital is, the easier it is to attract and retain good quality physicians, and ultimately to admit more patients (Lee 1971). This non-price competitive mechanism, which tends to increase the diffusion of innovation, has been empirically corroborated by various studies for diagnostic devices (Rapoport 1978; Hillman, Neu et al. 1987; Vogt, Bhattacharya et al. 1995; Chou, Liu et al. 2004) and for services such as 24-hour emergency care and cardiac catheterization (Luft, Robinson et al. 1986). Also, the supply of specialized services has been found to be more intensive and duplicative in competitive settings in order to attract physicians and patients (Robinson, Garnick et al. 1987; Dranove, Shanley et al. 1992; Dranove and Satterthwaite 2000), a phenomenon known as the "medical arms race" (Foote 1992). In general, scholars agree that services increasing patient admissions are more likely to diffuse widely (Luft, Robinson et al. 1986).

Intraspeciality rivalry as a special form of competition has also been viewed as increasing the speed of diffusion. For example, the rapid diffusion of laparascopic cholecystectomy has been attributed to competition among surgeons (Escarce, Bloom et al. 1995; Denis, Hébert et al. 2002). In this case, surgeons compete to stay in the cholecystectomy market. Interspeciality rivalry has also been identified as a force increasing the diffusion of innovations for the treatment of angina pectoris and gallstones to capture patients who would otherwise be treated by other specialists (Gelijns and Rosenberg 1994).

If competition is believed to be a powerful force increasing the rate of diffusion of innovation, economists assume that adoption behaviour can be oriented toward policy objectives if appropriate rules and financial incentives are provided. One heavily studied avenue in health economics is the relationship between hospital payment methods and the rate of diffusion. While retrospective payment stimulates adoption of innovation by reimbursing costs already incurred (Hillman and Schwartz 1985; 
McClellan and Kessler 2002; Chou, Liu et al. 2004), DRG-based prospective payment ${ }^{2}$ may decrease diffusion by shifting the financial risk from insurers to hospitals but further empirical results are still required (e.g. Hillman and Schwartz 1985). The yearly fixed global budget is believed to be the most stringent hospital payment method affecting the diffusion of technologies (McClellan and Kessler 2002), but again robust empirical results are needed.

Doctors' payments may also influence the diffusion of innovation. In their study, McClellan \& Kessler (2002) found that the fee-for-service payment of doctors was associated with a higher rate of diffusion. Doctors paid on a salary basis were less likely to adopt new technologies. Both substantial out-of-pocket patient participation in health care costs and the presence of a unique health insurance with universal coverage are believed to limit the diffusion of innovation strongly (McClellan and Kessler 2002). In contrast, low or zero out-of-pocket payment and various possible choices of health insurance are correlated with a propensity for technological diffusion (McClellan and Kessler 2002).

Whereas economic incentives may influence the use and diffusion of innovation, they can also have detrimental effects on patients. In a study on the penetration of laparoscopic cholecystectomy in Quebec (Denis, Hébert et al. 2002), strong financial incentives stimulated a too rapid and uncontrolled diffusion of this technique with unfortunate results for patients such as complications and avoidable premature deaths. In a different setting, to compensate revenue loss consequential to lower birth rate, some obstetricians preferred caesarean procedures over natural delivery, despite the former bearing higher risks than the latter (Gruber and Owings 1996; Gruber, Kim et al. 1999).

Other studies indicated that the presence of strict regulations on major investments in technology strongly limited the diffusion of technology in the treatment of heart attack (McClellan and Kessler 2002). However, while regulation seems at best to have had the effect of postponing adoption (Schenzler 1998), it did not limit diffusion in the long run (Hillman and Schwartz 1985). Although the presence of regulations may affect diffusion, the lack of regulatory control in the US tends to produce indiscriminate adoption of innovations whose real benefits to patients are not clear (Rosenau 2000). Thus, according to Rosenau, considering market alone seems to give

\footnotetext{
${ }^{2}$ DRG stands for Diagnosis-Related Group. It is a classification system categorizing patients into different groups of pathologies which are expected to use approximately the same resources. For each DRG there is a payment which is associated and which covers at least the average costs for treating a given pathology.
} 
rise to anarchic diffusion and favours private benefits at the expense of public institutions (Rosenau 2000).

These results suggest that regulations and financial incentives are critical in determining the route and pace of innovation and imply that innovations may diffuse differently accordingly to various regulatory and financial mechanisms in the institutional environment. Therefore, the rational-economic approach assumes that, with adequate incentives, actors will react rationally, adopting innovations that offer the highest return. Also, to capture scarce resources, competition may encourage earlier adoption to obtain a competitive advantage in terms of perceived quality.

\subsubsection{The Evidence-Based Medicine Movement - A Logic of Information}

Another rationally-based perspective deserves attention in the field of the diffusion of medical innovations. The evidence-based medicine movement is a relatively recent tradition which emerged in the seventies from a growing body of research that identified a large variation of medical practice for a given pathology (Eddy 2005). Evidence-based medicine conceives actors as rational and responsive to new information (Greenhalgh, Robert et al. 2005) and assumes that disseminating scientific information based on randomized controlled trials may change physicians' behaviour. Thus, the purpose of evidence-based medicine is to "provide a stronger scientific foundation for clinical work, to achieve consistency, efficiency, effectiveness, quality, and safety in medical care" (Timmermans and Mauck 2005). By and large, there are two sources of evidence. On the one hand, evidence-based medicine encourages physicians to integrate best evidence in their practice, and on the other hand physicians are asked to follow interdisciplinary and consensually designed clinical guidelines (Eddy 2005).

For proponents of evidence-based medicine, institutional environment can be composed of a set of normative guidelines, and adoption by physicians is based on the best evidence available, clinical judgement and patient values (Sackett, Richardson et al. 1997). Information overload, non-adherence and variation in practice are considered as variables impeding diffusion processes. Unfortunately, many studies show that the mere presence of information is not sufficient for physicians to change their behaviour (Greenhalgh, Robert et al. 2005).

At the basic level, the rational-economic perspective assumes that a more centralized institutional environment dominated by the public sector, such as that of Quebec, will 
not necessarily be conducive to innovation; while Switzerland would be the theatre of faster and wider diffusion. However, while competition increases the speed of diffusion, most studies have not traced the processes of diffusion in depth (Renshaw, Kimberly et al. 1990), apart from indicating that diffusion flows from higher status teaching hospitals to less prestigious ones (Lee 1971; Rapoport 1978; Vogt, Bhattacharya et al. 1995). By considering economic incentives or the availability of knowledge and information as the prime factor behind the diffusion of innovation, the rational perspective assumes that actors may make choice of adopting an innovation only through a cost-effectiveness analysis or through a detailed analysis of scientific evidence and neglects other important aspects of the diffusion of innovation such as the role played by interpersonal communication, the social network and norms shared by the community. The next approach addresses these deficiencies.

\subsubsection{The Relational-Network Perspective - A Logic of INTERPERSONAL COMMUNICATION}

The relational-network perspective assumes that it is the interpersonal communication within a social network that is the main determinant of the diffusion of innovations and that the experience of near-peers is central for modeling and imitation (Rogers 2003). By studying the diffusion of hybrid corn amongst Iowa's farmers, Ryan and Gross (1943) were the first to demonstrate that the diffusion of innovation is a social process rather than a rational and economic one. This was based on their astonishing observation that although hybrid corn seeds were genetically and economically superior, it still took 14 years for farmers to adopt this innovation (Valente and Rogers 1995). This seminal paper constitutes the endowment of the relational-network paradigm by identifying that: 1) the adoption of innovation is a decision-making process composed of different stages such as awareness, trial and adoption; 2) the source of information about innovation influences adoption, with farmer neighbours being more influential than sales representatives; 3) the rate of the diffusion of innovation follows an "S" pattern suggesting an initial slow diffusion followed by an acceleration and a deceleration of the adopting rate; and 4) that some characteristics of the adopters, such as cosmopolitanism (i.e. the number of trips to Iowa's largest city), made farmers more likely to adopt (Ryan and Gross 1943).

Moreover, these authors elaborated the embryo of the famous typology popularized by Rogers (2003), characterizing adopters as innovators, early adopters, early majority, late majority and laggards according to the timing at which they adopted an innovation. These parameters, established by Ryan \& Gross (1943), have dominated the literature since 1943 (Valente and Rogers 1995) and certainly contributed to the 
classical definition of diffusion as the "process in which an innovation is communicated through certain channels over time among the members of a social system" (Rogers 2003: 5).

Using network analysis, Coleman et al. (1966) extended the work of Ryan and Gross (1943) by studying the diffusion of the antibiotic tetracycline among doctors in Illinois. This study suggested that the network of social relations affected the likelihood of adoption by constituting the channels through which communication takes place. Indeed, doctors who were more integrated into a social network were more likely to adopt earlier, and more isolated doctors tended to adopt at a later stage. Social networks are defined as "the pattern[s] of friendship, advice, communication or support which exist among members of a social system" (Valente 1996: 70). They are dichotomously characterized as homophilous or heterophilous networks. Homophily is believed to accelerate the diffusion of innovation (Rogers 2003: 306) because communication is more likely to be effective when people share values, norms, perceptions and experience, and because interpersonal influence is likely to be stronger. However, as Granovetter (1973) points out in his influential paper "The strength of weak ties", a homophilous community must have a pinch of heterophily, which refers to the diversity of ties between people having different values and objectives, in order to welcome new ideas from another community.

If awareness of a medical innovation is often triggered by pharmaceutical companies, the legitimacy and influence for adopting new technologies often comes from evaluative information gathered through discussions with colleagues (Coleman, Katz et al. 1966; Escarce 1996). This suggests that the position of doctors in the network determine their propensity to adopt innovation or to influence diffusion (Coleman, Katz et al. 1966). Since communities are rarely composed of homogenous individuals, opinion leaders may have more influence on the diffusion of innovations than other actors.

Opinion leaders are "those perceived as having particular influence on the beliefs and actions of their colleagues in any direction, whether positive (in the eyes of those trying to achieve change) or negative" (Locock, Dopson et al. 2001: 746). They have greater interaction with their network, have a higher socio-economic status, have more relationships with the external world, are more exposed to mass media and are more innovative than their followers in a setting where innovation is regarded as valuable (Rogers 2003). Locock et al. (2001) distinguish expert opinion leaders from peer opinion leaders. The former are more heterophilous than their followers and, due to their position, they can reduce uncertainty about an innovation by confirming the 
strength of its evidence. Typically, their influence is drawn from their knowledge and from the academic or consultant position they hold. Peer opinion leaders are homophilous and reduce uncertainty about implementation issues. Because they hold the same position as their colleagues, they exert their influence through informal authority.

If opinion leaders provide legitimacy for innovation by lowering uncertainty related to evidence and implementation issues, champions advocating an innovation are essential to its adoption. As Greenhalgh et al. (2005: 126) remark: "the axiom that an innovation requires active and energetic efforts by particular individuals to "keep it alive' and create a robust coalition for change is a recurring theme in the literature." Thus champions can provide autonomy to innovators for generating original ideas or solutions (organizational maverick role), convince others to support the adoption of an innovation (transformational leader), loosely monitor the adoption process (organizational buffer role), and ensure the institutionalization of the innovation (network, facilitator role) (Shane 1995).

In contradiction to the assumption of evidence-based medicine (Sackett, Richardson et al. 1997), the availability of valid scientific evidence is apparently not a sufficient condition for the diffusion and the adoption of innovations (Greer 1988; Greer 1994; Dopson, FitzGerald et al. 2002; Fitzgerald, Ferlie et al. 2002; Rogers 2003; Ferlie, Fitzgerald et al. 2005). Because scientific evidence does not inform practitioners about how innovation should be incorporated into practice, professionals need to develop and capture a kind of knowledge that is practical and tacit, in contrast to the explicit and codified scientific knowledge present in scientific articles. This forces them to be active in searching for local information that shows an innovation to be effective (Greer 1988). Thus, the adoption process is facilitated if a consensus emerges within the community about the effectiveness of the innovation (Greer 1988).

This local information on the effectiveness of innovations and technologies is obtained by referring to expert and peer opinion leaders. However, the safety, efficiency and cost-effectiveness of medical innovations are not sufficient for adoption: other characteristics of the innovation (quantity of resources required to implement a change) and the provider (younger actors, specialists, urban settings, under competitive pressure) influence the diffusion of innovation (Fendrick and Schwartz 1994). From this perspective, the institutional environment is considered as a set of social networks where interpersonal communication is the main medium influencing the diffusion of innovations. Interestingly, the notion of risk in adopting an innovation was evacuated from this literature. Nowadays there are still remarkably 
few studies in this tradition which actually consider risk as a significant factor affecting diffusion rate (Greenhalgh, Robert et al. 2005). Even more surprising is the fact that, although there are many publications in this literature, little is known about why people actually adopt innovation (Rogers 2003). The next approach provides an interesting answer to this question.

\subsubsection{The Socio-political Perspective - A Logic of Power, VALUES \& INTERESTS}

The socio-political perspective conceptualizes the adoption and the diffusion of innovation as the product of the interaction between the values, interests and power dependencies of the adopting system and the distribution of benefits and risks embedded in an innovation (Denis, Hébert et al. 2002). Because institutional environments are heterogeneous, this approach assumes that innovation adoption is not purely an individual decision (as it is often assumed in the rational choice theory), but rather involves an array of actors having different motivation and agenda.

Power is the domination of some over others and is embedded and distributed in organizational structures (Hardy and Clegg 1996). Because the formal structure may determine who participates in decision-making processes, it can also determine who can exercise power by at least being represented in this process. Given that the adoption of innovations can be seen as a decision-making process, power can significantly affect adoption. Indeed, when dominant actors support an innovation, the likelihood of adoption increases (Champagne, Denis et al. 1991) because means are likely to be available for adoption to proceed. For example, the government endorsement of a medical innovation can significantly increase its adoption rate (Dopson, FitzGerald et al. 2002). Thus, support from a powerful actor for an innovation may influence its diffusion.

Although domination may be achieved through the formal hierarchical structure, controlling the access to environmental resources which are critical for the operation of the organization is a strong form of power (Pfeffer and Salancik 2003 (1978)). Indeed, power belongs to those who control uncertainties which may directly affect the production processes or organizational goals (Hardy and Clegg 1996), and to those who control scarce resources such as expertise, information, credibility, prestige, money and sanctions (Pfeffer and Salancik 2003 (1978)).

A socio-political perspective would imply that dominant actors in an organization will

tend to impose an organizational structure that better suits their interests. For 
example, it has been shown that organizations having a CEO with a background in sales, marketing or finance had a greater probability of adopting the multidivisional form because this structure has advantages for these specialists (Fligstein 1985). This suggests that while power is a facilitating factor, interest in an innovation certainly encourages adoption. Interest is defined in this approach as the idiosyncratic advantages or profits one derives from something.

One of the most significant illustrations of the role of interest in the adoption of innovation was developed by Fennel (1984), to explain some surprising results. He found that the presence of unions and medical departments in 173 firms were negatively correlated to the adoption of an in-house program for the treatment of alcoholism, which would normally be beneficial for the health of employees. His ad hoc explanation for these findings was that, because these programs might compete with or represent an unwanted responsibility for medical departments, resistance emerged. The unions would perceive the innovation as a way to increase management control over employees (Fennel 1984). Moreover, professionals may not be disposed to recognize the validity of the evidence supporting an innovation if it threatens their interests i.e. their organizational position and status (Fitzgerald, Ferlie et al. 2002). Thus, interest seems to be instrumental in adoption as well as rejection of innovation and can be defined as the idiosyncratic advantage actors may derive from something.

Values are beliefs about what is right and wrong and what people consider important in life. Values complement interests as motivation for adopting. For example, social groups sharing the same values are more likely to interpret the meaning of the innovation in the same terms (Pinch and Bijker 1987). Klein and Sorra (1996) found that implementation is more likely to occur when values embedded in an innovation correspond to organizational values. Moreover, different types of potential adopters may value certain forms of evidence at the expense of others. For example, while teaching hospitals may consider randomized controlled trials as the gold standard for evidence, smaller hospitals may value the adoption by leading institutions as a requisite for implementing an innovation (Denis, Hébert et al. 2002).

In the theory of organizations, the socio-political perspective considers that organizations are composed of units having divergent interests (Cyert and March 1963) and different values (Lawrence and Lorsch 1967). Because the specialization of organizational structure favours the emergence of needs, interests and goals which are specific to each sub-unit, resource allocation and strategic decisions are bargained for and negotiated (Hickson, Butler et al. 1986). This logic also applies to the adoption of innovations. In their empirical work, Fitzgerald et al. (2002) note that the adoption of 
an innovation is the fruit of a negotiation between stakeholders, and that the balance of power affects the likelihood of diffusion.

To gain power, organizational units create coalitions in order to impose their local rationality on other units (Cyert and March 1963). A coalition created by powerful actors and an absence of opposition may prompt over-diffusion. Indeed, the more the number of powerful actors has convergent interests and values mapping on an innovation, the more likely resources are to be devoted adoption and the less likely opposition may hinder diffusion. For example, low molecular weight heparin diffused rapidly because both hospital managers and doctors had financial or clinical incentives and therefore interest to create a coalition to support the adoption of this technique (Denis, Hébert et al. 2002).

In order to fit an innovation into a context, actors may re-invent it (Rogers 2003). Recently, scholars raised the issue of the transformation of innovation as it diffuses (Czarniawska and Joerges 1996; Westphal, Gulati et al. 1997; Lozeau, Langley et al. 2002), instead of considering it as discrete like earlier authors (Tolbert and Zucker 1983). For example, Westphal et al. (1997) observe that early adopters customize innovations - in this case Total Quality Management - in order to better suit their needs, and that later adopters adopt merely conform to the normative model prescribed by network ties. Hence, actors may customize innovations in order to fulfil their own agendas (Fitzgerald, Ferlie et al. 2002). In the same manner, innovations are likely to be corrupted in order to fit the current power distribution of the adopting system when there is a compatibility gap between the assumptions embedded in the managerial innovation and the organizational context (Lozeau, Langley et al. 2002).

If interest, values and power distribution affect the diffusion and adoption of innovations, their use has considerable consequences at the social and political levels as well. As Lehoux and Blume (2000: 1091) argue:

\footnotetext{
"Medical innovations, because of their values and through their social utilization, may reinforce hierarchical relations (i.e., computerized information systems), contribute to the exclusion of certain groups (i.e., designated services and programs for AIDS patients), impede the social development of individuals (i.e., genetic screening for 'noninsurable' conditions), or extend questionable social practices (i.e., ultrasonography leading to selective abortion of female fetuses)."
}

This suggests that socio-political issues are related to the adoption of innovation as well as to the consequences of its use by affecting power dependencies and the social position of some groups. 
This conception of the diffusion process has some of the features identified by actornetwork theorists (e.g., Callon 1987; Latour 1989). In particular, the idea that objects may have different meanings for different actors and that this is key to understanding if and when adoption will occur is shared with this perspective. Conceptualizing innovations and networks as co-evolving over time is also common to both approaches. In one sense, the socio-political perspective described here takes the rational-economic perspective described earlier and breaks it down, bringing it inside the adopting system. Both rational-economic and socio-political perspectives tend to assume that self-interest largely governs organizational and individual behaviour with respect to innovation.

\subsubsection{The Neo-Institutional Perspective - A Logic of LEGITIMACY}

From the point of view of institutional theory, within the same institutional environment, organizations are subjected to similar constraints which tend to homogenize them. Coercive, mimetic and normative mechanisms constrain organizations to resemble other organizations "that face the same set of environmental conditions" (DiMaggio and Powell 1983: 149). These so-called isomorphic mechanisms homogenize organizations in a given population because compliance with them may bring about or maintain legitimacy; which is defined as a "generalized perception or assumption that the actions of an entity are desirable, proper, or appropriate within some socially constructed system of norms, values, beliefs, and definitions" (Suchman 1995: 574). Hence, organizations may comply with isomorphic pressures by adopting compulsory or already widely diffused innovations in practice, structure or technology in order to gain or maintain legitimacy; even at the risk of being detrimental to organizational efficiency (Meyer and Rowan 1977).

Building on the isomorphic mechanisms documented by DiMaggio and Powell (1983), Scott (2001) identifies three institutional categories: the regulative, the normative and the cultural-cognitive pillars. The regulative element of institutions is composed of laws, rules, sanctions and incentives. Central to this pillar is the coercive mechanism which constrains behaviour by means of force, fear and authority. This mechanism is often associated with government agencies (Cetindamar 2001) acting as rule maker, referee and enforcer of the Law (Scott 2001), but it can also be incarnated by other institutional actors such as labour unions or professional bodies. Due to the legitimacy provided by the power of legal sanction (Scott 2001), coercive agents can legally impose the adoption of innovations. Abrahamson (1991: 607) termed this phenomenon the "forced-selection perspective," as it enables one organization to 
force another to adopt or reject an innovation. The ability to achieve forced adoption may be correlated with the degree to which an organization is dependent on the coercive organization for resources (Pfeffer and Salancik 2003 (1978)) or with the authority the latter derives from its legal status. For example, the civil service reform in the U.S. was adopted faster in states where it was mandated by the government (coercive pressure) and when it was directed by a single source (centralization) (Tolbert and Zucker 1983). Hence, while control through the use of force and sanctions constitutes the basic principle behind the regulative pillar, these mechanisms may not be sufficient to bring about social order. Indeed, if the rules and the rulers have to be perceived as legitimate in order to secure compliance (Scott 2008), there are other sources of legitimacy that actors can rely on.

The normative pillar is composed of values, which refer to what is preferred and desirable, and norms, which define legitimate means to achieve goals (Scott 2008). Norms and values provide a moral gauge with which to evaluate the legitimacy of entities and constrain actors' behaviour by social obligation (Scott 2008). This may occur through professionalization, an important normative mechanism, defined as "the collective struggle of members of an occupation to define the conditions and methods of their work, to control 'the production of producers' and to establish a cognitive base and legitimization for their occupational autonomy" (DiMaggio and Powell 1983: 152-153). Formal and in-service education provided to professionals contribute to the dissemination of professional norms. At the same time, professionals working in organizations are also members of professional networks with trans-organizational scope and which may act as carriers of values and norms (DiMaggio and Powell 1983). Hence, formal education and professional networks are powerful isomorphic forces tending to professionalize organizations and thereby homogenizing and legitimating professional behaviour. In the health-care sector, the elaboration of clinical guidelines is a normative tool aimed at reducing the variation of medical practice (Shaneyfelt, Mayo-Smith et al. 1999). Also, Health Technology Assessment Agencies may promote the adoption of innovations and organizations may adopt innovations for which the benefits are unknown (Arndt 1995) in order to conform to generally accepted norms thereby contributing to the legitimation of some technologies at the expense of others. Finally, certification and accreditation can be provided to organizations meeting certain standards of quality or proving that specific procedures are followed (Scott 2008). Institutional environment is conceived in this pillar as a set of forces promoting values and norms that influence other organizations. 
The cultural-cognitive pillar assumes that actors' cognitive processes are shaped by the cultural environment. Shared cultural beliefs and premises constrain actions and orient what is considered as meaningful, conceivable and natural (Scott 2008). For example, routines in organization can be taken for granted while other courses of action may be inconceivable. In the cultural-cognitive element, isomorphism operates through the imitation of other organizations due to uncertainty. Thus, organizations can engage in imitation to gain legitimacy when organizational technologies and goals are ambiguous or when stakeholders' expectations are unclear (DiMaggio and Powell 1983). For example, managers have a tendency to observe competitors and to adopt organizational forms that they perceive as successful (Fligstein 1985). Hence, besides being an isomorphic mechanism, mimetism contributes to the spread of innovations. Abrahamson (1991) coined the term "fads perspective" to qualify the imitation that results from a wide diffusion of an innovation which prompts organizations to adopt it in order to gain legitimacy or to preclude competitors from maintaining an advantage.

According to the institutional theory-based literature on innovations, while early adoption is often associated with the will of organizations to improve their performance (Westphal, Gulati et al. 1997), late adoption is more often the result of institutional forces because, as innovations diffuse, they gain legitimacy and become institutional imperatives, even though they might not lead to better performance (Tolbert and Zucker 1983). In the health care sector, Walston, Kimberly and Burns (2001) found the same pattern where early adopters of process re-engineering were driven by economic factors and tended to implement it more extensively in order to gain competitive advantage; while late adopters were more permeable to institutional pressures and tended to undertake lighter implementation.

Although there have been some attempts to theorize the development of idiosyncratic solutions which may eventually be institutionalized (Tolbert and Zucker 1996), early neo-institutional theories assume that innovations often come from external pressure rather than from inside organizations. However, when organizations are simply going through the motions of ceremonial adoption to achieve legitimacy, their capacity and motivation to make the innovation work in technical terms may be lacking. As Meyer and Rowan (1977) indicate and as revealed in many studies of institutional processes in health care (Westphal, Gulati et al. 1997), importing innovation from outside sources bears the risk of achieving only partial implementation (Walston, Kimberly et al. 2001) or even of making an alteration to the innovation which may threaten its performance (Lozeau, Langley et al. 2002). Hence, in the neo-institutional perspective, 
adoption and diffusion of social innovations stem from the need for legitimacy or to adapt to isomorphic pressures. To achieve such objectives, actors tend to imitate other similar organizations, to conform to emergent norms, or to comply with coercive pressures.

\subsection{Conceptual Framework}

From these four theoretical perspectives, I developed and present here a conceptual framework that forms the backdrop of my analysis and served as a guideline for data collection. It defines in broad terms the set of factors that need to be considered to understand the patterns of innovation diffusion in both jurisdictions. This conceptual framework is not deeply rooted in any theoretical perspective, but borrows from different traditions to provide an overview of the phenomenon under study.

As the economic perspectives assume, the benefits an actor or an organization can derive from an innovation - be it financial, clinical or of any other nature - may positively influence adoption (Denis, Hébert et al. 2002) and thereby increase diffusion. Yet institutional environments are composed of various actors having divergent values, interests and power and the interpretation of innovation attributes may differ from one potential adopter to another (Downs and Mohr 1976; Greenhalgh, Robert et al. 2005). In this context, the benefits and risks of innovation may mean different things to different people (Pinch and Bijker 1987) whether inside or outside organizations, and institutional reference points for different groups of stakeholders may be divergent, especially in the pluralistic context of the health sector (Ferlie, Fitzgerald et al. 2005; Kraatz and Block 2008). For example, while physicians may be highly responsive to professional norms which emphasize the quality of medical practice, government officials and administrators may be more sensitive to efficiency norms. In a pluralistic context, specific adoption decisions involving several stakeholders are likely to be the result of socio-political processes. To influence the decision-making process for adoption, actors with common goals may need to create a coalition (Denis, Hébert et al. 2002) thereby generating a negotiated outcome (Maguire 2002) in which the balance of power affects the likelihood of diffusion (Champagne, Denis et al. 1991; Fitzgerald, Ferlie et al. 2002) and where congruence between the perceived benefits and risks of an innovation and the interests and values of adopters is the motor of adoption.

Thus, while recognizing that rationality influences adoption and diffusion, this conceptual framework mainly draws on the socio-political approach which assumes 
that the decision to adopt an innovation involves a large array of actors having different power, interests and values. However, for diffusion and adoption to occur, power, interests and values might not be sufficient as communication has to be involved. In this respect, the relational-network view proposes that communication through near-peer experience or through different media (scientific journals, pharmaceutical salespersons, etc.) is central for diffusion to occur. While I concur with this argument, I argue that the criteria of what constitutes convincing evidence as to why an innovation is adopted are provided by the institutional environment (Suddaby and Greenwood 2005; Scott 2008). Hence, rationalities or positive near-peer experience cannot be separated from the wider institutional context. As Scott indicates: "Social action is always grounded in social contexts that specify valued ends and appropriate means; action acquires its very reasonableness from taking these social rules and guidelines for behaviour." (Scott 2008: 69). In other words, what counts as rational or effective is itself partly defined and structured by the institutional environment (Friedland and Alford 1991). For example, the values and interests of physicians - and thus their motivations - derive partly from the institutional structures within which they work and partly from the cultural-cognitive assumptions that underlie these structures. In turn, the values and interests that physicians uphold have contributed over time to the very formation of these structures (Scott, Ruef et al. 2000; Scott 2008). Thus, in this thesis, I view innovation adoption as a socio-political process embedded in and structured by its institutional context.

This socio-political conception of diffusion of innovation embedded in an institutional environment is schematized in figure 2.1. This conceptual framework should not be seen as a set of tight formal relationships to be tested but rather as a starting point for analysis as suggested by Miles \& Huberman (1994) in their treatise on qualitative data analysis.

The process of diffusion of innovations is conceived in this study as an interaction between: (a) an innovation with its key attributes: associated benefits and risks, evidence of clinical- and cost-effectiveness and evolution of the technology (see Innovation Attributes box in figure 2.1); and (b) adopters and key institutional actors with a certain set of power dependencies, values and interests that may or may not be compatible, and who may pursue different discursive or behavioural strategies (see Adopters and key institutional actors box in figure 2.1). This basic model of the diffusion process is embedded in an institutional environment which may influence both the adopting system and the innovation itself. Drawing principally on Scott et al. (2000) and partially inspired by the economic literature, the institutional environment is 
described here in terms of (c) governance structures (market versus state model, a set of regulations and normative mechanisms, different systems of incentives, private/public balance) and (d) institutional logics (see Institutional Environment box in figure 2.1). Over time, under the influence of the institutional environment, interactions between key institutional actors and adopters and an innovation lead to a distinct pattern of diffusion (see Diffusion box in figure 2.1).

Figure 2.1:

Conceptual Framework of THe InNOVation Diffusion Process
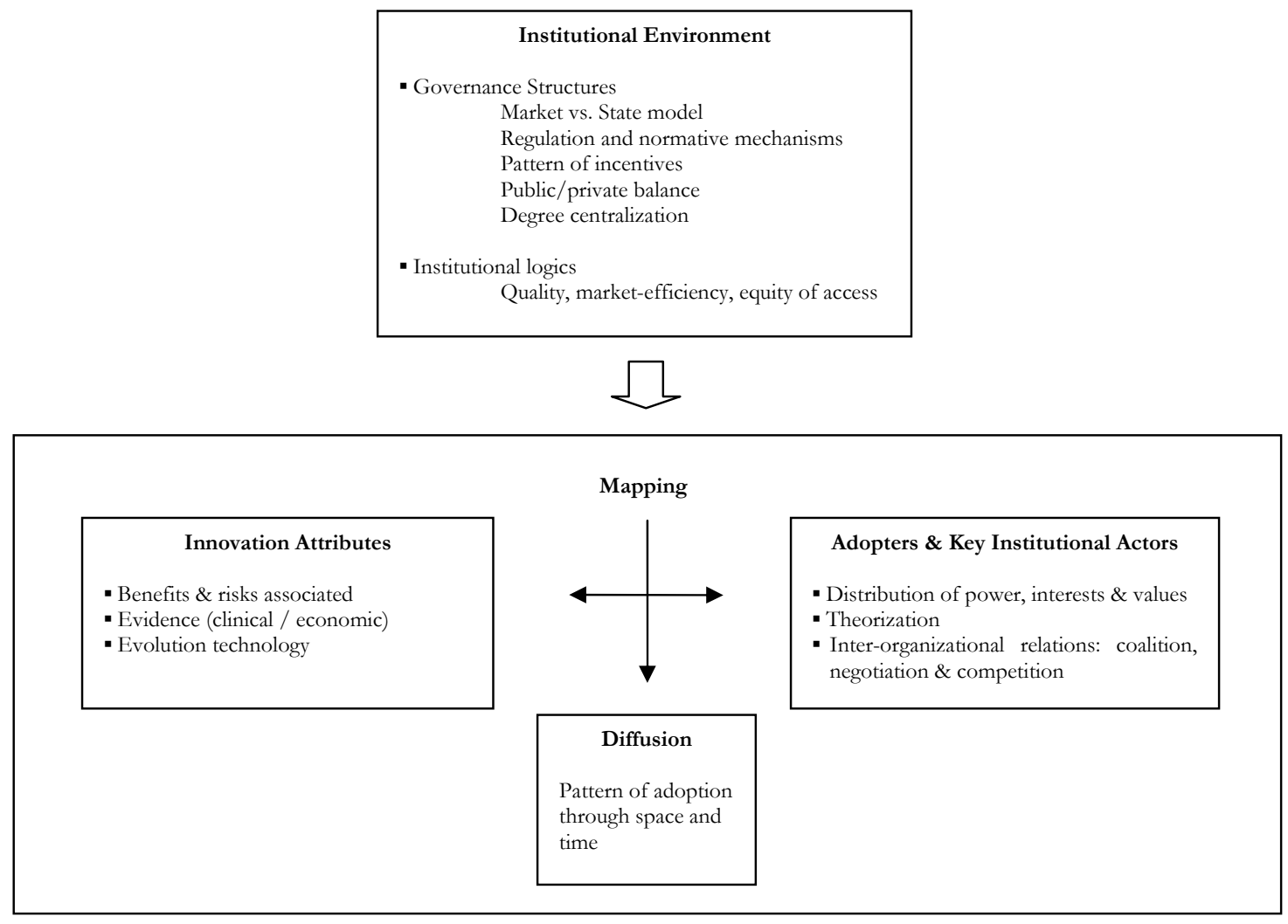

In the next sections, I provide a detailed description of each box of the conceptual framework presented in figure 2.1. After presenting the elements of the innovation attributes and the characteristics of the adopters and key institutional actors, the key components of the institutional context (governance structure and institutional logics) are described and the notion of theorization which is associated with the concept of institutional logic is introduced.

\subsubsection{INNOVATION ATTRIBUTES}

In order to understand the adoption of innovation within this conceptual framework, three aspects of innovation are relevant. First, instead of focusing only on the relative 
advantage of one innovation over others (Rogers 2003), this conceptual framework predominantly considers its concordance with interests and values of would-be adopters (Meyer and Goes 1988; Denis, Hébert et al. 2002). Accordingly, perceived benefits and risks of innovations by potential adopters in terms of clinical and economic advantage are understood here as central in the diffusion pattern of an innovation.

Because the value and interpretation of evidence differs from one professional group to another (Denis, Hébert et al. 2002; Fitzgerald, Ferlie et al. 2002; Ferlie, Fitzgerald et al. 2005), the body of evidence selected by each actor to assess an innovation is part of the conceptual framework developed. Consequently, evidence aligned with actor interests is more likely to be mobilized by would-be adopters. On the contrary, stakeholders without interest in seeing an innovation being diffused may boycott it by negatively interpreting evidence or selecting unfavourable evidence.

Finally, the evolution of the technology is also a factor that might influence the understanding and the diffusion of the technology (Pinch and Bijker 1987; Munir and Phillips 2005). Indeed, the complexity of use or function of a technology may impede its diffusion (Rogers 2003). With its development, technology may become easier to use and a wider supply of related products may increase the likelihood of diffusion. Typically, internet is a technology which evolved to become more user-friendly and the fact that it started being widely supplied in the nineties certainly facilitated its diffusion.

Thus, the innovation attributes which I consider central in this conceptual model are: benefits and risks associated with the innovation, clinical and economic evidences and the evolution of the technology. However, as already stated it is not the benefits and risks per se that drive adoption, but their concordance with interests and values of would-be adopters.

\subsubsection{ADOPTERS AND KEY INSTITUTIONAL ACTORS}

Apart from innovation attributes, this conceptual framework places power, interest and values of adopters and key institutional actors at the hub of the diffusion of innovations. This assumption is based on the socio-political perspective which states that innovations are more likely to be adopted if they are instrumental to the achievement of idiosyncratic or organizational goals (Champagne, Denis et al. 1991) or to be rejected if not aligned with the actors' interests and values (Fennel 1984). In other words, when actors' interest is compatible with the benefits an innovation 
offers, the likelihood for adoption increases (Meyer and Goes 1988). In this perspective, interest is defined as the idiosyncratic advantage which potential adopters obtain from adopting an innovation, due to the perceived benefits and risks that are embedded in it; adopters' values are beliefs about what is right or wrong (appropriateness) and what is considered important in life (priority). In the same manner as interest, congruence between values in adopters and key institutional actors and the social desirability of an innovation increases the likelihood of adoption and successful implementation of an innovation (Klein and Sorra 1996). When different groups share common values, the uptake of innovation may be faster then when there is a clash of values between would-be adopters (Ferlie, Fitzgerald et al. 2005). The model developed in this section suggests that actors' values should be taken into consideration in order to understand the motivation behind adoption.

If actors' interests and values constitute fundamental criteria for innovation adoption and are thus part of this conceptual framework, power is crucial because it provides both the levers for action inside a structure and the possibility of imposing action upon others (Crozier and Friedberg 1977). The power perspective states that dominant actors tend to impose innovations that better suit their interests (Fligstein 1985). In the conceptual framework presented in figure 2.1, power takes on three different forms: 1) expertise; 2) authority; 3) controlling resources. Expertise and organizational skills in mastering a technology were associated with an increase likelihood of adoption (Greer 1984). Opinion leaders having specific experience, and thus expertise with regard to an innovation, can also have a powerful influence on their peers (Coleman, Katz et al. 1966; Locock, Dopson et al. 2001) if their experience is positive. The other dimension of power in my model is authority, which can be defined as being legitimate in asking for obedience. Consequently, the support of an innovation by actors in a position of power increases the likelihood of adoption (Champagne, Denis et al. 1991; Klein and Sorra 1996; Dopson, FitzGerald et al. 2002). Finally, controlling resources is also a form of power if organizations or individuals are dependent on these for the performance of their activities (Pfeffer and Salancik 2003 (1978)). In this conceptual framework, resources can take different forms such as human, financial or informational.

Any person, group or organization affecting any part of the adoption decision-making process is considered as a key actor in the conceptual framework proposed here. Institutional actors are agents with different degrees of power to influence the diffusion and adoption of innovations according to their interests and values and their position in the institutional environment. In the health care sector, the institutional 
actors most likely to influence the diffusion of medical innovation are: potential adopting hospitals and physicians; diverse government agencies concerned with the provision of health care including health technology assessment agencies; health insurance companies; professional associations; pharmaceutical and medical device companies.

In this model, instead of examining the compatibility of interest and values of one actor with the benefits and risks embedded in an innovation (Meyer and Goes 1988; Denis, Hébert et al. 2002), those of an array of actors involved in the diffusion of a technology are taken into account. This conception implies that when the decision to adopt an innovation involves many stakeholders, adoption is likely to be a political resultant (Allison 1971) that is the fruit of negotiation among stakeholders, each having their own sources of influence to orient the decision favourably according to their viewpoint, and who may create coalitions to influence decision-making processes related to adoption (Denis, Hébert et al. 2002) or compete in order to adopt an innovation before another entity (Foote 1992; Dranove and Satterthwaite 2000). Thus, the adoption of innovation is considered as a negotiated outcome (Maguire 2002) where the balance of power affects the likelihood of diffusion (Fitzgerald, Ferlie et al. 2002), and where the concordance between the perceived benefits and risks of an innovation and the interest and value of adopters is the motor of adoption.

Thus, power, interest and values as well as coalition, negotiation and competition are central in the box adopters and key institutional actors. The last of these elements, theorization, is so strongly associated with institutional logic that I prefer to present both consecutively in the next section which describes the components (i.e, governance structure and institutional logics) of the box entitled institutional environment.

\subsubsection{COMPONENTS OF THE INSTITUTIONAL CONTEXT}

According to Scott (2008: 48), organizational environments are constituted by institutions which are "comprised of regulative, normative and cultural-cognitive elements that, together with associated activities and resources, provide stability and meaning to social life." While such elements constitute the backbone of institutions, their combination contributes to the three components of institutional environments defined by Scott governance structures, institutional logic and institutional actors (described in the previous section) who serve as carriers or agents. 


\subsubsection{Governance Structures}

Governance structures are comprised of regulative and normative elements. They are defined as the "arrangements by which field-level power and authority are exercised involving, variously, formal and informal systems, public and private auspices, regulative and normative mechanisms" (Scott, Ruef et al. 2000: 173). While different typologies of governance structures are proposed (Williamson 1981; Streeck and Schmitter 1985; Lowndes and Skelcher 1998; Rodriguez, Langley et al. 2007), authors consider market and hierarchy as two fundamental archetypes. In the market mode of governance, competition is the main coordination mechanism. It is generally assumed that competition is the key mechanism by which innovations will diffuse and that profit maximization is the incentive for firms to adopt them. Firms are the key institutional actors which respond to economic incentives in order to maximize advantage through profit or material benefits, and the predominant legal foundation is the property right (Streeck and Schmitter 1985). Regulations provide the market framework within which actors compete for scarce resources and governmental agencies are expected to correct market failure (Alexander and D'Aunno 2003) by adjusting rules of the game or providing appropriate financial incentives.

Apart from payment mechanisms ${ }^{3}$ to correct market failure or orient technological change, other regulatory devices have sometimes been introduced into health care systems to control the diffusion of technology. Certificate-of-need ${ }^{4}$ is one of these mechanisms which were intended to limit the diffusion of expensive technologies. Empirical findings, however, suggest that this type of regulation was bypassed by hospitals and doctors who relied on different strategies (James, Perry et al. 1991). For example, to avoid going through a long process of authorization with the risk of refusal, public hospitals relied on private clinics to adopt MRI and signed contracts with them. This was possible since only public organizations were subjected to the certificate-of-need regulation.

Conversely, in the hierarchic mode of governance, authority and coercion are the principle mechanisms of coordination. Bureaucratic agencies are the prevailing institutional actors who strive to minimize risks and maximize predictability. Fear of punishment is the main incentive for actors to comply with the authority and formal administrative procedures constitute the legal foundation of this mode (Streeck and

\footnotetext{
${ }^{3}$ Although I take payment mechanisms into consideration in my analysis, this thesis does not focus exclusively on the impact of financial incentives on the diffusion of innovations.

${ }_{4}^{4}$ The certificate-of-need regulation forces hospitals, and only hospitals, to prove the epidemiological necessity for an additional adoption of a technology in a given area.
} 
Schmitter 1985). Hence, if the administration of organizations in a field is centralized to the state, resources might be allocated according to some centrally determined criterion such as population needs (Streeck and Schmitter 1985) and regulatory mechanisms such as laws and rules will influence the degree to which coercive pressures may be used to force adoption of innovations (Tolbert and Zucker 1983; Abrahamson 1991) or, alternatively, to control or prevent them. Hence, the extent to which power is centralized to the state or decentralized in regional agencies affects the distribution of power and authority in an institutional field, and consequently may influence the diffusion of innovation. Because public and private non-profit organizations do not have the same financial incentives as commercial organizations, the assortment of the ownership and the legal status of adopters may also affect the diffusion of innovation (Scott 2008). In any particular case, governance structures are likely to involve a mixture of mechanisms supported by regulatory frameworks which establish rules and generate a variety of incentives for action.

While regulations can be a powerful mechanism to promote or inhibit the diffusion of innovations, normative elements also influence diffusion by propagating ideas about what is morally acceptable and appropriate. For example, in many health care systems, technology assessment agencies produce studies to inform authorities and health care providers about the effectiveness and safety of medical interventions (Lehoux 2006). Professional associations may also promote or hinder the transformation of an institutionalized field (Greenwood, Suddaby et al. 2002) as well as the diffusion of innovation.

\subsubsection{Institutional Logics}

While regulations and normative elements are part of the governance structure, institutional logics shape organizational action (Friedland and Alford 1991) acknowledging key sources and meanings of power (Friedland and Alford 1991; Thornton and Ocasio 1999) by providing interpretive schemes (Ranson, Hinings et al. 1980; Barley 1986). Institutional logic is defined as "a set of material practices and symbolic constructions - which constitute [a field's] organizing principles and which are available to organizations and individuals to elaborate" (Friedland and Alford 1991: 248). Institutional logics were identified at different level of analysis, but most importantly at the societal and organizational field levels. At the societal level, Friedland and Alford theoretically identified five institutional spheres (capitalism, state, democracy, family, and religion) which may contradict each other, interact and bear the seed for institutional change. In the conventionalist school, Boltanski and Thévenot (2006) identified six worlds, 
inherently in contradiction (inspirational, domestic, opinion, civic, merchant, industrial), but which are locally integrated through negotiated conventions accommodating their differing interests and logics (Denis, Langley et al. 2007). Recent work on pluralism has also recognized that institutional environments are composed of multiple co-existing institutional logics along with several incompatible regulations and norms that organizations have to reconcile through their activities (Denis, Langley et al. 2007; Kraatz and Block 2008).

At the organizational field level, Scott et al. (2000) identify three institutional logics that emerged sequentially during the transformation of health care in the San Francisco Bay Area. First, quality of care is a longstanding institutional logic that has been inherent to health care since its origins. This logic is displayed by physicians and professional associations who promote technological change in order to provide the best quality of services to patients. According to Scott et al. (2000), the Great Society movement following the Second World War brought in its wake a second institutional logic of equity of access to health care, whose emergence coincided with the development of universal coverage systems in most OECD countries (WHO 2000) and was sustained by governmental bureaucracies to ensure that everyone had access to care. However, universal coverage sparked increasing costs which stimulated pressure for enhanced control. Taking the private sector as an archetype of success, market mechanisms based on the managed care concept were introduced in the US, thereby creating a third institutional logic related to market-efficiency.

Each of these three logics is presumed to be dominant for some period of time, thereby sculpting the dynamics of the organizational field for health care in the United States. This approach implicitly assumes that a dominant logic prevails and homogeneously affects organizational forms in a particular field (Glynn and Lounsbury 2005), while secondary logics have less important effects (Scott, Ruef et al. 2000). Researchers have examined transitions from one logic to another by investigating how a dominant institutional logic tends to legitimize the adoption of certain organizational forms while delegitimizing others (Scott, Ruef et al. 2000; Thornton 2002) or by looking at how shifts in dominant institutional logics shape organizational action and decisions (Thornton and Ocasio 1999; Scott, Ruef et al. 2000; Lounsbury 2002; Thornton 2002; Glynn and Lounsbury 2005; Lounsbury 2007).

While institutional theorists (e.g. Friedland and Alford 1991), conventionalists (Boltanski and Thévenot 2006) and recent traditions on pluralism (Denis, Langley et al. 2007; Kraatz and Block 2008) have raised the possibility of multiple logics, most empirical research has considered them sequentially (Thornton and Ocasio 1999; 
Scott, Ruef et al. 2000) rather than simultaneously, with some exceptions (e.g., Zilber 2006; Lounsbury 2007).

Clearly, certain institutional logics may have greater cultural resonance at particular points in time and in particular geographic locations. However, because the health care sector is complex and inherently pluralistic (Denis, Lamothe et al. 2001; Glouberman and Mintzberg 2001; Kraatz and Block 2008), I expect multiple logics to coexist in these systems as Scott et al. (Scott, Ruef et al. 2000; Thornton 2002) have shown. Quality, equity of access and efficiency institutional logics which are inherent to OECD's health care systems (Tuohy 1999) are much in evidence in the contexts studied both previously (Denis, Lamothe et al. 2003) and here as will be seen.

Governance structure and institutional logics constitute the two main components of the institutional environment box in figure 2.1. However, theorization is also a potential contributor to the diffusion of innovations, as it is described in the next section.

\subsubsection{Theorization}

During the analysis of my data the concept of theorization appeared to be relevant to explain the discursive strategies used by actors to justify their need to adopt or to legitimate their institutional position. To gain legitimacy, organizations adopt different strategies ranging from actions such as complying to rules, norms and culturally shared beliefs, to the manipulation of their environment by means of discursive manoeuvres (Oliver 1991; Suchman 1995). By providing general abstract models and rationalized causality (Strang and Soule 1998), theorization is a discursive strategy which enhances legitimacy as it contributes to the propensity of an innovation to be taken for granted and to its objectification (Tolbert and Zucker 1996). While local theorization involves ad hoc peer-to-peer interactions to "make sense of the world" (Strang and Meyer 1993: 493), global theorization is believed to accelerate and widen the diffusion of innovation by abstractly homogenizing a potential population of adopters, by specifying the properties and outcomes of an innovation, and by identifying theorists behaving according to the theoretical model as channels of diffusion (Strang and Meyer 1993). The more abstract the theorization, the greater its influence. Thus, theorization can be conceptualized as a discursive strategy providing rationales, meanings and interpretations which legitimate and make sense of adopting innovations.

When applied to the diffusion of technology, theorization has been found to be involved in defining the position of new actors in the organizational field, as well as 
creating new objects and new concepts (Munir and Phillips 2005). Yet, although theorization is associated with the legitimization of novelty, to be effective it must also be embedded in, or artfully connected to, shared cultural understandings (Strang and Soule 1998; Munir and Phillips 2005), prevailing discourses (Vaara, Tienari et al. 2006), or institutional logics (Scott, Ruef et al. 2000; Scott 2004). Hence actors tend to rely on institutional logics to build theorizations. Theorization is operationalized in this conceptual framework as what the purpose of the technology is, why the technology should be adopted, who should adopt it, and how it should be diffused. In this thesis, it is through the study of theorizations generated by organizational actors around the PET scanner technology that we attempt to understand how institutional contexts influence the meanings given to the technology and how these meanings are in turn mobilized within the process of diffusion. Theorization is part of the adopters and key institutional actors box in the figure 2.1 because it is part of the range of strategic behavior of would-be adopters.

Overall, structural elements of the institutional framework (e.g. market vs. state models, regulation mechanisms, patterns of incentives, public/private balance, degree of decentralization) and cultural elements (i.e. institutional logics) are expected to influence the key actors involved in innovation decision making as well as their relative power. The pattern of incentives in place and the position of actors in the institutional environment combined with extant value systems may influence the interests and values of these actors and determine the identity of those who are allowed to compete and those who may collaborate. The distribution of benefits and risks perceived and interpreted as being embedded in the innovation may also impact the diffusion of innovation. Finally, regulatory mechanisms may influence the degree to which coercive pressures may be used to force innovations or alternatively the extent to which they may act as barriers to innovation. Taken together, innovation attributes, adopters and key institutional actors' values, interests and power as well as governance structure and institutional logics are all expected to influence the diffusion and adoption of innovation through space and time (see the diffusion box in figure 2.1).

This research aims to trace out in detail the mechanisms by which innovations diffuse and how the institutional environment intervenes in this process. I argue that, through in-depth exploration of complex inter-organizational processes over a fairly long time period, studying all cases of PET scanner adoption in both jurisdictions (Quebec and Switzerland) should raise many of the important factors that can explain how and why the diffusion of complex innovations may proceed differently in different contexts. 
The analysis of my data gave rise to new concepts, some of which are briefly defined in this paragraph. The diffusion of innovation appeared in my data set to be characterized by struggles for control and struggles for meaning. Struggle for control concerns the competing effort deployed by actors to influence the course of the diffusion of the technology by mobilizing power in the form of material resources, formal authority or expertise. Struggle for meaning involves competing arguments or theorizations in order to influence the perceived purpose of the technology, how and why it should be diffused and who should legitimately acquire it. Both struggles represent competing attempts to orient adoption decisions according to one's own interest. However, while actors involved in promoting or hindering the diffusion of innovations are engaged in a struggle to control the technology, they are not all struggling to provide meaning to the technology since some actors may adopt a technology regardless of its meaning. Therefore, struggle for meaning mediates struggle for control when actors estimate that the use of discourse can influence the diffusion of innovation in their favour. Struggle for meaning involves the interplay of theorization and counter-theorization based on dominant institutional logics. 


\section{CHAPTER III}

\section{RESEARCH CONTEXT AND METHODOLOGY}

Investigating the impact of the institutional environment on the diffusion pattern of a complex innovation is the scope of this study. Considering the context-sensitive aspect of this research which also targets processes evolving over time, a comparative and retrospective case study design with embedded units of analysis ${ }^{5}$ is appropriate (Patton 2002; Yin 2003).

In order to show how different institutional environments may variously impact patterns of diffusion of this technology, the study compares jurisdictions with contrasting modes of governance: the more centrally planned Quebec health care system and the more market-oriented Swiss health care system. These two jurisdictions constitute extreme cases in terms of governance structures while being sufficiently similar in terms of population size to allow useful comparisons (Eisenhardt 1989; Langley 1999). To understand the key features of the two institutional contexts, documentary data about each health care system was collected and reviewed.

While the previous chapter detailed the conceptual framework of this analysis, the current chapter focuses more specifically on the presentation of the PET scanner

${ }^{5}$ An embedded unit of analysis means that data is simultaneously analysed on multiple levels of analysis. 
technology, the jurisdictions under scrutiny, as well as the research design, data collection methods, and data analysis strategies which were mobilized in this study.

\subsection{RESEARCH CONTEXT}

The Positron Emission Tomography (PET scanner) is a complex and expensive diagnostic imaging technology that was initially rather controversial. The PET scanner has an initial history in neurology where it provided revolutionary imagery of brain functioning and in cardiology where it has been used to diagnose severe cardiac conditions. Nonetheless, it is the discovery of fluorodesoxyglucose (FDG), the most important radio-isotope (Rohren and Coleman 2004) enabling the diagnosis of cancer by means of the PET scanner, which remains its main clinical application. Compared with the Computed Tomography (CT-scanner), which provides structural anatomic clichés, the PET scanner produces functional images of the body, i.e. images showing activities of the body. Although clinical applications are now fairly universally accepted, the cost-effectiveness of this technology is still debated (Adams, Almazan et al. 2006). Indeed, the high acquisition cost (1.8 millions USD / machine) and running cost (1.3 million USD / year) are major counterweights to the benefits at least in some jurisdictions (Adams, Almazan et al. 2006). Assuming the PET scanner is useful, some experts suggest that one PET scanner for each million of population is sufficient for clinical and research purposes (Cleemput, Camberlin et al. 2008).

This technology derives its complexity in large part from the necessity, at least in the early years of diffusion, of having a cyclotron nearby to produce the radio-isotope injected into the patient during the diagnostic procedure. This is due to the short halflive of radio-isotopes. For example, the half-life of the FDG is 110 minutes and, in cardiology, the half-life of the radio-isotope oxygen-15 is only two minutes. The snag is that a cyclotron costs around $\$ 3.6$ millions USD and requires highly qualified and scarce personnel (radio-pharmacists) as well as a major improvement to hospital infrastructure to comply with nuclear regulations. However, by the year 2003, private companies started producing and supplying FDG in both jurisdictions thereby facilitating the adoption of this technology by organizations not having a cyclotron nearby. Figure 3.1 shows a PET scanner (left) and a cyclotron (right). 
FIGURE 3.1:

A PET SCANNER AND A CYCLOTRON
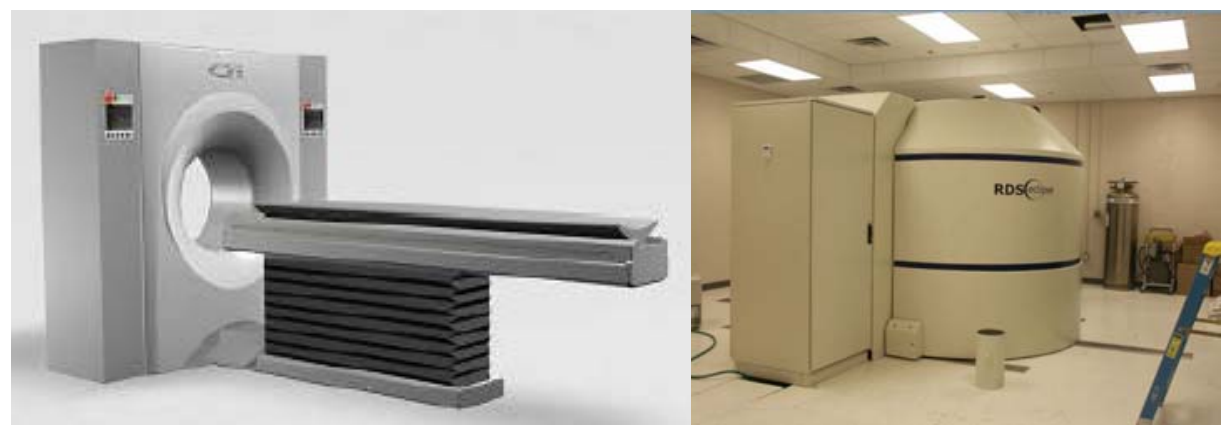

The adjunction of a CT scan to the PET scanner in 2001 and more extensively commercialized in 2003 was a breakthrough in the world of medical imaging. With this combination, the PET-CT scanner technology superimposes both structural and functional images of the body thereby increasing the precision of the diagnosis. In addition, the PET-CT scanner allows hospitals to perform 12 cases per day instead of 8 with a stand-alone system, due to time ${ }^{6}$ reduction in acquiring the data. PET-CT is believed to add clinical value to stand-alone PET added-value for approximately 15\% of cases, mainly in the otorhinolaryngology speciality, and costs around 3.7 millions USD.

The diffusion of this technology was felt to be particularly interesting for this study in that it revealed how different jurisdictions dealt with bandwagon tecbnology (i.e., a technology whose diffusion is hard to stop due to the powerful incentives associated with it; this concept is further developed at the beginning of chapter IV). Its applications for diagnosing cancer, cardiac and neurological diseases, as well as its high acquisition cost suggested analogies with other technologies such as Magnetic Resonance Imaging (MRI) and CT scanning that were known to have been subject to bandwagon pressures. Moreover, since there are many applications in cardiology, neurology, and oncology, inter-speciality competition to acquire the technology can occur.

\subsubsection{Two INSTITUTIONAL ENVIRONMENTS}

The publicly funded Quebec health care system and the more market-oriented Swiss health care system are particularly suitable for this study in that both are sufficiently

${ }^{6}$ Working alone, the PET scanner has to perform a correction in order to detect anatomical structures. This correction takes approximately 20-30 minutes. With the adjunction of a CT scanner, the production of anatomical images is quasi instantaneous. This speeds up the acquisition process of images. 
small to enable an in-depth study including virtually all individual adoption decisions of the PET scanner beginning in 1985 and ending in 2006.

Before mentioning the key differences between both health care systems, it is important to underline commonalities between both jurisdictions. First, both jurisdictions have a population of around 7.5 millions habitants. Life expectancy is also remarkably similar: overall, life expectancy at birth is 77.2 for men and 82.4 for women in Quebec, and 77.8 for men and 83.0 for women in Switzerland, suggesting that both health systems sustain the population with almost the same result. Table 3.1 details the number of inhabitants in both jurisdictions and life expectancy for the year 2003.

The descriptions and statistics of the Quebec and Swiss health care systems reflect their state between 2001 and 2003. During this period, pressure for the diffusion of PET scanner increased importantly in both jurisdictions.

TABLE 3.1:

Population, Life Expectancy at Birth for MEN \& Women in 2003

\begin{tabular}{lccc} 
& Quebec & & Switzerland \\
\cline { 2 - 2 } Population & $7,486,114$ & $7,339,000$ \\
Life expectancy at birth for men & 77.2 & 77.8 \\
Life expectancy at birth for women & 82.4 & 83.0 \\
\hline \multicolumn{2}{l}{ Sources: OECD Reviews of Health Systems - Switzerland (2006) \& Eco-santé Quebec } \\
2007 (http://www.ecosante.fr/)
\end{tabular}

\subsubsection{The Quebec Health Care System}

\subsection{Principles \& Regulations}

The general principles which guided the evolution of the Quebec Health and Social Services Systems are universality, equity and public administration. The Hospital Insurance Plan of 1961 and the Health Insurance Plan of 1971 allow all citizens to have free-of-charge access to the same set of services independently of her/his revenue and without discrimination. The Quebec health care system is mainly a public planned economy administered by the central government for resource allocation, health provisions, and to insure all citizens. The Quebec health care system is organized in three levels, central, regional and local, each with its own sphere of responsibility. 


\subsection{Institutional Actors}

The Ministry of Health and Social Services is the central level and is accountable for funding and organizing most health care activities in the province. Thus, it is responsible for planning the provision of health care services, for funding and allocating financial resources and for supporting and evaluating activities taking place in the Quebec health care system (Gouvernement du Québec, 2008). To fulfill this mission, the central government has the responsibility for investment in infrastructure and for acquiring targeted expensive technology, as well as negotiating remuneration with professionals and global budgets with organizations to ensure that health care services will be delivered to the population.

The central government relies on different organizations in order to obtain advice or to administer some facets of the Quebec health care system. Two of these organizations may play an important role in the adoption and the use of the PET scanner. The Health Technology Assessment Agency was created in 1988 with the mission to assess health services and technologies at the clinical and economic levels. These assessments are normally mandated by the central government to generate specific recommendations as to the use or adoption of a technology or a service.

Earlier than the creation of the Health Technology Assessment Agency was the foundation in 1969 of the public health insurance agency called the RAMQ (Quebec Health Insurance Agency) which was a key element in the institutionalization of the universal health care system. This body does not have a power per se, but has an important administrative role as it reimburses doctors, hospitals and in some cases patients.

At the regional level, each of the 18 territories of the province of Quebec has a Health Services Regional Agency which coordinates and controls activities between organizations and orchestrates the implementation of programs designed at the central level. The movement towards regionalization of the health care system started in 1990 after the publication of the Rochon Report in 1988. One of the objectives behind this movement was to give more responsibility to these agencies but, according to Lemieux, Bergeron et al., (2003), attempts to decentralize the decision-making process entirely to the region were not fully successful (Lemieux, Bergeron et al. 2003) and the agencies are perceived more as relaying orders from the central government. Consequently, regionalization should not be equated to decentralization, especially as regards the adoption of expensive technology such as the PET scanner. Indeed, in this case, the regional agencies do not have any real power, and negotiations take place 
between health care providers and the central government (i.e., the Ministry of Health) directly.

At the local level, public health care organizations have to fulfill their mission. Around 200 public organizations, 50 non-profit organizations, and 50 for-profit organizations offering long-term care compose the panorama of the Quebec health care system. These organizations were grouped by mission to fit into 5 categories. Hospital Centres $(\mathrm{CHs})$ "ensure the provision of short-term primary, secondary and tertiary services in general or specialized health care and in psychiatric care". The Local Centres for community services (CLSCs) are public clinics providing primary health care services including the prevention and promotion of health. Besides, there are private clinics that have similar missions to the CLSC with the exception that they can provide specialized services such as radiology, some of which can be reimbursed by public insurance. Three other missions complete this picture: residential long-term care centres (CHSLDs) are for people with decreasing autonomy; rehabilitation centres (CRs) specialize in helping people having physical impairment; child and youth protection centres (CPEJs) offer social services to young persons and their families. Moreover, around 3000 community organizations offer different services to the population such as preventing suicides or providing food for the homeless. Patient associations, with almost no power, may also be involved in defending patient interests.

The design of the Quebec health care system changed significantly with the 2004 reform which created Health and Social Service Centres (CSSS) that regrouped CHs, CLSCs and CHSLDs under one administrative board. This rearrangement did not change the distribution of organizations interested in obtaining the PET scanner technology.

While the number of health care organizations was around one thousand by the end of the eighties, there were 482 organizations in the network in 2001. In this system, many organizations accumulate more than one mission. The Quebec health care system had 4 teaching hospitals (excluding hospitals affiliated to a university), 125 general hospitals, 116 public clinics and around 2000 private clinics in 2001. The total number of doctors was 15,267 and the number of specialists was 7,717 among which 555 were radiologists and 85 were nuclear doctors for the year 20067 .

\footnotetext{
7 The year for hospitals and clinics and to doctors and specialists is not the same due to data availability.
} 
Professionals are members of medical associations which represent their interests mainly to the government and negotiate budgets to be allocated. These budgets directly affect the revenue of the two main professional associations for doctors. While the FMOQ (The Quebec Federation of General Practitioners) represents the interest of general practitioners (GPs), the FMSQ (The Quebec Federation of Specialist Doctors) defends the position of specialists (Fournier 2001). Once a budget is allocated, each specialty within its Federation negotiates the amount it should receive. Typically, the Quebec Association of Nuclear Doctor and the Association of Radiologists are two different entities that are part of the FMSQ, and each one negotiates its own budget. Only nuclear doctors can operate PET scanners.

\subsection{Funding and Allocation of Resources}

In 2003, total expenditure in health care was around 18.6 billions USD, which represents about 10.4 percent of the GDP, and total expenditure per person was 2,487 USD per year. With such a high ratio of health-care expenditure to its GDP, the province of Quebec would come fourth among the OECD countries, after USA (15.0\%), Switzerland (11.5\%) and Germany (11.1\%) (OECD 2006).

This system is in large part funded through taxation: $71.2 \%$ of the total health expenditure in 2000 was funded through taxation (Lemieux, Bergeron et al. 2003). Private expenditure on health accounts for $28.8 \%$ of the total expenditure. Pharmaceutical products and professionals other than doctors (e.g. dentists) are two major domains that are largely financed though private sources with $57.2 \%$ for the former, and around 88\% for the latter (Lemieux, Bergeron et al. 2003). While public coverage pays for essential medical care, private insurance included as employee privilege can pay for supplementary services such as dentists, and for a PET scan before it was covered by the government of Quebec. However, only 2.0\% of doctors' remuneration is private (this is due to the public health insurance), and less than $10 \%$ of hospital expenditure comes from private sources (Lemieux, Bergeron et al. 2003). This suggests that essential medical care is mainly financed through public funding.

With the universal health insurance adopted in 1971, doctors began to be paid on a fee-for-service basis by a single health insurance agency (RAMQ) and lost their right to charge fees on a private basis to patients covered by this public health insurance (Lemieux, Bergeron et al. 2003). As a consequence of implementing universal coverage, health care costs and doctors' revenues exploded, thereby forcing the government to introduce new methods to control remuneration. In 1976, the law of health insurance stipulated that doctors' remuneration be the product of negotiation 
between the government and two professional union associations regrouped under the banner of FMOQ and FMSQ (Fournier 2001). Both associations agree on a revenuetarget based on average revenue of GP and specialist doctors. If the negotiated average revenue is surpassed, the amount that has to be paid in excess is deducted from the next year's increased rate of the budget.

The individual revenue for GP is capped, i.e. once this revenue is reached doctors are paid at $25 \%$ of the normal rate; this revenue cap was set at about $33 \%$ higher than the average revenue. These caps are applied by sections of three months to make sure that doctors will still have incentives to work by the end of the year. In 1995, things slightly changed as an annual global budget was going to be negotiated with each association. From this moment, the system of capped individual revenue was also adopted by specialists (Fournier 2001) and the annual global budget had to be divided between 35 specialties.

Teaching and general hospitals were and are largely financed through public funds on a global budget, with the previous year being the criteria for allocation with adjustments for the costs of production factors and change in activities of the organization. Within the global budget and the limit of the law, managers are free to administer their organization as they wish.

To counter deficits generated by hospitals, the Government adopted in 1996 a law forbidding hospitals to generate deficits at the risk of seeing authorities imposing a trusteeship or of changing the management team. To balance their budgets and comply with this regulation, the number of acute care beds is often reduced which entails an increase in the waiting list.

\subsection{Regulations Specific to Expensive Technologies and the PET Scanner}

Since expenditure on hospitals and doctor remuneration is directly paid by the government, the latter is more likely to be reluctant to invest or to allow reimbursement of costly procedures given its limited budget. This is exacerbated in Quebec since the provincial government is one of the most indebted in Canada and a large part of its budget (around 40\%) is already dedicated to the health care system. Hence, to ensure that an innovation is worthy of being reimbursed and diffused, the government often relies on the recommendations of a Health Technology Assessment Agency. To control the diffusion of the PET scanner, the law specifies that under the public regime no organization can provide PET scanner procedures or acquire this technology without the authorization of the Ministry of Health. If this Ministry 
refuses to support projects financially, some hospitals may rely on their private foundation for funding. However, even in this case, the acquisition of such technologies as the PET scanner, must be approved by the Ministry of Health.

Interpretation of PET scans is reimbursed to doctor only if they perform this procedure in a public hospital. Nuclear doctors are paid on a fee-for-service basis for each of their interpretations of PET scans (up to the point where they have reached their revenue cap) and hospitals received an annual budget for the PET scanner which allows this technology to work properly.

Overall, because the State administers the health care system and is the single authorized insurer for universal basic health care coverage for a wide range of medical services, the adoption of new technology is not accounted for as a source of profit by the regulator, but as a cost. Moreover, while the health care system is centrally managed and publicly funded, different forms of non-price-based competition are embedded within it. Most critically, physicians are generally paid on a fee-for-service basis and therefore may compete with each other in a market for patients. Moreover, a hospital's survival depends on attracting qualified medical specialists who thus have an important influence on organizational strategy. Competition for prestige, resources, and investment among institutions can therefore be intense. Since resources are largely controlled by government, this competition often plays itself out in the public sphere.

\subsubsection{The Swiss Health Care system}

\subsection{The Federal Health Insurance Law}

Second only to the United States when it comes to Health Care expenditures as a share of GDP (OECD 2006), Switzerland has not only one of the most expensive health care system in the world, but also one of the more complex. Whereas the Quebec Health Care System is centralized and publicly funded, Switzerland's health care system is highly decentralized (OECD 2006) and more market oriented. Indeed, because federalism is embedded in its political system and is at the hub of this health care system, it endows the 23 cantons with the responsibility of organizing the provision of health care in their territory and of financing major investment such as new expensive technologies. This highly decentralized political structure comes with a market for health care where competition takes place between health insurance companies as well as between health providers.

The introduction of the Federal Law on Health Insurance (LAMal) in 1996 brought a significant change at least in the spirit of the preceding 1911 Federal Law on Health 
Insurance by imposing compulsory universal coverage. Within this new law, reimbursable health services were to be exhaustively defined by the Federal Office for Social Insurance ${ }^{8}$ (OFAS), and each insurer would provide flat fee premiums to clients for compulsory health insurance without discrimination as regard to age, gender and medical profile. Compulsory health insurance confirms the same package of essential medical services for all, but does not provide free choice of physicians in hospital settings nor the possibility of enjoying extraordinary "hotel" services such as having a private room. For these privileges, supplementary health insurance must be bought.

\subsection{Institutional Actors}

Federal Level. Under the Federal Department of Internal Affairs, the highest instance of Switzerland as regard to health, social affairs, education and culture, the Federal Office for Social Insurance (OFAS) regulates and proposes reforms related to the Federal Law on health insurance (LAMal) and other social insurances, and decides what medicines and health technologies should be covered by compulsory health insurance as well as the price at which drugs should be sold (European Observatory, 2000). The Federal Department of Internal Affairs is also responsible for the protection, prevention and promotion of health, as well as for medical training and scientific research.

The Federal Department of Internal Affairs has several advisory units and organizations to support its activities. For example, it relies for recommendations on the Federal Commission for Health Insurance when reimbursements of medical procedures are contested. To make sure that the PET scanner responds to nuclear norms, the Department of Radioprotection which is part of the Federal Office of Public Health (OFSP) is involved in measuring radiation and approving its use. To be commercialized, therapeutic products must be approved by Swissmedic, a federal organization which ensures the quality, safety and effectiveness of health related products. To produce and sell FDG, producers must have the authorization of Swissmedic.

Despite the absence of a formal, legitimated and independent health technology assessment agency, the Federal Office for Social Insurance (OFAS) conducts its own cost-effectiveness analysis before granting reimbursement of health innovations. Unlike the health technology assessment agency in Quebec which publishes reports regularly, OFAS does not make its cost-effectiveness analyses available to the public.

${ }^{8}$ The LAMal was under the responsibility of the Federal Office of Social Insurance (OFAS) up to 2003 when it passed to the Federal Office for Public Health (OFSP). 
However, there is an independent organization called The Swiss Centre for Technology Assessment (TA-Swiss) ${ }^{9}$ which aims to assess health technology, although many interviewees agreed that this organization does not have significant political weight.

Cantonal Level. Cantons have a high degree of independence in the organization and management of their health care system and as a consequence technology acquisition regulations change from canton to canton. The LAMal compels cantons to plan hospital provision, to limit the range of providers to be reimbursed and to finance health services partially (European Observatory, 2000). As such, cantons assure the provision of health care by owning some hospitals, by subsidizing a variety of health care institutions and by the planning and monitoring of health care activities. However, although cantons have a planning role in hospital setting, ambulatory activities are left to market forces. Cantonal tax revenue pays public and publicly subsidized hospitals for capital investment, education and research costs (European_Observatory 2000). Moreover, fee schedules negotiated between service providers and SantéSuisse (the cantonal association of health insurance companies) at the cantonal level have to be approved by the canton.

Local Level. The local level is constituted by 2700 communes and by public and private organizations. While the former participate in the provision and subsidies of care for the elderly and for physically and mentally handicapped people (European_Observatory 2000), the latter provide primary, secondary and tertiary services whether from hospitals, specialized clinics or independent professionals. Hospitals can be public, publicly subsidized or private. While public hospitals are the property of cantons, associations of communes, independent communes or foundations (European_Observatory 2000), publicly subsidized hospitals are private but come under the control of the canton and have to account for their financial management. These two situations allow hospitals to receive cantonal subsidies and to be covered in case of deficit andreimbursed for services falling under compulsory health insurance (European_Observatory 2000). Entirely private hospitals do not receive financial subsidies from the canton and cannot be reimbursed under compulsory health insurance. They can only be financed by supplementary health insurance payments or by out-of-pocket payments. Between 1997 and 2002, Switzerland has seen the number of hospitals reduced from 406 to 365 in-patient hospitals (Office_fédérale_de_la_statistique 2004). From this number, 5 were public

\footnotetext{
${ }^{9}$ Centre d'évaluation des choix technologiques.
} 
teaching hospitals, 215 were public or publicly subsidized hospitals, while 134 were private (these data include specialized clinics in surgery, rehabilitation and in psychiatry). Public and private hospitals in Switzerland are represented by an association called $H+$ The Swiss Hospitals. Besides political lobbying, this association provides its members with training, management tools and hospital statistics and, at the cantonal level, $H+$ negotiates fee schedules with health insurance companies.

Table $3.2^{10}$ compares the number of hospitals in both jurisdictions and underlines their similarity in terms of the number of teaching hospitals, and their dissimilitude over the number of public and private hospitals (354 in Switzerland against 125 in Quebec). Unfortunately, there are still no statistics on the number of organizations or clinics which provide ambulatory services exclusively.

TABLE 3.2:

NUMBER OF HOSPITALS IN BOTH JURISDICTIONS

\begin{tabular}{|c|c|c|}
\hline & Quebec & Switzerland \\
\hline Public teaching hospitals & 4 & 5 \\
\hline $\begin{array}{l}\text { Public hospital (including publicly } \\
\text { subsidised and excluding teaching } \\
\text { hospitals) }\end{array}$ & 125 & 215 \\
\hline Private hospital & 0 & 134 \\
\hline $\begin{array}{l}\text { Public clinics } \\
\text { ambulatory only }\end{array}$ & 116 & N.A. \\
\hline $\begin{array}{l}\text { Private clinics } \\
\text { ambulatory only }\end{array}$ & around 2000 & N.A. \\
\hline
\end{tabular}

In 2002 the density of physicians in Switzerland (3,6/1000 inhabitant) was one of the highest of all OECD countries (OECD 2006), partly because the organization of the ambulatory setting is mainly driven by market forces. To counter this phenomenon, some cantons have imposed a moratorium on licensing doctors in private practice, but allow doctors to work on public or publicly subsidized hospitals. Compared with Quebec, Switzerland had almost twice as many GPs (27,268 vs. 15,267) and specialists $(17,995$ vs. 7,717$)$ in 2003 . Table 3.3 compares the number of physicians and hospitals in both jurisdictions. Interestingly, while there are more GPs and specialists in Switzerland, there are, apparently, more radiologists (555 versus 348) and nuclear doctors (85 versus 45) in Quebec. Each cantonal medical association represents doctors to

${ }^{10}$ In Quebec, for organizations cumulating several missions, only the mission of $\mathrm{CH}$ was computed in this table. 
negotiate their fees with the respective cantonal association of health insurance companies.

TABLE 3.3:

NUMBER OF DOCTORS IN BOTH JURISDICTIONS

\begin{tabular}{|c|c|c|}
\hline & Quebec & Switzerland \\
\hline Total number of doctors & $15^{\prime} 267$ & $27^{\prime} 268$ \\
\hline Number of physician specialists & $7^{\prime} 717$ & $17^{\prime} 995$ \\
\hline Number of radiologists & 555 & 348 \\
\hline Number of nuclear doctors & 85 & 45 \\
\hline $\begin{array}{l}\text { Sources: The number of doctors and s } \\
\text { Statistics and Indicators for } 30 \text { countr } \\
\text { The statistics of radiologists and nucle } \\
\text { FMH in } 2007 \text {, and the same statistics } \\
\text { year } 2006 \text {. }\end{array}$ & $\begin{array}{l}03 \text { comes frc } \\
\text { té Quebec } 2 \\
\text { witzerland c } \\
\text { mes from } \mathrm{E}\end{array}$ & $\begin{array}{l}\text { ource data } 2006 \\
\text { www.ecosante.fr/ } \\
\text { the website of the } \\
\text { ebec } 2007 \text { for the }\end{array}$ \\
\hline
\end{tabular}

In contrast to the Quebec health care system where there is only one public health care insurance, Switzerland had 101 different insurance companies offering health plans in 2000. In 1997, 15 companies were covering 68,4\% of the population for compulsory health insurance, while $71 \%$ of all other companies were covering less than 10,000 people (European_Observatory 2000). Not-for-profit health funds and for-profit health insurance companies can offer health insurance plans provided they register with the Federal Office of Social Insurance (OFAS). However, no profit can be made out of selling compulsory health insurance, only by selling supplementary health insurance. Insurers have to comply with different rules such as obligation to contract with service providers, obligation to cover people living in Switzerland, obligation to deliver services included on the Federal Office for Social Insurance health services list, to participate in a risk-compensation fund ${ }^{11}$ and to constitute reserves $^{12}$ (OECD 2006). Health insurance companies are represented in every canton by an association called SantéSuisse. This association offers various services to its members such as making political representations to cantonal authorities, negotiating tariffs at national and cantonal level, and promoting the corporate image of its members.

The Swiss Nuclear Medicine Association represents nuclear doctors in Switzerland at the political level, develops recommendations on the use of nuclear products in medicine, informs the public and promotes the training of nuclear doctors. In 1999, the Swiss

\footnotetext{
${ }^{11}$ In Switzerland, all insurance companies must participate to a risk-compensation fund which is redistributed to companies having a pool of clients with age and gender structures which entail higher risk.

${ }^{12} \mathrm{~A}$ reserve is a compulsory amount of money that companies must keep in order to be able to pay debts engendered by their clients. By law, reserves must be constituted of at least $15 \%$ of premiums received if a company covers more than $250^{\prime} 000$ people.
} 
Nuclear Medicine Association was mandated by the federal government to find a new way to accredit PET scanner providers for reimbursement purposes. The case study of the diffusion of the PET scanner in Switzerland documents this mandate. This Association is also the required to keep statistics on the number of PET scanner procedures performed in each PET centre throughout Switzerland.

\subsection{Funding and Allocation of Resources}

Switzerland recorded a GDP percentage of $11,5 \%$ and a per capita spending of 5,035 USD for its Health Care system in 2003. As compared with Quebec, Switzerland spent about one percent more of its wealth in health care (expenditure as a share of GDP), but spent twice as much as Quebec in absolute terms. Table 3.4 compares health care expenditures in both jurisdictions.

TABLE 3.4:

Total Expenditure on Health, Per Person, and as a Share of GDP in 2003

\begin{tabular}{lccc} 
& Quebec & & Switzerland \\
\cline { 2 - 2 } $\begin{array}{l}\text { Total expenditure on health at USD } \\
\text { exchange rate ('000 000) }\end{array}$ & $18^{\prime} 640$ & $36^{\prime} 949$ \\
$\begin{array}{l}\text { Total expenditure on health per } \\
\text { person at USD exchange rate }\end{array}$ & 2 '487 & 5 \\
$\begin{array}{l}\text { Total expenditure on health as a } \\
\text { share of GDP (\%) }\end{array}$ & 10.4 & 11.5 \\
\hline $\begin{array}{l}\text { Sources: OECD Source data } 2006-\text { Statistics and Indicators for } 30 \text { countries \& Eco-santé } \\
\text { Quebec } 2007 \text { http://www.ecosante.fr } / .\end{array}$
\end{tabular}

The Swiss health care system is financed through three main channels. In 2003, 1) $23.9 \%$ of health care expenditures came directly from the government (Federal, Cantonal and Communal), 2) 10.5\% through social insurances schemes (accident insurance, military insurance, and disability insurance) and other social protection, 3) $65.7 \%$ from private households such as compulsory and supplementary ${ }^{13}$ health insurances, cost-sharing and out-of-pocket (OECD 2006). Thus, it can be argued that only $34.3 \%$ of the Swiss health care system is publicly funded through tax-collection and $65.7 \%$ is private.

Representing $35.7 \%$ of the total expenditure in Switzerland, health insurance premiums for compulsory $(26.8 \%)$ and supplementary $(9.0 \%)$ health insurances is the largest part of private payment shared by households (e.g. visiting a private hospital is not covered by compulsory health insurance). Compulsory health insurance premiums

\footnotetext{
${ }^{13}$ Supplementary health insurances are risk-related, which mean insurance companies can charge clients according to their personal medical history.
} 
are fixed according to market conditions by estimating the total expenditure per canton in the year to come and dividing it by the number of clients expected to subscribe to a health insurance company. These premiums are systematically audited by the Federal Office of Social Insurance.

Cost-sharing which mainly includes deductible (varying negatively with premium costs and ranging from $500 \mathrm{CHF}$ to $2500 \mathrm{CHF}$ in 2005$)$ and co-insurance (10\% beyond the value of the deductible up to an amount of $700 \mathrm{CHF} /$ year) account for $5.3 \%$ of total expenditure in health care, and $23.7 \%$ comes from out-of-pocket. For very low income households, the federal and cantonal governments offer programs of aid.

Overall, the proportion of expenditure sustained by private households is higher in Switzerland (65.7\%) than in Quebec $(28.8 \%)$ in 2003. This suggests that health care expenditure in the Quebec health care system is more collectively shared. Table 3.5 compares the percentage of public and private health expenditure in both jurisdictions.

TABLE 3.5:

Percentage of Public and Private Health Expenditure in 2003

\begin{tabular}{lccc} 
& Quebec & & Switzerland \\
\cline { 2 - 2 } Public & 71.2 & 34.3 \\
Private & 28.8 & 65.7 \\
\hline
\end{tabular}

Sources: OECD Reviews of Health Systems - Switzerland (2006) \& Eco-santé Quebec 2007: http://www.ecosante.fr/.

Hospital Payment. While outpatient interventions are entirely covered by health care insurance, $50 \%$ of costs incurred for public hospital in-patients are covered by health care insurance with the other 50\% being financed from the global budget. In hospital settings, reimbursement for in-patient services under compulsory health insurance was performed using different payment methods such as per diem, APDRG, global budget and a combination of these which varies from canton to canton. Consequently, reimbursement is not based on a uniform tariff across cantons. However, these fees are negotiated between individual or groups of hospitals, the cantonal association of insurance companies and the cantonal authority. To alleviate the financial burden, most cantons impose a "fixed budget for the subsidies paid to public and publicly subsidized hospitals as well as nursing homes" (European_Observatory 2000: 68). 
When services are provided under supplementary health insurance, negotiated rates are higher to cover the more costly "hotel" and medical services. Costs generated by out-patients and by in-patients staying less than one night in hospital are covered by insurers often by using APDRG ${ }^{14}$.

Physician payment. Doctors are paid according to different regimes. In most hospital settings, doctors are salaried, but can make substantial bonuses through the redistribution of the profit generated by their Unit. "They also receive limited additional payments for services provided to people with supplementary health insurance" (European Observatory, 2000: 69). However, for ambulatory services and less-than-one-night hospital in-patients, fee-for-service reimbursed by health insurances is the dominant payment mechanism. Doctors in private practice are paid on a fee-for-service basis, and no limit is set on their revenue.

Before 2004, there were no flat rates across cantons in ambulatory settings and tariffs were negotiated at the cantonal level. However, since January 2004, a nationally unified structure of ambulatory medical fees called TARMED has been adopted to standardize tariffs across cantons. In an ambulatory setting, there is no limit to a doctor's revenue. Ambulatory health care is provided outside hospitals by general practitioners and specialists as well as by dentists, physiotherapists, psychotherapists, chiropractors, homoeopathic practitioners, acupuncturists, dieticians, chiropodists, analyses in pharmacological or medical laboratories, etc.

\subsection{Regulations Specific to Expensive Technologies}

From 2004 onwards, the reimbursement of the PET scanner procedures has been covered by TARMED, and the tariff negotiated nationally, instead of for each canton. As a result, it removed the barriers on private hospitals to buy expensive technologies because it guarantees the same tariff to everyone, private or public hospital, or doctors with an independent practice. However, even after the introduction of TARMED, if an organization is refused reimbursement by the federal government, it can still negotiate reimbursement with the Cantonal Association (SantéSuisse at the cantonal level) of Insurance.

In most cantons, the acquisition of expensive technology by public and publicly subsidized hospitals requires the authorization of the cantonal government. Investments of over 500,000 CHF in some cantons and of over 1 million CHF (i.e.

14 APDRG: All Patient Diagnostic Related Group is a method of classifying patients in order to receive payment according to the patient's group. 
approximately one million USD) in others need the consent of cantonal authorities. However, most cantons do not require private organizations to obtain such authorization, only a few cantons having a certificate-of-need regulation which requires private organizations to obtain the consent of the cantonal government.

Before 2001, PET providers had to be nominated by the Federal Office for Social Insurance (OFAS) for health insurance companies to reimburse PET scanner procedures. This health care system was flexible to the extent that if the federal government refused to nominate a PET provider for reimbursement, it was still possible to negotiate at the cantonal level with health insurers to be reimbursed for certain applications. Since 2001, the Swiss Medical Association accredits PET centres for reimbursement according to quality criteria.

In this health care system, adopting new technologies can be considered as a source of profit for PET providers since it may contribute to attract patients and to increase the number of payments. In Quebec, new technologies can be perceived as a source of cost since the government is systematically paying for all health care services. Consequently, the institutional environment can alter the way a technology is perceived and may influence the rate of diffusion of expensive technologies. This, combined with open competition in Switzerland between insurers and between health care providers, probably serves to explain at least partially why this jurisdiction has one of the highest density of high-end technological equipment among OECD countries (OECD 2006), and why it has a higher number of MRIs (93 versus 19) and CT-scanners (127 versus 93) than in Quebec as shown in table 3.6.

TABle 3.6:

NUMBER OF CT-SCANNERS AND MRI IN OPERATION IN BOTH JURISDICTIONS IN 2001

\begin{tabular}{|c|c|c|}
\hline & Quebec & Switzerland \\
\hline $\begin{array}{l}\text { Computed Tomography Scanners } \\
\text { (CT-scanners) }\end{array}$ & 81 & 127 \\
\hline $\begin{array}{l}\text { Magnetic Resonance Imaging } \\
\text { (MRI) }\end{array}$ & 19 & 93 \\
\hline
\end{tabular}


TABLE 3.7:

Governance Structures of The Quebec and Swiss Health Care Systems

\begin{tabular}{|c|c|c|}
\hline Dimensions & Québec & Switzerland \\
\hline Economy & More centrally planned & More market oriented \\
\hline Centralization & Centralized & Decentralized \\
\hline Funding sources & One & Many \\
\hline $\begin{array}{l}\text { For public hospitals, authorization } \\
\text { to buy expensive technology or to } \\
\text { obtain a budget to do so }\end{array}$ & From the central government & From the cantonal governments \\
\hline $\begin{array}{l}\text { Financing the operation of } \\
\text { expensive technologies }\end{array}$ & $\begin{array}{l}\text { Operational budget from the central } \\
\text { government }\end{array}$ & $\begin{array}{l}\text { Authorization to reimburse from the } \\
\text { federal government }\end{array}$ \\
\hline Physician payments & Fee-for-service (capped) & $\begin{array}{l}\text { Hospitals: salaried } \\
\text { Private: fee-for-service }\end{array}$ \\
\hline Ambulatory Hospital Payment & Global Budget & Fee-for-service \\
\hline Types of hospitals & Public & Public and private \\
\hline Health insurance companies & One, entirely public & Many \\
\hline Technology Assessment Agency & One & None \\
\hline
\end{tabular}

Overall, using the criteria of Scott (2004) the governance structure of Quebec's health care system appears to be more cohesive than the Swiss one. Indeed, 1) it is centrally administered and funded by the Ministry of Health which delegates operations to Regional Health Authorities and health care institutions. Because the governance structure is centrally administered, 2) unity of governance is fairly high. Moreover, 3) the principal mode of governance is mainly public (one mode of governance dominates), 4) there are a limited number of structural models for hospitals (structural isomorphism), and 5) formal organizational linkages are numerous. These five dimensions tend to produce a highly structured organizational field according to the dimensions proposed by Scott (2004) and a high degree of structural isomorphism (DiMaggio and Powell 1983; Scott 2004). This high degree of structural coherence would tend to give the State a tighter control on the distribution of funds in the health care system. This picture contrasts with the governance structure in Switzerland which has a more fragmented health care system as there is no unity of governance, a decentralized administration, a high level of involvement of private institutions, and where there are numerous structural models for hospitals and formal organizational linkages are not so intense as in Quebec. Table 3.7 summarizes the main differences between the governance structures of these two health care systems. 


\subsection{Methodology}

\subsubsection{Research Design and Data Collection}

Case study research methodology is particularly appropriate for the study of processes and for highly context-sensitive inquiry (Patton 2002; Yin 2003). As Eisenhardt (1989) and Yin (2003) suggest, case studies are particularly useful for answering "why" and "how" questions, examining emergent relationships (Eisenhardt 1989) and understanding how processes evolve over time (Langley 1999).

Data on the adoption and diffusion processes for the PET scanner was collected through interviews and documentation. Overall, 88 semi-structured interviews (42 in Quebec and 46 in Switzerland) transcribed by a professional typist were carried out with key people involved in the diffusion or the adoption of the PET scanner at all levels of analysis: national (federal), regional (cantonal) and at each adoption site. More specifically, 33 interviews of 40 to 110 minutes and 9 interviews of 20 to 40 minutes were conducted in Quebec and 36 interviews of 40 to 110 minutes and 10 interviews of 20 to 40 minutes in Switzerland. Table 3.8 gives an overview of the total number of interviews per organization that was performed in each jurisdiction.

To maximize the time devoted to the interview and to cover all relevant aspects, an interview guide was crafted according to the conceptual framework (Miles and Huberman 1994; Patton 2002) synthesized in figure 2.1 (see section 2.2). The interview guide covered respondents' perceptions of the institutional environment, of the innovation itself, and of the role of different participants in adoption both within their own local context and more broadly. Interviews began by asking the interviewee to tell the story of the PET scanner in which she/he was involved. Respondents were then asked to explain what the technology meant to them, what were the arguments for and against the technology, what legitimization strategies were used, what was the impact of the adoption, and to describe the decision processes in which they participated as well as the role of all institutional actors involved. The interview guide was adapted according to the particularities of each jurisdiction (see Appendix A for the French version of the interview guide used in Switzerland). To participate in the research, informants were asked to sign a consent form (see Appendix B) stating their right to withdraw from the research and the purpose of the research. The consent form also guaranteed the confidentiality of the data. 
TABLE 3.8:

NUMBER OF INTERVIEWS PER ORGANIZATION

\begin{tabular}{|c|c|c|c|c|}
\hline \multirow[b]{2}{*}{ Level } & \multicolumn{2}{|l|}{ Quebec } & \multicolumn{2}{|c|}{ Switzerland } \\
\hline & Organizations & $\begin{array}{l}\text { Number of } \\
\text { interviews }\end{array}$ & Organizations & $\begin{array}{l}\text { Number of } \\
\text { interviews }\end{array}$ \\
\hline \multirow[t]{5}{*}{ National } & $\begin{array}{l}\text { Ministry of Health \& Ministry } \\
\text { of Economy }\end{array}$ & 5 & Department of Health & 5 \\
\hline & Medical Associations & 4 & Medical Associations & 1 \\
\hline & Patient Association & 1 & Health Insurance Association & 2 \\
\hline & Manufacturers & 2 & Manufacturers & 2 \\
\hline & $\begin{array}{l}\text { Health Technology Assessment } \\
\text { Agency }\end{array}$ & 3 & & \\
\hline Regional & Regional Agencies of Health & 3 & $\begin{array}{l}\text { Cantonal Department of } \\
\text { Health }\end{array}$ & 4 \\
\hline \multirow[t]{15}{*}{ Local } & THA1 & 5 & THD & 6 \\
\hline & THA2 & 4 & THN & 4 \\
\hline & THA3 & 2 & THS & 4 \\
\hline & THB & 5 & THU & 3 \\
\hline & THC & 4 & THV & 4 \\
\hline & GHC & 2 & $\mathrm{CHG}$ & 1 \\
\hline & PCA & 1 & CHR & 2 \\
\hline & PCC & 1 & CHT & 1 \\
\hline & PCQ & 0 & $\mathrm{CHZ}$ & 3 \\
\hline & & & PCXS & 0 \\
\hline & & & PCD & 1 \\
\hline & & & PCDV & 1 \\
\hline & & & PCV1 & 1 \\
\hline & & & PCV2 & 1 \\
\hline & Total & 42 & Total & 46 \\
\hline
\end{tabular}

Internal and external documents were also collected and analyzed to document processes, to examine written theorizations of the technology, to identify institutional logics inherent to each system and for triangulation purposes (Eisenhardt 1989; Miles and Huberman 1994; Patton 2002). Because triangulation involves the comparison of information collected in interviews with written documents, it provides higher validity to analysis (Miles and Huberman 1994). At the end of each interview, interviewees were asked to provide internal documents related to the diffusion or adoption of the PET scanner in their organizations. National and regional newspapers were also screened to collect public information related to the subject.

\subsubsection{Data ANALYsis}

To compare diffusion patterns, detailed case narratives were constructed for each region in each jurisdiction through iterations between data collection and data analysis (Eisenhardt 1989; Miles and Huberman 1994) and with the help of a visual mapping strategy (Langley 1999; see examples in sections 4.2 and 4.4). The narratives were useful in breaking down the complexity of the data into manageable chunks and 
allowing meanings and specific mechanisms to emerge (Eisenhardt 1989; Langley 1999). Each narrative was then revised by two interviewees of each jurisdiction to testify its validity and to suggest improvements. Each individual adoption or attempt at adoption in both Quebec and Switzerland was documented and analyzed in terms of the rationales used by adopters, their actions and their outcomes. The case studies thus cover three regions in Quebec and nine cantons in Switzerland and involve nine organizations in the former and fourteen in the latter.

However, the use of narrative strategies has clear limitations in terms of generality and simplicity ${ }^{15}$ (Miles and Huberman 1994; Langley 1999). Thus, complementary analytical strategies were mobilized. The main idea is to combine different analysis techniques in order to avoid bias and to allow theoretical generalization (Yin 2003). As Eisenhardt (1989: 540) remarks:

“...people are notoriously poor processors of information. They leap to conclusions based on limited data (Kahneman \& Tversky, 1973), they are overly influenced by the vividness (Nisbett \& Ross, 1980) or by more elite respondents (Miles \& Huberman, 1984), they ignore basic statistical properties (Kahneman \& Tversky, 1973), or they sometimes inadvertently drop disconfirming evidence (Nisbett \& Ross, 1980). The danger is that investigators reach premature and even false conclusions as a result of these information-processing biases. Thus, the key to good cross-case comparison is counteracting these tendencies by looking at the data in many divergent ways."

To counter these biases and to explore similarities and discrepancies between cases, visual mapping strategies and matrix displays were used to synthesize the data (Miles and Huberman 1994; Langley 1999) and to compare the evolution of the processes across the two jurisdictions. By showing precedence, parallel processes, and passage of time (Langley 1999), visual mapping strategies enable the detection of key macro patterns. This strategy allows the simultaneous representations of many dimensions of phenomena thereby showing macro processes at work (Langley 1999). This technique was also used conjointly with narrative strategy to build case studies. Matrix displays are also helpful to explore, analyse and display results of within-case analysis and are remarkably useful for the synthesis of data for cross-case analysis (Miles and Huberman 1994). Examples of how I grouped citations in order to create categories and analyse data are presented in Appendix C.

Theory building strategies not only allow, but also encourage iterations between data collection and data analysis (Eisenhardt 1989; Miles and Huberman 1994). This increases the probability for the researcher to discover new relationships and to

15 According to Langley (1999), generality refers to the range of circumstances in which the theory would be valid, and simplicity implies a high explanatory power with few elements and theoretical relationships. 
exploit opportunities as they show up (Miles and Huberman 1994). Accordingly, my data collection was conducted iteratively with a wave of interviews being performed and then analysed in each jurisdiction: further interviews were conducted in order to address gaps in the data set. In the case of Quebec, 22 interviews were performed and analysed in the first wave. This was an opportunity to identify new concepts and new relationships and led to some modifications of the interview guide (Eisenhardt 1989; Miles and Huberman 1994). Then, 13 interviews were carried out in Switzerland to explore the compatibility of this jurisdiction with the research imperatives. While a second wave of 20 interviews was conducted in Quebec to saturate the data set, successive waves of 21 interviews and 12 interviews were carried out in Switzerland.

Iterations between data collection and data analysis stopped when the marginal benefit of analysing and collecting further was negligible in providing additional information about the elements of the conceptual framework, the relationships between them and their deployment through time (Eisenhardt 1989). Thus, interviews were performed and documents were collected up to the saturation ${ }^{16}$ of the data set (Strauss and Corbin 1998). Where in some instances only one interview was performed, documentation was systematically collected to support actors' arguments. In Switzerland, only one organization refused to participate in the study, but many documents were made available to compensate this gap. In Quebec, one organization was not included due to its very low potential for adding significant input to this research.

Analysis of the data led us to identify the importance of struggles between actors in the organizational field along two axes, described as vertical and horizontal. On the one hand, vertical struggles refer to confrontations between the regulator (Ministry of Health in Quebec, various agencies in Switzerland) and other institutional actors. The term horizontal struggle was used to refer to the competition among institutional actors for scarce resources. As the case studies show, although Quebec's health care system is not theoretically a competitive market, competition among health care providers nevertheless permeated the diffusion process. As mentioned at the end of the previous chapter, I also came to qualify these struggles in terms of two inter-related modes of action: struggles for meaning, in which participants drew explicitly on different theorizations to justify their positions and to translate the technology in terms that were favourable to them; and struggles for control in which organizational actors mobilized authority and material resources to achieve their goals. I adapted the notion

\footnotetext{
${ }^{16}$ Saturation refers to the point where additional interviews or documentation does not provide new information.
} 
of theorization (Strang and Meyer 1993; Tolbert and Zucker 1996; Strang and Soule 1998) to include statements dealing with four questions: what was the purpose of the technology, why the technology should be adopted, who should adopt it, and how it should be diffused. Once theorizations were identified, public documents and reports were screened in order to identify institutional logics inherent in both health care systems.

When data was close to saturation and analyses were almost complete, propositions were shaped. As compared to a hypothesis-testing approach, hypotheses emerged from the analysis instead of being set a priori (Eisenhardt 1989). To achieve this, process data, observed patterns across cases and conceptual constructs were compared to identify similarities and differences across case studies. In order to attain construct validity, data and observed patterns or theoretical constructs were constantly and iteratively compared (Eisenhardt 1989). Because the results of this study are replicated in the two jurisdictions, this research has stronger theoretical generalization (Yin 2003). Finally, to ensure internal validity and to generalize the study, results were connected to existing literature to find similarities and discrepancies (Eisenhardt 1989). For this purpose, a broad range of literature was presented in the theoretical background section in the previous chapter. The following section presents the case narratives of the diffusion processes in Quebec and in Switzerland, emphasizing how struggles for meaning and struggles for control punctuated the processes and how the institutional environment modulated these struggles. 


\section{ChAPTER IV}

\section{Case Studies \& WiThin Cases Analysis}

This chapter presents the narratives of the diffusion of the PET scanner in Quebec (more centralized) and in Switzerland (more market-oriented). These detailed case studies are punctuated by short analysis which synthesizes events of each subsection and are each followed by a larger within case analysis which theorizes the diffusion process in each jurisdiction. Before moving to the presentation of the narratives, the characteristics of the PET scanner as a bandwagon technology are exposed as these attributes influenced the diffusion of this innovation.

\subsection{The PET SCANNER AS A BANDWAgON TECHNOLOGY}

Prior to detailing the key events in the two diffusion narratives, it is important to note certain commonalities that emerged from the analysis of these narratives. This initial analysis of the data provides the readers with the motivation behind adoption and the broad picture of the diffusion process, thereby easing the understanding and reading of these narratives. It is clear that in both jurisdictions the PET scanner took on the qualities of a bandwagon technology i.e., a technology that is hard to stop diffusing due to powerful convergent incentives. The governance structures in both institutional contexts afforded incentives for nuclear doctors and hospitals to adopt the technology as quickly as possible - and preferably in advance of rivals - in order to provide the 
best care for patients, consolidate prestige, maintain their position with respect to other providers, attract patients and doctors, enhance revenues and remain viable sites for clinical research. For example, hospitals in Quebec were eager to receive a budget for PET scans due to the profit that could be generated. Specialist doctors also derived benefits from adopting this technology despite capped quarterly revenue. Once this limit is reached, the money earned is taxed at around $75 \%$ so there is a disincentive to do further work, but there is an important incentive to reach this limit as soon as possible in order to perform other activities inside or outside the hospital. In Switzerland, some hospitals made a substantial profit for each PET scan performed and profit redistribution also advantaged some doctors.

If direct financial benefits are one important dimension of bandwagon technology as we shall see in the narratives, horizontal struggles impel would-be PET providers to adopt as quickly as possible in order to obtain a significant share of the benefits by attracting patients and increasing organizational prestige which can in turn attract good quality doctors and research funds. Moreover, providers in Switzerland were even more eager to adopt earlier because a critical mass of 4 to 5 patients per day has to be reached to be profitable. This clearly incites organizations to be the first movers not only in their canton, but throughout Switzerland. Hence, this urge to adopt lies at the root of the horizontal struggles and is illustrated in table 4.1 by excerpts from interviews in the two jurisdictions. As we will see, regulatory bodies in both institutional contexts attempted to control the diffusion of the technology (with greater or lesser success) because of concerns about effectiveness (quality), efficiency and economy. This gave rise to vertical struggles between would-be adopters and regulators.

TABLE 4.1:

THe PET SCANNER AS A BANDWAgON TECHNOLOGY

\begin{tabular}{|c|c|c|}
\hline & Quebec & Switzerland \\
\hline $\begin{array}{l}\text { Best care } \\
\text { Beating the } \\
\text { competition }\end{array}$ & $\begin{array}{l}\text { "If we want to give the best cancer care, we } \\
\text { have to have this equipment. There's } \\
\text { competition between the general hospital and } \\
\text { the teacbing hospital to determine who will } \\
\text { dominate cancer programs in the region." }\end{array}$ & $\begin{array}{l}\text { "Losing this technology would mean weakening } \\
\text { our cancer institute in relation to the competition } \\
\text { and we can't allow that if we want to remain } \\
\text { leaders in this sector." }\end{array}$ \\
\hline $\begin{array}{l}\text { Benefits to } \\
\text { doctors }\end{array}$ & $\begin{array}{l}\text { "We learn things and we have the impression } \\
\text { that we are giving better services to clients. } \\
\text { And its an activity that generally brings in } \\
\text { revenues..." }\end{array}$ & $\begin{array}{l}\text { "This way, Nuclear Medicine doctors gained an } \\
\text { additional 20,000 CHF a year per doctor." }\end{array}$ \\
\hline $\begin{array}{l}\text { Maintaining } \\
\text { research } \\
\text { viability }\end{array}$ & $\begin{array}{l}\text { "At X university, they are excluded from over } \\
30 \text { multi-centre clinical protocols [for lack of a } \\
\text { PET scanner]. They become regional, they } \\
\text { can't bave an impact." }\end{array}$ & $\begin{array}{l}\text { "To position ourselves in research who don't give } \\
\text { pharmaceuticals projects if the institute does not } \\
\text { have a PET scanner." }\end{array}$ \\
\hline $\begin{array}{l}\text { Prestige, } \\
\text { attractiveness }\end{array}$ & $\begin{array}{l}\text { "Pride in having something that others don't } \\
\text { have. The pride or desire to be bigger... } \\
\text { always bigger." }\end{array}$ & $\begin{array}{l}\text { "The CEO of the teaching hospital needed a } \\
\text { new boss for the nuclear medicine department, } \\
\text { and he bad to offer a PET scanner [to make the } \\
\text { hospital attractive]." }\end{array}$ \\
\hline
\end{tabular}


This bandwagon effect which was influenced by horizontal and vertical struggles is an important motor for the diffusion of the PET scanner in both jurisdictions. The diffusion curves of the PET scanner in both health-care systems are drawn in figure 4.1. They show that from 1986 till the end of 2006, Switzerland had adopted twice as many PET scanners as in Quebec (22 versus 11). Considering the initial date of adoption in each jurisdiction up to the end of 2006, the rate of adoption in Switzerland is 1.10 PET scanners per year on average (22 PET scanners / 20 years), while Quebec has an adoption rate of 0.34 PET scanners per year (11 PET scanners / 32 years).

FIGURE 4.1:

Diffusion OF THE PET SCANNER IN QUEBEC AND SwITZERLAND ${ }^{17}$

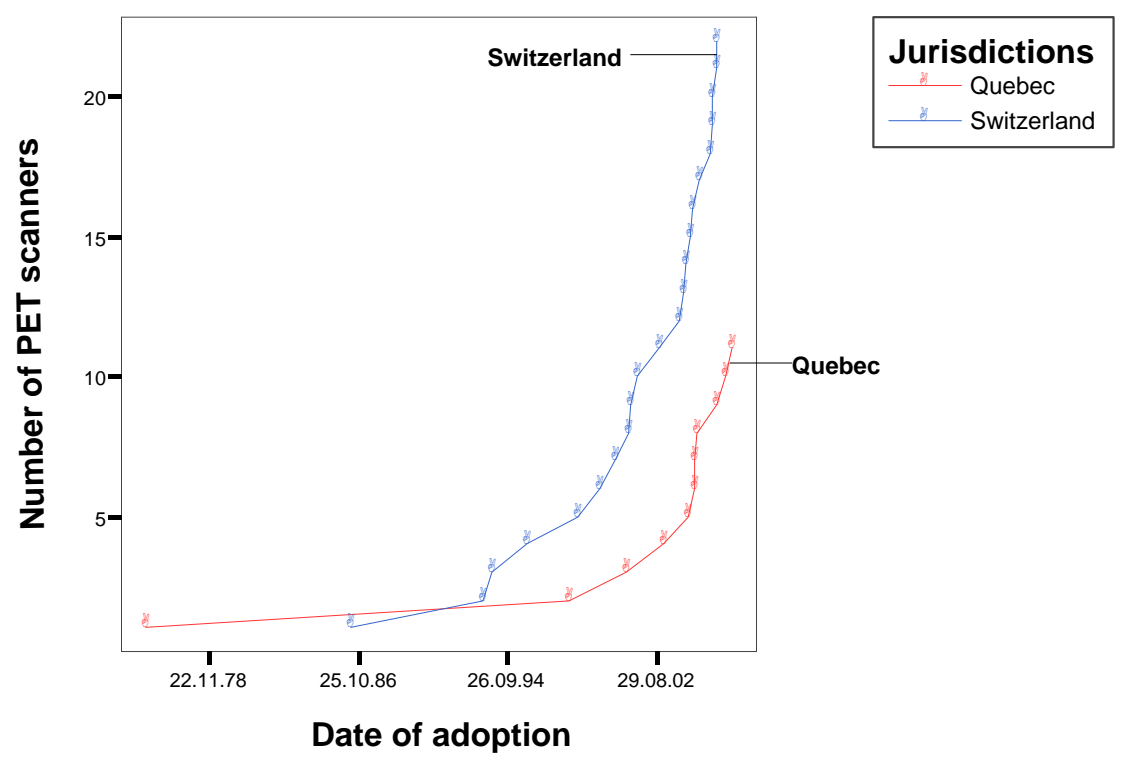

Comparing the number of the PET scanners adopted in both jurisdictions shows the diffusion to be much faster and wider in Switzerland than in Quebec. This is not surprising given that the set of governance mechanisms is clearly more market-driven in Switzerland and that the distribution of MRI and CT scanners in both jurisdictions (see table 3.6) clearly suggests a more extensive diffusion in Switzerland. The dates of adoption of PET and PET-CT scanner in Quebec and in Switzerland, from which the diffusion curves were built, are presented in tables 4.2 and 4.3 respectively.

${ }_{17}$ These curves begin at the moment each jurisdiction had a PET prototype sufficiently developed to produce reliable clinical data. Figure 4.1 includes all PET and PET-CT scanners acquired under both health care systems. 
TABLE 4.2:

Adoption Dates of THE PET Scanner In QUebec

\begin{tabular}{|c|c|c|c|c|}
\hline $\begin{array}{l}\text { Number of } \\
\text { PET scanners }\end{array}$ & $\begin{array}{l}\text { Adoption } \\
\text { Dates }\end{array}$ & $\begin{array}{l}\text { Organi- } \\
\text { zations }\end{array}$ & $\begin{array}{c}\text { PET } \\
\text { scanners }\end{array}$ & Regions \\
\hline 1 & 01.06 .1975 & UA2 & $\overline{\text { PET }}$ & A \\
\hline 2 & 01.01.1998 & THB & PET & B \\
\hline 3 & 01.01 .2001 & THB & PET & B \\
\hline 4 & 01.01 .2003 & THA1 & PET & A \\
\hline 5 & 17.05 .2004 & THA2 & PET-CT & A \\
\hline 6 & 01.09 .2004 & PCA & PET-CT & A \\
\hline 7 & 01.10 .2004 & GHA & PET-CT & A \\
\hline 8 & 15.10 .2004 & PCQ & PET-CT & Q \\
\hline 9 & 01.11 .2005 & THA1 & PET-CT & A \\
\hline 10 & 01.05 .2006 & THC & PET-CT & C \\
\hline 11 & 01.10 .2006 & PCC & PET-CT & C \\
\hline
\end{tabular}

TABLE 4.3:

Adoption Dates of the PET ScanNER in SwitzerLand

\begin{tabular}{|c|c|c|c|c|}
\hline $\begin{array}{l}\text { Number of } \\
\text { PET scanners }\end{array}$ & $\begin{array}{l}\text { Adoption } \\
\text { Dates }\end{array}$ & $\begin{array}{l}\text { Organi- } \\
\text { zations }\end{array}$ & $\begin{array}{c}\text { PET } \\
\text { scanners }\end{array}$ & Cantons \\
\hline 1 & 01.06 .1986 & $\overline{\text { IR }}$ & $\overline{\text { PET }}$ & $\mathrm{R}$ \\
\hline 2 & 01.06.1993 & THV & PET & V \\
\hline 3 & 01.12 .1993 & THU & PET & $\mathrm{U}$ \\
\hline 4 & 01.10 .1995 & THV & PET & $\mathrm{V}$ \\
\hline 5 & 01.06.1998 & PCXS & PET & S \\
\hline 6 & 01.09.1999 & THU & PET & $\mathrm{U}$ \\
\hline 7 & 01.07 .2000 & SPHS & PET & S \\
\hline 8 & 01.03.2001 & THU & PET-CT & $\mathrm{U}$ \\
\hline 9 & 01.05.2001 & SPCHT & PET & $\mathrm{T}$ \\
\hline 10 & 02.08.2001 & PET PCN & PET & $\mathrm{N}$ \\
\hline 11 & 01.11 .2002 & THD & PET & $\mathrm{D}$ \\
\hline 12 & 01.11 .2003 & $\mathrm{CHR}$ & PET & $\mathrm{R}$ \\
\hline 13 & 01.03 .2004 & PCV1 & PET-CT & $\mathrm{V}$ \\
\hline 14 & 01.04 .2004 & PCV2 & PET-CT & V \\
\hline 15 & 01.06 .2004 & $\mathrm{CHG}$ & PET & G \\
\hline 16 & 01.08 .2004 & THU & PET-CT & $\mathrm{U}$ \\
\hline 17 & 01.12 .2004 & PCDV & PET-CT & $\mathrm{D}$ \\
\hline 18 & 01.07 .2005 & PET PCN & PET-CT & $\mathrm{N}$ \\
\hline 19 & 01.08 .2005 & SPCHZ & PET-CT & $\mathrm{Z}$ \\
\hline 20 & 01.09 .2005 & PCD2 & PET-CT & $\mathrm{D}$ \\
\hline 21 & 01.12 .2005 & THV & PET-CT & V \\
\hline 22 & 02.12 .2005 & THV & PET-CT & V \\
\hline
\end{tabular}


These dates and curves are revealing in themselves. However, they do not tell us anything about the actual processes through which diffusion took place, in particular how the tensions played themselves out. These processes are elaborated in detail in the current chapter with the successive presentation of the narratives of Quebec and Switzerland.

\subsection{The Diffusion of The PET Scanner IN Quebec}

This case study describes in details the diffusion of the PET scanner in Quebec and is characterized by two periods which are separated by the publication of a health technology assessment report on the PET scanner. Before this publication, there was mounting pressure for diffusion which corresponds to the struggle of actors in defining the major applications of this technology i.e. whether in cardiology or in oncology ${ }^{18}$. The period following the publication of this report which provided legitimacy to the PET scanner is characterized by two interacting stories. One of these features the clash of incompatible and divergent theorizations based on institutional logics of quality and access where interest groups are disputing the way this technology should be implemented. While theorization is a discursive strategy providing rationales, meanings and interpretations which legitimate and make sense of adopting innovations, institutional logics are organizing principles which orient actor behaviour and cognitive schemes. In the second story, actors began adopting the technology without the consent of the authorities. This adoption which challenges the position of the government is a form of what I call institution testing, i.e. an action against regulatory constraints. To stop this deviant behaviour, a dissemination plan specifying which and when organizations can obtain the PET scanner was elaborated. Figure 4.2 provides an overview of the chronology of events (visual mapping) that marked the diffusion of this technology in Quebec's organizational field.

The study examines adoption in three natural geographic regions that are fairly physically remote from one another. These are designated by the letters $\mathrm{A}, \mathrm{B}$ and $\mathrm{C}$ where $\mathrm{A}$ is the most populated region with around three millions people, $\mathrm{C}$ the second most demographically important with about half a million people, and B a relatively less populated area with a little more than a hundred thousand people that nevertheless includes a university with a faculty of medicine.

${ }_{18}$ The PET scanner was and is also marginally used in neurology. Neurologists were not involved in defining the purpose of the PET scanner. 
Figure 4.2:

Visual MAPPING OF THE Diffusion OF THE PET SCANNER IN QUEBEC

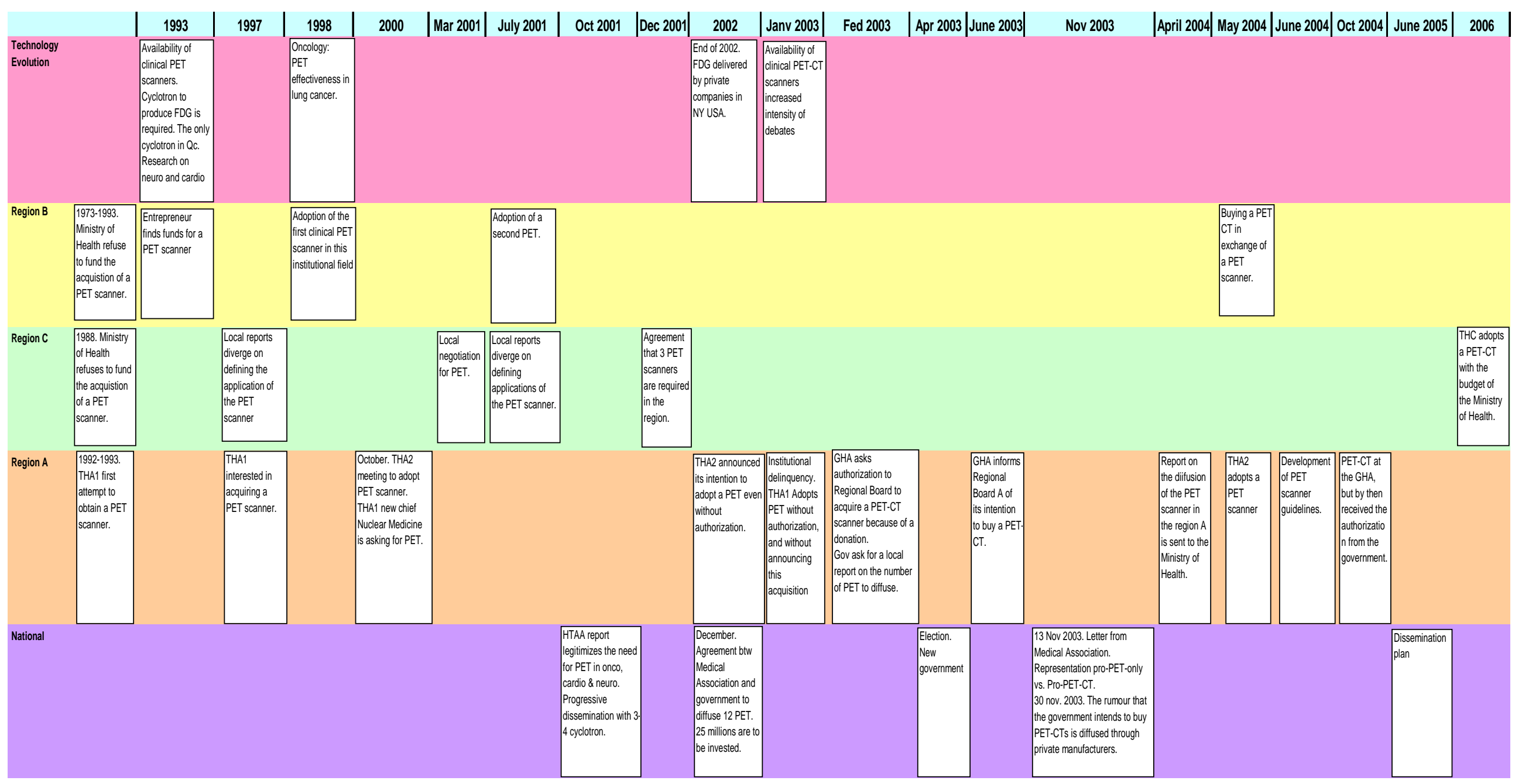




\subsubsection{Defining The PET sCANNer TeChNology}

\subsubsection{Region A: Developing the Machine THA2 - 1975}

The first PET scanner in Quebec was acquired in 1974 in the region A by the Department of Neurology at the University UA2. This acquisition was entirely financed through research funds and produced the first brain image in 1975. In 1981, following the acquisition of a cyclotron by the research team in neurology, radioisotopes started being produced locally. Four years later, the Quebec Association of Nuclear Medicine which was and is still defending the interests of patients and of nuclear doctors asked the Quebec Health Insurance Agency to reimburse doctors at a rate of $\$ 250 \mathrm{CND} /$ procedure for the PET scanner. This request was accepted.

\subsubsection{Region B: Adopting a PET Scanner for Clinical Applications - 1998}

The adoption of the second PET scanner in Quebec at the teaching hospital THB resulted from the enterprise of a nuclear doctor who relentlessly fought to persuade the Quebec Ministry of Health to invest in the creation of a research center, which would include a PET scanner and a cyclotron for research applications in oncology. For twenty years, this entrepreneur built up organizational assets such as developing an internationally renowned group of researchers in radiation technology, offering a unique $\mathrm{PhD}$ in radiation in Canada, and patenting a PET scanner prototype, all of which contributed to consecrate THB as a major centre in nuclear medicine. These assets and the competence developed provided legitimacy to THB which persuaded first the Ministry of Industry of Canada as well as private donators to finance this project. It is only when half of the financial resources were gathered that the Quebec Ministry of Health did agree to participate financially in this project; although region B was clearly less populated than regions A and C.

In 1995, the main purpose of the PET scanner was still to perform research. However, with the development of new indications in oncology and the underutilisation of the PET scanner in research, the newly appointed nuclear doctor who was completing his training in the USA, started organizing from abroad what was required to use the machine for clinical applications. To do so, he needed an operating budget. Because the Ministry of Health did not want to provide him with financial resources to run the PET scanner, he persuaded the hospital to provide him with a small budget. 
In 1998, the first PET scanner procedures were financed through research funds and through a special budget supplied by the teaching hospital. However, this small budget was largely insufficient and teaching hospital THB was insistently asking the Ministry of Health for an operating budget ${ }^{19}$ to run this expensive technology. Clinical arguments as well as citing cost-benefit studies were developed to defend the case:

\begin{abstract}
"These arguments, coming from scientific publications, clearly proved that, for example, when planning a lung cancer therapy, an exam done prior to a chirurgical intervention would reveal numerous unsuspected ailments. A better evaluation of the physical condition eliminated useless operations. [...] Moreover, a few American publications also demonstrated that a favourable cost-profit ratio could be produced with this exam, within an American situation."
\end{abstract}

While these arguments may have influenced the Ministry of Health to provide an operational budget to the teaching hospital THB, patients who began going to the USA to undergo a PET scan were more problematic. Indeed, the law states that once a procedure is recognized as being medically required, if the technology is not available in Quebec, doctors can send their patients to the USA. In this case, the Ministry of Health has to reimburse the procedures to the patient, and here USA PET scanner expenditures were important. Hence, funding the operations of one PET scanner centre avoided having to pay for expensive examinations outside Quebec:

"Once the technology is approved in the United States, Quebec doctors will often send their patients over there to get the exam, saying that the procedure has been approved and that the exam is available. But this was accomplished at an enormous cost. First, US medical bills are much more expensive there than in Quebec. Second, many Quebecers do not speak English, and needed numerous translating services, which added to the bill. [...] Theses facts led to the conclusion that, if the exam is requested from a medical standpoint, it must also be made available inside our own health care system."

The first use of the PET scanner in a clinical setting aroused consternation among nuclear doctors around the province, especially from those practising in major teaching hospitals in the regions $\mathrm{A}$ and $\mathrm{C}$, and it prompted those hospitals to press for a PET scanner for themselves. No one actually understood why a PET scanner was installed in a relatively small and remote area. Irrationality and political games were invoked to explain this unexpected situation.

\footnotetext{
19 Obtaining an operational budget for the PET scanner was not the only challenge faced by teaching hospital THB. Indeed, before being used or commercialized, pharmaceutical substances have to be registered with Health Canada to prove its harmlessness. Since the FDG is a public molecule, no private company intended to pay $\$ 400 ' 000 \mathrm{CND}$ for the registration procedure, and no public hospital had the financial capacity to do so. Negotiations between teaching hospital THB and Health Canada led to an agreement which allowed the use of FDG under a clinical trial protocol. This agreement is still in force nowadays.
} 
In addition to this, the decision of the Centers for Medicare and Medicaid Services to authorize the reimbursement of the PET scanner for lung cancer as well as the wide and fast diffusion of this technology in USA contributed to build up pressure on the Ministry of Health to diffuse this technology on a larger scale:

\begin{abstract}
"The FDA [Federal Drug Administration] had an impact on demand because, once the FDA had recognized the technology, and especially the Centres for Medicare and Medicaid Services... which is the payer, when they began to pay in the States, then of course there were huge pressures here because we always compare ourselves with the United States in a North-American environment."
\end{abstract}

In July 2001, THB surprisingly acquired a second PET scanner; officially for research purposes. This adoption was the consequence of a private-public partnership with the manufacturer $\mathrm{W}$ which became involved in order to develop a new PET scanner. In exchange, the manufacturer W would sell the PET scanner at a lower price. The choice to deal with THB was attributed to the highly positive reputation of this organization in this domain. This second adoption increased the general misunderstanding of region B having two PET scanners while major centres in the most populated area of Quebec had none.

Meanwhile, though hospitals in the region A were astonished, most of them were caught in political tensions due to the merger of teaching hospitals. Hence, many cases were dropped temporarily in favour of other important issues related to these mergers.

\title{
4.2.1.3 Region C: Competing in Vain to Obtain a PET Scanner - 1988- 2001
}

While the acquisition of the PET scanner by the teaching hospital THB encountered no competition either locally or nationally, competition in region $\mathrm{C}$ between the hospital GHC, a specialized hospital in cardiology and in lung cancer, and THC, the most important teaching hospital in the area, seriously impeded any attempt at adoption. As early as 1988, both hospitals were already striving to persuade the Ministry of Health to acquire a PET scanner for clinical purposes as well as for research, but the technology was not sufficiently mature from a clinical point of view to convince the authority and for hospitals to continue struggling for this cause. In 1995, cumulating evidence for lung cancer revived interests of both hospitals in obtaining this technology, and in 1997-1998 each hospital submitted a report to the Health Services Regional Agency. In 2001, both hospitals sent an up-dated version of these reports to the same agency: 
"Medical literature reported awesome clinical results when using PET scans for, among others, lung cancer. This was the first kind of cancer where their efficacy was documented. (...) This produced a renewed interest for PET scans around 1994-1995. It became known, in oncology circles, that using the procedure could yield significant information on lung cancer diagnosis. This led us to produce a brand new report on this topic in 1997."

TABLE 4.4:

Competing QUality-Based TheORIZATIONS IN REgion C

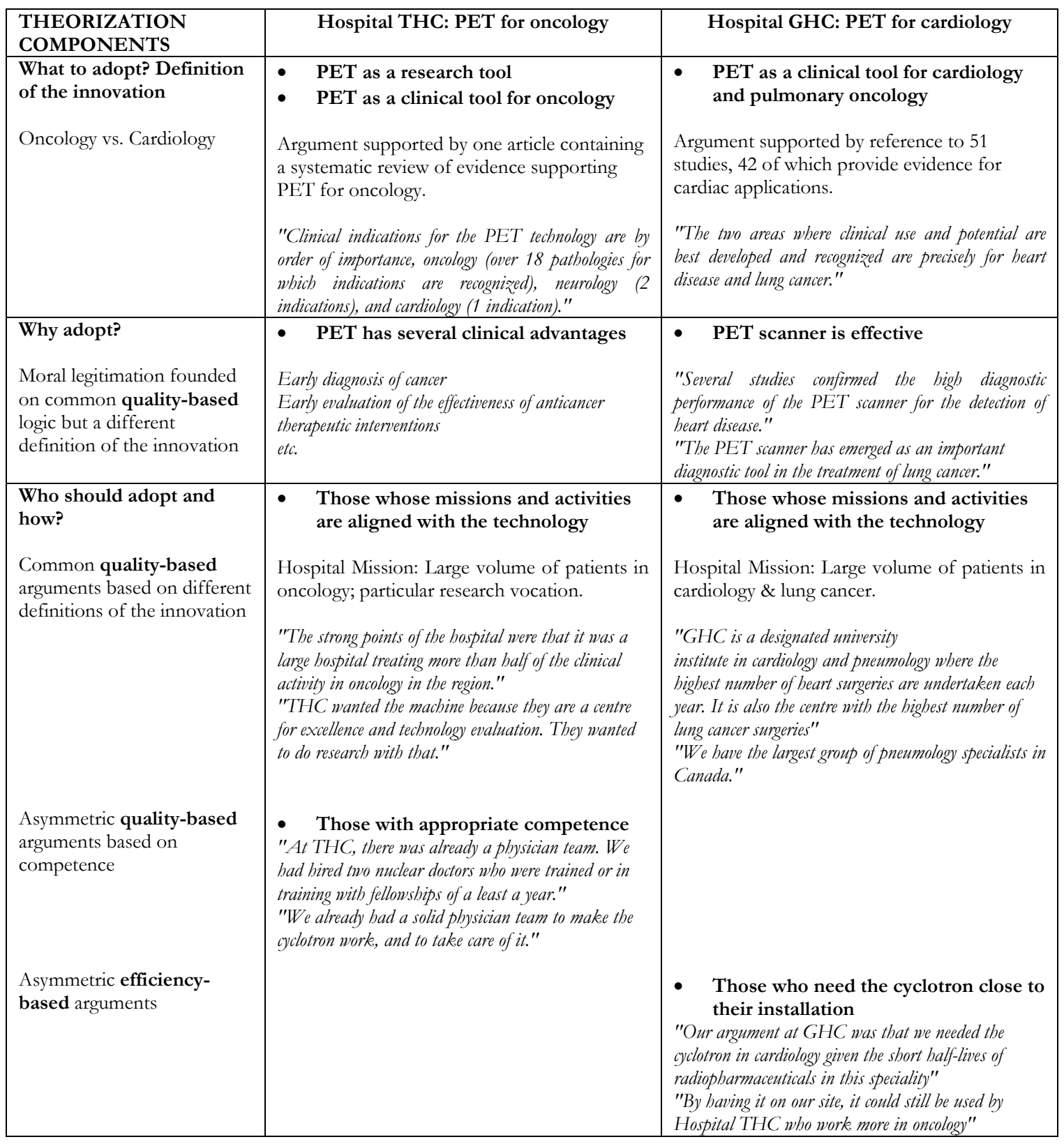


These reports draw on competing theorizations which are summarized in Table $4.4^{20}$. In this case, both hospitals were in competition and each theorized in such a way that its own site would be perceived by the authorities to be most appropriate for a PET scanner:

\begin{abstract}
"When teaching hospital THC realized that we handed in an application for a PET scanner, they quickly reacted by writing one in which they argued that it was their hospital that should have everything [a cyclotron and a PET scanner]. They were directly competing against us. There was a competition between us to convince the authorities."
\end{abstract}

Specifically, because of its dual mission in cardiology and in lung cancer, the hospital GHC declared itself to be the best centre to receive a PET scanner. It contended that its supra-regional mission combined with the fact that it performed the highest number of cardiac surgical operations justified obtaining a PET scanner. Since the evidence on the potential in the case of lung cancer was indisputable, the hospital GHC also emphasized the fact that they were performing the highest number of surgeries in pulmonary cancer. On the other hand, teaching hospital THC argued that oncology was the main application of PET scanner. Given that more than half of the clinical activities in oncology in the region $\mathrm{C}$ were performed at THC, it argued that it should be the first centre to adopt a PET scanner. Also, since the cyclotron was essential to the production of radiopharmaceuticals, its location also became an issue. Because the half-life of the radiopharmaceutical used in cardiology is approximately 2 minutes, the hospital GHC argued that the cyclotron should be close to their building. Emphasizing its mission in research and in evaluating new technology, THC argued that the cyclotron should be in their organization. These self-interested arguments and destructive battles did not accelerate the diffusion of the technology given that the government was trapped, not knowing who should obtain the technology. Moreover, important financial constraints such as a high deficit did not allow the government to provide both hospitals with this technology:

"Confronted with this tug-of-war, how did the Managers of the Health Services Regional Agency react? They took no decisions. They did nothing. They did not know what to do. And don't forget that, for them, cost is the most important consideration. They did not mind investing nothing, especially in a context where hospitals are still in deficit."

${ }^{20}$ Excerpts are drawn from the 2001 reports. Arguments mobilized in this report mirror the ones of the previous 1997-1998 reports. 
Institutions were involved in several political style approaches, and sometimes getting quite close to interference. [...] Some direct interventions were made towards members of the Regional Board Commission, trying to influence them, so they would vote in favour of a given option. [...] People wrote extensive letters, presented their report, made numerous phone calls and other similar approaches.

Hence, confronted with these struggles, the Ministry of Health had no choice but to avoid announcing an investment that might turn out to be in its disfavour:

"Even in 'C' region, there were debates between THC and the GHC. They told us: 'settle your own problems. The minister won't get the news out, only to be fired upon by one of the two hospitals." "

Later on, the Committee of the Regional Health Services Agency of region C agreed that three machines were required in the area given that a third hospital in the region manifested its interest in obtaining a PET scanner. This recommendation to the Ministry of Health initially relieved THC and hospital GHC from their fierce competition, at least regarding this issue.

\subsubsection{ANALYSIS}

The strategy deployed by teaching hospital THB to find financial resources for a PET scanner through alternative channels (the Ministry of Industry and from private donators) reveals the entrepreneurship of this doctor who found alternative ways to finance the new machine. This was a convincing strategy to get the Ministry of Health involved in the project. While adopting the technology for research purposes was certainly an important issue, obtaining an operational budget from the government for clinical applications was another. This gave rise to a vertical struggle between THB and the Ministry of Health. While the former wanted a budget in order to use its machine more efficiently and to continue developing an expertise in the domain, the Ministry of Health was confronted with the continuous challenge of costcontainment. The case illustrates that it is when the Ministry of Health understood that providing funds might limit expenses by preventing doctors from referring patients to the USA that a budget was granted to THB.

While THB was in a situation of monopoly in its region, region $C$ was the theatre of intense horizontal struggle which pushed the hospitals to develop different theorizations aimed at shaping the perception of authorities regarding what the purpose of the technology was, as well as why and how it should be diffused (see Table 4.4). They mainly drew on clinical scientific evidence to support their arguments. Accordingly, each hospital deployed a quality-based theorization to convince the 
authorities. Our analysis illuminates three dimensions of theorization: 1) the definition of the technology (what), 2) benefits of the technology (why), and 3) justifying a solution (who and how). First, given the uncertainty surrounding what the technology could actually achieve, both camps were using different scientific evidence to define the technology in a way that supported their positions. For example, THC argued that there were potentially many more applications in oncology using one paper developing a systematic literature review, whereas hospital GHC displayed a large array of studies in cardiology involving the PET scanner to prove its significance in this domain while also emphasizing its maturity for lung cancer applications. Considering why this technology should be diffused, both actors emphasized similar arguments but aligned them with different definitions of the technology. Again, as to how to diffuse or how to implement the technology locally, the actors proposed to align diffusion of the technology with their interpretation of the evidence and its correspondence (or fit) to the hospital's mission. Indeed, each hospital asserted that its specialty was precisely related to the state of the evidence in order to provide legitimacy to its institutional position in the field as being a potential receiver.

In addition, THC used competence-based arguments to enhance its organizational legitimacy, while hospital GHC invoked pragmatic issues of efficiency related to the location of the cyclotron. Nevertheless as shown in table 4.4, the dominant institutional logic invoked in this debate was clearly based on quality of care (Scott, Ruef et al. 2000). The arguments about the evidence and the clear perception that the two hospitals saw evidence differently and were at the same time undermining the theoretical claims of their adversaries did not contribute to accelerating diffusion at this point.

\subsubsection{The Health Technology Assessment Report and ITS CONSEQUENCES: A CLASH BETWEEN TWO FACTIONS}

\subsubsection{Legitimizing the PET Scanner through a Report - October 2001}

Altogether, quarrels in region $\mathrm{C}$, the first clinical use of the technology in the province of Quebec, the authorization to reimburse the PET scanner procedure by the Centers for Medicare and Medicaid Services in USA, and the emerging evidence in the scientific literature praising the clinical benefits of the PET scanner stimulated both the president of a Quebec Association of Nuclear Medicine and a Patients' Association for Cancer to ask the Ministry of Health to produce a report on the cost- 
effectiveness of this technology. This request was addressed to the Health Technology Assessment Agency in September 2000.

While the legitimization of the PET scanner as a clinical tool in this organizational field was strongly enhanced with its first clinical use and with the authorization for reimbursement by the Centers for Medicare and Medicaid Services in the USA, the publication of the Health Technology Assessment Agency (HTAA) report in October 2001 confirmed the evidence-based legitimacy of the PET scanner in this organizational field as an indispensable diagnostic tool for specific conditions. The clinical conclusions of this report were unequivocal and claimed that at least 15,000 examinations were required annually. Although the report does not proclaim any dominant application (cardiology, oncology, neurology), it definitively supports its legitimacy. Indeed, from that moment, the legitimacy (derived from evidence) of this technology was associated with an intensification of hospitals asking to have a PET scanner, especially in the region A:

"After the HTAA report, the first impact and the most visible one is that we received rapidly many applications from the organizations that were all referring to this report."

Besides legitimating the technology in this organizational field, the HTAA report suggested how the PET scanner should be disseminated in the province of Quebec. Table 4.5 provides the quality-based theorization in the report that legitimized the PET scanner.

The following quotations from interviews support our contention that from then on the technology was perceived as legitimate from a clinical point of view. Indeed, all the citations point to an evidence-based legitimacy that would eventually lead to the technology being taken for granted as an essential medical tool based on a quality of care institutional logic:

"It's like asking whether you need an operating room in a hospital. (...) It's an indispensable and necessary tool."

- Nuclear doctor

"It's inevitable; it's a question of the quality of medicine. Some will even say that it is bad medical practice not to use it in diagnosis."

- President of a Medical Association

"After the Health Technology Assessment Agency report, the first and most visible impact is that we rapidly received many requests from the hospitals that were all referring to this report."

- Biomedical engineer 
TABLE 4.5:

Quality-Based Theorizations of THE HeAlth TeCHNOLOgY Assessment AgENCY REPORT Providing Legitimacy TO THE PET SCANNER

\begin{tabular}{|c|c|}
\hline $\begin{array}{l}\text { What to adopt? } \\
\text { Definition of the } \\
\text { innovation }\end{array}$ & - The PET scanner as a clinical and a research tool. \\
\hline $\begin{array}{l}\text { Why adopt? } \\
\text { Moral legitimation } \\
\text { essentially grounded in } \\
\text { quality-based arguments }\end{array}$ & $\begin{array}{l}\text { - Population clinical needs } \\
\text { "Clinical needs appear sufficient to justify an adequate deployment of PET } \\
\text { technology." } \\
\text { - Clinical utility of the technology } \\
\text { "The HTAA study confirms the clinical usefulness of PET in several } \\
\text { oncological, neurological and cardiological applications." }\end{array}$ \\
\hline $\begin{array}{l}\text { How it should be } \\
\text { deployed? } \\
\text { Distribution based on } \\
\text { equity (access-based logic), } \\
\text { but with a major economic } \\
\text { dissuasive argument }\end{array}$ & $\begin{array}{l}\text { Progressively because of the high cost } \\
\text { "These estimated needs can only be satisfied progressively. In a normal } \\
\text { operating mode, PET scans would require from ten to twelve cameras, } \\
\text { powered by three or four cyclotrons (including those already available). } \\
\text { According to accepted implementation schemes, the global cost of } \\
\text { deploying additional PET resources could reach more than a hundred } \\
\text { million dollars." } \\
\text { - Progressively because competence has to be developed } \\
\text { "A progressive deployment is even more advisable considering that a PET } \\
\text { center demands specialized material and human resources to function } \\
\text { properly. At the present time, available human resources trained } \\
\text { specifically for PET are insufficient in Quebec. They could not sustain this } \\
\text { planned deployment. Training of specialized personnel should be a top } \\
\text { priority." }\end{array}$ \\
\hline $\begin{array}{l}\text { Who should adopt? } \\
\text { Distribution based on } \\
\text { competence (quality-based } \\
\text { logic) }\end{array}$ & $\begin{array}{l}\text { - Those whose mission is to evaluate the technology } \\
\text { "Since this PET plan should include an element of efficiency evaluation in } \\
\text { addition to its deployment for clinical purposes, its realization must be } \\
\text { done in strict collaboration between University Hospital Centers and } \\
\text { University Centers." }\end{array}$ \\
\hline $\begin{array}{l}\text { Distribution based on } \\
\text { research activities (quality- } \\
\text { based logic) }\end{array}$ & $\begin{array}{l}\text { - Those who are performing research } \\
\text { "This plan must take into account that PET deployment for clinical } \\
\text { purposes can not be realized without planning research activities aimed at } \\
\text { promising activities, recognized as potentially constructive for the } \\
\text { moment, even if their efficiency and cost effectiveness are not yet } \\
\text { demonstrated." }\end{array}$ \\
\hline
\end{tabular}

\subsubsection{Reacting to the HTAA Report: Confronting two Institutional Logics}

Although the clinical conclusions of the Health Technology Assessment Agency report provided evidence-based legitimacy to the PET scanner based on the logic of quality of care, the recommendations suggesting that the PET scanner technology should be "progressively deployed in collaboration with teaching hospitals and university institutes" and "through research activities" raised several concerns among nuclear doctors. The recommendations were perceived by the Quebec Association of Nuclear Medicine as a signal that the PET scanner technology was going to be diffused to teaching hospitals only, given their mission in research, and that the report was suggesting that more cyclotrons (an expensive machine mainly used in research) 
should be bought to produce FDG. This was perceived to be favouring research at the expense of clinical applications:

"The Report's first conclusions were appalling, because several actors in this report had private interests. [...]. I said : "We're trapped", because these two centers wanted major investments to become great training, teaching and research centers. But all we wanted was to develop a clinical tool $[. .$.$] to detect$ sickness and take the best possible clinical decisions for a patient to avoid removing half his face if he had tongue cancer."

Reacting to this report, the Quebec Association of Nuclear Medicine created a special committee rallying nuclear doctors in remote hospitals in order to negotiate directly with the Government in power. By primarily defining the PET scanner as a clinical device and not a research tool, the aim of this special committee was to counteract the recommendations favouring teaching hospitals, and to democratize access to this high-end medical technology by proposing that 12 major centres in oncology should obtain a PET scanner, but at once and not progressively. This was technically possible since by the year 2002 the FDG was being supplied by American private companies so a nearby cyclotron was no longer necessary.

By December 2002, after intense negotiations and after teaching hospital THA2 announced its intention to buy a PET scanner with or without the consent of the government, the Ministry of Health agreed to invest $\$ 23$ millions USD to buy 12 PET scanners and to diffuse them all over the province. This agreement brought a short period of truce up to the election of April 2003 which witnessed the change of the party in power and the nomination of a new director of hospitals at the Quebec Ministry of Health. This marked a radical shift in the informal agreement to diffuse the technology widely.

Moreover, from the beginning of 2003, the debate over how the technology should be diffused took a new turn with the availability of the relatively new and more effective architecture $^{21}$ (Henderson and Clark 1990) of the PET-CT scanner. Because the CT scanner provides quasi instantaneous anatomical images while the PET scanner provides unrivalled functional images, the combination of both increased the precision of the diagnosis. With the emergence of this alternative, two types of architecture were available on the market: PET-CT scanners and standalone PET scanners.

Experts estimated that the clinical added-value of the PET-CT scanner over the standalone PET scanner was for approximately $15 \%$ of cases, mainly in the Oto-

21 "The essence of an architectural innovation is the reconfiguration of an existing system to link together existing components in a new way” (Henderson \& Clark: 1990: 12). 
Rhino-Laryngology speciality. In addition, the PET-CT scanner allowed a hospital to perform 12 cases per day instead of 8 with a standalone PET scanner. This was due to the fact that the addition of the CT scanner reduced the time ${ }^{22}$ required to scan a patient. Besides allowing more patients to be diagnosed per day per machine, acquiring a PET-CT scanner would allow teaching hospitals to participate in international research protocols. Indeed, the PET-CT scanner was becoming a standard in research for OECD countries:

"Even at the University UB, they were excluded from over 30 multi-centers protocols. As a result, they are becoming regional, and can not longer have any impact in terms of research."

The parallel development of this new architecture with the publication of the Health Technology Assessment Agency report combined with the election of the new government turned the institutional dynamic into a confrontation between two clans: the Pro-stand-alone-PET clan which favoured the diffusion of 12 PET scanners against the Pro-PET-CT coalition which wanted the technology to diffuse progressively from teaching hospitals to other hospitals. Table 4.6 summarizes arguments mobilized by each clan in this struggle. Because the cost of a PET-CT scanner ( $\$ 3.7$ millions USD) was twice the price of standalone PET scanner, promoting the diffusion of the former was equivalent to encouraging narrower diffusion considering that only $\$ 23$ millions USD were available and that financing the building of hospital infrastructure had to be taken into account. Hence, the advent of the PET-CT was not good news for those who wanted the PET scanner to be widely diffused.

To make sure that the PET scanner would be widely available, the Quebec Association of Nuclear Medicine invested in different lobbying actions to persuade the government of the necessity of diffusing the PET scanner to as many places as possible for people to have access to this technology. As one interviewee reports:

"We made our presentation by sending a letter. We try to contact people in the Ministry. We sent a letter signed by three department heads and the president of the medical council. We showed them the facts, we gave the arguments that I listed just now to sensitize people. The Association also sent a letter to say that we did not agree that it would only be in the teaching hospitals. As an association, we wanted a wider deployment of the PET scanner to 12 centres."

Disagreeing with the policy of the new government, these lobbying activities were even more acute with the information circulating at the annual meeting of the Radiological Society of North America that the newly elected government was

\footnotetext{
${ }^{22}$ See footnote number 6 on page 37
} 
intending to go with the PET-CT scanner and to diffuse it to only few teaching hospitals.

This information flowed from private manufacturers who had an incentive to influence the diffusion of the PET-CT scanner given that the profit margin on this technology was higher than for the standalone PET scanner. Of course, part of the margin came from the higher selling price, but also from the yearly recurring maintenance costs which correspond to $10 \%$ of the selling price - twice as high as for a standalone PET. This prompted private manufacturers to ally with teaching hospitals in using lobbying activities to promote the diffusion of the PET-CT scanner to a smaller number of sites:

"And then came two troublemakers. Some companies, not all of them, but some of them, influential companies who sell equipment, and want to sell it at the highest possible price [...] started to harass administrators and chief public servants. They wanted to meet them, to talk with them, to take them along on trips, and everything else."

Also, although officially neutral, some radiologists favoured the diffusion of the PETCT because at least part of the examinations would procure them an advantage as only radiologists can read CT scanners.

At that time, this technology tended to be privileged by the government due to the international trend on the PET-CT over the standalone PET scanner, and because private companies were more inclined to develop the PET-CT scanner technology in the future:

\footnotetext{
"Finally, we realized that an agreement had being reached. This technology was going to be the most popular and appropriate. [...] There was a new French report, in 2002 I think, from the French Hospital Federation. They submitted a document on the PET-CT, and they seem to orient themselves towards the new developments of this technology. We realized that, in fact, everyone was going in that direction. The industry also made us see that it was abandoning standalone PET development to concentrate on PET-CT developments."
}

However, this tendency was not enough for the government to announce that a decision had been made. Indeed, the Ministry of Health needed to get the support of the Pro-stand-alone-PET coalition which was still promoting a wider diffusion. 
TABLE 4.6:

Competing Theorizations Emerging After the Publication of the HTAA Report

\begin{tabular}{|c|c|c|}
\hline $\begin{array}{l}\text { THEORIZATION } \\
\text { COMPONENTS }\end{array}$ & $\begin{array}{c}\text { Stand-alone PET } \\
\text { Access-based logic }\end{array}$ & $\begin{array}{c}\text { PET-CT } \\
\text { Quality-based logic }\end{array}$ \\
\hline $\begin{array}{l}\text { What to adopt? Definition } \\
\text { of the innovation }\end{array}$ & $\begin{array}{l}\text { - PET as a proven clinical tool needed } \\
\text { by all regardless of location }\end{array}$ & $\begin{array}{l}\text { - PET-CT as a high-performing proven } \\
\text { clinical and research tool }\end{array}$ \\
\hline $\begin{array}{l}\text { Why adopt? } \\
\text { Moral legitimation essentially } \\
\text { grounded in equity of } \\
\text { access-based arguments vs. } \\
\text { quality-based arguments }\end{array}$ & $\begin{array}{l}\text { - PET scan for all } \\
\text { "Chemotherapy is hard as a treatment. That's why } \\
\text { with the PET scanner, we can evaluate whether local } \\
\text { radiotherapy or chemotherapy would be better and } \\
\text { protect the child from suffering. [...] Just think if you } \\
\text { have a } 12 \text { year-old child who needs radiotherapy and } \\
\text { you have to send them to the big citw. It's torture." }\end{array}$ & $\begin{array}{l}\text { - Better quality diagnoses } \\
\text { "A PET scanner will locate the tumor... in the body but } \\
\text { not in a specific way. It will say: it is there. But with the CT, } \\
\text { we can take a tomographic image which will locate the tumor } \\
\text { in the tissue so we can see exactly where it is." }\end{array}$ \\
\hline $\begin{array}{l}\text { Competing interpretations of } \\
\text { efficiency-based logic tied } \\
\text { to access-based and quality- } \\
\text { based arguments respectively }\end{array}$ & $\begin{array}{l}\text { - Low purchase costs and lower travel } \\
\text { costs with greater equity and access } \\
\text { "Oncology is permanent. You have your cancer, you } \\
\text { come back, you are re-evaluated. There's a lot of } \\
\text { travelling. So the PET will allow the regionalization } \\
\text { of care, keeping resources, people, and avoiding } \\
\text { excessive travel costs." } \\
\text { "The Association favours the dedicated PET cameras } \\
\text { that are twice as cheap [than PET-CT], but everyone } \\
\text { would get one." } \\
\text { "[With PET] we can save } \$ 15,000-\$ 20,000 \text { for } \\
\text { people we operate on unnecessarily." }\end{array}$ & $\begin{array}{l}\text { - Lower cost per examination with higher } \\
\text { quality } \\
\text { "So, typically, if you look today at a typical hospital they } \\
\text { take may be } 15-20 \text { minutes to do the attenuation correction } \\
\text { a piece [with a standalone PET scanner] versus } 30 \text { seconds } \\
\text { [with a PET-CT]. [...] [Moreover], The FDG cost per } \\
\text { patient is significantly less." } \\
\text { "An ordinary PET scanner can do about six or seven } \\
\text { patients per day. With the PET-CT, we can go up to } 12 \text { so } \\
\text { we can double the volume." }\end{array}$ \\
\hline $\begin{array}{l}\text { Asymmetric naturalization } \\
\text { arguments }\end{array}$ & & $\begin{array}{l}\text { - Inevitability of PET-CT } \\
\text { "In the conference] basically nobody was speaking of } \\
\text { standalone PET. Nobody. [...] I can't think of a single } \\
\text { institution that bas actively gone to tender for standalone } \\
\text { PET." }\end{array}$ \\
\hline $\begin{array}{l}\text { Who should adopt and } \\
\text { how? } \\
\text { Distribution based on equity } \\
\text { (access-based logic) vs. } \\
\text { competence (quality-based } \\
\text { logic). }\end{array}$ & $\begin{array}{l}\text { - PET for all, coherence with prior } \\
\text { distribution of oncology centres } \\
\text { "Better give everyone a good Chrysler than giving a } \\
\text { Ferrari to } 3 \text { or } 4 \text { people, that's what we wanted at the } \\
\text { Association." } \\
\text { "With the government, we proposed that the 15,000 } \\
\text { exams that were necessary per year in oncology, that } \\
\text { the } 12 \text { first pieces of equipment be installed in the } \\
\text { regional centres for oncology as the government had } \\
\text { already done it." }\end{array}$ & $\begin{array}{l}\text { - Competence has to be developed first } \\
\text { before allowing adoption } \\
\text { "They'll say, "I am a Cessna pilot, I can also pilot a } \\
\text { 747." People will say that, but it makes no sense! (..) } \\
\text { They'll say: 'It's not complicated - I'll put it on automatic } \\
\text { pilot." OK, but is that the function of a } 747 \text { pilot? So you'll } \\
\text { place your life in the hands of someone who doesn't have the } \\
\text { expertise necessary to make complex and major adjustments } \\
\text { that a technology like that requires." }\end{array}$ \\
\hline
\end{tabular}

\subsubsection{ANALYSIS}

The first clinical use and the reimbursement of the procedure by the Centers for Medicare and Medicaid Services contributed, at least partially, to the legitimacy of the procedure in this organizational field. Indeed, while the former launched a signal that the technology was mature enough to be used in the clinical setting of Quebec, the latter demonstrated that the technique was recognized as effective in another organizational field. Maybe even more important is the conclusion of the Health Technology Assessment Agency report which recognized without any doubt the clinical usefulness of the procedure thereby legitimating this technology. This was accomplished through the use of a quality-based theorization (see table 4.5). This episode illustrates three dimensions: 1) the demand for and the usefulness of the 
technology (why?), 2) the speed of diffusion (how?), and 3) organizations having capacity in evaluating technologies (who?). Clearly, this report legitimized the diffusion of the PET scanner in specifying not only its usefulness, but also how it should be diffused and who should adopt it.

While the HTAA report legitimized the PET scanner as an essential medical tool in this organizational field, it sharpened the appetite of those who were endlessly waiting for a PET scanner, and encouraged the Quebec Association of Nuclear Medicine to promote the diffusion of this technology to a wider extent than was advocated in the report. This initiative prompted a horizontal struggle between the Quebec Association of Nuclear Medicine and the teaching hospitals. Transformed into a legitimization battlefield with two confronting factions, this organizational field witnessed several theorization strategies deployed by the two camps to justify what type of machine should be diffused (see Table 4.6). The Pro-stand-alone-PET coalition used an accessbased theorization strategy, composed of moral arguments, to deplore the insufficient number of PET scanners in the Quebec health care system (why adopting more machine; problem), and to justify a wider diffusion of the technology to the previously-designated regional centres in oncology (who and how to adopt; solution). The rationale was to give the population access to the technology independently of their location, a real challenge in a huge territory like the province of Quebec. To support this view, it was argued that it was unethical for children to go through useless chemotherapy as well as asking them to travel long distances to get a PET scan. Other arguments involved reference to the common good and solidarity given that adopting 12 machines would economize on useless surgical procedures, thereby allowing better resource allocation.

In contrast, the Pro-PET-CT coalition invoked arguments related to the technical superiority of the PET-CT - a quality-based logic. Whereas the access-based theorization stressed the importance of widely diffusing the technology (quotation in table 4.6: "Better give everyone a good Chrysler than a Ferrari to 3 or 4 people"), the quality-based theorization defined efficiency in techno-economic terms related to a single machine and not to the impact of the diffusion of many machines across the organizational field. Arguments related to the inevitability of the PET-CT were also put forward. In consonance with its quality orientation, the Pro-PET-CT coalition proposed that the technology should be diffused along competence-lines (quotation in table 4.6: a Cessna pilot should not pilot a 747). This group argued that nuclear doctors must be well trained to perform good quality diagnoses, and that this technology had to be further developed, thereby deeming the PET scanner technology 
to be a research as well as a clinical tool. Hence, this coalition defended the idea that the best technical machine had to be purchased to ensure quality.

Overall, while the access-based perspective promoting a wide diffusion is at the heart of the legitimization strategy of the Pro-stand-alone-PET coalition, the Pro-PET-CT clan is clearly in favour of narrower diffusion of more highly-performing machines as shown in table 4.6. These two divergent legitimization strategies are the expression of a horizontal struggle between two factions having divergent interests in the diffusion of the PET scanner. For the Quebec Association of Nuclear Medicine, wider diffusion would satisfy more members and would reinforce the profession of nuclear doctors, while rendering the services accessible to a larger portion of the population. For doctors in teaching hospitals, adopting a PET-CT scanner would allow them to participate in international protocols as well as to have more effective and efficient machines, and in the end would increase their prestige through the acquisition of the latest technology.

Because the two factions within the profession of nuclear doctors could not agree on which architecture of the innovation should be diffused and to what extent, the government decided to withhold any decision. Indeed, moving without the support of the Quebec Association of Nuclear Medicine would have been politically risky.

This period shows how multiple institutional logics may be mobilized to elaborate competing theorizations in order to defend different modes of diffusion of a technology, even when its basic utility has been fully legitimized as it was in the Health Technology Assessment Agency report. Each theorization relies on different moral imperatives presenting plausible but incompatible arguments. While the access-based theorization strategy focuses on the idea that failing to diffuse the technology widely is unethical because suffering and useless operations could be avoided, the quality-based theorization underlines the superiority of the more recent technology, its technicoeconomic advantages and the need for it to be calibrated and operated by highly skilled and competent professionals who master its complexities. Efficiency-based arguments are also mobilized by both camps, but they tend to be subordinated to the dominant access- and quality-based logics.

The acceptance of one or other theorization could have a huge impact. As compared with the access-based theorization which contended that this technology should be available in 12 centres in oncology all over the province, the quality-based theorization was more oriented towards the performance of the machine itself. As a consequence, while the Pro-stand-alone-PET clan was arguing that with 12 machines, 96 patients 
per day (12 patients times 8 patients/day) could have a PET scan in the province, the PET-CT clan was arguing that it was better to have 4 machines serving 48 patients per day (4 centres times 12 patients / day) in Quebec, but with good quality diagnosis performed by competent staff. The significant underlying consequences of adopting one strategy or the other clearly illustrate that effectiveness is socially defined (Suchman 1995) and inevitably implies ethical choices.

\subsubsection{LOCAL STRATEgic ACtions IN REgion A}

The need to be supplied with FDG to produce images was a major technological constraint preventing hospitals from adopting the technology by their own means. As long as a cyclotron needed to be near the scanner, acquiring this technology was especially difficult because of the costs and expertise required to operate a cyclotron. Moreover, the production of teaching hospital THB was not perceived by other hospitals as being sufficiently reliable to supply hospitals in the province of Quebec. It is only by the end of 2002 that this barrier was removed when the FDG started being supplied by private companies:

"At the time, we needed a FDG source and that didn't come instantly. We needed that source because even if you open a PET, if you do not have a reliable FDG source, you can not operate. But one supplier of FDG had been created in Albany NY, and it was able to feed us. [...] For that reason, we thought: 'OK, we have our source. Now we can proceed."

\subsubsection{The First Deviant Adoption - January 2003}

The confrontation between the Quebec Association of Nuclear Medicine and teaching hospitals that followed the publication of the HTAA report as to how to diffuse the PET scanner was not a good omen for a quick diffusion of this technology. This combined with repeated informal and unanswered requests from hospitals to obtain a PET scanner and the fast diffusion of this technology in the USA induced disillusionment and cynicism in many nuclear doctors with regard to the possibility of obtaining a PET scanner:

\footnotetext{
"The deployment of PET scanners, I've been hearing about that for four years, and another announcement arrives every $15^{\text {th }}$ of the month. It's the classic running gag. I've stopped believing in that."
}

Since it was the most advanced detecting technology, doctors as well as administrators of teaching hospital THA1 understood the strategic importance of the PET scanner and its alignment with their mission and strategy. 
However, being aware that no budget announcement for the deployment of the PET scanner would be made in the short term, Doctor Z, a nuclear doctor working at THA1, asked the private foundation of the hospital to buy a PET scanner. The stratagem consisted of renting the technology to THA1 for a symbolic sum. This allowed the teaching hospital indirectly to buy and have access to the technology, thereby evading the law which compels hospitals to have the consent of the government before acquiring a PET scanner or expensive technology. Because people in the Foundation were surprised at the deficiency of the Quebec health care system in the number of PET scanners, members of the board were easily persuaded by Doctor $Z$ that financing this technology made sense. This was reinforced by the fact that THB had a PET scanner, while THA1 had none:

"Members of the foundation were surprised. They wondered: 'How come region A has no PET scanner and region B has one? And when everybody says 'It doesn't make any sense!' the legitimacy is there, with no questions asked."

As a result, by January 2003, THA1 acquired a PET scanner without asking for the authorization and even without informing the Ministry of Health. When the story came out in the lay press in the same month, the official version stated that the machine was financed by research funds and used for research purposes. Interestingly, the media were already announcing that privately selling services was an option if the teaching hospital were to lack financial resources for operating the machine.

Because THA1 could publicly legitimate this acquisition by invoking the fact that the machine was for diagnosing a widespread deadly and highly publicized condition (cancer), it was unlikely that the Ministry of Health would denounce it:

\footnotetext{
"Put yourself in the shoes of the Minister who comes to tell us: "Whoah! You are going to get the machine out of there and you are not going to use it." That's a risky business. If that went to the media, we would have several very sensible and logical explanations to give to the people. The government would look pretty silly. (...) Especially as there are so many cancer cases... [the government wouldn't want to hear us] tell patients, "Well - we're ready to offer you a useful service, but the Minister has decided that you can't have it" Politically, you have to be careful."
}

After this adoption, doctors from various hospitals called THA1 to have information on how this strategic move was carried out:

"Five or six doctors called me to know how I had done it. How I dealt with the board of directors, the general management staff, and the Foundation, to do it, and make it official. They really wanted to know how I had pulled that off."

Given that access to health care is a public service in Quebec, doctors cannot, by law, receive private payment for health care services which are insured by the universal 
coverage. Despite this rule, THA1 had to find a way to finance the running costs of its PET scanner. The solution found was to offer PET scanner services at nights and on week-ends on a private basis to private clinics that were willing to pay. This would give patients or organizations access to a PET scanner within three to four days instead of two to six months, which corresponds to the normal public waiting time:

"By paying 2500\$ to the clinic associated with Doctor $\mathrm{Z}$ (the director of the Nuclear Medicine Department in THA1), a cancer patient can get a Positron Emission Tomography (PET scan) in three or four days at teaching hospital THA1 of region A, bypassing the usual waiting list that varies from two to six months."

$$
\text { - A public journal, April 30th, } 2004 .
$$

With the surplus generated from this activity, THA1 was able to fund its public activity, and also to charge the Quebec Health Insurance Agency for each act publicly performed.

Fifteen months after the acquisition of the PET scanner, the manoeuvre which consisted of prioritizing private before public patients was reported in the media and provoked a swift reaction from deputies at the legislative and from the Minister of Health who asked THA1 to stop selling public services to the private sector:

"Political actions were taken. After all, we are part of a Health System that is socialist. People said: 'It's not fair that a public hospital with public funding is used for activities tied to the private sector."

This situation had to be handled rapidly by the government because the health insurance law forbids organizations from the public health care network to be financed through private activities. Moreover, the situation was critical to the point that publicly paid staffs were employed to run the PET scanner to generate private revenue. To enable THA1 to stop financing its operation through private funds the Minister of Health announced that an operational budget of 1250 cases for 2004-2005 would be allocated to them.

In February 2003, the combination of the deviant adoption of THA1, the announcement from teaching hospital THA2 of its imminent intention to buy a PETCT scanner, and the request from the general hospital GHA to be authorized to acquire the same technology provoked the Ministry of Health to ask the Health Services Regional Agency to evaluate urgently the clinical needs of PET scanners in region A. This was necessary to avoid a further uncoordinated and irrational diffusion of PET scanners, as had happened previously with the MRI and was just starting with the case of THA1: 
"The danger was that we would have rather anarchical development. It would be those who had the money or those who screamed the most or those who made the most pressure that would get the machine."

By April 2004, the committee of the Health Services Regional Agency produced a document which was submitted to the Ministry of Health concluding that seven cameras were necessary to cover the needs of the population in oncology for region A.

\subsubsection{Analysis}

The vertical struggle between teaching hospital THA1 and the Ministry of Health is the expression of, on the one hand, hospitals' interests in adopting such a prestigious technology (prestige, higher fee-for-service, research protocol) and, on the other, the cost-containment imperative of the government. Because hospitals need the authorization from the government to acquire this technology, the government can use its regulatory power to hinder any adoption by delaying the announcement of a dissemination plan. However, wide diffusion in the USA, the confirmation of the effectiveness of the technology by the HTAA report, the special status of cancer, which is often synonymous to a sentence of death, and patient needs, all contributed to build normative legitimacy of this technology and a strong pressure to adopt. Further, given its mission in cancer and in technology assessment, THA1 had an important incentive to acquire this technology. This normative legitimacy of the technology and the interest of THA1 to adopt advanced technology are two powerful incentives to acquire a PET scanner. The legitimacy of the technology was such that it outweighed the legitimacy of the regulation which was impeding such adoption. This adoption against the will of the government is a form of what I call institution testing, which I define as an action against regulatory constraints.

While institution testing was a strategic move to pre-empt the adoption of the PET scanner, other actions in this case can also be considered deviant. For example, the private funding of the daily public operation of the PET scanner is questionable as regard to the law. The problem stems from the situation where patients willing to pay were jumping the waiting list, something the public and the government could not tolerate because it goes against equity of access. Another problem was that publicly paid human resources were used for diagnosing private patients. Overall, it is because this technology is aligned with the mission of the organization and also because legitimacy of the technology is greater than the legitimacy of the regulation that institution testing was possible. 
Interestingly, this behaviour was successful for at least two reasons. While institution testing pre-empted the adoption of this technology, it also allowed THA1 to obtain a budget. Indeed, when the story of privately funded operations at THA1 came out in the lay press, the government reacted to calm the tension by providing an operational budget. In this case, the government was literally trapped because it could not hinder access to a cancer diagnosing device nor could it sanction a deviant behaviour which was generating inequity in the system as other hospitals did not have this technology.

\subsubsection{A Second Deviant Adoption - May 2004}

The new director of the Nuclear Medicine Department at teaching hospital THA2 arrived in 2000 with the intention of obtaining a PET scanner. With the unanimous support from of various clinical directors, the administration of THA2 asked the Ministry of Health to finance the acquisition of this technology, but never received an answer. Instead of relying on governmental funds, THA2 started to meet with diverse private potential donors for this acquisition, but in vain. When the HTAA report was published, a new attempt was made to persuade the Ministry of Health to invest in the technology, but still without any result.

Surprised by the necessity of travelling as far as teaching hospital THB to undergo a PET scanner, a public personality decided to open a private foundation in 2002 to finance the acquisition of a PET-CT scanner at THA2. Following the strategy of THA1, the nuclear doctor of THA2 met with the private foundation of the hospital to finance part of the acquisition. The new foundation of the public personality together with the traditional one of THA2 gathered the amount of money required to acquire a PET-CT scanner. Before proceeding with this acquisition, THA2 informed the Health Services Regional Agency, the interlocutor of the Ministry of Health, that they were inviting companies to tender for a PET scanner. Promptly the Health Services Regional Agency sent a letter to THA2 urging them to stop this acquisition process:

\footnotetext{
"We told the Health Services Regional Agency that we were offering tenders to acquire the equipment. The Agency sent us a letter telling us that we could not do that. There were laws at the Ministry level, and they sent us a copy of those laws. They said that only the Minister had the right to decide new programs. We could not invest money in this project, and so on."
}

Although THA2 did not obtain the authorization to acquire this technology, the adjunct director of the hospital decided to move forward with the project. This choice was strategic for THA2 as the PET-CT scanner was aligned with its mission and was also a good way to compete against the general hospital GHA in oncology: 
"It is part of our mission. If we want to provide the best care available for cancer patients, we must acquire this equipment. [...] There is also this competition between General Hospital GHA and teaching hospital THA2. They both want to dominate the oncology program in region A."

The letter from the Health Services Regional Agency was insufficient to stop the movement given that adopting the technology was of little risk for THA2 because, as one interviewee stated, if the technology had to diffuse, it had to diffuse in a teaching hospital:

\begin{abstract}
"Granted, we went against the rules, but it was a calculated risk. If a machine was to be deployed in the province, it had to be in a teaching hospital first, as there were already two machines at the teaching hospital THB."
\end{abstract}

Interestingly, THA2 decomposed the project into smaller amounts to tender for building the hospital infrastructure to receive the PET-CT scanner. This was a way to bypass the normal regulation for invitation to tender which takes much more time than when a project is broken is smaller parts. As a result, THA2 pre-empted the beginning of the operation of their machine:

\begin{abstract}
"We played the game to a certain extent. We went through the bidding process but we didn't follow all the bureaucratic rules. That would have taken too much time. Maybe six to eight months more if we had followed all the regulatory steps. [...] Invitations to tender are so regulated. Here's what we did. Instead of a one million dollar project, we broke it into several smaller parts. All the steps were worth less than a million dollars. With this approach, the bidding process was shortened by quite a bit, and it took much less time."
\end{abstract}

Once the hospital infrastructure for the PET scanner was under construction, THA2 asked the government for an operational budget, but once again this was a dead letter. To finance its operation, THA2 drew on its global budget thereby increasing its deficit. Because generating deficit in hospitals was and is still prohibited by the law ${ }^{23}$, this behaviour is rather unexpected. While THA2 started operating its PET-CT scanner by May 17th 2004, its budget constraint limited the number of patients to undergo examinations to 2 patients / day instead of 12 patients / day. This precaution was taken to avoid ending up with a huge operational deficit if the Ministry of Health would not provide an operational budget.

In the Quebec health care system, there are no specific reimbursed indications and doctors are free to use their equipment as they please. However, the second deviant acquisition of a PET-CT scanner in May 2004 by THA2 prompted the Ministry of

\footnotetext{
${ }^{23}$ By reporting the deficit of a given year on the budget of the following year, the bill 107 passed in June 2000 has the consequence to reduce hospital deficit. This law was enforced in June $21^{\text {st }}$, 2001, by the bill 28 which states that hospital CEOs can be destitute if they engender deficits.
} 
Health to create an advisory committee in June 2004 to recommend the indications for which the PET scanner should be used. To develop guidelines, the advisory committee followed the vein already exploited in the HTAA report and reviewed the literature in search of evidence that the PET scanner would improve patient management. By March 2005, the advisory committee sent the guidelines developed to inform PET scanners providers about indications supported by the Ministry of Health.

\subsubsection{Analysis}

Again, in this episode institution testing was possible because the legitimacy of the technology was greater than the legitimacy of the regulation, and also because the technology was aligned with the mission of THA2. As one interviewee noted, "if there was one PET scanner to be diffused, it had to be in a teaching hospital". This confirmed that institution testing, a deviant adoption in this case, was a relatively low risk behaviour given the mission of the teaching hospital in oncology and in technology assessment. Moreover, institution testing spreads to this hospital for competitive reasons. Indeed, for THA2 to remain a reference in oncology, acquiring a PET scanner was necessary.

THA2 was deviant not only in acquiring the technology, but also in the way it financed its operation. Because the government did not allow an operational budget, this hospital drew on its global budget to finance its operation despite the risk of deepening its deficit, an offence in the eye of the law since 2002 in Quebec.

Finally, the way the technology was implemented was also strategically designed to avoid the normal invitation-to-tender procedure which would have taken much longer. In order to speed up the construction of the PET scanner infrastructure, THA2 broke up the project into smaller pieces to bypass the heavy regulations which applied to projects over one million dollar CND.

Although the Ministry of Health has no control on the behaviour of doctors who themselves decide for which indications the PET scanner should be used, the second deviant adoption gave a good incentive to the Ministry of Health to develop guidelines in order to try to encourage an effective use of the PET scanner. 


\subsubsection{Private clinics adopt the PET-CT scanner - $2004 \& 2006$}

The impressive waiting time of two to six months to undergo a PET scanner at the teaching hospital THA1 was a clear indicator of the huge demand for this type of procedure. After having received a budget from the Ministry of Health for the PET scanner at THA1, Doctor $Z^{24}$ intended to respond to this demand by buying a PETCT scanner for his private clinic PCA ${ }^{25}$. This would allow the private clinic PCA to have the best technology in the region A:

“The Public Health system's provision for PET scans was inadequate. This created a demand for more. We thought that people were increasingly unwilling to linger for months on a waiting list. And services in the Public Health System are not always top notch. For example, in the teaching hospital THA1, we still don't have the best PET technology, which is PET-CT."

The acquisition of a private PET-CT scanner caused consternation in the media, and the complexity of the regulation was explained as being the reason behind the fact that a private clinic could unjustifiably offer health care services to people willing to pay. By and large, the debate was around the notion of medically required treatment. If the PET scanner is considered as being medically required, then the law states that it should be entirely covered by the universal public insurance and private clinics should not have the right to offer private PET scanner procedures reimbursed by private money. However, if the PET scanner does not have this status then private clinics should be able to offer this service on an experimental basis to patients willing to pay.

The following two quotations express the ambiguity of the status of the PET scanner:

"So is it legal or not? Well, yes ... and no [...]. The vice-president of the Canadian Association of Radiologists condemns this regulatory free-for-all: 'This is clearly illegal, but who can say that having a PET scan is not necessary, from a medical point of view? Government officials excuse themselves, arguing that the technology is still in its experimental stage. People take advantage of this fuzzy area, and of governmental inertia, to get a piece of the action. This situation is quite ridiculous.' And this situation is not new. During the last 15 years, private clinics offering MRI services have existed in Quebec. And no solution has been found yet."

Local newspaper, January $6^{\text {th }}$, 2005

${ }^{24}$ The same doctor that made teaching hospital THA1 to acquired the first PET scanner in the region A.

${ }^{25}$ Because equity of access is a central value in the Quebec's health care system, the Ministry of health did not welcome the opening of this private clinic in 1999. This is due to the privileged access the private clinic offers to patients willing to pay for health care services. However, the Government could not sanction the private clinic PCA to operate on this basis since the law proscribing doctors to be privately paid is only relevant for those working in the public health care sector. To legally generate private revenues, doctors have to be exclusively reimbursed privately and not by the RAMQ. 
"At the Federal Protecting Agency, the spokesperson explains that PET technology is still considered experimental, and not medically necessary. It can be thus offered in the private sector. Once this service is considered medically necessary, each province will have to provide it."

Local newspaper, January $6^{\text {th }}, 2005$

One month after the acquisition of the PET-CT scanner by the private clinic PCA, the private clinic PCQ which is situated in a city nearby also acquired a PET-CT scanner. Because they are sufficiently far away from one another, they did not compete for patients. A third private clinic PCC opened in October 2006 in the region C with the help of the same nuclear doctor who adopted the first PET scanner at public teaching hospital THA1 and the first PET scanner in the private clinic PCA.

However, these private clinics suffer from not having enough patients to reach the profitability threshold. Many factors are mobilized by owners to explain this situation.

Firstly, the unfamiliarity of the patients and doctors with the service seems to explain at least partly the low flow of patients these clinics experience. Secondly, some patients prefer to be on the waiting list and wait for their turn instead of paying for the service. As such, it seems that waiting lists became with time a normal phenomenon and people were no longer outraged by this:

"I think that the demand here for such a service is relatively low, for the time being. Patients in Quebec have become accustomed to waiting for doctors' services, with passing years."

Thirdly, patients are often not aware that they have complementary private health insurance which covers PET scanner procedures up to 80 to $90 \%$ of the total cost:

"People in Quebec are not always aware ... you may ask them 'Are you insured?' And they are unable to tell what type of insurance they have. They are not informed, even if they pay for their insurance via their employer. Most insurance companies pay for the larger part of a PET scan. Maybe 80 or $90 \%$, depending on the company."

This explains why most of private clinic patients come from outside the province of Quebec.

\subsubsection{Analysis}

Despite the non-reimbursement of PET scanner procedures to private organizations, three private clinics acquired a PET-CT scanner. Because there was a long waiting list of two to six months in public hospitals for PET scans, each of these adopters assumed that there was a huge demand for this type of examination. By providing PET-CT scanner, a superior technology, to the local population, private clinics 
calculated that the doctors in the public sector would prefer referring patients to the most advanced technology. However, this is not exactly what happened, partly because there is a strong belief in Quebec that health is a public good and so few citizens are willing to pay for health care despite a long waiting list. Absence of willingness to pay is an indication that there is no legitimized free market institutional logic in this health care system. This is also corroborated by the lack of knowledge about private insurance covering patients outside the public health care system and by the fact that doctors did not refer many patients to private clinics. Consequently, private clinics were barely surviving with one going bankrupt mainly because patient demand was too low in the private sector although it was high in the public system.

\title{
4.2.5.7 A Third Deviant Adoption - October 2004
}

In 2003, the general hospital GHA was approached by a citizen who wished to present the hospital with a major donation for the acquisition of a PET-CT scanner, provided that the hospital agreed to buy from a specific private company and within a certain timeframe. After having been informed about this unique opportunity, the Health Services Regional Agency, under the authority of the Ministry of Health, considered that other organizations in the region A would qualify for a PET scanner before this general hospital. Under the threat of losing the donation, the general hospital GHA informed the Health Services Regional Agency that it was inviting companies to tender for a PET-CT scanner despite the opposition of the Ministry of Health. An internal document reports:

\footnotetext{
"We moved to take advantage of the unique opportunity of a major donation that will allow us to totally finance the purchase of this equipment, including installation costs. We had to prove our benefactor that the case was progressing, or else this financing would have been cancelled."
}

Since the Health Services Regional Agency of region A did not want to be held responsible for the general hospital GHA to have lost this donation, the Ministry of Health did not respond to this letter:

\begin{abstract}
"No one wants to be the person who will explain to the media that a benefactor cancelled his pledge because we waited too long, and we could not buy the equipment. The Health Services Regional Agency's civil servant understood this perfectly. He was stuck between a rock and a hard place. So he let us proceed with the invitation to tender, even if it did not suit him at all."
\end{abstract}

Although funds were immediately available to acquire a PET-CT scanner, the general hospital GHA decided to wait for the authorization of the Ministry of Health. After a few months, the government came up with a plan of dissemination (see next section) 
of the PET scanner technology in Quebec and since the general hospital GHA was in this plan, the government authorized this hospital to acquire a PET scanner. However, the authorization was not accompanied by the necessary operational budget. Applying the same strategy as the teaching hospital THA2, the general hospital GHA financed its operations through its global budget thereby incurring the risk of increasing its deficit. Nonetheless, since the risk of not being reimbursed was quite low, the general hospital GHA started examining patients in October 2004, before receiving its operational budget, but using a cautious approach and not spending too much on this technology. The government committed itself to pay an operational budget to GHA by August $5^{\text {th }} 2005$ to cover its costs since the beginning of its operation:

"At the General Hospital GHA, a generous benefactor has promised to pay the total sum for the acquisition of a PET scanner, but the government has given no hint it was willing to pay for the annual operating costs of this equipment. The hospital has been waiting for a year and a half..."

Local newspaper, January $6^{\text {th }}, 2005$

\subsubsection{Analysis}

The desire of general hospital GHA to take advantage of the donation inspired it to test the government institution by acquiring a PET scanner despite opposition from the Ministry of Health. Hence, institution testing is still an issue in this episode, although a milder case. The main difference with the two previous cases is that general hospital GHA waited for government approval before really acquiring it. While it still somehow forced the hand of the government to be on the dissemination plan, the status of this general hospital, which is not as prestigious as a teaching hospital, and its mission, which is not so centred on evaluating technology, may explain its more conservative behaviour as regard to the adoption of this technology.

Although the donation was an important factor for adoption, competition between hospitals to become or to remain a local reference in oncology is clearly the motor that brought the general hospital GHA to acquire a PET-CT scanner. It is not the donation per se that seems to cause adoption but competition between actors to be a reference centre in oncology. Moreover, because general hospital GHA called teaching hospital THA1 to know how the latter managed to obtain this technology, mimetic isomorphism might be driving not the acquisition per se, but the process of acquiring a medical technology. Furthermore, because general hospital GHA does not have the budget to run its machine, like THA1, it drew on its global budget to do so. 
Hence, starting the adoption process before having the authorization of the Ministry of Health was a good strategy to pre-empt the adoption of this technology. Most probably, without deviant action, general hospital GHA would have had a PET scanner, but at a later time; and it might not have been the more sophisticated PETCT scanner.

\subsubsection{Disseminating PET Scanners in Teaching Hospitals}

To avoid the chaotic diffusion of PET scanners, the government of Quebec had a strong incentive to develop a dissemination plan:

"So, I guess government decision takers thought they better take charge of this matter and manage it, or else, it would manage itself by itself."

The Quebec Association of Nuclear Medicine and the Ministry of Health finally reached an agreement as to how to disseminate the PET scanners and a plan was created giving priority to those who already had a PET scanner, i.e. those who were defending a quality-based diffusion approach. According to the dissemination plan of June 2005, the PET scanner technology would be disseminated in three phases with an emphasis on providing PET-CT scanners to teaching hospitals first or hospitals on the way to acquiring one. Thus, adopting a PET scanner without the consent of the government was a good strategy. As one interviewee remarks:

\footnotetext{
"The consequence for GHA in adopting a PET scanner earlier is that they accelerated their case [at the Ministry of Health]. Maybe they would have received their authorization later."
}

Phase 1 was already in progress with the enhancement or purchase of new equipment in some teaching hospitals, while increasing the number of reimbursed case for them. Phase 2 would provide PET scanners to major centres in oncology in the region A, and Phase 3 would allow other important hospitals all over Quebec to have a standalone PET scanner. By the end of 2004, the government announced the purchase of a PET-CT scanner for THC (which actually obtained its machine in May 2006) and an upgrade to the PET-CT scanner for THA1. Interestingly, hospitals already having a PET scanner were included in an earlier phase then they might have been otherwise.

\subsubsection{Analysis}

Not controlling the diffusion of the PET scanner might have led to a delicate situation where the government would have had to provide deviant adopters with operational budgets in order not to be discredited. Furthermore, this situation would encourage 
inequity as some organizations having sufficient financial resources could adopt the technology to the detriment of others. It is the legitimacy of the technology, an echo of the institutional logic of quality that empowered hospitals to adopt without the consent of the government. To stop deviant adoption by the proponents of the quality-based theorization, a dissemination plan which was moulded on the actual diffusion pattern of the PET scanner was elaborated and even negotiated with the Quebec Association of Nuclear Medicine. Announcing a dissemination plan had the effect of stopping a chaotic dissemination process that could have escalated further out of control. Thus, the institutional logic of quality and access succeeded in shaking the foundation of the governance structure in the sense that the regulation governing the dissemination plan was aligned with the actual dissemination of the PET scanner. The consequence was that the government kept its legitimacy as regulator and regained control over the diffusion of this technology.

\subsection{Within CASE ANALYsis - Quebec ${ }^{26}$}

\subsubsection{STRUGGLES FOR CONTROL}

The case studies exhibit struggles for the control of the technology between the government and all would-be adopters. In these struggles, the government is constantly committed to limiting the diffusion of the PET scanner because of costcontainment considerations. To control the diffusion of the PET scanner, the Ministry of Health relies on its legal authority by declining or accepting hospital requests. On the other hand, hospitals rely on their expertise to strive to control the technology by deploying different rhetoric and strategies to obtain the authorization to adopt a PET scanner.

In the attempts to influence the diffusion of the technology, reports were produced by hospitals and meetings held to persuade the government to invest in this technology. Only one hospital was successful in persuading the Ministry of Health to finance a research project which included a PET scanner. However, to achieve this goal, a deviant entrepreneur used alternative channels to funds this acquisition. This is deviant behaviour because it defies the decision of the Ministry of Health which denied for years a PET scanner to this entrepreneur.

${ }^{26}$ This section analyses the events that are described in the Quebec health care system case study. While this analysis is rather synthetic, a more detailed one is presented in chapter $\mathrm{V}$. 
While obtaining a budget to acquire a PET scanner was the first struggle for controlling the technology, the second struggle was related to receiving an operational budget. This time, struggle for control refers to the use of the PET scanner. Although there was theorization from THB to persuade the government to provide an operational budget, it was the patients going to USA to undergo PET scanner procedures that incited the Ministry of Health to provide a budget to THB. Because it is less costly to undergo a PET scan in Quebec, it is clear that the budget was provided because it was aligned with the interest of the Ministry of Health.

\subsubsection{StrugGLES FOR MEANING}

Vertical struggles affect every aspect of this case study and they are also behind horizontal struggles. Indeed, it is because the government intends to limit the diffusion of this technology, thereby controlling resources, that there are horizontal struggles (competition) between actors to be a site of adoption.

Hence, the struggle for control in the region B precipitated a horizontal struggle between hospitals. Mobilizing scientific evidence, hospitals in competition used different quality-based theorizations which were aligned with their mission to influence the Ministry of Health, at a time when the purpose of the PET scanner was still ambiguous. The production of competing quality-based theorizations led to struggles for meaning. Each theorization provides meaning on what is the nature of the technology, why it should be diffused, and who should adopt it, and how it should be diffuse (see tables 4.4, 4.5 and 4.6).

The publication of the health technology assessment report from the HTAA agency also provides meaning to the PET scanner by defining what the technology is (a clinical and a research tool), why the technology should be diffused (clinical needs and clinical utility of the technology), how it should be deployed (progressively by beginning with teaching hospitals), and who should adopt it (competence and research activity). All these recommendations relate to the concept of quality (Scott, Ruef et al. 2000) and are therefore based on a quality-based institutional logic. These theorizations respond to the interest of teaching hospitals since the report clearly identifies them as the prime recipients of the diffusion of PET scanners, and also insists on the necessity for further research effort on the technology.

The publication of this report gave rise to intense horizontal struggles for providing meaning to the technology. Given the mission of the Quebec Association of Nuclear Medicine to represent its members, an access-based counter-theorization was 
developed to legitimize an alternative way of diffusing the technology. The countertheorization defined what the technology was (a proven clinical tools), why it should be adopted (PET scan for all and efficiency-based logic tied to an access-based logic), who should adopt and how (distribution in coherence with existing oncology centres). This conflict over the distribution of the PET scanner in this organizational field was even more acute with the apparition of the PET-CT scanner. With this new technology, teaching hospitals started being more active by re-emphasizing the theorization of the HTAA report.

At each stage of the diffusion of the PET scanner in this organizational field, the vertical struggle to obtain authorization to adopt a PET scanner results in intensive horizontal struggle for meaning; given that the meaning of the technology will ultimately influence who is more legitimate and competent to obtain it. Interestingly, these theorizations are the perfect reflection of major institutional logics in this institutional field. Thus, it can be assumed that actors draw on institutional logics which are already legitimated in the wider environment to gain organizational legitimacy. However, when acquiring a technology through legitimate means fails, some actors may have the power to shift their strategy in order to acquire a technology through deviant or illegitimate means. The next section analyses how actors in this case study used illegitimate means to obtain a PET scanner, a strategy that I call institution testing.

\subsubsection{Struggling FOR CONTROL THROUgh INSTITUTION TESTING}

It was because the technology had become so widely accepted as being a legitimate tool in medicine [the wide diffusion outside this organizational field; the legitimacy of the PET scanner granted by the Health Technology Assessment report as being an essential tool in diagnosing life threatening conditions (cancer); and patient needs] that hospitals could, in the first place, adopt the technology without the consent of the government. Because it was considered an essential clinical tool, the risk incurred by actors who adopted the technology was limited, since the government was powerless to respond to their actions. Indeed, any government attempt at retaliation against the hospital could have easily been denounced in the media as preventing hospitals from providing good quality technology for cancer patients, a widely publicized condition high in the political agenda - not a wise move. This supports the idea that the institutional logic of quality had such strength in this organizational field that it justified, on the one hand, that hospitals could adopt the technology without the consent of the government, with good justification to provide to the population if the 
government dared to retaliate. On the other hand, the government adjusted its regulation, i.e. the dissemination plan, to the actual diffusion pattern. This suggests that the quality-based institutional logic forced the governance structure to adapt to its imperatives.

There was basically no regulative sanction possible from the government if a hospital exhibited such behaviour. Moreover, the inertia of the government regarding horizontal struggles between professionals and which brought conflicting demands from nuclear doctors to obtain PET scanners stimulated the institution-testing behaviour by giving the impression that this was the only remaining strategy to obtain the technology. Thus, institution testing is a deviant behaviour according to the law but one which can be perceived as legitimate by professionals and the population in a given setting. In other words, institution testing is a strategic behaviour that is rendered possible when normative and cultural-cognitive forces are stronger than regulative ones.

This case suggests that four conditions have to be present for institution testing to take place. Firstly, the state of the technology has to be sufficiently mature. Indeed, the supply of FDG is an essential ingredient to produce PET scanner images. It was only when the private companies could distribute the substance in Quebec that institution testing became an option for potential adopters. Secondly, only organizations having greater access to financial resources could undertake deviant strategies. Thirdly, since legitimate strategy to adopt the PET scanner was not successful, institution testing was the only remaining alternative. Thus, institution testing tends to occur when legitimate means to reach a goal have failed. Fourthly, actors perceived no regulative or moral sanctions in performing deviant behaviour because it was risky for the government to sanction this behaviour and because institutional deviants felt their action was not prejudicing anyone. Finally, having the competence to run a PET scanner inside the organization seemed to be not a condition but a facilitating factor as the two teaching hospitals had a nuclear doctor trained to use the machine.

THA1 had an important impact on the subsequent dynamics of the diffusion of the PET scanner, bringing another teaching hospital in its wake. THA1 was contacted by other hospitals for tips on how to perform institution testing. It also forced the Ministry of Health to create a regional committee to address the number of PET scanner needed in the region. Since the Ministry of Health did not announce a dissemination plan for the technology, and because no sanctions were applied to the first deviants, another hospital adopted the same strategy. To remain competitive, it 
became necessary to acquire the technology as quickly as possible. Indeed, competition between hospitals was one important drive for institution testing. Not adopting the PET scanner might have meant more than just delaying the acquisition process: it might also have implied losing reputation as a major institution in oncology.

While institution testing has many ramifications in three sites of adoption, adopting the PET scanner without the consent of the government is probably the most defiant action. Other deviant behaviour includes launching the acquisition processes without authorization; operating the machine with private funds which is prohibited in this jurisdiction, increasing the deficit of their organizations which is also illicit, and one of them broke down the infrastructure project to prepare the room for the PET scanner into smaller units to bypass the normal auction rules in order to accelerate the acquisition process.

\subsection{The Diffusion of THE PET SCANNER IN SWITZERLAND}

This case study is characterized by an intense vertical struggle which opened up the diffusion of the PET scanner. Indeed, while the PET scanner was confined to a duopoly, the extension of reimbursement to cancer indications caused a private clinic to challenge the Federal government to open up this technology to newcomers. In this struggle, while the private clinic mobilized an institutional logic of free-market to obtain the right to be reimbursed, the Federal government was defending an efficiency-based institutional logic. The action of the private clinic is a form of what I call institution testing that is a strategic action which contests established institutions. The threat of a trial under the Anti-trust Commission was sufficient to change the organization of the duopoly to open up the market for organizations meeting specific quality criteria. After the establishment of these quality criteria, the case study explores vertical and horizontal struggles that took place in nine cantons as well as the strategies deployed by organizations to bypass regulations under the public regimes. Figure 4.3 gives an overview of the chronology of events that marked the diffusion of this technology in the Switzerland's organizational field.

The study examines adoption in nine cantons. These cantons are designated by the letters $\mathrm{D}, \mathrm{G}, \mathrm{N}, \mathrm{R}, \mathrm{S}, \mathrm{T}, \mathrm{U}, \mathrm{V}$ and $\mathrm{Z}$ where $\mathrm{N}$ and $\mathrm{U}$ are the most populated cantons with more than 900,000 inhabitants, D, R, T, V are a little less populated with a population ranging from 400,000 to 899,999 , and G, S, Z the less inhabited cantons having acquired a PET scanner with a population of less than 400,000. 
FIGURE 4.3:

Visual MAPPING OF THE Diffusion OF THE PET sCaNNER IN SWITZERLAND

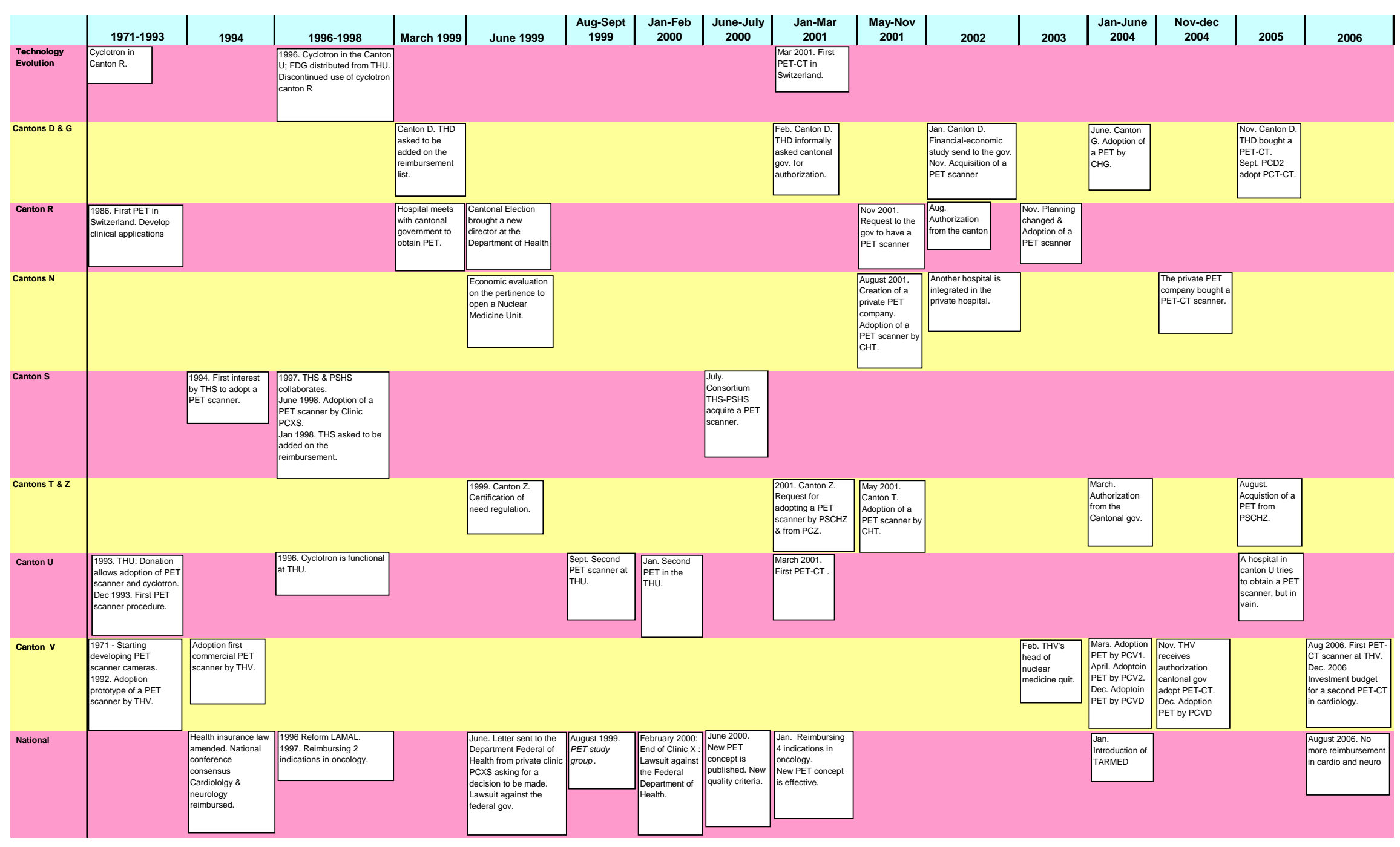




\subsubsection{Developing THE PET Scanner Technology}

In 1986, the first PET scanner was adopted by the Institute IR in the Canton R, a reputed research institute in engineering and natural sciences. Since Institute IR had the facility to produce radiopharmaceuticals with its cyclotron, an inter-university committee composed of heads of nuclear medicine selected this institution to develop this technology. This institution performed the first PET scanner clinical applications in cardiology and neurology with their own research funds. While patients were sent by the teaching hospital THU and by the cantonal hospital CHR to undergo this procedure, THU stopped sending patients when it acquired its own machine in 1992. The Institute IR discontinued the use of its outdated PET scanner in 1996.

\subsubsection{Canton V: Developing the Machine - 1971}

After an intensive development of PET scanner prototypes which started in 1971, an internationally renowned physicist finally came up with an almost ready to commercialize version in 1992 and moved to another country. To continue the local development of the prototype in the canton $\mathrm{V}$, this physicist hesitated to keep on working with teaching hospital THV given that no cyclotron was functional there, an important element to develop the technology. However, because of this, the physicist was more inclined to give a PET scanner to the Institute IR.

This threat of losing a machine was perceived by the head of the Department of Nuclear Medicine of THV as an opportunity to convince the State Counsellor of Health of the urgency of acquiring a cyclotron. In 1993, having been convinced that acquiring a cyclotron could enhance the chance of one city in the canton $\mathrm{V}$ to be selected for a major national event, the State Council forced each department of THV to draw on its budget to finance the technology, albeit without foreseeing the need for an operational budget. As a result of the hospital having been forced into it, neither the Faculty of medicine nor the administration supported this acquisition, and the cyclotron stayed in its original packaging for six years. Nonetheless, the promise to buy a cyclotron was sufficient to convince the developer to send its almost ready to commercialize PET scanner prototype to THV for further development.

Later on, in exchange for bringing the patent and the know-how related to the PET scanner, the private company which hired the physicist offered a PET scanner to THV for $1 / 3$ of its market price. With this new PET scanner, THV decided to discontinue the use of the first prototype because of the low demand for this type of procedure at the time and the absence of a nearby cyclotron. 


\subsubsection{Canton U: Building a Quasi-Monopoly - 1993 / 1999}

Dr Y, the head of the Nuclear Medicine Unit at teaching hospital THU, arrived in 1987 with the firm intention of promoting what he felt was a promising diagnostic technology. Although he convinced his superior, the head of the Department of Radiology, and made a good impression on the head of the Cantonal Department of Health, the cost of the PET scanner technology was too high and cantonal authorities refused to fund this acquisition. While THU was still sending its patients to the Institute IR in the Canton $\mathrm{R}$, the sudden donation of 12 millions from a patient revived the hope of acquiring a PET scanner in the canton $U$. The head of the Cantonal Department of Health, who believed THU should be the flagship of medicine in Switzerland, proposed not to spread this amount throughout the hospital, but to invest it in a PET scanner and in a cyclotron. Having secured the financial resources, choosing the right PET scanner manufacturer was the next step. Dr Y thought that acquiring the PET scanner from the Manufacturer AY, which had its headquarters in a foreign country, would enable THU to become the centre of reference in Europe for this company and even to "derive some perks from it".

While the first PET scanner clinical procedures were performed in December 1993 at THU, the cyclotron was not functional until 1996 due to the heavy infrastructure that had to be built. Once the cyclotron was functional, THU stopped being supplied in FDG (Fluorodesoxyglucose: the radio-isotope that is essential for the use of the PET scanner) by the Institute IR. Nevertheless, due to the absence of highly qualified staff to perform radio-pharmacy operations at THU, Dr Y asked the Institute IR to be responsible for the new cyclotron operations. To avoid competition, the Institute IR stopped producing FDG thereby leaving THU with a monopoly in Switzerland.

Obtaining the funds to acquire a PET scanner was one thing, being financed through the reimbursement of PET scanner clinical applications was another. After long negotiations succeeded in obtaining the reimbursement of clinical applications, Dr Y was committed to extending the quasi-monopoly of THU to the whole of Switzerland, assuming that teaching hospital THV would continue to have a low level of PET scanner activity for a while:

"If you look also at Dr Y, when he got his PET scanner he came out with: "you don't need to buy one, just send your patients to the teaching hospital THU; we can cover all patients in Switzerland". He was actively promoting that only THU should have PET, and only THU is going to be reimbursed for PET."

The increasing number of patients undergoing PET scanner diagnostics (around 1500 cases in 1998) encouraged THU to adopt a second PET scanner. By September 1999, 
the second machine was acquired, and with it the even more active dissemination of the idea that THU should have the monopoly of PET scanners in Switzerland.

Although this second acquisition absorbed PET scanner demand, Dr Y from THU had the idea of asking manufacturer AY to build and commercialize the concept of a well-known physician who was working in Switzerland. This concept consisted of combining the PET scanner technology, which provides functional images, with the CT scanner technology, which produces anatomical images, to create the PET-CT scanner.

After hard negotiations with Manufacturer AY to produce the machine, the first commercial PET-CT scanner was installed at THU in March 2001. Later on, in 2004, a second PET-CT scanner replaced the older PET scanner at THU.

\subsubsection{Analysis}

The high technological dependence between PET scanner and cyclotron characterizes the early diffusion of the PET scanner technology. As both elements were required to produce images, only a few centres had access to this technology. This explains the choice of the inter-university hospital committee to support the development of clinical applications at the Institute IR which had a PET scanner and a cyclotron, as well as the competence to run it. Since the PET scanner and the cyclotron were initially tightly coupled, extremely high investment was required to obtain the technology. The necessity for major investments may have significantly hindered the diffusion of the PET scanner at the outset. Clearly, the early diffusion of this technology is largely tributary to a researcher's intention to further develop this technology, whether the scanner itself or clinical applications.

While on the one hand the Cantonal Department of Health of the Canton U was reluctant to fund the acquisition of a PET scanner, on the other hand, teaching hospital THU was eager to obtain one; the sudden donation of 12 millions CHF to THU relieved the vertical tension between both entities. The forced adoption of the PET scanner in the Canton V depicts a vertical struggle between the Cantonal Department of Health and the teaching hospital THV, but exceptionally in this case, where the former is imposing the adoption of the technology, despite internal resistance at THV. This was clearly due to the interest of the cantonal government to promote Canton V in Switzerland. 
Although an agreement was finally reached, the adoption of a cyclotron by THU, while the same technology was already in service in Canton $\mathrm{R}$, expresses a competition for the control of the production of FDG in Switzerland. To a certain extent, this event reflects a horizontal struggle between THU and Institute IR.

By intending to build a PET scanner monopoly, THU is horizontally struggling with other centres desiring to acquire a PET scanner. This is performed by propagating the idea that, as a provider, THU is sufficient to cover patient needs all over Switzerland. This is a good strategy to maximize the PET scanner investment and to derive profit from this exploitation. Moreover, the adoption of two PET-CT scanners was, among other things, a strategy to fortify the position of THU as a quasi-monopoly.

\subsubsection{The Challenge of Reimbursement: Colliding logics at THE FEDERAL LEVEL}

\subsubsection{Two logics for Reimbursement: Sensitivity versus Patient Management}

Due to the high operational costs, the previous experience of Dr Y with an MRI scanner ${ }^{27}$ showed him that obtaining the compulsory reimbursement of PET scanner procedures by health insurance companies is a prerequisite to ensuring the sustainability of expensive technology, both in clinical and research settings:

\footnotetext{
"We had a pretty strong focus on clinical applications. I had a very strong focus on clinical applications. I had a very clear view and I said: "We are a university which cannot afford to run PET scanners for research". We need to have clinical justifications. [...] And so I always said PET is expensive, we need a good application, that we can justify to run these expensive scanners, and when we have that, we can do research"
}

To reach this target, Dr Y, who is both the head of the Department of Nuclear Medicine at the teaching hospital THU and the president of the PET committee at the Swiss Medical Association, organized a National Consensus Conference with the participation of international nuclear medicine experts, one representative from the Swiss Hospital Association ${ }^{28}$ and one from the Health Insurance Association, a doctor from the teaching hospital THV and an official from the Federal Department of Health.

\footnotetext{
${ }^{27}$ Magnetic Resonance Imaging is a diagnostic device in radiology to visualize functions and structures of the body.

${ }^{28}$ This association represents hospital interests.
} 
According to the health insurance law in effect in 1993, a new procedure must meet three criteria to be added to the reimbursement list: it must be considered as being 1) effective, 2) appropriate and 3) economic. In this context, the challenge for the National Consensus Conference was to obtain from the federal government the compulsory reimbursement for some PET scanner indications, despite the lack of evidence on these three criteria. The previous experience of the government official with MRI qualified him to be critical in front of spectacular images like the ones produced by the PET scanner and he was insistent in demanding proof of the value of the technology in terms of patient management and clinical outcomes ${ }^{29}$ :

\footnotetext{
"It was for health and brain that we saw that it was good and that there was no risk. However, benefits for patients were not clear. We had opinions from experts, but not hard facts."
}

While the government official was asking for results on these dimensions, nuclear doctors were talking in terms of the high quality of functional images produced by the PET scanner:

\begin{abstract}
"I think the evidence that PET was relevant was that doctor B from NIH said that in brain tumors you could measure the site where tumors are with PET. So, this was mainly the words of Doctor B who said that there was clear clinical use of PET in the brain. And then, in the late 80's, there was a publication in the New England Journal of Medicine by the UCLA group which demonstrated that you could identify hibernating myocardia with PET. And so, at the time, around 1990, I think the community at large had a pretty good understanding that PET was going to be helpful for brain and heart.”
\end{abstract}

These positions were clearly two different ways of approaching quality in terms of the value of technology.

Because the quality of images was amazing and experts' opinions as well as their publications were persuasive, the government official thought that the population might benefit from having access to this technology. This led the government official to propose the elaboration of a special ordinance (amending the current Health Insurance Law) which would allow designated hospitals to be reimbursed for new technologies despite the lack of evidence on the three reimbursement criteria (effectiveness, appropriateness and economic value), as long as PET scanner providers agreed to evaluate the technology. In the long run this would allow evidence to be gathered on the impact of the technology in terms of patient management and clinical outcomes:

${ }^{29}$ While patient management refers to the existence of a treatment in the case of a positive diagnostic, clinical outcome is related to the impact of the technology on the evolution of the disease. 
“...Because knowledge about PET scanner in '94 was not the same as today. We were not sure if it was a technology to produce good images or if it was appropriate to improve patient management. That's why we elaborated a system which was in effect up to May 2006 to assess new technologies."

Given the state of the evidence in 1994, the National Consensus Conference settled the reimbursement for neurological and cardiac procedures with the condition that its eligibility for reimbursement should be reassessed by December 2005. Because PET providers had to evaluate the technology ${ }^{30}$, a fairly generous reimbursement rate was authorized. For example, while the PET scanner was initially reimbursed at a rate of around 2200 USD per examination, MRI was reimbursed at about 800 USD per exam. However, to limit cost expenditure and to ensure that the technology would actually be evaluated, only two centres were nominated for reimbursement: THU and THV. This ordinance allowing reimbursement for promising technology and specifying which centres would be reimbursed was introduced in the 1996 health insurance law called LAMal."

Although the reimbursement in neurology and cardiology was granted by the government, these clinical applications were limited to a few patients and were not sufficient to ensure the funding of related PET scanner research activities. Since Dr Y foresaw a huge potential for the technology in tumour staging ${ }^{31}$, THU in collaboration with other internationally renowned research institutes started investigating clinical PET scanner applications in oncology. Because THU published these papers in major journals, the reimbursement process was facilitated as it demonstrated their competence:

\begin{abstract}
"They said: "What you have to demonstrate is that your method works well, based on the literature and that you can perform it." Since we published the literature essentially by ourselves, it was easy because we said: "Look, here we have studies in a top level imaging journal. We have evidence which we have acquired [ourselves]. This means [that] we are competent.”
\end{abstract}

In January 1997, the publication of two papers in prestigious journals was sufficient to convince the Federal Department of Health to start reimbursing two indications in oncology: melanoma and bronchiocarcinoma. Later on, the Swiss Medical Association and PET providers asked the Federal Department of Health to further extend the reimbursement for PET scanner indications in oncology. However, there were still palpable tensions between the officials of the Federal Department of Health, who were much more focused on the value of the technology in terms of clinical outcomes

\footnotetext{
${ }^{30}$ The obligation to evaluate the technology will finally be abandoned in 2005 when an ethical committee estimated that this procedure was discriminative for patients who would refuse to be part of this research protocol.

${ }^{31}$ Tumour staging identifies the developmental phase of a malignant disease when a diagnostic is made.
} 
(the invasiveness of the procedure, the comparison with other diagnostic tools, the availability of treatment in case of positive result), and PET providers, who tended to evaluate the benefits of the technology in terms of the increased precision of the diagnostic tool without any consideration of the availability of a treatment in the case of positive result. Hence, for the government, the criterion of effectiveness (quality) which is mentioned in the law has two dimensions: the first is related to the specificity and the sensitivity of the procedure which were defended by nuclear doctors, and the second refers to the clinical value of the technology in terms of patient management and clinical outcomes. In order to be reimbursed, the government considered that these two criteria had to be met:

"PET scanner manufacturers tended to suggest medical guidelines for reimbursement that went along these lines: 'Our machines can detect this and that.' But the Federal Commission of Health Insurance and the Federal Department of Health replied something like: "That's not enough. Tell us how your procedure will finally benefit the patient." "

In 2000, a group of nuclear doctors called PET working group, which was by then the entity in charge of dealing with PET scanner issues (see the next section for further details), succeeded in persuading the government to provide additional reimbursements for lymphoma, breast, testicular and colon-rectal cancers. These new indications were reimbursed from January 2001 onwards.

The special agreement dating from 1993 between PET providers and the Federal Commission for Health Insurance specified that the PET scanner was to be reassessed by the end of 2005. In order to get an objective evaluation, the Federal Department of Health ordered an independent assessment. The conclusions of this evaluation were striking as it stated that the PET scanner had no clinical benefit in neurology for epilepsy and dementia, and no clinical benefit in cardiology in terms of patient management (two original applications that were reimbursed since 1994), except for an evaluation before cardiac transplantation. As a consequence, the reimbursement for these indications was suppressed from the positive list in August 2006. This decision was highly controversial as these indications were still reimbursed in other countries: 
"Alzheimer's disease was taken off the list, as were all other neurological pathologies. All around the world, we have clinical indications. Alzheimer's is being accepted. PET scans are part of the standard preoperative strategy as a clinical indicator for recurrent epileptic conditions that need surgery. This is an approved clinical procedure all over the world. It was reimbursed everywhere, and it still is. But here, in Switzerland, no reimbursement is granted for that. Neurologists can't believe it, and neurosurgeons are wondering what happened."

Some other sources argued that this is the result of the lobby of health insurance companies which were actively involved in suppressing expensive indications:

“... [governmental] decision-making is subjected to enormous pressures coming from lobbyists who want to eliminate clinical indications. In fact, insurance companies work very hard to take as many indications off these lists as they can. They have an army of experts who are trained to do only that."

\subsubsection{Analysis}

This episode illustrates the necessity for THU to obtain financial resources to perform research with the PET scanner and to further develop this technology, and it suggests that bottom-up championship is essential for its initial diffusion. In this case, gaining access to financial resources is mediated through a negotiation involving many actors, but with a clear vertical tension between the government officials and the nuclear doctors. This tension stems from the clash of two logics on what constitute the effectiveness of a medical intervention which is the first criterion in the law to provide reimbursement. The Nuclear Doctor Association argues more on the specificity and sensitivity of PET scanner images, while the government stresses the value of the technology in terms of patient management and clinical outcomes. Hence, although both sides draw on the institutional logic of quality, effectiveness was not defined in the same terms. Indeed, each actor was defining quality according to its own interests. On the one hand, the Federal government was concerned with patient management to make what would be reimbursed really worth it. This relates to the concept of "value for money" in the economic literature and suggests that this discourse on quality is grounded in an efficiency logic because the idea behind this concept is to optimize the use of money. On the other hand, the Nuclear Doctor Association intended to expand the reimbursement list to other clinical applications in order to have more flexibility in using the technology and to derive financial resources from it.

In the early diffusion, this tension was resolved through the imaginative solution of the government officials which consisted of amending the law to allow the reimbursement for health technology which was not yet evidence-based, with the condition of evaluating the technology to establish clinical outcomes evidence. In 
2006, cost-containment pressures and concerns for value for money brought the Federal Department of Health to suppress indications in neurology and cardiology, the same indications which were originally the factors causing the law to be amended.

Hence, while regulations specified that a health technology must prove to be effective, appropriate and economic to be reimbursed, this coincidently restricted the reimbursement of the PET scanner and forced the Swiss Medical Association to negotiate with the government to be on the reimbursement list. Since the law was amended, the case suggests that the institutional logic of quality made the governance structure (the regulation) change.

\subsubsection{Opening up Reimbursement}

\subsection{Canton S: Two Hospitals Collaborate}

By 1994, a nuclear doctor from the teaching hospital THS intended to acquire a PET scanner. The lack of maturity of the technology raised strong opposition from doctors who estimated that the global budget of the hospital should be spent for other purposes. However, things started to change from 1997 with the reimbursement of PET scanner procedures in oncology. Indeed, the publicly subsidized hospital ${ }^{32}$ SPHS reoriented its strategy to include a Nuclear Medicine Unit and asked the Federal Department of Health the authorization to adopt a PET scanner. In this case, profitmaking was clearly a motivation for adopting this technology:

"We [hospital SPHS] knew it was possible to make profit with this technology because the tariff was known. Teaching hospital THU had one [...] We talked to the great doctor in THU."

Surprisingly, despite the proximity of one of the most concentrated collections of pharmaceutical companies, this factor was not crucial in the adoption of this technology as there was no agreement and no discussion between these entities.

Hearing about the intention of hospital SPHS to acquire a PET scanner, teaching hospital THS swiftly met the cantonal government to ask for the authorization to acquire this technology, despite the tendency of their global budget to shrink by 33\% in the last few years. However, because the canton is small, less than 200,000 inhabitants, it was clear that there was room for only one PET scanner. With the demand from two organizations to acquire a PET scanner, the cantonal government

\footnotetext{
32 Publicly subsidized hospitals are privately owned, partially funded by the government and are part of the health provision cantonal planning. For this reason, any investment exceeding one million CHF (about 900 '000 USD) have to be approved by the cantonal authority.
} 
was not disposed to authorize two machines given the well-known phenomenon that health care cost increases with concentration of supply. Given the small size of the canton, the position of the Cantonal Department of Health was to authorize only one PET scanner, and strongly recommended the two hospitals to work on a collaborative scheme:

"So, the political body that has authority forced us to try to make the investment and to collaborate with the private hospital SPHS."

Despite this coercive pressure, both hospitals found an interest in collaborating. While THS would have the financial support required, teaming up with the public hospital would make it easier for hospital SPHS to legitimate politically the fact that a publicly subsidized hospital would adopt this technology. Because there was still no national reimbursement for this procedure, sharing the acquisition of the machine also lowered the financial risks, although there was a huge potential for profit. In January 1998, the two hospitals submitted a joint document to the Federal Department of Health asking to be added to the reimbursement list.

Because they intended to collaborate, the Cantonal Department of Health welcomed their initiative and was disposed to examine their request:

"The proposition was considered favourably. It set an example that hospitals don't just compete with each other, but could also sometimes work with each other."

Regardless of an embryonic collaborative scheme that was negotiated, the unexpected adoption from the private clinic PCXS destabilized everyone and led the Cantonal authorities to postpone its decision to authorize the acquisition of a PET scanner in the canton. The next sections describe this surprising adoption and struggle in canton $\mathrm{S}$ to acquire the PET scanner technology.

\subsection{Colliding Institutional Logics \& Lawsuit}

With the new reimbursement for PET scanner in oncology, a condition affecting many people, the private clinic PCXS in Canton S foresaw an appealing business opportunity and unpredictably for the government bought a PET scanner in June 1998. In spite of the clear prescription of the law that compels health insurances to 
reimburse only the two nominated PET centres $^{33}$, the clinic asked the Federal Department of Health to be on the reimbursement list.

In July 1998, the Federal Department of Health met the owners of the private clinic PCXS. While the quality of the installation of the private clinic PCXS was impressive, the uncertainty related to the clinical effectiveness of the technology, which was still under evaluation, made the Federal Government reluctant to open up the reimbursement list to other providers. Indeed, this application from the private clinic was interpreted by the Federal government official as opportunistic behaviour with the aim of capitalizing on the new article in the Health Insurance Law instead of evaluating promising technology. As a result, the Federal Department of Health was not inclined to grant PCXS the right to be on the reimbursement list:

“...because we established a new law that allowed us to introduce new technologies faster, Mr. X wanted to make profits and more money from it. And he messed up our new system of introduction for new technologies."

The Federal Department of Health justified its position by saying that the social insurance law provided access to advanced technology to the population (qualitybased institutional logic), but in way that limits cost expenditures (efficiency-based institutional logic). This was not contrary to the law since article 36 of the constitution asserts that the State can restrain free market competition if it is in the public interest. However, instead of directly answering the request of private clinic PCXS, the Federal Department of Health delayed the decision. On June $16^{\text {th }} 1999$, the private clinic PCXS sent a letter to the Federal Department of Health blaming them for not making a decision in regard to its request of June 1998.

By June 24th 1999 , the Federal Department of Health responded to this allegation by specifying in a letter that this subject was going to be discussed in the next meeting of the Federal Commission for Health Insurance 34 in August 1999. Impatient, the private clinic PCXS hired a law firm and brought a lawsuit against the Federal Department of Health in front of the Federal Tribunal of Insurance ${ }^{35}$. The law firm was extremely active and sent a huge number of documents arguing that the ordinance was too restrictive and was contrary to the free practice of medicine in a free market. Table 4.7

\footnotetext{
${ }^{33}$ Being on the reimbursement list compels health insurance companies to reimburse PET providers for specific indications. Otherwise, health providers may locally negotiate a reimbursement rate with the Cantonal Health Insurance Association with the risk to not reaching an agreement.

${ }^{34}$ Federal Commission for Health Insurance advises the Federal Department on the services that should be delivered in the Switzerland's health care system.

35 The Federal Tribunal of Insurance receives and treats complaints related to insurance issues in Switzerland.
} 
synthesizes the competing theorizations of both parties in their struggle to control the technology.

TABLE 4.7:

Competing Theorizations Related to Influencing ReImbursement Policy

\begin{tabular}{|c|c|c|}
\hline Theorization components & $\begin{array}{l}\text { Efficiency \& Quality based } \\
\text { Logics } \\
\text { Government }\end{array}$ & $\begin{array}{l}\text { Free Market-based Logic } \\
\text { Private Clinic }\end{array}$ \\
\hline $\begin{array}{l}\text { What to reimburse or not? } \\
\text { Definition of the innovation }\end{array}$ & $\begin{array}{l}\text { PET scanner in oncology, but } \\
\text { also in cardiology and neurology }\end{array}$ & $\begin{array}{l}\text { PET scanner in oncology, but } \\
\text { also in cardiology and neurology }\end{array}$ \\
\hline $\begin{array}{l}\text { Why reimbursing or not? } \\
\text { Moral legitimation essentially } \\
\text { grounded in quality-based logic } \\
\text { but tied to an efficiency-based } \\
\text { arguments in the first case vs. } \\
\text { pure free-market-based } \\
\text { arguments }\end{array}$ & $\begin{array}{l}\text { Because the PET scanner is still } \\
\text { being evaluated and as such } \\
\text { should not be widely diffused } \\
\text { for cost-containment purpose. } \\
\text { "We attempted to defend a system of } \\
\text { open social insurance with complete } \\
\text { modern services for all citizens but at a } \\
\text { reasonable financial cost." }\end{array}$ & $\begin{array}{l}\text { Because the PET scanner should } \\
\text { be available to all health care } \\
\text { providers, to freely practice } \\
\text { medicine. } \\
\text { "[The firm] mobilized liberal economic } \\
\text { argument, about open markets, the } \\
\text { right to exercise the medical profession } \\
\text { as freely and as completely as possible, } \\
\text { even invoking the European } \\
\text { convention on human rights." }\end{array}$ \\
\hline $\begin{array}{l}\text { Who should be reimbursed, } \\
\text { and how? }\end{array}$ & $\begin{array}{l}\text { To nominated centres for cost- } \\
\text { containment purposes. }\end{array}$ & $\begin{array}{l}\text { To all organizations wishing to } \\
\text { offer PET scanners. }\end{array}$ \\
\hline $\begin{array}{l}\text { Moral legitimation essentially } \\
\text { grounded in quality-based logic } \\
\text { but tied to an efficiency-based } \\
\text { arguments vs. free market- } \\
\text { based arguments }\end{array}$ & $\begin{array}{l}\text { "The two centres were the initatiors. } \\
\text { We wanted to limit it to the two } \\
\text { centres to allow the evaluation of the } \\
\text { technology." }\end{array}$ & $\begin{array}{l}\text { "Normally, everyone should be able to } \\
\text { use this technology" }\end{array}$ \\
\hline
\end{tabular}

In the lawsuit, the litigant asked the Federal Department of Health to stop delaying the decision related to authorizing the reimbursement of its PET scanner and to allow anyone wishing to use this technology to do so. In its complaint, the litigant advised the federal government to use quality criteria to allow reimbursement.

After having examined the complaint, the Federal Tribunal of Insurance returned its verdict by February 2000 and concluded that the complaint lodged against the Federal Department of Health was inadmissible because in its letter of June 24th 1999 , the Federal Department of Health made no decision and the Federal Tribunal of Insurance cannot conclude on a non-decision.

\subsection{Two Hospitals, but one PET Scanner -July 2000}

The sudden adoption of a PET scanner by the private hospital PCXS in June 1998 placed the consortium composed of THS and the publicly subsidized hospital SPHS under great pressure to convince the cantonal authorities that the PET scanner should be under public control. To reach this objective, the consortium started lobbying many stakeholders: 
"Word got around that a PET scanner was already installed at the PCXS clinic. There was an enormous pressure at the time. And we clearly played the political game to get the authorization before anyone else. [...] We lobbied right and left arguing that high-tech medicine belonged in principle to teaching hospitals. [...] Finally, we fought side by side [i.e. hospitals THS and SPHS]."

When the consortium finally obtained the authorization from the cantonal government to obtain a PET scanner, they informally met the Federal Department of Health to be added to the reimbursement list. However, the Federal Department of Health refused arguing that two PET scanners were enough in Switzerland and that there would be too many PET scanners in this small canton. In this case, too many PET scanners increased the risk of social security costs going up:

"There were suddenly two centers in a fairly small region [who wanted to be on the reimbursement list]. We feared that too many PET scans would be performed and which would have increased social security costs."

However, since in Switzerland health insurance companies can accept to reimburse some medical procedures or companies at the cantonal level, the consortium and the Cantonal Health Insurance Association came to an agreement as to the reimbursement of some indications with the PET scanner:

"The insurance companies are organized on a cantonal level, and they're organized on a federal level; and you have these cantonal concordats of the insurance companies, and they have agreed to come to...if it was not opened federally, they agreed to have a contract between the PET supplier [the hospital SPHS and the teaching hospital THS in the canton S] and the cantonal insurance concordat, so that they would reimburse their patients to have PET."

At this point, for the consortium, acquiring a PET scanner was only an administrative formality. The technology was adopted in July 2000.

\subsection{New PET Concept: Quality Imperative}

If the lawsuit did not provide the private clinic PCXS with a victory, it made the Federal Department of Health realize that the position of the government would be difficult to defend before the Swiss Anti-trust Commission. Because many centres were by then already sending letters to the Federal government to be added to the reimbursement list, the head of the Federal Department of Health considered reevaluating the concept of having a positive list of two PET centres: 
"The government worried that centres which were not included on this list would complain to the Anti-Trust Commission. This would have challenged the legitimacy of federal authorities to designate centres [...]. It would have been tough to defend this list during a trial."

In August 1999, the Federal Commission for Health Insurance entrusted a unit of the Federal Department of Health to create a PET Study Group with the mission to find a new PET concept. In other words, the group would have to come up with an innovative way to nominate PET centres. Since the Federal Department of Health lacked the required human resources to work on a solution, the task was delegated to the Swiss Medical Association which had the expertise to deal with this issue. The PET Study Group was composed among others of Dr Y who was both the head of the Nuclear Medicine Department in THU and the president of the Nuclear Medical Association, a representative from the Swiss Health Insurance Association, a Federal Department of Health official, the head of the Nuclear Medicine Unit from the Cantonal Hospital SPCHT, and the owner of the private clinic PCXS.

After long discussions, the PET Study Group proposed that PET centres should be nominated on the basis of quality criteria. Quality was perceived by actors as being the most powerful argument to persuade stakeholders since no one can be against this virtue:

"I guess the best argument was to establish quality criteria. No one will dare say: 'We're against quality.' So that was the main argument that made them change their mind."

By June 2000, the PET Study Group published quality guidelines specifying the conditions to fulfil in order to be added to the reimbursement list. Among other things, centres must meet minimal technical requirements for the performance of the PET scanner, having a competent nuclear doctor to interpret clinical results and maintaining a registry of PET scanner procedures for evaluation purposes. These criteria were to be in force by January 2001.

Unfortunately, although the head of the private clinic PCXS was part of the PET Working Group, four years were necessary to find a nuclear doctor willing to work in his clinic. To permit the reimbursement of its PET scanner, the Federal Department of Health suggested that the private clinic PCXS should work with the consortium of hospitals in the same canton S. However, the consortium refused to collaborate for personal conflict issues and because the private clinic had already bought a PET scanner which would provide it the control of the technology over the two other partners. The situation was so critical that even the manufacturer AY was involved in 
asking Dr $\mathrm{Y}$ to find a nuclear doctor for this private clinic by arguing that having one more clinic buying FDG would be profitable for THU.

\subsubsection{Analysis}

This episode is characterized by a mixture of vertical and horizontal struggles at the cantonal and federal levels. At the cantonal level, the governance structure required health care providers to have authorization from the cantonal authority before acquiring expensive technology. This rule constrained hospital behaviour regarding investment and constituted the local conditions for an initial horizontal struggle between hospital SPHS and THS for control of the technology and led both hospitals to ask for the cantonal authorization to acquire a PET scanner. Aware of the supplyinduced demand phenomenon, the cantonal government was worried that having two PET scanners in such a small canton would increase cantonal health care expenditure. With the resistance of the cantonal authority, both hospitals were therefore vertically struggling to convince cantonal authority. Finally, instead of continuing struggling, the cantonal authority came up with the idea of forcing collaboration between the two hospitals, to which they agreed. Despite the good will of both hospitals, the unexpected acquisition of a PET scanner by a private clinic delayed the cantonal authorization because there was still a possibility of having too many PET scanners in Canton S. The spectre of seeing the PET scanner technology being controlled by the private clinic PCXS to the detriment of both hospitals was unthinkable and led the consortium to intensify its horizontal struggle by actively lobbying with the Cantonal Department of Health to have the authorization to acquire a PET scanner. To convince authority, the consortium argued that PET scanner facilities should be offered by public institutions and not by private institution motivated by profit.

Although the cantonal governance structure requires health care providers to be authorized to adopt a technology, the possibility of being reimbursed by health insurance companies can be obtained at both cantonal and federal levels. Once the consortium received a negative response to be on the federal reimbursement list, it still had the possibility of negotiating a tariff to be reimbursed locally with the Cantonal Health Insurance Association. This bi-cephalous structure allows actors an alternative in the case of failure to convince the federal government and reflects the fragmentation of the governance structure in this jurisdiction. This particularity of the governance structure did not help authorities to control the diffusion of technology.

At the federal level, there was an intense vertical struggle between the private clinic PCXS and the Federal Department of Health which ultimately led to a lawsuit. 
Interestingly, each entity drew on different institutional logics to defend their respective positions. Hence, an institutional logic of free-market was mobilized by the private clinics by invoking arguments related to the free practice of medicine and to opening up the market. On the other hand, the federal government was theorizing its position by mobilizing a quality- and an efficiency-based institutional logic (see table 4.7 for further details). It was trying to defend its new procedure of introducing promising technology at a reasonable cost while assessing it.

The legal threat of potential adopters to sue the Federal Department of Health under the Anti-trust Commission was a powerful determinant in changing the nomination of PET centres. Indeed, the Federal Department of Health thought it had a chance of losing its case in court. This reflects the power of the free market institutional logic embedded in this jurisdiction. Indeed, it appears that the weight of this institutional logic is so important that it bent the governance structure in such a way that the law was amended to allow the reimbursement to health care providers fulfilling quality criteria instead of being nominated by the government. This new legislation drew on the institutional logic of quality and is supported by a strong normative argument: "no one can be against quality". Because a logic of quality was aligned with the free-market institutional logic, it allowed organizations to become PET centres which was aligned with the interest of every would-be adopter.

By attempting to change the law through a lawsuit, the private clinic PCXS was testing the legislation and its regulator. This is a form of institution testing because this lawsuit was an attempt to change the governance structure. It is because the government wanted to avoid a confrontation before the Anti-trust commission and to keep its legitimacy that it readjusted its legislation according to the market-based institutional logics, but through quality-based criteria.

\subsubsection{Local Strategic ACtions to ObTain A PET SCANNER}

\subsubsection{Canton T: A Fluid Adoption - May 2001}

In one of the most important oncology centres in Switzerland, oncologists and nuclear doctors asked the management board of the publicly subsidized cantonal hospital SPCHT to acquire a PET scanner in 1997. Because the reimbursement was still confined to only two providers, the board denied this request and consequently there was no chance to make profit. However, this situation changed with the new PET concept which was developed with the participation of nuclear doctors from the hospital SPCHT. As soon as the new PET concept was published, nuclear doctors 
met the management board which was inclined to examine their demand if a business plan was produced. The Department of Finance of the hospital SPCHT was mandated to evaluate the economic aspects of the PET, while doctors were assessing its effectiveness. Given that the business plan was favourable for the adoption of a PET scanner, the hospital SPCHT acquired a machine in May 2001. Because there was no law in this canton requiring the cantonal hospital to ask for authorization before making a major investment, the acquisition of a PET scanner was financed from their annual budget.

For this hospital, competition for professionals and for patients is a major incentive to adopt the PET scanner in the Cantonal Hospital SPCHT. Indeed, adopting an advanced technology attracts patients and reduces the risk of losing them to THU in the Canton U. The PET scanner also attracts nuclear doctors from Austria, Germany and the Canton U. In January 2006, the cantonal hospital SPCHT upgraded its PET scanner to a PET-CT scanner.

\subsubsection{Analysis}

What is striking in this case is the absence of vertical struggle between local authorities and the cantonal hospital. This is due to the absence of regulation compelling the cantonal hospital SPCHT to obtain the authorization of the cantonal authority for major investment. However, the motivation for adopting a PET scanner is highly related to the revenue the technology can generate and that is why managers were not interested in funding this technology as long as there was no compulsory reimbursement. To justify the adoption of the PET scanner internally, a business plan had to be produced and profitability demonstrated. With the new reimbursement in oncology, the business plan proved the technology to be profitable. This shows that the notion of profitability is crucial in this jurisdiction and that staying competitive in order to attract patients and nuclear doctors is important.

\subsubsection{Canton N: Setting up a Private Company - August 2001}

In teaching hospital THN, the Nuclear Medicine Unit had not been operational since 1993 as the only position in nuclear medicine was vacant since then. However, in 1999 the increasing interest of other teaching hospitals in adopting the PET scanner prompted the Department of Radiology to elaborate an economic evaluation of the pertinence of developing this specialty. This was motivated by the competition between teaching hospitals in Switzerland. As one interviewee notes: 
"It was somehow related to these PET scanners [in other cantons] because the knowledge about PET scanners came to these cantons, especially from the Canton U, and I think there is ongoing competition between the teaching hospitals of the Canton U, S and N. And THN, not having the financial support of the cantonal government $\mathrm{N}$, it wanted to keep up with the other two cities to have a PET scanner."

The conclusions of the economic evaluation report were unequivocal: a Nuclear Medicine Unit would add economic value to THN. At that point, a procedure to recruit a chief of the Nuclear Medicine Unit began. To attract a good academic candidate, the CEO of THN knew that obtaining a PET scanner was a key element:

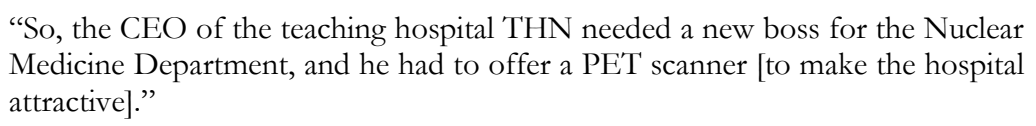

However, in this canton the acquisition of a PET scanner by THN is tied with the decision of the Cantonal Department of Health to authorize this acquisition. Due to the important deficit of the Canton $\mathrm{N}$ and to the high costs engendered by the previous chaotic diffusion of no less than around $40 \mathrm{MRI}$ in this canton, the Department of Health of the Canton $\mathrm{N}$ refused to finance another expensive technology which would contribute to the increase of health care costs. To justify its position, the cantonal government invoked the already high number of PET scanners in Switzerland:

\footnotetext{
"The official line was that five PET scanners in Switzerland are enough, so they [the politicians of the Canton N] didn't want to have a PET scanner in the Canton N."
}

Because cantons U, V, T and S already had this technology and PET scanner procedures were reimbursed if quality criteria were met, the CEO of THN was determined to overcome this obstacle. After having met with a local private hospital, PHN1, both hospitals agreed to build a private company, the PET PCN Company, with the unique mission to offer PET scanner procedures. Given the relatively small population to be served (despite the fact that this is one of the most populated canton in Switzerland), this arrangement is a wise strategy to reach the profitability threshold. Indeed, , diluting the limited number of patients through many centres would lower the number of case per machine. Since the price of FDG radically decreases with the number of doses ordered, gathering patients on the same site engenders important economies of scale. Moreover, to amortize the machine before it becomes obsolete, a certain average number of patients per day has to be reached. While this arrangement allowed THN to have access to a PET scanner, it substantially decreased the financial risk for both hospitals for two reasons. First, it would avoid local competition: 
"With three PET scanners here in the Canton N, no PET scanner would have reached break even, and so, it made no sense [to compete]. The idea was to have one PET scanner for everyone who wants to use it, and to have a successful business. [... Moreover], there was quite a high probability that no other clinic would really come up with another PET scanner for competition reasons."

Second, since there was no guarantee that the PET scanner would be reimbursed by local insurance if it was an unapproved acquisition, it was wise for the private hospital to collaborate with the public hospital to be more legitimate as regard to health insurance companies and to share the financial risk in case there were no profit:

"In the Canton N, only public hospitals need authorization from the government before buying an expensive technology. Private hospitals are not constrained by this. As a consequence, insurance companies can refuse to pay for a procedure following from the acquisition of an unapproved acquisition."

To fund the PET scanner, the president of the PET PCN Company who was also the newly appointed head of the Nuclear Medicine Unit at THN, signed a lease with the manufacturer $Z$ and acquired the PET scanner in August 2001. The machine was installed at THN site because it was where the competence lay, and it was more legitimate to put high-cost technologies in a public teaching hospital:

"Because they have the manpower there. [...] And politically it's better in the university hospital than in a private hospital."

However, the Canton $\mathrm{N}$ still disapproved this acquisition and an increase in the health care cost was anticipated as a consequence:

"...the Cantonal Department of Health, they were disappointed and angry about the PET scanner here in Canton N, because they thought it would increase the cost of health care. So, they didn't want it."

While profit may be an argument for adopting the technology, the intention was not to split it between owners of the private company, but to reinvest in the company to acquire other technologies such as a PET-CT:

"We don't split it [the profit]. It rests in the company for our new investments. It's how we upgraded to a PET-CT with the profits made."

In 2002, another major private hospital, PHN2, explored the possibility of acquiring a PET scanner to perform cancer staging. The idea was to adopt a PET scanner to attract radio-therapy patients. However, quick estimations from the CEO caused him to abandon this project. He believed that there were not enough patients and clinical applications in the Canton $\mathrm{N}$ for a second PET scanner. Consequently, instead of competing with the two other hospitals with the financial risks that this implied, the 
private hospital PHN2 asked to become a member of the PET private company. By December 2003, this company had a new partner. With the profit generated, the PET PCN Company upgraded their machine to a PET-CT in July 2005.

\subsubsection{Analysis}

The adoption of this technology by other hospitals appears to be one important factor that incited the Department of radiology to ask for an economic evaluation. With the distance between THN and other hospitals, the hospital was not primarily adopting to compete for patients, but much more to keep up with other teaching hospitals, i.e. to imitate other teaching hospitals in order to maintain their teaching hospital status in Switzerland. However, imitation was certainly not an argument to convince the hospital and the authorities that the project was worthy. An evaluation had to demonstrate that the project was financially viable.

Despite a positive evaluation, the obligation of THN to ask for authorization to invest in an expensive technology, combined with the need for financial resources from the canton, provoked a vertical struggle between the cantonal government and the cantonal hospital. Indeed, the cantonal authority was reluctant to invest in this technology due to its important debt and to the preceding chaotic diffusion of MRI. This struggle ended with the refusal of the cantonal government to authorize this acquisition and forced THN to find an alternative way to adopt this technology. The co-existence of a public and a private regime eased the elaboration of a stratagem to adopt a technology legally by setting up a private company. Hence, in Switzerland, when the public regime obstructs entrepreneurial initiatives, there is the possibility for public actors to find a safe refuge under the private regime.

Not being financially supported by the Canton $\mathrm{N}$ and with no budgetary surplus, THN had to find a collaborative arrangement with the private hospital PHN1. Teaming up was lowering the financial risk that competition may have caused by impeding profitability. Hence, there was no horizontal struggle in this canton because actors had an incentive to collaborate. This is confirmed by hospital PHN2 joining the PET PCN Company instead of acquiring a PET scanner for itself and competing with the two other hospitals.

Moreover, collaboration was believed to be a good strategy to attract the sympathy of the health insurance companies. Indeed, because there was still no uniform tariff at the time, tariffs had to be locally negotiated with the Cantonal Health Insurance 
Association. This was the case until TARMED came into force in 2004 with a uniform tariff for ambulatory services across Switzerland.

\subsubsection{Canton D: Controversial Adoptions - November 2002}

From the eighties, nuclear doctors at the teaching hospital THD were desperately trying to obtain a PET scanner. The rumours that hospitals from the canton $\mathrm{S}$ were asking the Federal Department of Health to be on the reimbursement list combined with the waiting list of the closer incited THD to create an internal working group to acquire a PET scanner. By March 1999, the group sent a document asking the Federal Department of Health to add THD to the reimbursement list. The main argument presented in this document was related to the incapacity of the closer THV to meet local demand. Moreover, THD argued that adopting a PET scanner would reinforce the collaboration between cantons $\mathrm{D}$ and $\mathrm{V}$ since the cyclotron in canton $\mathrm{V}$ would supply their PET scanner. Initially, the Federal Department of Health did not grant them the right to be on the reimbursement list; however, the criteria to be nominated as a reimbursable PET scanner provider changed before the cantonal government authorized this acquisition.

Because the budget of THD had been blocked for years, the working group knew that it would be difficult to convince the cantonal government ${ }^{36}$ to authorize the acquisition of a PET scanner. To convince the Cantonal State to provide this authorization, a financial-economic study was performed to prove that the PET scanner could add value to THD and to estimate the temporal horizon for profitability. Since the chief of the Department of Radiology refused to use part of his budget to acquire this technology, a special financial strategy had to be agreed upon. Building on his previous experience with MRI, the Director of Finance proposed the creation of an auto-financed PET Unit which took these constraints into consideration. This solution implied that THD would loan money to the PET Unit. In exchange, the latter would reimburse the hospital with the profit it generated in the same way as a bank would loan money to an enterprise.

By December 2000, the financial-economic study demonstrated that there was a return on investment after 8 to 9 years of operation:

36 The Teaching Hospital THD has to request the authorization of the Cantonal Council of State when investing on projects of more than $500^{\prime} 000 \mathrm{CHF}$. 
"The pay-back, or investment recovery rate, varies between 8,15 years in the best scheme, and 9,44 in less favourable conditions. It can thus be predicted that the initial 2,500,000 investment will undoubtedly be recovered between years 2007 and 2009, depending on interest rates."

In February 2001, given the positive result of the financial-economic study, the Board of Directors of THD agreed that a request to invest in this technology should be lodged with the Cantonal Council of State. However, after having informally discussed with the Cantonal Government Official, the General Director understood the timing was not good and did not pass the document on to the cantonal authority. Indeed, since the private clinic PCV2 intended to acquire a SPECT ${ }^{37}$ scanner, the cantonal government preferred to study carefully whether a PET scanner would actually perform the same type of diagnostic as the SPECT scanner. This precaution was taken in order to avoid an over-diffusion of this technology in the canton:

"The intent was to check if there was not too much equipment in this region."

The norm in this canton is that when the private sector is providing a service, the cantonal government would be disinclined to let the public hospital duplicate it, as it would by acquiring a PET scanner:

\footnotetext{
"The PET file stayed on the General Director's shelves for a long time, because the State Counselor was not convinced easily. He didn't trust new technologies, and was more open to requests from the private sector. This is the way things work in Switzerland. When the private sector takes charge, there is a feeling that the public sector should step aside."
}

Nearly one year after having received the financial-economic study of the PET scanner, THD finally sent the document to the Cantonal Government in January 2002. The approval came shortly after the Cantonal government realized that the SPECT scanner was not a technical equivalent to the PET scanner. Consequently, this technology was missing in the Canton $\mathrm{D}$ which provides a rationale for the cantonal government to authorize this investment.

With the acquisition of a SPECT scanner by the private clinic PCD2 a few months before THD, doctors operating in the private sector started sending their patients to this private clinic. Interestingly, when a PET scanner was operational at THD in November 2002 it did not change the behaviour of doctors in the private sector who continued to send their patients to the private clinic, despite the technically less

\footnotetext{
${ }^{37}$ The SPECT (Single-photon emission computed tomography) is a machine used in radiology to measure blood flow.
} This type of camera functions on the same principal than the PET scanner, but produces far less precise images. 
performing machine. The competition for patients between the private sector and the public sector might explain this behaviour:

"There is a SPECT at private clinic PCD2. [...] Doctors from the private sector will instinctively send their patient to another private institution, rather than at the [public] hospital because they fear [...] their patient will be taken away from them, and private doctors also support each other."

For a teaching hospital to buy a stand-alone PET scanner when a PET-CT scanner was available is surprising. Two reasons seem to explain this choice. First, the PETCT integrates the work of a nuclear doctor and a radiologist. In order to avoid confusion as to which professional should interpret PET-CT scans, the head of the Department of Radiology encouraged the acquisition of a stand-alone PET scanner:

"He also wanted only a stand-alone PET. He did not want a PET-CT. As this is a scanner, he thought it concerned the radiology department. Since then, the situation has evolved. There have been several demonstrations of the use of PET-CT at the international level that were justifying this technology inside a nuclear medicine service and that it's not always competing with scanners in radiology. But when things started, there were fears, and everyone was trying to defend his own territory."

Also, given the uncertainty related to the market, choosing less expensive technology was more reasonable. Moreover, the financial-economic study of the PET-CT scanner may not have been favourable:

"We had to choose between a stand-alone PET or a PET-CT. We thought about it for a while. The exorbitant price of the latter made us opt for the standalone machine. [...] The market was yet untested, and there was no guarantee things would work. At the time, reimbursement laws for PET and PET-CT exams were still limited to a few types of exams."

In 2004, as more patients and more indications were reimbursed, the head of the Department of Radiology realised that the PET-CT was not going to compete with other scanners in radiology. Consequently, THD elaborated another report to upgrade their machine to a PET-CT. Since there was a limit set by the manufacturer AY to upgrade PET scanner to PET-CT scanner without having to buy a new machine, THD had a strong incentive to act quickly. The upgrade took place in April 2005.

\subsection{A PET-CT at the Private Clinic PCD2 - September 2005}

In parallel to this upgrade by teaching hospital THD, the private clinic PCD2 decided to acquire a PET-CT scanner. In 2003, a new nuclear doctor trained in radiology was appointed at PCD2. Realising that SPECT scanner does not provide good quality images; he started militating for the clinic to buy a PET-CT scanner. After a consensus was reached inside the clinic to buy a PET-CT scanner instead of a stand- 
alone PET scanner, a request was sent to the private Foundation of the clinic to fund this acquisition. The PET-CT scanner was preferred because it would send a powerful marketing signal of the quality of services offered by the clinic. After having examined the business plan produced by the administrator of the Department of Radiology, the Foundation agreed to invest in this technology, based on many supporting factors. First, by acquiring this technology, the private clinic PCD2 would have the first private PET scanner in canton $\mathrm{D}$ which would confer an advantage over other clinics since it would saturate this small private local market:

"Obviously, we were afraid of the competition. I talked earlier that we managed to buy a PET-CT pretty quickly because we wanted, to use the marketing terminology, to padlock the region. We followed what private clinics did in the region $\mathrm{V}$ where they installed 3 PET-CT in this small geographical region. We wanted to avoid this situation. [However], we were scared when we heard that [a private clinic nearby] was getting information as regard to this modality."

However, the intention of the clinic PCD2 to acquire a PET scanner was not welcomed by THD which put enormous pressure on the clinic to stop this adoption. This hospital lobbied the Nuclear Medicine Association to delay as much as possible the accreditation of the private clinic PCD2 which would certify its conformance to the new PET concept quality criteria established in 2000. Interestingly, at the time, the newly appointed president of this association was precisely the head of the Nuclear Medicine Unit of THD and was actively militating, with a group of nuclear doctors working in teaching hospitals, to stop the spread of the PET scanner to private clinics. The danger these doctors perceived was that there would not be enough demand to make this technology profitable. The private clinic PCD2 acquired a PET-CT scanner in September 2005.

\subsubsection{Analysis}

As in the preceding case of adoption in canton $\mathrm{N}$, the requirement for would-be adopters to have the authorization of the cantonal government is the structural component that caused vertical struggles between teaching hospital THD and the cantonal government. This vertical struggle was fuelled by the desire of THD to acquire a PET scanner; the last teaching hospital to adopt one. However, the costcontainment commitment of the cantonal government - which is reflected by the frozen budget of the teaching hospital and the necessity to prove the financial viability of this acquisition - incited the former to be reluctant to invest in this technology. This is even more acute since there is potentially a private clinic which may offer this service to the population of the canton D. According to some respondents, there is a norm in this canton stating that if the private sector can provide a service, the public 
sector should not compete with them. The vertical struggle between the cantonal government and teaching hospitals is coloured by this norm as the former delayed the authorization precisely to inquire if this technology is already available in the canton, in this case at the private clinic PCD2 with their intention to acquire a SPECT. It was only when the cantonal government realized that this camera would not perform the same job that the authorization was granted to THD. Hence, it appears that the weight of the private sector in this canton is impressively strong. Interestingly, although the PET scanner in THD is in the public sector, it is managed as if it were in a private sector with the necessity to prove its profitability.

The choice of adopting a PET instead of a PET-CT scanner at THD is also related to vertical struggle. Indeed, the higher price of the PET-CT would have delayed the break-even point in terms of the return on investment and would have been insufficient to convince the authority of the viability of the project. Moreover, the reimbursement for the PET scanner was still limited to only a few pathologies, which lowered its profitability. However, to avoid competition between nuclear doctors and radiologists inside THD, adopting the PET scanner was a safer choice.

There was also a fierce horizontal struggle between the private and the public hospitals in this canton. The adoption of a SPECT scanner is more probably pressing THD to adopt a PET scanner to avoid losing patients who may be taken in charge by the private clinic. Private practice doctors preferred to send their patients to the private clinic PCD2 despite the higher performing machine at the public hospital. The competition between the teaching hospital and the private clinic PCD2 is also expressed by the action undertaken by the former to impede the adoption of the technology by the latter, and by slowing down as much as possible the accreditation process from the Nuclear Medical Association. Underlying these horizontal struggles is the necessity for the independent PET Unit at THD to break even in its budget and for the private clinic to generate profit; a target that is more difficult to attain with more competition.

\subsubsection{Canton R: Convincing Authorities for Adoption - September 2003}

The cantonal hospital CHR, having one of the largest oncology divisions in the country with a cantonal population of about 550,000 inhabitants, naturally became interested in adopting a PET scanner as the increasing use of the PET scanner in oncology caused an increasing number of their cancer patients to be referred to the teaching hospital THU: 
"...they saw of course how many patients they sent meanwhile to the teaching hospital THU for the PET scan, so they saw that they would lose patients if they have no PET scanner and that was actually the basis of the business plan..."that there would be a demand for this type of procedure."

The nuclear doctors and the hospital management board met the cantonal government at the beginning of 1999 to obtain authorization to buy the technology. Despite a strong consensus within the 17 members of the board of directors of the Cantonal Hospital CHR, the head of the Cantonal Department of Health was unwilling to fund this acquisition which would cost 2,450,000 CHF to the State, as he was also against the acquisition of MRI by smaller hospitals. To justify his position, he argued that he preferred to wait until this technology was more mature before adopting it. Also, he wanted to evaluate the tendency in the diffusion of this technology in the surrounding cantons:

"The head of the Health Department said: "we should wait for this technology to develop in other cantons before adopting one in the Canton R. In general, he thought that medicine in this canton should stay at a lower level in terms of medical technology and that we should keep health care costs low in the canton"

"Officially, the government position was that the canton did need such a technology and that the cantonal government did not want to become a major player in health care. "

Apparently, these reasons hide a cost-containment agenda on the side of the cantonal government:

"He preferred to leave big ticket technologies to canton U, V, D and the like. Behind this discourse is the idea of saving costs and to keep the insurance premium costs low."

The election of June 1999 brought a technologically open-minded candidate to head the Cantonal Department of Health. After having discussed with the new director, CHR renewed its request for the acquisition of a PET scanner to the cantonal government in November 2001. After an evaluation by the Cantonal Department of Health and the approval of the Great Cantonal Council, the authorization arrived in August 28, 2002.

The 10-year-old cantonal hospital plan of the Cantonal Department of Health still specified that patients should be sent to the institute IR for PET scanner applications, despite the fact that the research institute IR had already discontinued its use in 1996. Thus, this procedure had first to be changed before adoption. However, it was the responsibility of the Parliament to amend this planning and, since it was not a priority 
for the parliament, the change was finally approved in 2003. By November of the same year CHR acquired its PET scanner through its global budget.

Once implemented, CHR was surprised to observe that the other nearby cantonal hospital CHR2 did not refer its patients there, but continued to send them to THU. While some argue that this was due to the fact that THU had a PET-CT scanner, others saw a historic rivalry between not only two hospitals, but between two distinct regions within the canton:

\footnotetext{
"There's a big rivalry between these two hospitals, but actually, I'm working at both hospitals. [...] This is really an old story between these two cities, and it's not only the hospital, it's not only the PET scanner, it's also for surgery, the school systems, etc."
}

No matter the reasons underlying this rivalry, CHR intended to upgrade to the PETCT scanner apparently to attract patients that might be referred to THU.

\subsubsection{Analysis}

In this case, the vertical struggle for controlling the technology was a long process that lasted over three years. With its imperative for cost-containment, the government clearly had no short term interest in supporting adoption of this technology and postponed authorization until after re-election. However, the election turned out differently and brought a new person into power who opened up the adoption process. While CHR finally obtained the authorization, the hospital planning had to be changed by the parliament. This struggle for the control of the technology was particularly beneficial to the government which succeeded in postponing the acquisition for at least three years.

The motivation to obtain a PET scanner is clearly related to a horizontal struggle with THU which was draining oncology patients from the canton R. By acquiring this technology, the cantonal hospital CHR thought patients living in the canton R would be less often referred to THU, and to some extent that was the case. Nevertheless, historical rivalry made another nearby hospital continue to send patients to THU. In this canton, competition is not just a matter of patient management but seems to be related to profound historical causes. 


\subsubsection{Canton V: Private Clinics Competing with Teaching Hospital THV}

\subsection{Private Clinics PCV1 and PCV2 adopt a PET-CT-2004}

Due to the obsolescence of the PET scanner of the teaching hospital THV, the private clinics PCV1 and PCV2 - two independent entities operating in the Canton V

- began receiving repeated requests from oncologists in private practice to have access to a PET-CT scanner in the region. Moreover, the imminent change of the unified ambulatory tariff (TARMED) in 2004, which was going to be applied homogeneously for all providers across all cantons, was going to guarantee the same tariff for private clinics as for public hospitals. This significantly lowered the risk for private clinics to buy an expensive technology because the universal tariff would be known before the acquisition.

Considering that private doctors tend to send patients to private clinics; both private clinics perceived a business opportunity to acquire this technology:

\footnotetext{
"The private sectors offered none of these services. There was a competition between the private and the public sector in oncology in canton V. At the teaching hospital THV, the technology had been obsolete for quite a long time already. Since budgets were blocked and there was no plan for a PET scanner in the public sector, and because we did not know the situation prevailing in private clinic PCV2 at the time, we thought there was a terrific potential with private oncologists, and even with the other oncologists at the hospital."
}

Acquiring a PET-CT scanner would also allow both private clinics to offer a complete range of services to doctors and patients:

"Very rapidly, everyone concluded that even if the PET was not profitable by
itself, there would be other paybacks. With a PET in the place, there would be a
demand for other exams. Patients could come in, get several types of exams at
the same clinic and have a complete clinical assessment in the same building."

While there is clear competition between private and public health organizations, there is also a competition for patients between the two private clinics. Whereas the private clinic PCV1 was the first to begin an acquisition process to obtain a PET scanner, the long delay it experienced before obtaining the authorization from the Federal Nuclear Regulation Department, due to the fact that it was situated in an inhabited building, made them lose their first-mover advantage as the private clinic PCV2 opened its stand-alone PET scanner just one month after clinic PCV1.

Because Dr Y helped the private clinic PCV1 to install its PET-CT scanner, which was bought from the Manufacturer AY, the FDG was bought from THU where Dr Y 
worked. These private clinics never reached the threshold of profitability due to the high number of PET scanners in this area.

\subsection{Private Clinic PCDV Adopts - December 2004}

Although administratively belonging to the Canton D, the private clinic PCDV is geographically closer to teaching hospital THV and to the private clinics PCV1 and PCV2 than to THD which makes it more in competition with its nearer neighbours than with this last. This is corroborated by the fact that patients of the private clinic PCDV mainly came from the Canton V and from foreign countries.

The director of radiology and the nuclear doctor of the clinic were the first to be convinced of the necessity for the clinic to acquire a PET-CT. Indeed, there was an increasing demand for this type of procedure:

"This is when I realized that finally, there was a demand for PET-CT exams, and that demand was increasing all the time. I thought getting this type of machine here really worth the trouble."

Because the clinic PCDV specialized in oncology, adopting such a complementary diagnostic tool for its Centre of Oncology as a PET-CT scanner became imperative to allow patients access to all services inside the house. As such, the PET-CT scanner was an important asset for its owner to be well positioned in the local health care market:

“...we had a clinic with a developing oncology centre. It was essential for us to acquire a PET-CT to be able to provide patients with a complete diagnostic. And for a technological park in a radiology institute like ours, a PET-CT machine was becoming indispensable. (...) We had to position ourselves on the market."

This last reason became the only tangible advantage for having a PET scanner as the fierce competition between providers annihilated the chance for profit. Moreover, the expectation of the clinic PCDV of attracting patients from Canton D was abandoned. Indeed, given that there was no private PET-CT scanner in canton D and that private doctors tend to deal primarily with private clinics, the clinic PCDV counted on private doctors from this canton to send their patients, which did not happen: 
"At the start, I thought I could count on more prescribing oncologists coming from Canton D. As always, in big cities, there are oncologists from the private sector, and oncologists from the public sector. The two sectors do not often collaborate effectively with each other then I thought there were opportunities with PET in the private sector. And at the beginning I thought we would drain more people from Canton D that would be coming to our clinic, as there were no other private clinics in the canton."

\subsection{Teaching Hospital THV Reacts - 2006}

In the Canton V, the head of the Nuclear Medicine Unit who convinced the Cantonal Government to invest in a PET scanner and a cyclotron retired in 1997. Due to the way the PET scanner was funded in 1993, the new head was not successful in implementing a PET scanner as the chief of the Department of Radiology was radically against any investment in nuclear medicine:

\footnotetext{
"The problem was that radiology and nuclear medicine are in the same department. And as such, they share the same budget envelop. So, by principle, radiologists wanted us to invest in MRIs or scanners and not at all in PETs. They thought that if they could keep the others from developing their PET, they stood a better chance to get a third MRI (...) There was an enormous fight on that account."
}

In February 2003, many intestinal wars that had been going on for months incited the head of the Nuclear Medicine to leave THV for the private sector. At about the same time, the head of the Department of Radiology quit, leaving space for new staff.

In only a few months, three private clinics near THV started offering PET-CT scanners and all these clinics hired nuclear doctors who had left THV. With its obsolete machine, THV was no longer competitive. The intensifying competition from the private clinics combined with the vacant positions of chief of the Department of Radiology and of chief of the Nuclear Medicine Service forced the management of THV to find someone quickly to lead the development of the whole Department of Radiology. In 2005, a double board certified doctor (in radiology and in nuclear medicine, and specialized in cardiology) accepted the challenge. Aware of the obsolescence of the PET scanner, the double board certified doctor negotiated before his arrival an upgrade of the technological park inside the Department of Radiology including the acquisition of a PET-CT scanner. To persuade the Cantonal Department of Health to invest in a PET-CT scanner, the future head of Department of Radiology argued that THV was late in its technological development and, implicitly, that the private clinics were attracting more patients than the hospital THV: 
"The main argument is that we were way behind the competition. We no longer had an adequate park to provide for patient care."

In addition to this, two things seem to have persuaded the State Council to upgrade the technological park of the hospital with a PET-CT scanner: 1) the exodus of doctors to the private sector and 2) competition for patients:

"[The private sector] certainly contributed [to get things going] in two ways: first, by competing and then, by draining away all the doctors."

Private clinics near THV did not welcome this initiative and lobbied the cantonal government to stop the process of adoption. Indeed, this abundance of PET-CT in this relatively small canton represented a threat that they would lose patients to THV:

"There was some opposition, with a PET-CT already bought. Not so much at the hospital level, but outside, in the private sector, there was some lobbying going on. They said there were enough machines. Two had already been installed inside the city. They did not want a third one. They had already gone through the same situation with the MRIs, where the private sector got their machines before the hospital. And as a result, the hospital was sending their patients in the private sector. Or they said the investments were too costly. They had already invested in the technology, and they wanted to provide the service for the hospital, and so on."

The project was submitted to the State Council in November 2004 and was rapidly authorized. The first PET-CT was adopted by March 2006.

Taking advantage of his contacts with the industry, the newly appointed head of radiology obtained a second PET-CT in exchange for developing new applications in cardiac imagery. The decision to acquire a second PET-CT was accepted in December 2006 by the State Council:

\footnotetext{
"I negotiated with Manufacturer Z. I wanted a second PET-CT at my disposal almost simultaneously. That was a great move, from a strategic standpoint. [...] The hospital did the investment, and I brought the second one in with a pledge to buy. So we acquired two PET-CTs. [With one of those] we would develop new imagery strategies for cardiology applications."
}

Besides modernizing the medical imaging equipment of THV, the newly appointed head of radiology had the ambition to refurbish the cyclotron which was never used. This was perceived as a competitive threat by THU which lowered by $30 \%$ the selling price of its FDG. This price was actually lower than the production cost and was economically imperilling the viability of the cyclotron at THV: 
"There is a fierce competition in Switzerland. There are four providers in the Canton $U$ which want to monopolize the whole market [...] Three months after our certification; teaching hospital THU lowered its prices by $30 \%$ to break the market. [...] If we lowered our own prices by $30 \%$, we were no longer meeting our costs. THU does not care if it no longer meets its costs. It has a university (so it doesn't have to be profitable). As for us, we did not have to care because we had not been meeting our costs for ten years anyway, but the private company that distributed our products could not take it."

\subsubsection{Analysis}

The obsolescence of the PET scanner of THV and its location in a public hospital seems to have increased the demand for PET-CT scanners from private practice doctors specialized in oncology. This led private clinics to perceive a nice business opportunity. Indeed, three private clinics acquired PET-CT scanners in a relatively short period of time. The horizontal struggles between private clinics aimed to attract patients and doctors, and to be the first in the market. What mattered for these clinics was to be well-positioned in the market. However, with the high concentration of PET-CT scanners in the canton, no private clinic reached the profitability threshold although the PET scanner was still considered important as it was perceived as a complementary asset.

Horizontal struggles intensified when the teaching hospital decided to add a PET-CT scanner to its Department of Radiology. This gave rise to intensive lobbying activities from the private clinics to stop this process, because they had already made an important investment which was not profitable in itself although it increased their prestige. At the federal level, there was a horizontal struggle between THU and THV for the control of the supply of FDG in Switzerland. Indeed, once the cyclotron of THV was refurbished, THU lowered its price by 30\% which was even below the production cost of THV. This is clearly the expression of a horizontal struggle.

With the catastrophic situation of having many resignations from nuclear doctors in the Department of Radiology and its complete lack of competitiveness with the private sector, the Cantonal Council was aware that there was a need to attract nuclear doctors to THV. With so many doctors having left THV and with the outdated PET scanner, there were no real vertical struggles in this canton. 


\subsubsection{Canton G: A Tempting Opportunity - June 2004}

With a small Department of Nuclear Medicine and a small population (around 200,000 inhabitants), the cantonal hospital CHG did not plan in advance to acquire a PET scanner. While shopping for two gamma knives ${ }^{38}$, the newly appointed nuclear doctor received an offer from the manufacturer $Z$ which offered one gamma knife and one refurbished PET scanner for the same price as two gamma knives. This was a unique chance for this small hospital to obtain a PET scanner. With this offer in hand, CHG contacted the manufacturer $\mathrm{W}$ and got a better price.

Enthusiastic, the nuclear doctor of the hospital decided to present this unique opportunity to the administrative board which was chaired by the head of the Cantonal Department of Health. To be persuasive, the doctor elaborated a business plan where he argued that while the canton would offer an additional service, this opportunity to acquire a PET scanner would be funded through the current global budget already dedicated to the Nuclear Medicine Unit, a sum that is symbolically already spent:

\footnotetext{
"The root argument was that we had to offer a complete array of services to a population that did not have nuclear medicine, where supply was really quite scarce $[\ldots]$. The main argument was that we could do better with the same money. Budget did not have to be increased. [...] The final argument was that the machine was not that expensive. With the annual budget, we could do all of those things, and that really convinced them."
}

Relying on his previous experience, he estimated that within two to five years, the machine would be profitable. Moreover, to facilitate the overall adoption process, a uniform tariff across Switzerland named TARMED came into effect by January 2004. This relieved the Cantonal Hospital CHG of the obligation to negotiate tariffs with health insurers. The adoption of the PET scanner occurred in June 2004.

\subsubsection{Analysis}

This process of adoption was particularly smooth with no real struggle between hospitals or with the cantonal government. It seems that the adoption of this technology suited everyone. The low price and the fact it was funded through the global budget of the hospital satisfied the cantonal government, the cantonal hospital was happy to increase its prestige and to offer an additional service to the population. What is interesting though is that the introduction of the national tariff for ambulatory

\footnotetext{
${ }^{38}$ By using high dose radiation, this device is mainly used to remove or shrink brain tumours.
} 
medicine actually eased the process of adopting the PET scanner because there was no need for CHG to negotiate locally with the insurers.

\subsubsection{Canton U: Hindering Regional Competition}

While teaching hospital THU did not succeed in keeping the monopoly of the PET scanner technology in Switzerland, it clearly tried to maintain control at least regionally. Indeed, in 2005, the second most important cantonal hospital of Canton U met Dr Y to ask if he would support the acquisition of a PET-CT scanner by this cantonal hospital. The answer was straightforwardly negative because it would have been detrimental to THU which might have lost between 400 to 500 patients:

"I was not in favour just because of the commercial aspects, because they would probably take 400 or 500 patients away from us, which means that the cost structure wouldn't be the way I like it."

Considering the strong influence of Dr Y in Switzerland combined with the fact that this cantonal hospital is public and therefore required the authorization of the cantonal government before any important investment, the Cantonal Department of Health would not have allowed them to obtain this technology because Dr Y would have been against this initiative.

\subsubsection{Analysis}

This episode in the Canton $\mathrm{U}$ is symptomatic of the harsh horizontal struggle between hospitals where the PET scanner incumbent strives to defend its territory by not allowing local competition. This indicates that horizontal struggles took place at different levels even for organizations that still did not possess a PET scanner.

\subsubsection{Canton Z: Adopting a PET-CT Scanner - August 2005}

Canton Z represents a linguistic minority of around 300,000 inhabitants, and has one of the highest densities of private clinics in Switzerland. In 1999, this Canton passed a certificate-of-need law forcing public and private providers to require authorization from the Cantonal State Council to acquire technologies figuring on a positive list which included the PET scanner.

In 2001, the Cantonal State Council received a request from the publicly subsidized cantonal hospital SPCHZ to adopt a PET scanner. Because SPCHZ is the main centre in oncology in this Canton, oncologists in the canton strongly supported this 
adoption. One of the main arguments invoked was that they were afraid of losing their position of leader in the Canton if a private hospital bought a PET-CT scanner before them. Indeed, there was a fierce competition for patients between the cantonal hospital SPCHZ and private clinics:

"We concluded that, from a health effectiveness perspective, [the acquisition]
would improve our position. We were competing fiercely with private clinics in
Canton Z. We estimated that we were doing around $65 \%$ of the cases, and them
$35 \%$. We had to be on time not to lose the opportunity to get this technology."

Only a few months later, the private clinic PCZ informed the cantonal government of its intention to acquire the same technology. Because it was previously estimated that Switzerland needed no more than 5 to 7 PET scanners, the Cantonal Department of Health suggested that the two claimants collaborate on this issue. In 2003, the Cantonal Department of Health received notification from SPCHZ that it was still intending to adopt this technology, despite the impossibility of reaching an agreement with the private clinic PCZ. Meanwhile, the private clinic abandoned its intention to adopt a PET scanner, leaving the cantonal hospital as the only would-be adopters.

If remaining a regional leader in oncology was vital, attracting research money and participating in pharmaceutical research protocols to test new drugs was also a strong motivation for obtaining this technology:

\footnotetext{
"We moved to position ourselves from a strategic point of view to respond to a demand that existed inside the Oncology Institute, to position ourselves towards research activities that did not grant drugs projects to institutes that did not own a PET."
}

The likelihood of obtaining authorization from the cantonal government was increased because the hospital was funding the PET-CT on their global budget. However, due to the certificate-of-need regulation, the Cantonal hospital had to demonstrate the clinical need for the population to have access to a PET-CT scanner. In a letter addressed to the Cantonal Department of Health in December 2003, SPCHZ estimated at 1,000 the number of PET-CT scanners required in the canton. Since authorities felt that it would not be wise to asphyxiate a centre of research excellence in order to control supply-induced demand, the former proposed to limit the number of procedures to be reimbursed in the canton to 1000 per year: 
"There is a certain risk involved. But at the same time, we do not want to say no. We do not want to kill a research and an excellent clinical site like the Oncology Institute of the [Canton Z]. And so finally, this sentiment [...] prevailed on the other. To avoid any excesses of supply-induced demand, we hold the volume of acts down to a maximum of 1000 exams each year for the next three years - 2005, 2006, 2007."

Another reason that favoured the acceptation of the request from the hospital was that the Cantonal Department of Health feared that the law proposed by the Federal Intercantonal Commission for the Concentration of Specialized Medicine ${ }^{39}$ would come into force in a relatively short time. This would have impeded any attempt at promoting the technology in the canton because this law might have limited the number of PET scanners all over Switzerland, which might have definitively excluded the possibility for Canton $\mathrm{Z}$ to have access to this technology locally. Hence, the authorities felt they had to act quickly:

"The risk existed that, if the law bill submitted by the Group of Specialized Medicine was passed, Canton $\mathrm{Z}$ would not get its machine. We thought it was advisable to authorize the acquisition of the PET scanner before that bill became law, because then, Canton Z could have lost this opportunity."

The final authorization from Cantonal authorities came in March 2004, and the machine was acquired in August 2005.

\subsubsection{Analysis}

The PET scanner started to be of interest in this canton after the new reimbursement criteria came into force in 2001, two years after the certificate-of-need regulation. This regulation probably affected the diffusion of this technology as it compelled both the private clinic and the semi-public hospital to ask for an authorization. Given the relatively small size of the population, it did not make sense to authorize two PET scanners in this small area. Consequently, there was a vertical struggle with the cantonal government which did not want to provide the authorization to two organizations, and a horizontal struggle where each actor was competing to obtain the authorization. Without being able to reach an agreement, the private clinic finally abandoned this project estimating there was not room for two PET scanners in this canton $\mathrm{Z}$ and that it would be tough to compete against the semi-private cantonal hospital.

${ }^{39}$ This group has the purpose to propose amendments to the health insurance law (LAMal) to concentration highly specialized medical procedures. 
The vertical struggle between the cantonal government and the cantonal hospital is also reflected in the limitation of the number of examinations allowed per year to control health care expenditure in the canton. However, because of the threat of the application of the Federal Inter-cantonal Commission for the Concentration of Specialized Medicine, the cantonal Department of Health was inclined to provide the authorization to the cantonal hospital in order not to lose the opportunity to obtain this technology in the canton. Indeed, the amendment of the Federal health insurance law (LAMal) might have limited the number of PET scanners in Switzerland thereby depriving Canton $Z$ from the possibility of obtaining a PET scanner.

Motivations for obtaining a PET-CT scanner were multiple: having a PET-CT scanner would increase the number of research contracts from pharmaceuticals which could increase the prestige of the cantonal hospital; the canton would be able to offer one more service to the population.

\subsection{Within CASE ANALYSIS}

\subsubsection{STRUgGLES FOR QUALITy AT THE FEDERAL LEVEL}

Regulations on the reimbursement of medical procedures are of federal competence. The Health Insurance Law of Switzerland required that any new medical interventions must be effective, economic and appropriate in order for the government to oblige health insurance companies to reimburse for health care interventions. This regulation gave rise to vertical struggles between the federal government which was striving to control the diffusion of the PET scanner and the health care providers which were promoting the reimbursement of the PET scanner procedures.

In 1993, despite the lack of evidence on the effectiveness of PET scanner procedures, teaching hospital THU asked the Federal Department of Health for this procedure to be reimbursed. On the one hand, the teaching hospital and international experts were arguing that the PET scanner was destined to have clinical applications in many fields, and that this technology was already producing spectacular images in neurology and cardiology. On the other hand, the Federal Department of Health was looking beyond simple detection by insisting on the need for the technology to show how the PET scanner could change patient management. Hence, each of these factions was drawing on the institutional logic of quality to defend their points of view, but focussed on different definitions of quality. While, for hospitals, quality was defined in terms of the performance of the diagnostic tool (i.e., sensitivity and specificity), the government 
insisted on the value of the technology (i.e., patient management). Hence, this episode illustrates a struggle for providing meaning to this technology by considering it either as increasing image precision or as improving patient management.

Because the teaching hospital was legally bound by the decision of the Federal Department of Health, it can be argued that this struggle for meaning in defining PET scanner was related to the governance structure of this health care system through a struggle for control which underlay the struggle for meaning. Thus, this struggle for meaning which used theorizations that drew on the institutional logic of quality mediated a struggle for control of the technology. Indeed, struggle for control involved the action of the government which slowed down the diffusion of the technology by nominating two centres and by asking for an assessment of the technology.

This struggle for meaning was resolved in an innovative way involving a win-win solution. Since the Federal Department of Health felt that the PET scanner was promising, an agreement was reached to create an ordinance which would allow the reimbursement of promising technologies if a limited number of centres were committed to evaluating the value of technology. By nominating only two centres, the Federal Department of Health was ensuring the control of cost expenditure at least to a certain extent. Hence, while the Federal Department of Health compels hospitals to demonstrate how the technology may improve patient management, this rhetoric is also a cost-containment strategy.

\subsubsection{Struggles for MeANing: EfFiciency Versus Free Market LOGICS}

\subsubsection{Federal Level}

The new ordinance allowing the reimbursement of procedures that are not yet effective, appropriate or economic was strategically used by a private clinic to be on the reimbursement list for PET scanner procedures. The private clinic used an institutional logic of free market to argue that the PET scanner should not be the exclusive right of two teaching hospitals, but ought to be a technology available for whoever intends to offer this type of diagnostic. However, animated by an imperative of cost-containment, the Federal Department of Health mobilized an institutional logic of efficiency to justify the rejection of the demand of the private clinic. While the private clinic argued that the PET scanner was an object for commerce, the Federal Department of Health defended a prudent approach to limit the diffusion of this 
technology. These institutional logics were mobilized in theorizations that address the questions of what, why and who to reimburse, and how this should be achieved. For further details please refer to table 4.7 .

Finally, the threat of failure in the face of the Anti-trust Commission brought about a revision of the nomination of centres which was performed under the umbrella of quality, but which was clearly tied to the free-market institutional logic. This appears to reflect the power of the free-market institutional logic which lies at the heart of the health care system of Switzerland. Indeed, quality criteria favoured the promoters of the free market approach as, from 2001, any organization having a PET scanner and meeting these requirements was almost automatically added to the reimbursement list. Thus, like the deviant adoptions in Quebec, this initiative is what I call institution testing which in this case took the form of contesting the law by mobilizing a market-based institutional logic (the concept of institution testing is further discussed in Chapter 5 and 6). Facing contestation, the government had to adjust its regulation to suppress discrepancy between the governance structure and the institutional logics.

Antecedents of institution testing are similar to the one in the Quebec health care system. First, the legitimacy of the PET scanner is expressed by the reimbursement of two centres for at least 5 years as well as the fact that the PET scanner is used to diagnose cancer. Another dimension of legitimacy is its profitability. Indeed, it was already well-known that the PET scanner was generating interesting profit per scan. Given that the PET scanner was conceptualized as a profitable machine, the private clinic clearly had interest in adopting. Regarding the necessary conditions; because FDG could be delivered throughout Switzerland, the technology was mature enough, the financial resources were available to buy the machine and there was no normative or regulative disincentive to pursue the Federal Department of Health against the Antitrust Commission.

Overall, the clash between the Federal Department of Health and the private clinic clearly represents a struggle for controlling the PET scanner which is revealed by the desire to enhance and to limit diffusion, and which is mediated by a struggle for meaning materialized by the interplay of theorizations and counter-theorizations.

\subsubsection{Cantonal Level}

While the federal level of analysis was the seat of strategy deployed by actors to obtain financial resources for operating the PET scanner, the cantonal regulation compelling public organizations to obtain the authorization of the cantonal government before 
making major investment is designed to help authorities to restrain the diffusion of medical technologies. This regulation brought vertical struggles between would-be adopters and cantonal governments in cantons N, D, R, Y, and S. This contrasted with the adoption of a PET scanner where there was no such regulation, as in the canton $\mathrm{T}$, or for private clinics in most cantons. In this situation, there was no vertical struggle.

However, hospitals and private clinics are not passive entities and they may adopt different strategies to deal with this regulation, varying from waiting passively for the authorization to negotiating a solution or by simply acquiring a PET scanner under a private banner. Having an imperative of cost-containment, several cantonal governments used an institutional logic of efficiency to hinder adoption. Justifications of why not adopting are related to the fact that there were enough PET scanners in Switzerland. However, other cantonal governments agreed that a PET scanner would be an asset for the canton, but forced a partnership between public and private organizations in order to minimize the number of PET scanners. On the other hand, would-be adopters mainly justified this acquisition to the authority by demonstrating the financial viability of the PET scanner (i.e. it will not cost anything to the canton) and by arguing that there is a demand from patients. In using demand arguments and economic viability, potential adopters are mobilizing a market institutional logic ${ }^{40}$.

This struggle for the control of the technology was resolved in different innovative manners. In the canton S, vertical struggles brought the cantonal government to force a partnership between a public hospital and a publicly subsidized hospital. This was intended to reduce health care costs in the canton. In the canton $\mathrm{N}$, the vertical struggle ended with a radical refusal for the teaching hospital to adopt a PET scanner. As a result, the teaching hospital formed a partnership with a private hospital and together created a private joint venture to acquire and provide PET scanner procedures. In the canton $\mathrm{D}$, because the global budget was blocked, the teaching hospital had to demonstrate the economic sustainability of an independent PET Unit. However, it was the absence of PET scanners in private organizations that made the government changed its mind. In the canton $\mathrm{R}$, the cantonal hospital had to wait three years before obtaining from parliament the authorization to buy this technology. In the canton $\mathrm{V}$, it was the cantonal government that forced the adoption of the PET scanner. However, many doctors in this canton had already dispersed to private clinics ${ }^{40}$ Readers might be inclined to see here an access-based institutional logic. However, as I will argue later on, there is a
fundamental difference in the argument. While the market-based institutional logic defends the right for providers to compete, access-based institutional logic defends patient's right to be treated near their household. 
to access a PET scanner. In the canton Z, the cantonal government did not intend to authorize two PET scanners and forced cooperation although only the publicly subsidized hospital finally obtained a PET scanner. In the canton $U$, the tension between the teaching hospital and the cantonal hospital was exceptionally resolved due to a sudden generous donation. The only exceptions to vertical struggle and its resolution were in the cantons $\mathrm{T}$ and $\mathrm{G}$. In the canton $\mathrm{T}$, the cantonal hospital CHT is not obliged to ask for authorization before buying expensive technology, so there was no reason for having a vertical struggle. In the canton $G$, because this acquisition was late, the PET scanner was already fairly well institutionalized in medical practice, the cantonal hospital had a good bargain in buying a refurbished machine, and furthermore the State did not have to pay for it since it was a cost that had already been budgeted for another medical technology. Overall, the dynamic of vertical struggles at the federal and cantonal level can be summarized in this quotation:

"Everybody was fighting at the local level to get the machine, and at the federal level to get the reimbursement."

\subsubsection{Horizontal Struggles Between Hospitals in Different CANTONS}

Although would-be adopters and cantonal governments are vertically struggling with one entity devoted to restraining the diffusion of medical technology while the other is promoting it, horizontal struggles (competition) take place between similar actors (at least in terms of their mission) whether to obtain the technology before rivals or to create obstacles for them to obtain it.

For example, early in the diffusion process, teaching hospital THU argued that there was no need to have more PET centres in Switzerland. This reflects the intention of this hospital to keep its quasi-monopoly ${ }^{41}$ on this technology at the national level. Later, the way THU thwarted another hospital in its own canton which wanted to adopt a PET scanner is also a sign that this hospital intended to dominate horizontal struggles in this health care system:

"Dr Y was mounting a plot, saying that there was a need for one centre in Switzerland, and only one: teaching hospital THU. That is his goal and his political mandate."

If dominating an organizational field or a market is one manifestation of horizontal struggles, attracting patients to the detriment of other hospitals is a motivation for

41 Although teaching hospital THV was using PET scanners, it was not really clinically active and had a very low volume of patients undergoing this procedure. 
hospitals to adopt a PET scanner as early as possible. This justification was relentlessly mentioned in the data set of this research. Because THU was attracting most patients before 2001, there was room for other hospitals to acquire a PET scanner to compete for attracting patients closer to their location and to derive financial benefits from it:

\begin{abstract}
"Health institutions compete with each other in Switzerland [...] to recruit patients. Teaching hospital THD is trying its best to recruit [patients] from Canton X1 and X2. I am currently negotiating to draw contracts with Canton $\mathrm{X} 3$, and I have totally taken back Town X4 and recruited more patients for PET. Canton X5, for example, is completely swallowed up by THN; THU tries to steal these patients. So there is an awesome competition for patients."
\end{abstract}

Moreover, having a PET scanner is a market advantage since it reduces patients' references to other organizations thereby retaining financial resources tied to the patient inside one's organization. Finally, hospitals may benefit from adopting a PET scanner as it attracts research funds from pharmaceuticals. This seems to be a prerequisite to being selected by the pharmaceutical firms to conduct research protocols:

\begin{abstract}
"We could never have retained our competitive edge, especially in the domain of new medications for oncology, if we did not own a PET scanner. Businesses which finance studies put as a prior condition that we have a PET scanner, as you doubtlessly know."
\end{abstract}

\title{
4.5.4 Horizontal Struggles AT THE CANTONAL LEVEL
}

While the vertical struggle between hospitals and the cantonal authorities slowed down the adoption process, horizontal struggles at the cantonal level certainly concurred to increase the speed of adoption, as was also true at the federal level:

\footnotetext{
"That element had to be taken into consideration, because losing this technology meant weakening our Oncology Institute relative to the competition. And we cannot afford that, if we want to stay leaders in this sector."
}

Although teaching hospitals are generally struggling at the federal level to attract patients, less prestigious would-be adopters are competing at the local level in order to achieve a first-mover advantage. This strategy is beneficial since being the second to acquire a PET scanner in a canton increases the risk of not reaching the threshold of profitability, given the small size of cantonal populations. For example, there were at least two private clinics that were striving to obtain a PET-CT scanner before other organizations in the canton $\mathrm{V}$. The unfortunate simultaneous acquisitions of two PET-CT scanners combined with the three other PET-CT scanners in this canton led to a difficult situation where none of the scanners could reach the threshold of profitability as there were not enough patients for this type of procedure in this 
canton. Moreover, there is still the hypothetical risk of not being perceived as legitimate by the authority to adopt this technology.

Besides first mover advantage, there was a clear rivalry between the public and the private sectors, especially after the introduction of TARMED. With this new tariff system, health insurance companies had to reimburse private clinics at the same tariff as public hospitals in the ambulatory setting. This brought a large movement towards acquisition of PET-CT scanners from private clinics and a quick reaction from teaching hospitals to stop this proliferation. This phenomenon was especially stringent in the canton D where the head of the Nuclear Medical Unit pressed the Swiss Medical Association to postpone the authorization of a private clinic to be reimbursed by health insurance companies.

By and large, competing for the PET scanner seems to be much more related to the need to control the technology and the benefits it generated for the hospitals and the doctors than to serve the population as the following excerpt suggests:

\footnotetext{
“So, there's some kind of PET competition and it's a very stupid fight of having the power over these things and sometimes it's much more a game of power than the power of necessity for the needs of people."
}

The next section compares diffusion processes in both health care systems. 


\section{CHAPTER V}

\section{Comparing Diffusion Processes in Two INSTITUTIONAL CONTEXTS}

In this chapter, I highlight the main results of the comparative analysis of the diffusion processes in Quebec and Switzerland health care systems. I examine how institutional logics are involved in struggles for meaning, how the governance structure is involved in struggles for control, and how institution testing pre-empts the diffusion of innovations. I conclude this chapter by evaluating the performance in terms of efficiency and access of both institutional environments.

\subsection{COMPaRATIVE ANALYSIS: HOW THE INSTITUTIONAL Context Shapes the Diffusion Process}

Neither case suggests a highly ordered diffusion process governed primarily by a rational evaluation of patient needs, the equitable distribution of resources and cost effectiveness calculations, although such considerations were explicitly and extensively invoked at different times by different actors. Rather, in both cases, the spread of the diffusion process over time is marked by two kinds of competitive and political struggles: horizontally between different health-care institutions competing to acquire the technology faster than their rivals and vertically between would-be adopters and regulatory bodies attempting to influence diffusion, often by restraining it. These 
conflicts manifest themselves in two distinct but interacting forms of action, called here struggles for control and struggles for meaning.

Actors engage in struggle for control that is the fight to obtain and use a technology despite efforts deployed by other stakeholders to impede adoption, by strategically mobilizing power in the form of material resources, authority and expertise. While the power of both governments lies mainly in their authority to allow adoption or reimbursement, expertise often lies with potential adopters, giving them legitimacy in the struggle to control the diffusion of this technology. Material resources take the form of the capacity of actors to mobilize financial resources for the acquisition of a PET scanner. For example, in Quebec the Ministry of Health has the authority to allow the adoption of expensive technology but also often provides acquisition and operational budgets. On the other hand, prestigious teaching hospitals can counteract government control through their private Foundations which can buy a technology and rent it to the hospital. In Switzerland, authority is diluted between the cantonal and the federal governments; while the former has material power to fund and to authorize acquisition, the latter has the authority to permit the reimbursement of health insurance. Hence, the governance structure determines who has access to material resources, authority and expertise thereby assigning roles, identities and responsibilities to institutional actors. In this jurisdiction, many strategies can be used to bypass government control including the intervention of private Foundations.

The struggle for the control of the diffusion of the PET scanner takes place in relation with struggles for the meaning of the technology. Struggle for meaning is the attempt by actors to gain legitimacy by providing an interpretation for a material object which is aligned with their own values and interests, and which manifests itself in the interplay of theorizations and counter-theorizations. Theorizations are strategically mobilized arguments aimed at legitimizing the purpose of a technology, the adequacy of a potential adopter to acquire such a technology, and the appropriate way to disseminate it. In turn, institutional logics provide a repertoire of cultural-cognitive resources which may be mobilized in theorizations.

The case studies suggest a number of ways in which the institutional contexts influence the technology diffusion process. It is clear that institutional logics and governance structures interact and are mutually supportive in these cases. However, they are separated initially for analytical purposes in the next section. 


\subsubsection{INSTITUTIONAL LOgICS \& STRUGGLES FOR MEANING}

This study identifies different kinds of theorization involved in the legitimation of the diffusion of complex technologies. Some theorizations rely on scientific evidence to support them. Because science provides procedural legitimacy (Suchman 1995), a special type of moral legitimacy, and because science is a cultural-cognitive institution in our modern society, evidence-based theorization that is further sanctioned by a reputed scientific body embedded in a regulatory structure (such as the Health Technology Assessment Agency in Quebec) can be an extremely powerful force for legitimation. This type of theorization draws on an institutional logic associated with quality (Scott, Ruef et al. 2000) as was clearly apparent in this study. Theorizations which focus on competence are again based on the professional discourse of quality, this time associated with buying the best available technology (PET-CT scanner) although it may be more expensive. Finally, theorizations based on patient management also rely on scientific evidence, but more on how technology would change the way patients are treated.

In contrast, access-based theorizations rely on the institutional logic of access (Scott, Ruef et al. 2000), a logic that has had currency in both institutional environments since the introduction of universal coverage in these health-care systems. Arguments surrounding this type of theorization are infused with moral elements (Suchman 1995) to support the wider diffusion of the less expensive form of the technology thereby democratizing access to it. This theorization was particularly intensively mobilized in Quebec. Although it is present in Switzerland, it was not instrumentally selected in struggles for meaning. However, the free market-based institutional logic was particularly apparent in Switzerland and was absent in Quebec. This is different from the access-based institutional logic in the sense that while the latter defends the right of patients to have access to a technology, the former is related to the right of doctors and hospitals to access the market freely. Market-based institutional logic is also infused with moral elements i.e. it provides an appropriate way ("the right thing to do") to organize and perform activities (Suchman 1995).

That the efficiency-based institutional logic is more present in Switzerland than in Quebec; is seen especially in the endeavour of the Swiss Federal government to limit the diffusion of the technology. Theorizations based on this institutional logic were manifest when the federal government struggled to keep the technology in a duopoly instead of widely opening up its diffusion. In Quebec, efficiency-based institutional logic was also used in some theorizations, but more in a supporting role than as a central component. This is rather ironic given the high cost of this technology and the 
obvious impact of economic concerns in the dynamics of diffusion. Again, moral elements permeated these theorizations.

This suggests the simultaneous co-existence of multiple logics of legitimation, such as those of quality, efficiency, access and market. This analysis confirms the theoretical work of scholars who identified multiple institutional logics at different levels of analysis (Thornton and Ocasio 2008), whether at organizational level (Thornton 2002; Zilber 2002), at the organizational field level (Scott, Ruef et al. 2000) or at the societal level (Friedland and Alford 1991; Boltanski and Thévenot 1999; Zilber 2006). It is also aligned with the nascent interest for institutional pluralism which assumes that the institutional environment is heterogeneous i.e., composed of different regulatory regimes, multiple institutional logics and several normative orders (Kraatz and Block 2008).

Because the PET scanner is a complex technology whose applications were not initially clear, this technology left room for professionals to provide meaning to the PET scanner in ways that suited their interests. Although a quality-based institutional logic was initially mobilized to legitimate the PET scanner and potential adopters, different institutional logics available in each institutional environment were used by actors to justify the way the PET scanner should subsequently be diffused. In each case, the legitimation strategy utilized was in the form of theorizations and was aligned with the would-be adopter's interests. In Quebec, it was assumed by actors that grounding the purpose of the technology in scientific evidence would increase the likelihood of obtaining the PET scanner or orient the diffusion of the PET scanner according to the interest of certain actors. The publication of the Health Technology Assessment Agency's report on the PET scanner legitimated it as a useful clinical tool which needed to be further developed by research. This theorization was sanctioned by teaching hospitals who mobilized a quality-based institutional logic by underlining the importance of their competence to interpret PET scanner results, to disseminate this technology slowly, and to perform further research. However, the limited resources available for PET scanners generated struggles for the meaning of the technology. In this context, the quality-based theorization was counter-theorized with an access-based institutional logic by the medical professional association and regional hospitals to ensure that smaller hospitals would obtain this technology. The theorization and counter-theorization between two factions tended to paralyze decision-making at least initially given that the government was not inclined to fund the acquisition of two PET scanners in the same region. 
In Switzerland, while the government developed an efficiency-based and quality-based theorization by contending that the reimbursement of PET scanner should be restricted to nominated centers for cost-containment and quality purposes, and because it was still under evaluation, the private clinic used a free-market countertheorization by arguing that providers should be able to practice medicine freely and that all organizations wishing to offer this service should be allowed to do so. In other words, the free-market institutional logic was instrumentally mobilized by a private clinic to build a theorization challenging the efficiency-based institutional logic defended by the federal government. Thus in each jurisdiction, institutional actors mobilized the institutional logic which best suited their values and interests; and through the interplay of theorization and counter-theorization they competed on institutionally established legitimate grounds to capture resources. Table 5.1 summarizes the theorizations mobilized in each jurisdiction to influence the diffusion of the PET scanner technology.

TABle 5.1:

THEORIZATIONS \& COUNTER-THEORIZATIONS INFLUENCING DIFFUSION IN BOTH JURISDICTIONS

\begin{tabular}{|c|c|c|c|c|}
\hline \multirow[b]{2}{*}{$\begin{array}{l}\text { Theorization } \\
\text { components }\end{array}$} & \multicolumn{2}{|c|}{ Quebec } & \multicolumn{2}{|c|}{ Switzerland } \\
\hline & Quality-based Logic & Access-based Logic & $\begin{array}{l}\text { Efficiency \& Quality- } \\
\text { based Logic }\end{array}$ & $\begin{array}{c}\text { Free Market-based } \\
\text { Logic }\end{array}$ \\
\hline Proponents & Teaching Hospitals & $\begin{array}{l}\text { Professional } \\
\text { Association }\end{array}$ & Government & Private Clinic \\
\hline $\begin{array}{l}\text { What to adopt or to } \\
\text { reimburse? } \\
\text { Definition of the } \\
\text { innovation }\end{array}$ & $\begin{array}{l}\text { PET-CT as a proven } \\
\text { high-performing clinical } \\
\text { \& research tool }\end{array}$ & $\begin{array}{l}\text { PET as a proven clinical } \\
\text { tool needed by all } \\
\text { regardless of location }\end{array}$ & $\begin{array}{l}\text { PET in oncology, } \\
\text { cardiology \& neurology }\end{array}$ & $\begin{array}{l}\text { PET in oncology, } \\
\text { cardiology \& neurology }\end{array}$ \\
\hline $\begin{array}{l}\text { Why adopt? Why } \\
\text { reimbursing PET? }\end{array}$ & $\begin{array}{l}\text { Better quality diagnoses } \\
\text { Lower cost per } \\
\text { examination with higher } \\
\text { quality } \\
\text { Inevitability of PET- } \\
\text { CT. }\end{array}$ & $\begin{array}{l}\text { PET scan for all } \\
\text { Low purchase costs and } \\
\text { lower travel costs with } \\
\text { greater equity and } \\
\text { access. }\end{array}$ & $\begin{array}{l}\text { Federal: PET still being } \\
\text { evaluated; should not } \\
\text { be widely diffused to } \\
\text { contain costs. } \\
\text { Cantonal: Enough PET } \\
\text { in Switzerland; } \\
\text { to limit chaotic } \\
\text { diffusion of PET; } \\
\text { Expensive. }\end{array}$ & $\begin{array}{l}\text { Federal: PET should be } \\
\text { available to all } \\
\text { providers, to freely } \\
\text { practice medicine. } \\
\text { Cantonal: Demand } \\
\text { from patients } \\
\text { Profitability of the PET. }\end{array}$ \\
\hline $\begin{array}{l}\text { Who should adopt or } \\
\text { be reimbursed? And } \\
\text { how dissemination } \\
\text { should occur? }\end{array}$ & $\begin{array}{l}\text { Competence has to be } \\
\text { developed first before } \\
\text { allowing adoption }\end{array}$ & $\begin{array}{l}\text { PET for all, coherence } \\
\text { with prior distribution } \\
\text { of oncology centres }\end{array}$ & $\begin{array}{l}\text { Federal: Already } \\
\text { nominated centres } \\
\text { Cantonal: Refusal or } \\
\text { delay before } \\
\text { authorization to contain } \\
\text { cost. }\end{array}$ & $\begin{array}{l}\text { Federal: To all } \\
\text { organizations wishing } \\
\text { to offer PET scanners. } \\
\text { Cantonal: Alignment } \\
\text { with organizational } \\
\text { mission. }\end{array}$ \\
\hline
\end{tabular}

Because the governance structure of Quebec is closer to a state-based model, there was no room for theorizations stemming from a market-based institutional logic, although this type of logic exists in other forms of economic activity in Quebec. Mobilizing a market-based institutional logic is indeed absent from the rhetorical repertoire of institutional actors because market competition and profit are relative institutional taboos in this jurisdiction. In contrast, market competition in health care is institutionalized in Switzerland and institutional actors may draw on this institutional logic to defend their interests or to become institutional entrepreneurs 
(DiMaggio 1988), basing their action on institutional logics to adapt the institutional environment to their needs.

In short, while institutional logics structure the behavior of actors by providing them with cognitive templates for the organization of social life (Friedland and Alford 1991), they also enable actors to select institutional logics instrumentally so as to influence the perception of actors according to their own values and interest.

Proposition 1: Institutional logics structure the institutional field by restraining the rhetorical possibilities, but also enable actors to gain legitimacy or provide legitimacy to objects by instrumentally selecting the logic that best suits their values and interests.

While actors may instrumentally select one among multiple institutional logics available in the institutional environment in their struggles for meaning, theorizations may also be elaborated within the same institutional logic. In both jurisdictions, the initial institutional battles to legitimate the technology and to define its purposes occurred within a quality-based institutional logic. To win these institutional struggles, proponents gathered different bodies of scientific evidence that were aligned with their own interests and values, but also defined quality according to other criteria such as patient management (the way patients can be treated). For example, in the early diffusion of the PET scanner in Quebec, the hospital which specialized in cardiology and in lung cancer was grounding its arguments in the scientific literature by referring to the number of studies in cardiology and in lung cancer; meanwhile the teaching hospital specializing in oncology based its arguments on one meta-analysis, insisting on the larger number of applications in oncology (18 applications) and the limited number of applications in cardiology (only one application). In Switzerland, the federal government based its arguments for limiting the diffusion of the technology on the value of the technology i.e., on how the technology would change patient management, while teaching hospitals were also founding their arguments on scientific evidence and expert opinions to show the diagnostic power of this technology in terms of image quality.

Consequently, it appears that institutional logics can be interpreted in various ways. In this study, the dimensions of theorizations which were founded on quality-based institutional logic included scientific arguments on image precision, patient management, the number of clinical applications and the number of publications in a given medical discipline. Since various dimensions of institutional logics can be interpreted and mobilized in struggles for meaning, competing theorizations can be elaborated within the same institutional logic. 
Proposition 2: Competing theorizations can be elaborated within the same institutional logic because it can be interpreted by institutional actors along various dimensions which they rely on in their struggle for meaning.

\subsubsection{GovernanCE STRUCTURES AND STRUgGLES FOR CONTROL}

As noted earlier, the jurisdictions of both Quebec and Switzerland share governance structures which to some extent pit organizations against one another in the competitive struggle to adopt new technology, while at the same time setting bounds on this struggle through the use of regulatory bodies. However, some important distinctions between the governance structures produce effects which are evident in the patterns of diffusion described in this study.

The governance structure of the Swiss health-care system is highly fragmented and has two main cleavages: 1) the co-existence of market and public regulative regimes, and 2) the partial decentralization of the governance structure with responsibilities diluted between the cantonal and the federal governments and the health insurance companies. This has the effect of diluting the power of government by providing more freedom to other actors in their struggles for control and for meaning.

The public-private fragmentation of the Swiss health-care system allows public organizations to bypass the regulation demanding that they have authorization from the cantonal government before acquiring a PET scanner. Because private organizations are not subject to this law, some public hospitals found a strategy to acquire a PET scanner by subscribing to a private regime not by changing their legal status by starting up a company or collaborating with private hospitals. For example, the presence of the private sphere helped teaching hospital THN to acquire the technology in the face of denial or hesitation from government by starting up a private company to install the PET scanner. Hence, in Switzerland, since the public (state model) and the private (market model) structures are two complementary and legitimate regimes, institutional actors may position themselves under the regime which best suits their interests.

If the public-private fragmentation in this health-care system constitutes the first cleavage, decentralization between the federal, the cantonal governments and healthinsurance companies constitutes the second one. Fragmentation of the accountability between the federal government, the cantonal government and health insurers lowers the incentive to limit diffusion and reimbursement, and provides institutional actors with more freedom to act. Indeed, although the federal government was reluctant to offer reimbursement, the absence of accountability as regard to the payment of the 
machine or reimbursement certainly contributed to enabling initial reimbursement to the duopoly despite the lack of clinical evidence related to the PET scanner. Moreover, in spite of the fact that the teaching hospital THS was not initially on the federal reimbursement list, the decentralization of the governance structure allowed it to pass a contract with the cantonal health insurance body to have PET scanner procedures reimbursed.

Overall, it is clear that the relative fragmentation of the Swiss governance structure provided greater freedom to institutional actors to mobilize laws and rules strategically to suit their particular interests.

Proposition 3: The fragmentation [public-private and federal-cantonal] of the governance structure provides regulative slack or freedom to institutional actors who may choose which regime to comply with, thereby seeking their own interest while still being within the letter of the law.

Whereas the Swiss health-care system is largely fragmented, Quebec's health-care system is more coherent as decision-making processes are centralized. Authorization for acquiring expensive technology as well as obtaining an operational and acquisition budget is granted by a single central authority. Therefore, most actions by would-be adopters are directed toward governments given that they control material resources and authority to allow acquisition. This provokes institutional actors to engage in legitimate discursive battles through the interplay of theorizations and countertheorizations which draw on major institutional logics. Because there is no alternative legitimate mode of action such as switching from a public to a private regime in the case of government opposition, actors' freedom is significantly lowered, at least in the short term, in more coherent governance structures.

Proposition 4: The coherence of the governance structure allows the state to control the diffusion process of expensive technologies, at least in the short term, because the power to allocate resource is concentrated in the hands of one entity.

If struggle for control may occur vertically between governments and would-be adopters, horizontal struggle for controlling the technology takes the form of competition for scarce resources between providers in both governance structures. While this behavior is typical in market settings, it was surprising to find intense struggles for control in the more state-oriented health-care system of Quebec as this type of system is believed to be more rational in the way resources are allocated (Streeck and Schmitter 1985). Nonetheless in both contexts, horizontal struggle for controlling the technology is the result of actors' desire to gain competitive advantage, 
in this case through a technology, by attracting scarce resources such as patients, nuclear doctors, prestige and financial resources.

The higher the number of institutional actors who was striving to capture the same resources, the more intense the horizontal struggle is likely to be. In regions or cantons where many organizations were engaged in acquiring a PET scanner, fierce rivalries were observed between providers seeking to control the technology. For example, in region $\mathrm{C}$ of Quebec, there were intense horizontal struggles for control between hospitals THC and GHC in order to convince authorities as to which hospital was the more adequate site to acquire a PET scanner. In Switzerland, the absence of a good quality PET scanner in canton V encouraged private oncologists to ask private would-be adopters for this technology. Responding to this demand, three private clinics adopted PET-CT scanners with the idea that being the first to have a PET-CT scanner would be profitable. However, three PET scanners were later adopted by nearby private clinics with the consequence that none of the six was profiting, although they were able to offer the whole spectrum of diagnostic tools. To complicate this situation, the teaching hospital THV which saw its patients going to private clinics decided to acquire two PET-CT scanners. As a result, canton $\mathrm{V}$ has 5 PET-CT scanners for a population of around 400,000 inhabitants. In canton D, competition between THD and PCD2 drove the former to lobby the Nuclear Medical Association to postpone as far as possible the accreditation of PCD2.

These examples suggest that local horizontal struggles are more intense and apparent than national-level rivalries such as those taking place between far away teaching hospitals. This may be explained by the fact that, unlike widely separated organizations, those geographically close to each other are in competition for the same resources. Nevertheless, competition occurs only between organizations having an interest in adopting a PET scanner (e.g., having a Nuclear Medicine Unit or intending to open one) and not between all organizations within a certain geographical area. Therefore, geographical closeness is not the only criterion that should be use to assess competition.

These results contrast with those of regions and cantons where only one organization was intending to adopt a PET scanner, such as region B in Quebec and cantons T and $G$ in Switzerland, where there was no horizontal struggle between providers. Hence, the number of institutional actors striving for the same resources in a given organizational field affects the level of struggle for control, whether action takes place in a market or a non-market setting. 


\subsubsection{INSTITUTION TESTING}

\subsubsection{When Institutional Logics Preempt Governance Structures}

Although the governance structures in both jurisdictions gave theoretical control to regulatory agencies over certain key decisions (e.g., the authorization of adoptions in Quebec and reimbursement rules in Switzerland), this study shows in both cases that when regulatory bodies found themselves in positions where their actions placed them in contradiction with dominant institutional logics embedded in the field, they were unable to sustain their positions.

In Quebec, at the point where the PET scanner had acquired strong quality-based legitimacy through the Health Technology Assessment Report and through extensive diffusion in USA, it was no longer possible for the government to sustain objections to deviant adoptions without losing credibility and political capital. To maintain face, the government was obliged to generate a dissemination plan which largely satisfied potential adopters. The deviant and pre-emptive behavior by adopters was rendered legitimate when normative and cultural-cognitive forces were stronger than regulative forces.

Similarly, the Swiss federal government was faced with a potential revolt concerning its reimbursement rules. While the private clinic PCXS which legally contested these rules on the grounds of a market-based logic did not win its case, the Federal Department of Health was sufficiently worried about anti-trust issues to modify its rules about diffusion, setting new rules that allowed the market-based logic to flourish within a quality-based framework.

Note that in both cases, entrepreneurial action which contravened current rules was required by health-care providers to achieve adjustments in regulatory attitudes and requirements to concord with dominant institutional logics. This type of entrepreneurial action is labeled here institution testing. This is a strategic behaviour which pre-empts the diffusion of innovation. It is rendered possible when normative, cultural-cognitive or economic forces supporting a technology are stronger than regulative ones. A proposition is formulated: 
Proposition 5: Institution testing is a strategic behaviour that may speed up the diffusion of expensive and complex technology in highly regulated environments and may result in change of regulatory constraints when the normative and cultural-cognitive legitimacies of the position defended are grounded in dominant institutional logics and have acquired sufficient force to outweigh regulatory legitimacy.

Of course, in some circumstances, the government may not model its regulation to what actors already did, but may change payment incentives or mechanisms to influence actor's behaviour. However, this is not what I observed in my data set.

Besides the normative and cultural-cognitive forces which were stronger than regulative ones and which are the necessary conditions for institutional testing to take place, diverse incentives behind bandwagon technology also explains this behavior. The case studies reveal that competition was behind deviant adoption in Quebec and that the desire to be on the reimbursement list lied behind this behavior in Switzerland. In the former jurisdiction, organizations were afraid to lose their legitimacy in the domain of oncology and to lose their budget in subsequent years as a consequence; in the latter institutional environment, there was fierce competition in canton $\mathrm{S}$ and the perspective of making a profit was an incentive to be on the reimbursement list. The first to obtain the reimbursement might have impeded the other party from obtaining this technology. In both jurisdictions, the issue was to compete (struggle horizontally) to continue obtaining financial resources, although the situation in Quebec was less oriented toward the use of institutionalized means to acquire a PET scanner as the legal framework is bypassed by actors. As one interviewee in Quebec stated:

"It is those who cheat that succeed in having the most advanced technology before others."

Although interest for a technology is one reason for institution testing to occur, the legitimacy of the technology also influenced this phenomenon. In Quebec, institution testing happened when technological legitimacy was taken for granted by professionals, and when illegitimate behavior was the only remaining alternative when legitimate ways to acquire the technology were exhausted or when waiting was no longer possible. In this case, the wide diffusion of the technology outside the jurisdiction, the perceived adequacy of the technology in the organizational field through the support of a health technology assessment report, and, maybe even more importantly, the type of disease the technology was diagnosing (i.e., cancer) were pushing the diffusion of the PET scanner. Indeed, the nature of the disease the technology addressed weakened the recourse for the government to retaliate against 
deviant adopters because this condition was (and is still) high in the political agenda. Thus, it would certainly not be a wise move for the government to restrain the use of the technology. In Switzerland, two factors legitimated the PET scanner. First, the government was already allowing two PET centres to be reimbursed for the use of this technology and even changed the law to grant this reimbursement. Second, although it was not mentioned in interviews, the authorization for reimbursing PET scanner examinations for lung cancer by the Centers for Medicare and Medicaid Services in USA certainly influenced the adoption of this technology by a private clinic. Hence, a certain number of conditions had to be present for institution testing to take place. In both jurisdictions, potential adopters gathered financial resources to buy this expensive technology and also the FDG was easily supplied to adopters.

If the interests of hospitals and doctors as well as competition in the Swiss health-care system are powerful motors for the adoption of the PET scanner, the situation in Quebec is not dissimilar, with the variant that there, when legitimate means of acquiring this technology are no longer effective, illegitimate means becomes the only alternative. In Quebec, experience of not having been sanctioned for past deviant adoptions also helped organizations to adopt without the consent of the government. Table 5.2 synthesizes underlying causes and necessary conditions for institution testing which are present in each jurisdiction. The next section assesses the effectiveness of each health care system to rapidly diffuse the PET scanner and its efficiency in the use of this technology.

TABLE 5.2:

CAUSES \& NECESSARY CONDITIONS FOR INSTITUTION TESTING TO OCCUR IN EACH JURISDICTION

\begin{tabular}{|c|c|c|c|}
\hline $\begin{array}{c}\text { Causes \& Necessary } \\
\text { Conditions }\end{array}$ & Factors & Quebec & Switzerland \\
\hline \multirow[t]{3}{*}{$\begin{array}{l}\text { Legitimacy of the } \\
\text { technology }\end{array}$} & Large diffusion abroad & Yes & Yes \\
\hline & Adequacy of the technology inside this organizational field & Yes & Yes \\
\hline & Cancer is high on the political agenda, a priority disease & Yes & Yes \\
\hline $\begin{array}{l}\text { Interest in the } \\
\text { technology }\end{array}$ & Profitability, attracting budget & Yes & Yes \\
\hline \multirow[t]{4}{*}{ Necessary Conditions? } & Evolution of the technology i.e. FDG supply & Yes & Yes \\
\hline & Financial resources & Yes & Yes \\
\hline & No other legitimate ways available to adopt & Yes & Yes \\
\hline & No regulative or normative sanctions & Yes & Yes \\
\hline
\end{tabular}




\subsection{EFFECTIVENESS IN THE Diffusion AND EFFICIENCY IN THE Use OF THE PET SCANNER IN EACH Health CARE SYSTEM}

In this section, results as regard to the speed of diffusion and the efficiency in the use of technology of both health care systems are displayed and an explanation of these phenomena is sought.

\subsubsection{DIFFUSION CURVES}

Figure 5.1 shows that the PET scanners diffused faster in Switzerland than in Quebec. Why should this be? Both jurisdictions are characterized by intense early involvement of entrepreneurs who pushed for the development, acquisition or reimbursement of the PET scanner. For example, Dr Y was involved in calling for a National Consensus Conference on this issue in Switzerland and in Quebec a doctor had to find funds from

FigURE 5.1:

DifFusion OF THE PET SCANNER IN QUEBEC AND SWITZERLAND with Main Events and Private-Public Status

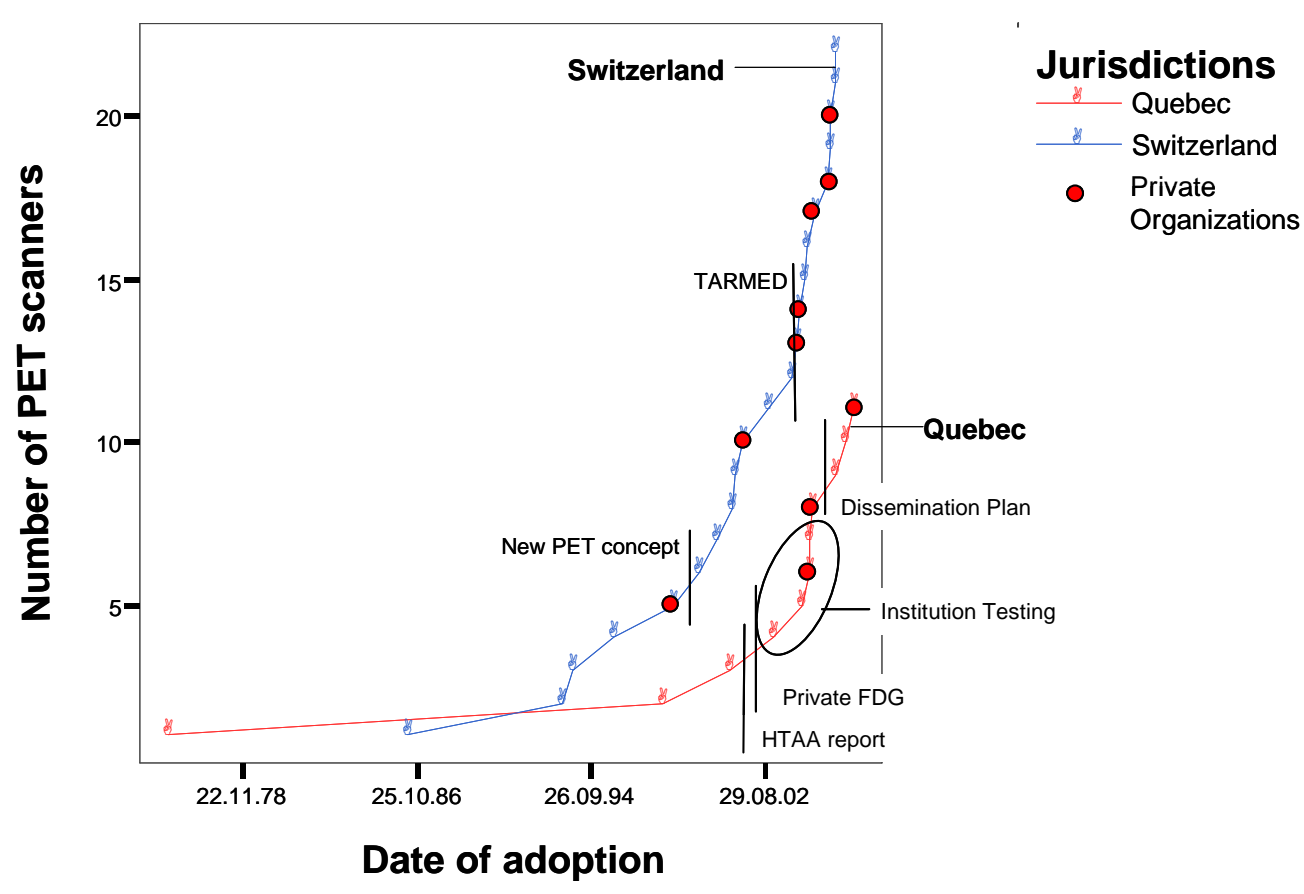

different sources to persuade the Ministry of Health to participate in this acquisition. Thus, the presence of active entrepreneurs does not seem to be sufficient to explain the more aggressive initial diffusion in Switzerland. Indeed, the case studies suggest that the fragmentation of the governance structure in the Swiss health-care system is 
the most probable reason for the more aggressive early diffusion of the PET scanner. This fragmentation diffuses the accountability for health-care costs between the federal and cantonal governments and insurance companies. While the federal government provides authorization for reimbursement, insurance companies cover out-patients' medical procedures and cantonal governments pay for the machines themselves and part of the cost of in-patient procedures. This diffusion of accountability certainly facilitated the amendment of the law to allow experimental procedures to be reimbursed. In Quebec, the dispute over the purpose of the PET scanner in region $\mathrm{C}$ and the many unanswered demands from the entrepreneur of region $\mathrm{B}$ reflect the capacity of a centralized government to control the early diffusion of a technological innovation by delaying adoption as much as possible. This tends to reinforce propositions 3 and 4 on the role of the coherence/fragmentation of the institutional environment.

However, the diffusion process in Switzerland really opened up as a result of institution testing which led to the domination of the market-based institutional logic and suppressed the legal barrier which was limiting the right to be reimbursed to only two PET scanner centers. This brought in the new PET concept which allowed any providers satisfying quality criteria to be reimbursed. The effect of the suppression of this barrier is apparent in figure 5.1 from 2001 and corresponds to an increase in the speed of the diffusion of this technology mainly in public hospitals. This episode is an indicator that market-based institutional logic had a profound effect on the barrier that was hindering the diffusion of the PET scanner. This contrasts with the effect of competition in the more centralized Quebec health care system where it actually restrained diffusion at least in the short run.

Besides the domination of the market-based institutional logic, the introduction of the TARMED regulation in Switzerland in 2004 widely opened the door to private clinics (figure 5.1 shows how TARMED speeded up the adoption from private PET providers), and especially in cantons $\mathrm{V}$ and $\mathrm{D}$ where there were intense horizontal struggles between providers (refer to table 4.6 for further details). With the introduction of a uniform reimbursement tariff all over Switzerland, private clinics were guaranteed to be reimbursed at the same rate as public hospitals, rather than a lower rate as allowed by the previous system.

However, although TARMED significantly lowered the reimbursement risk, gaining competitive advantage was what actually drove diffusion in these private clinics. Timing was also a critical issue since having too many PET scanners in a small area would not bring in enough patients, thereby impeding the profitability of each 
machine. Therefore, it appears that risk of not generating sufficient revenue is an important factor that may have impeded diffusion in private clinics before the introduction of TARMED.

In Quebec, the legitimacy of the technology which was sanctioned by the health technology assessment agency report, combined with actors' disillusionment and the availability of FDG from private suppliers, precipitated deviant adoptions. This institution testing is the main mechanism which opened up the diffusion of the PET scanner in Quebec. Its effect can be seen in figure 5.1 inside the oval. In contrast to Switzerland, where FDG was available from the beginning and did not really impede the diffusion of the PET scanner, the supply of FDG by private companies enabled deviant adoptions. In this jurisdiction, institution testing was clearly what sparked the diffusion process and what led the government to create a dissemination plan which was adjusted to the actual diffusion at the time. This plan came into force in June 2005 to stop eventual deviant adoption.

Overall, while the fragmentation of the Swiss governance structure is already central in the early diffusion, market forces and horizontal struggles are more at the base of the wider diffusion which occurred later on, and regulation guaranteeing uniform reimbursement (TARMED) was the last barrier to be removed for private clinics. In contrast, the coherence of the governance structure in Quebec and the rigidity of the system left actors with the only option to test institution in order to acquire this technology. Because institution testing in Quebec involves adopting a technology against the law, this action was undertaken as a last resort and explains the slower diffusion process. Conversely, in Switzerland actors could immediately find refuge under a private regime to adopt this technology, even when cantonal governments were against such acquisition.

\subsubsection{THE USE OF PET SCANNERS}

According to table $5.3^{42}$, the number of PET scanner examinations increases steadily in each jurisdiction to reach approximately the same number in both by 2006. The number of PET scanners in use ${ }^{43}$ for clinical purposes is also constantly increasing in both health-care systems. However, what is striking in this table is the difference between the average numbers of PET scanner procedures per machine performed in

\footnotetext{
42 Data are available in both jurisdictions from 1999 only.

${ }^{43}$ Note that the number of PET scanners in use is lower than the total number of PET scanners acquired in each jurisdiction. This is mainly due to the substitution of PET scanners by PET-CT scanners which tends to decrease the number of PET scanners in function because buying a PET-CT scanner often incites organizations to sell or stop running their stand-alone PET scanner.
} 
Quebec versus Switzerland. Except for the first three years, this difference is largely and increasingly in favor of the Quebec health-care system ${ }^{44}$. Considering that 8 examinations per day per PET scanner can be performed on an average of 250 business days, each PET scanner has a potential of approximately 2000 PET scans per year. In this respect, although both systems are underutilizing this technology, Quebec's health-care system is closer to an optimal use of this technology, at least for 2006.

TABLE 5.3:

Number of EXAMINATIONS IN ONCOLOGY PER PET SCANNER IN EACH JURISDICTION

\begin{tabular}{|c|c|c|c|c|c|c|c|}
\hline \multirow[b]{2}{*}{ Year } & \multicolumn{3}{|c|}{ Quebec } & \multicolumn{3}{|c|}{ Switzerland } & \multirow{2}{*}{$\begin{array}{c}\text { Differences } \\
\text { Qc - Swit. } \\
\text { Number of } \\
\text { exam/ PET } \\
\text { scanner } \\
\end{array}$} \\
\hline & $\begin{array}{c}\text { Number of } \\
\text { Exams }\end{array}$ & $\begin{array}{l}\text { PET } \\
\text { in use }\end{array}$ & $\begin{array}{c}\text { Number } \\
\text { exam/PET }\end{array}$ & $\begin{array}{c}\text { Number of } \\
\text { Exams }\end{array}$ & $\begin{array}{c}\text { PET } \\
\text { in use }\end{array}$ & $\begin{array}{c}\text { Number } \\
\text { exam/PET }\end{array}$ & \\
\hline 1999 & 573 & 1 & 573 & 1891 & 2 & 946 & -373 \\
\hline 2000 & 1223 & 1 & 1223 & 2937 & 3 & 979 & 244 \\
\hline 2001 & 1402 & 2 & 701 & 4415 & 6 & 736 & -35 \\
\hline 2002 & 2081 & 2 & 1040 & 5027 & 7 & 718 & 322 \\
\hline 2003 & 3941 & 3 & 1314 & 6792 & 8 & 849 & 465 \\
\hline 2004 & 5733 & 5 & 1147 & 8092 & 12 & 674 & 473 \\
\hline 2005 & 8483 & 6 & 1414 & 10124 & 15 & 675 & 739 \\
\hline 2006 & 11945 & 7 & 1706 & 11887 & 15 & 792 & 914 \\
\hline
\end{tabular}

The impact of the mechanisms behind the diffusion of this technology can be observed not only in the diffusion curves of figure 5.1, but also on the number of PET scanner procedures performed in oncology (by far the most common PET scanner application) in each jurisdiction (see table 5.3). The effect of institution testing is apparent in Quebec in 2004 with an initial decrease in the average number of examinations per PET (from 1314 to 1147 examinations). In Switzerland, the number of PET scanner procedures per machine decreased in 2001 with the opening of the market (from 979 to 736 examinations). This is also the result of institution testing. There is another drop in 2004 with the introduction of TARMED (from 849 to 674 examinations) which significantly reduced the financial risk to private clinics of adopting a PET scanner.

How can we explain these differences between health-care systems? It is clear that for a given number of examinations, if the number of PET scanners increases the number of examinations per scanner will decrease. Consequently, the same mechanisms as those mentioned for the higher rate of diffusion in Switzerland may explain the lower number of scans per machine in the more market-oriented health care system as well

${ }^{44}$ In Quebec, only publicly reimbursed PET scanners were computed as the number of non-reimbursed PET scanner procedures is unknown. 
as the lower efficiency of the overall system (for a given demand which is assumed to be constant across jurisdictions) as compared to Quebec.

Quebec's health-care system provides a limited budget to hospitals to perform a certain number of PET scanner procedures. While this financial strategy entails the risk of not fully responding to patient demand, it has the advantage of limiting healthcare costs in an elegant manner. On the other hand, Switzerland, which has the second most expensive health-care system in the world, has, not surprisingly, much more difficulty in controlling expenditure related to the PET scanner. Indeed, because insurance companies are paying for most of these procedures, there is basically no financial limit on their use. Thus, the facts that Quebec's health-care system has fewer PET scanners, has a higher average number of procedures per machine and has a limited budget associated with each machine may suggest that less fragmented healthcare systems are more efficient in limiting the use of technology.

On the criterion of the average number of PET scanner procedures per machine, the Quebec health-care system has a higher efficiency. However, assessing the performance of a system always entails relying on certain values to the detriment of others. It is clear that when access becomes the criterion for assessing these systems, Switzerland would be far better than Quebec, with almost no waiting list for PET scanner procedures ( 0 to 7 days in Switzerland as compared to approximately 3 months in Quebec) and a good distribution of this technology all over the country (15 PET scanners in use in a relatively small geographic area such as Switzerland compared with 7 PET scanners in use in the huge Quebec territory); two dimensions of the access criterion in which Quebec's health-care system's performance is relatively low. 


\section{CHAPTER VI}

\section{DisCUSSION AND CONCLUSION}

In this section, the results of my study are discussed in order to identify how they contribute to the literature. I begin this chapter by showing that my results confirm that institutional environments are composed of multiple institutional logics. This is followed by identifying the role of institutional logics as being both constraints and enablers, and by the fact that competing theorization can be elaborated by mobilizing the same institutional logic. Examining the coherence and fragmentation of the governance structure is also confirming the work of health economists. I further argue that institution testing and readjustment is a mechanism that maintains institutions as long as the governance structure can adjust to the mobilization of dominant institutional logics. This chapter closes with the limitations of this thesis, directions for future research, and practical implications before concluding.

As might have been expected, the PET scanner diffused more rapidly in Switzerland than in Quebec. The competitive environment of the Swiss health care system in which private and public health care institutions coexist and where there is relatively limited centralized decision making did enable hospitals to acquire the technology earlier. This appears to confirm the conclusions of the economic literature on the diffusion of innovations which states that environments conducive to competition are more prone to higher rates of diffusion (Lee 1971; Rapoport 1978; Hillman, Neu et al. 1987; Foote 1992; Vogt, Bhattacharya et al. 1995; Chou, Liu et al. 2004). This study 
also appears to confirm that strong incentives can lead to intense diffusion of innovations (McClellan and Kessler 2002) and sometimes overdiffusion (Foote 1992).

However, this broad global portrait hides several similarities in the dynamics of the diffusion processes. Specifically, both cases were characterized by horizontal and vertical struggles as seen by attempts to define the technology in ways that favored particular actors and by strategic behavior aimed at mobilizing material resources, authority and expertise to ensure desired outcomes.

If the benefits of a technology are obvious, multiple and, more importantly, are aligned with interest and values of an adopting system (Denis, Hébert et al. 2002), diffusion occurs in such a way that efforts to stop the bandwagon generated by strong incentives may be difficult. The label bandwagon technology has been used to characterize a technology which cannot be stopped from diffusing because of the perceived benefits it generates for powerful actors despite system-wide economic considerations. My cases suggest that bandwagon technology diffuses not only because it is perceived as technically efficient (Rogers 2003) or fashionable (Abrahamson 1991), but because adopters may derive benefits in various ways ranging from gaining competitive advantage in terms of profit, positioning or attracting different resources to strengthen their legitimacy or prestige. The next section explores how my results confirm the literature on institutional logic.

\subsection{MulTIPLE INSTITUTIONAL LOGIC}

The study of the health care systems in Quebec and Switzerland suggests that both institutional environments are composed of multiple co-existing institutional logics thereby indicating that organizational fields may be more complex than what is often documented in empirical studies. In Quebec, actors relied on logics of quality, access and efficiency to build their theorization, and in Switzerland the logics of quality, market and efficiency were mobilized. Although my results are at the organizational field level, they empirically confirms the theoretical work of Friedland \& Alford (1991) and of Boltanski and Thévenot (1999) which states that societies are composed of multiple institutional orders, each with its own institutional logic.

However, the majority of empirical works on institutional logic simplify the institutional environment by assuming that one institutional logic dominates at a time (DiMaggio 1988; Kitchener 2002; Lounsbury 2002; Thornton 2002; Reay and Hinings 2005). For example, Thornton and Ocasio (2002) show how professional-based 
organizational structure adopted divisionalized organizational forms in higher education editing as a consequence of a shift from an editorial-based to a marketbased dominant institutional logic. In a similar way, Kitchener (2002) argues that the mergers of academic health-care centers in the US is the fruit of a shift in dominance from a professional-based logic to a market-managerialism-based institutional logic. However, few empirical researches focused on the influence of multiple institutional logics at the organizational field level. Instead of conceptualizing institutional environment as being stable and homogeneously affected by dominant institutional logics, they assume that the institutional environment is heterogeneous and composed of multiple constituencies. For example, Lounsbury's (2007) results indicate that competing institutional logics can affect practices in the mutual funds industry, but that diverse logics dominate different geographical areas. The effort of Zilber (2006) is also impressive as she documented the interrelationship between multiple institutional logics at the societal level and their impact at the organizational field level. Finally, the concept of institutional pluralism goes one step further in the complexity of institutional environment by suggesting not only to integrate multiple institutional logics, but also to simultaneously take into consideration the logics, norms and regulation (Kraatz and Block 2008).

Closer to my result is the work of Scott (2000) who segments the evolution of the health care system of the San Francisco Bay area into three eras; each with its own dominant institutional logic. Chronologically, the domination of the professional logic of quality was subordinated to the logic of equity of access when the State institutionalized this logic. Then, with the explosion of health care costs, a marketmanagerial institutional logic emerged and prevailed. Thus, Scott et al. (2000) recognizes the co-existence of multiple institutional logics, but in each era one logic dominates the others.

In opposition to Scott et al. (2000) who mingled efficiency-based and market-based institutional logics, this study suggests that these two logics are clearly distinct as indicated also by Boltanski and Thévenot (2006). While market logics insist on the importance of freedom to compete according to instrumental interests, efficiencybased institutional logics give precedence to efficiency and economy, things that are not necessarily guaranteed by a market perspective as shown by my results in the previous chapter. Given that this study compares the same type of economic activity (i.e., the health care sector), one interesting corollary is that identical economic sectors in different countries can carry different institutional logics affecting the content of the rhetorical field. 
Thus, this study suggests that not only institutional environments are more complex than institutional theory usually assumes, but that identical contemporary economic activities may be grounded in different institutional logics and that the dominant institutional logic may be related to a specific sector of activity or object within an organization field. Having recognized that institutional environments are composed of multiple institutional logics, the next section shows how this thesis contributes to the literature on institutional logics.

\subsection{INSTITUTIONAL LOgiCS AS CONSTRAINING THEORIZATION AND ENABLING LEGITIMACY}

If institutional environments are composed of multiple institutional logics, what are their impacts on the behaviour of actors? My results show that institutional logics structure the institutional field by restraining the rhetorical possibilities for actors to gain legitimacy for themselves or to provide legitimacy to a technological innovation (see proposition 2). Hence, actors cannot spontaneously elaborate theorizations which are not deeply embedded in their institutional environment without imperilling the legitimacy of their claims. Consequently, actors' theorizations are constructed within institutional logics because these provide the criterion of legitimacy (Suddaby and Greenwood 2005). In my cases, struggles for meaning were always embedded in the mix of institutional logics (Scott, Ruef et al. 2000) which underpinned the different health care systems. For example, the most intensive struggles for meaning in Quebec involved competing theorizations about quality of care and equity of access. In contrast, in Switzerland, struggles for meaning developed around rights to compete in a free market (and profitability) and quality of care. Given that the market institutional logic has been an institutional taboo in the Quebec health care system, institutional actors did not mobilize this logic in this particular institutional field.

The constraining effect of institutional logics has been documented in different contexts. They are recognized to shape actors' cognition (Thornton and Ocasio 1999), to define the source of power (Friedland and Alford 1991), to provide interpretive schemas (Ranson, Hinings et al. 1980; Barley 1986) and to sculpt organizational action and behaviour (Friedland and Alford 1991). While a previous study indicated that institutional logics shape discourse (Glynn and Lounsbury 2005), my results show specifically that, although institutional logics do constrain actors' theorization, at the same time the multiplicity of institutional logics allows actors to select one which better serves their interest out of the pool of alternatives. This implies that actors may 
have much more freedom to act according to their interest than is assumed by the theory that prevailing institutional logic and institutional pressures force actors to bow to adapt to the iron cage (Meyer and Rowan 1977; DiMaggio and Powell 1983).

Thus, in their struggles for meaning, institutional actors in my cases were instrumentally selecting logics that were aligned with their interests in order to provide legitimacy for the technology and to justify themselves for adopting it (see proposition 2). In their struggles for meaning, actors manipulate institutional logics in order to generate a "generalized perception or assumption" that the adoption of the technology by an entity was "desirable, proper, or appropriate within some socially constructed system of norms, values, beliefs, and definitions" (Suchman 1995: 574). Therefore, struggles for meaning that I observe are indeed a struggle for legitimacy.

Since the seminal paper of Meyer and Rowan (1977), institutionalists argue that organizations must conform to their institutional regime or moral imperatives in order to gain legitimacy and derive material resources. Thus, legitimacy can itself be a resource for organizations (Meyer and Rowan 1977; DiMaggio and Powell 1983; Tolbert and Zucker 1983). Different strategies of acquiescence have been identified, ranging from following taken-for-granted norms, imitating organizations or complying with rules (Oliver 1991) to selecting the environment with which to conform (Suchman 1995). By selecting an institutional logic to gain legitimacy, institutional actors in Quebec and Switzerland are being agents who decide with which part of their institutional environment they comply with. Because institutional logics are normative elements, selecting these logics signal actors' conformance to specific norms and allow organizations to gain legitimacy.

Whereas organizational legitimation processes have been extensively studied (Aldrich and Fiol 1994; Suchman 1995; Suddaby and Greenwood 2005; Vaara, Tienari et al. 2006; Deephouse and Suchman 2008; Scott 2008), the way technology gains legitimacy has been documented only rarely. Hargadon \& Douglas (2001) suggest that Edison relied on existing installation such as gas lighting for electricity to gain acceptance in the public. Thus, referring to an institutionalized technical system is a strategy to legitimize innovations. Leblebici (1991) shows how actors were trying to legitimize and control radio frequencies through the use of analogies (i.e., public school system, magazine in the air or waterways) which refer to existing institutions. Munir \& Phillips (2005) demonstrate that legitimating new technologies involved discursive battles between incumbents who were engaged in legitimating the chemical-based technology, while new entrants who were trying to introduce the digital-imaging technology were striving to legitimate it by grounding it in existing institutions. While some studies 
demonstrate that legitimacy can be provided to technology by connecting it to shared cultural understanding (Strang and Soule 1998), my work contributes to these by showing how institutional actors mobilized institutional logics for legitimating the diffusion and adoption of technology, and by illustrating how struggles for meaning and struggle for control affect the diffusion of bandwagon technology.

These struggles for meaning are echoed in the literature where legitimation processes are often found to be characterized by socio-political struggles (Munir and Phillips 2005; Suddaby and Greenwood 2005; Vaara, Tienari et al. 2006). For example, Vaara et al. (2006) point out that the legitimation processes involve contradictions and ambiguities which are exploited by institutional actors to legitimize industry restructuration. Rivalry in legitimating new institutional order also resonates in the work of Suddaby and Greenwood (2005). They found that contradictions between institutional logics are resources on which actors rely in their attempts to deconstruct or reiterate institutional logics. Thus, exploiting contradictions between and within institutional logics is the main mechanism used by institutional entrepreneurs to bring about a shift in institutional logics and it is also the tool used by opponents to hinder any attempt at institutional change.

In the same manner, my study shows that legitimation processes may be highly competitive, may entail that some organizations are more legitimate than others depending on who is winning struggles, and are heterogeneous as not all organizations are affected in the same way by their institutional environment due to the multiplicity of institutional logics. Thus, legitimacy does not appear to be fundamentally non-rival, dichotomous and homogenizing as Deephouse and Suchman (2008) suggest. While these authors view legitimacy as a property, I conceptualize it as a process (Tolbert and Zucker 1996). These two dimensions of legitimacy cannot be split since legitimacy can be lost through delegitimation. Thus, legitimacy is not a stable property, but something that has to be constantly reiterated and maintained, and this path may be fraught with pitfalls.

Selecting institutional logics to generate competing theorizations that provide legitimacy might not be sufficient for struggles for meaning to take place. In their theoretical work, Phillips et al. (2004: 643) emphasize that texts are more likely to be embedded in the discourses of actors, "who have a legitimate right to speak, who have resource power or formal authority, or who are centrally located in a field". My results echo this assertion by showing that actors who theorize are, on the one hand, doctors having an expertise in nuclear medicine and, on the other, the government having authority to deal with the adoption of technology. This provides an indication that not 
all actors can pose a serious threat to established institutional orders and not all actors can be involved in struggles for control and struggles for meaning. Only those who are sanctioned by the governance structure and have power in the form of expertise, authority or material resources can intervene in such matters.

While actors can select from a pool of various institutional logics to build their theorizations and in the meantime they do constrain actors' choice in terms of the type of justification that are available to them, they can also mobilize different arguments within the same institutional logic as we should see in the next section.

\subsection{Competing Theorizations Within The SAME INSTITUTIONAL LOGIC}

Competing institutional logics have received considerable attention in the literature (Thornton and Ocasio 2008). However, the way institutional logics can be interpreted in different ways in the literature comes under label of the "translation" perspective. From this view, agents interpret and adapt logics to their local settings (Czarniawska and Joerges 1996; Creed, Scully et al. 2002; Zilber 2006).

In my cases, the institutional logic of quality was mobilized within competing theorizations in different innovative manners within and across organizational fields (see proposition 2). In Switzerland, actors interpreted the quality-based institutional logic according to their interests. Indeed, while professionals were invoking the performance of the technology as being the organizing principles underlying the diffusion of the PET scanner, the government was pushing for patient management as being the good organizing principle that should support the diffusion of this technology. In Quebec, a hospital was relying on the number of studies in cardiology while its competitor built its theorizations on the number of applications in oncology in order to demonstrate that the technology was more legitimate (effective in this case) in this discipline.

These examples suggest that institutional logics are not unambiguous rigid constructs. Rather, they are unstable and ambiguous constructs which may be interpreted in different ways through various theorizations. While actors are all talking about quality in health care systems, this organizing principle is interpreted differently by each actor in order to promote its own interests. This is closely related the concept of translation which relates to the interpretation of cultural accounts (Czarniawska and Joerges 1996; 
Creed, Scully et al. 2002; Zilber 2006). This brings me to the issue of agency in the diffusion of innovations.

These cases confirm that institutional actors are also institutional carriers (Scott 2008). Indeed, by mobilizing the logics, institutional actors reproduce different institutional orders and contribute to maintaining the legitimacy of institutional logics. My results support the recent claim (Zilber 2002) that actors are not simply passive in the diffusion process as was assumed in the early development of the neo-institutional theory, but are actively involved in legitimizing their position in the system and defining the technology by mobilizing arguments that are legitimate in the environment (Greer 1988; Greer 1994). Indeed, actors are not mere passive reproducers of institutions they are also active interpreters and meaning providers (Zilber 2002). While institutions define power, interests and rationality, they also enable actors to manipulate institutional logics to their benefit (Friedland and Alford 1991). However, in my cases, actors mobilized institutional logics not to transform institutions, but to gain the necessary legitimacy to win struggles for meaning and struggles for control over technology. Thus, my study suggests that institutional actors are deeply aware of the institutional logics that shape their environment and have enough freedom to manipulate theorizations in order to embed them in dominant logics. This implies that agents are not only aware but also intelligent at manipulating symbols, discourse and legitimation processes.

This strategic behavior of actors also resonates with the socio-political perspective which places agency at the centre of the scene. I concur with the view that actors whose interests and values correspond to the benefits and risks of a technology are more prone to adopt it (Meyer and Goes 1988; Denis, Hébert et al. 2002). However, my results extend this view in at least two respects. Firstly, the socio-political perspective tends to focus more on power, dominance relations, interest and values (Denis, Hébert et al. 2002) and do not consider elements such as theorization, institutional logics or struggles for meaning in the diffusion of complex innovations. Since my analysis suggests that legitimation processes play a role in the diffusion of complex innovations, my work contribute to the socio-political perspective by shedding light on legitimized meanings and on the rhetorical dimension of diffusion; although the diffusion of innovation was largely influenced by the capacity of actors to act without the consent of the government or by challenging the government through institution testing. Second, it extends this approach by highlighting that the governance structure has to be included in analysis since it defines who can 
legitimately enter into political struggles. The next section addresses issues related to the coherence and fragmentation of the governance structure.

\subsection{COHERENCE AND Fragmentation OF THE GOVERNANCE STRUCTURE}

The notion of coherence and fragmentation of the institutional environment characterizes the degree of structuration of an organizational field (DiMaggio and Powell 1983). For DiMaggio \& Powell (1983) this notion is mainly related to the connectedness between the totality of relevant institutional actors in a given field, i.e. 1) the extent of interaction between actors; 2) the presence of sharply defined interorganizational structures; 3) readily available information; and 4) the development of mutual awareness. These four indicators of structuration or cohesion are shaped by three homogenizing forces which are coercion, imitation, and professional norms. While these authors focused on the inter-organizational aspects of the structuration of an organizational field, Scott (2004) added three dimensions of the structuration of a field ${ }^{45}$ by focusing on the governance structure. According to him, funding centralization, unity of governance and public/private modes of governance influence the coherence of a field. Scott et al. (2000) provide an example of the fragmentation of a health care system in the San Francisco Bay Area. These writers mentioned that the development of medicine engendered the emergence of various specialties forming new medical associations which started competing with each other, thereby creating competing norms and in consequence an increasing fragmentation of this health care system. Extending this reasoning to governance structure, we can assume that fragmentation increases as it is characterized by various funding sources, multiple levels of governance (i.e. accountability is diffused) and shared funding between private and public sources.

In my cases, I observed a higher rate of diffusion in Switzerland than in Quebec probably because the former is more fragmented than the latter. This higher rate does not appear to be peculiar to the PET scanner and is thus unlikely to be merely idiosyncratic. Indeed, the higher number of MRI and CT scanners (see table 3.6) in Switzerland suggests that the diffusion pattern of the PET scanner may reflect struggles and opportunistic behaviors that may be generalized to other technologies.

${ }^{45}$ Scott (2004) adds a further dimension of the coherence of a field, namely the consensus in institutional logics. This dimension does not concord with our observation that many institutional logics can co-exist in an institutional environment and that consensus appears to be unlikely. 
In Switzerland, the higher degree of fragmentation of the governance structure in financial accountability and in availability of public and private regimes allows more freedom and regulative slack to institutional actors which enabled them to select the regime they wanted in order to accelerate adoption (proposition 3). The more fragmented picture of the Swiss governance structure contrasts with the more coherent governance structure of Quebec where decision-making and financial processes involved in the adoption of complex technology are largely centralized. In this case, the coherence of the governance structure restricted the diffusion of the PET scanner, at least in the short term, because authorities had financial incentives, and the power, to keep control over this technology (see proposition 4). Thus, it appears that both fragmentation and an environment conducive to competition facilitate the diffusion of innovation: if the former generates a higher number of opportunities for eluding government restrictions, the latter provides incentives.

Some health economists echoed this concept of fragmentation in terms of an increased participation of private funding, private insurance, and private delivery which is expected to lower controls in health care systems and implicitly to diminish the efficiency of the system. As Evans (1984: 336) remarks:

\footnotetext{
"Canadian past and United States present experience with multiple funding sources, mixed public and private insurance and self-pay, suggests that such a shift [dismantling Medicare i.e. universal coverage administrated by the State] would significantly redistribute wealth from ill to well, high-risk to low-risk people, and patients to providers. It would probably expand the volume of services provided, while making access more dependent on income. The key thing it would not do, however is constrain expenditure. It would not answer the question of how much to spend, other than by the professionals' answer more."
}

Thus, dismantling the centralized Medicare program is equivalent to increasing fragmentation by encouraging the provision of care, health insurance and funding through private sources. Although not directly invoking the impact of private participation on the diffusion of medical innovations, Evans' thoughts suggest that abandoning this centralized program may encourage opportunistic behavior from professionals.

Besides increasing the diffusion rate of innovation, fragmented governance structure seems to be less efficient in the use of expensive and complex technology. Indeed, given the number of PET scans in each jurisdiction, it is apparent that the number of scans per machine is lower in Switzerland than in Quebec. As demonstrated in the previous chapter, this implies that Switzerland under-uses its machines, with the consequence that health care costs are unduly increased by the duplication of services 
(Robinson, Garnick et al. 1987; Dranove, Shanley et al. 1992; Dranove and Satterthwaite 2000), as the result of a medical arms race (Foote 1992; Dranove and Satterthwaite 2000).

My results on the higher rate of diffusion and the lower efficiency in the use of technology of fragmented governance structure echoes the work of health economists who claim that more centrally governed health care systems are more effective in controlling costs than more market-based health care systems (Intignano 2001). Hence, my observations may serve as a hologram of what happens at a macro level. Indeed, fragmented health care systems such as those in the USA (15.0\%), Switzerland $(11.5 \%)$ or Germany $(11.1 \%)$ have the tendency to show higher health expenditure as a share of GDP than centralized health care systems such as those in the UK $(7.7 \%)$ or Canada (9.9\%) (OECD 2006).

Having described in the first sections how institutional logics constrained and enabled actors and how the degree of coherence of the governance structure affected actors' behavior, the next section explores how governance structure and institutional logics interact through institutional testing.

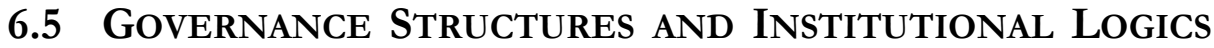 Aligned THROUGH INSTITUTION TESTING}

Beyond the pragmatic issue of the spread of technological innovations, the approach and findings of this study have some broader implications for institutional theory. The study shows how institutional structures and meanings may manifest themselves in the context of specific decisions within an organizational field. The particular decisions considered here required interactions and negotiations among multiple institutional agents embedded within the same environment. Thus, the type of analysis conducted in this study could be extended to multi-agent decisions in other institutional settings concerned with similar or different kinds of economic activity. Specifically, I argue that governance structures influence these processes by determining the patterns of material resources and authority available to actors in their struggles for control over decisions that concern them, while institutional logics constitute the discursive resources on which agents may legitimately and creatively draw to give meaning to their actions.

My results show that the making of meaning through theorization was an important activity. While meaning systems are indeed crucial in institutional analysis, I argue with 
Scott (2008) that attention should also be paid to the structural arrangements surrounding and supporting them and to the multiple ways in which institutional logics and governance structures interact. This interrelation (between governance structures and multiple institutional logics) in these health care organizational fields generated both struggles for control and struggles for meaning within and between institutional logics. The nature and outcomes of these struggles, as well as the way in which they are resolved (through discourse or through the mobilization of material resources) may provide hints as to the direction of future institutional shifts or institutional maintenance. I now identify the possible implications of the study for institutional maintenance and institutional change.

In this study, I focused mainly on how institutional environments influenced the dynamics of technology diffusion rather than on how these processes might eventually influence institutional environments. Yet the phenomenon of institution testing identified in both Quebec and Switzerland where entrepreneurial actors contested existing regulatory constraints (through unilateral action in one case and legal challenge in the other) suggests that there are potential reciprocal influences.

In these particular cases, the underlying normative and cultural-cognitive legitimacy of the institution testing actions ultimately overruled regulatory legitimacy (see proposition 5). Faced with a contest they felt they could not win, government actors quickly adjusted regulatory constraints to realign them with dominant institutional logics, preserving rather than fundamentally changing underlying belief systems and governance structures. Thus the process of institution testing and adjustment described here largely reproduced the institutional order.

In the literature, entrepreneurial actions which contest institutions in order to create new or transform extant institutions have generally been labeled institutional entrepreneurship (DiMaggio 1988; Maguire, Hardy et al. 2004). Institutional entrepreneurs mobilize meanings and material resources and engage in battles over practices, resources and meaning in order to create, disrupt or transform institutional orders (Hardy and Maguire 2008). I believe that the connotations of this term are too strong for it to reflect the kinds of institution testing which I have observed.

Although they were entrepreneurs in the sense of proactively pushing back regulatory boundaries, the people involved seemed motivated more by the short-term instrumental goal of acquiring a technology, than by a determination to disrupt institutions. Nevertheless, through their strategic actions and their theorizations, they were - though perhaps unwittingly - doing a form of "institutional work" (Lawrence 
and Suddaby 2006) which had the potential to generate incremental institutional adjustment. So, too, were the government actors who moved to preserve the integrity of their regulations (and their own credibility) in the face of this testing. Institution testing and institutional work share similarities in that they assume actors are culturally competent and are being aware, skilful, and reflective (Lawrence and Suddaby 2006) enough to mobilize meaning to their advantage. Like institutional entrepreneurs, institutional testers can construct legitimacy by adapting the innovation to wider cultural accounts (Hargadon and Douglas 2001).

In their typology of institutional work, Lawrence and Suddaby (2006) distinguish between actions which aim at creating, maintaining or disrupting institutions. Each of these dimensions of institutional work is composed of various forms of mechanisms. For example, advocacy and educating are two forms of institutional effort which are associated with the creation of institutions; enabling work and policing encourages the maintenance of institutions; and disconnecting sanctions or dissociating moral foundations are related to the disruption of institutions (Lawrence and Suddaby 2006). The assumption behind these mechanisms is that there is a political drive (DiMaggio 1988; Oliver 1991) which explains the dynamic and change of institution and it is in this trend of institutional theory that my contribution lies.

In my cases, institution testing took the form of unilateral action in Quebec and legal challenge in Switzerland. Both of these actions are strategic responses to institutional processes which defy, challenge or contest rules (Oliver 1991). While this behavior can be associated with the disruption of institutions (Lawrence and Suddaby 2006) or deinstitutionalization (Oliver 1992), it can also contribute to the maintenance of institutions as long as the government, when confronted with institution testing, responds by incrementally adjusting its regulations to fit the new configuration generated. This readjustment behavior is thus a mechanism that reproduces institutions. This form of contest has to be distinguished from enabling work which refers to "the creation of rules that facilitate, supplement and support institutions" (Lawrence and Suddaby 2006: 230) and is typically associated with the creation of roles or agencies having the responsibility to ensure the ongoing legitimacy of institutions (Leblebici, Salancik et al. 1991). If enabling work and readjustment serve the same type of objectives i.e. they both preserve the integrity of rule systems, the former fulfils this role through coercion and by reinforcing rules, for example, by creating new institutional components such as agencies, while the latter adapts the rule system in order not to lose face. Thus, altogether institution testing and readjustment 
complements the typology of institutional maintenance proposed by Lawrence and Suddaby (2006).

I suggest that episodes of institution testing and adjustment at the margins constitute one mechanism by which institutional frameworks may be stretched, reproduced and ultimately redefined in an organic and gradual manner as concrete problems and controversies succeed one another. Such a perspective contributes a much needed dynamic and recursive element to institutional analysis (Scott, 2008; Lawrence and Suddaby, 2006). In other words, while struggles for meaning and struggles for control surrounding specific issues within an organizational field clearly reflect the institutional contexts in which they are embedded, they may also contribute to the recursive reproduction and adaptation of those contexts, especially when the boundaries of legitimate struggle are tested.

We have seen that institution testing is a form of contestation which combined with readjustment constitutes a key mechanism for aligning governance structures with dominant institutional logics. However, the antecedents and conditions for institution testing need further explanation. Examining the common variables in both cases, it appears that the technology was legitimized and it was associated with powerful incentives to create a bandwagon which was stronger than regulatory forces (proposition 5). Besides having strong incentives and a legitimate and sufficiently mature technology, the availability of financial resources and the absence of sanctions were characteristics in both cases. The absence of sanctions and the divergence between the prescription of the governance structure and interests of would-be adopters are also factors recognized in the literature as being part of the repertoire of deviant behavior using defiance responses to institutional pressures (Oliver 1991).

Merton (1957 (1949)) suggested that deviant behaviours can emerge from the rejection of legitimate means, legitimate cultural goals, or both. In the case of Quebec, institution testing is closer to what Merton calls innovation as the institutional means to obtain the technology was not legitimated. However, this way of categorizing deviant behaviour and institution testing does not hold for Switzerland. In this jurisdiction, institution testers used institutionalized means and had legitimated goals, but were still testing the governance structure. Their contestation consisted in mobilizing institutional logics against the governance structure. By showing that even when means and goals employed by actors are institutionalized, the multiple logics of legitimation available in the environment allows contestation to occur, which ultimately may stretch, reproduce, redefine or test institutional frameworks. 
Over time, such contests can lead to more fundamental change if deinstitutionalization of some rules in favor of others occurs. Thus, one might hypothesize that in future, institution testing will be easier since there are successful precedents which have been tolerated and which make this type of action more acceptable. As Lawrence and Suddaby remark (2006: 232):

“...without such [institutional] work, the coercive foundations for institutions are likely to crumble, becoming empty threats or promises rather than selfactivating means of institutional control."

Hence, it is possible that in time such institution testing leads to more profound shifts not only in structures but also in institutional logics. Moreover, institutional change engendered by institution testing is more likely to appear if there is no external sanction (Oliver 1991). For example, the fragility of the government's stance in blocking technology adoptions in the Quebec health care system is starkly revealed by this case study. This is similar to the institutional work of disconnecting sanctions which is associated with disrupting institutions (Lawrence and Suddaby 2006).

\subsection{Limitations, Directions for Future Research AND PRACTICAL IMPLICATIONS}

It would be inappropriate to judge this type of inductive work using deductive criteria. However, generalization is always at the hub of qualitative research debate. While inductive study can make theoretical generalization (Yin 2003), statistical generalization is not realistic. Consequently, the conclusions of this research do not have the pretentiousness to be applicable to the diffusion of all innovations, although it certainly finds an echo in the diffusion of expensive diagnostic medical technology such as MRI and CT scanners. Furthermore, the dynamics of contestation and readjustment can probably be observed in many other situations where institutional actors mobilize institutional logics for purposes of self-interest to make governments bow before demands from different stakeholders. As Tuohy (1999: 116) remarks:

\footnotetext{
"In very broad terms, state actors function within systems in which those in command ultimately are dependent upon political support and therefore seek to accommodate a range of interests and opinions sufficient to maintain a coalition of support."
}

Thus, although such generalizations must be made with circumspection, I suspect that this study reflects a multitude of situations engaging actors competing for scarce 
resources and, more importantly, it calls for more research on the struggles for meaning and for control.

One strength of this comparative study is the similarity of the size of the population and life expectancy in both jurisdictions. This resemblance renders the comparison attractive. Although I strictly follow the traditional guidelines of scholars in qualitative analysis and case studies (Eisenhardt 1989; Langley 1999; Patton 2002; Yin 2003), comparing two jurisdictions necessarily entails differences that may have colored the dynamics of the diffusion of innovations. For example, one major difference between jurisdictions is the size of their territory. In Quebec, the distances between centres are huge. This may have influenced struggles for meaning and the type of theorization privileged by actors. The stronger financial capacity of Switzerland may also have impacted on the diffusion pattern of the PET scanner. This capacity might have been translated into a wider and faster diffusion of the PET scanner. Nevertheless, since strong vertical struggles were observed between the governments and professionals and actors relied on strategies to bypass regulations in both cases, it seems that the difference in financial capacity does not invalidate my results.

Participation in interviews was excellent. Only one person in each jurisdiction refused to be interviewed. Given that many interviewees had Swiss German as their mother tongue, language was one of the main issues affecting interviews surrounding data collection. Indeed, the use of English might have impoverished their narrative. Also, the translation of narratives from French speaking interviewees to English may contain some imperfections. Despite this limitation, interviews and narratives were of sufficiently good quality to generate valid theory.

Directions for future research. This thesis is one of the few studies which considers how a wide range of institutional logics affects the struggle for meaning involved in the diffusion of innovations. In my view, more research on how institutional environment affect the diffusion of different types of innovations is required. Finer-grained analysis is further needed to achieve a better understanding of how different institutional logics may clash in competing theorizations. While the fragmentation of the governance structure is somehow the corollary of multiple competing institutional logics, scholars have been more inclined to study institutional change and institutional logics. Clearly, the literature shows important deficits as to the study of the impact of fragmentation of governance structure and institutional logics on the diffusion of innovations. Further study of the interaction between governance structure and institutional logics is also necessary. Although studies on the structuration of organizational fields have been made, much more work is required in this direction. 
While this thesis answers the call from scholars to investigate further the role of the institutional environment on the diffusion of innovation in health care (Fitzgerald, Ferlie et al. 2002; Greenhalgh, Robert et al. 2004; Gelijns, Brown et al. 2005), the wide variety of jurisdictions, governance structure, institutional logics, and institutional actors can produce different patterns of negotiation and diffusion and these would also need to be documented.

The legitimation of technology is also clearly under-studied. With only few exceptions (Leblebici, Salancik et al. 1991; Hargadon and Douglas 2001; Munir and Phillips 2005), legitimation as a discursive strategy would need much more attention from scholars. I also rejoin Lawrence and Suddaby (2006: 234) who claim that most of the institutional literature focuses on institution diffusion and that few scholars have investigated institutional maintenance. This issue needs also more study.

Consequently, more work is required on institution testing. While contestation and readjustment constitutes one key mechanism behind institution maintenance, more studies are needed to observe how this mechanism play out in other settings. Furthermore, antecedents of institution testing deserve more attention from researchers. More cases have to be explored to identify the characteristics of institution testers, and under which conditions this behavior appears.

Practical implications. Given that struggles for control and struggles for meaning seems to be inherent to the diffusion of expensive and complex innovations, governments could invite organizations to submit proposals in order to better identify which technology should be bought and by whom. This would allow interested hospitals to elaborate arguments to convince the government that they should be the recipient of a specific technology and it may also help government to establish priorities. Another avenue could be to involve different stakeholders (doctors, insurance companies, patients, government) in the decision process to adopt different technology. Clinical and economic criteria could be elaborated to assess the state of evidences related to specific innovations. If these criteria are not met, reimbursement of procedures involving this technology should not be granted.

Regulations like certificate-of-need should also be harmonized and embrace both the private and the public sector. As long as regulations are not harmonized, actors will always prefer to operate where they can derive more benefits. Moreover, my cases clearly show that the absence of sanction is a signal that institutional actors can act in their own interest without suffering negative consequences. Therefore, it is clear that without sanctions authorities cannot control or encourage the dissemination of 
innovations in a rational way. These practical implications for authorities can clearly contribute to better control the sometimes chaotic diffusion of innovations and as a consequence decrease unjustified health care expenditure.

\subsection{CONCLUSION}

In this thesis, I have examined the diffusion process for a bandwagon technology, the PET scanner - a complex medical technology -, in two different health care systems, one of which is more market-oriented and the other more centrally managed by a public agency. I find that diffusion proceeded more rapidly in Switzerland than in Quebec, but that processes in both jurisdictions are characterized by intense struggles among providers and between providers and public agencies.

While governments in both jurisdictions tried to manage the diffusion process, intense bandwagon pressures undermined these attempts, though in different ways. For example, in Switzerland, public hospitals found innovative ways to bypass opposition from cantonal authorities by creating private initiatives and collaborations where different rules applied. In Quebec, government inertia prompted one teaching hospital to adopt the technology without official government consent. The forms of strategic behavior used by adopters can also be related to institutionalized value systems. In Quebec, the high legitimacy of quality-of-care considerations established by the health technology assessment report was sufficient to override regulatory constraints, rendering institution testing possible. In Switzerland, shared beliefs in the values of the free market contributed to legitimizing the behavior. In both cases, the normative legitimacy of the technology and powerful incentives that were associated with it were sufficient to override regulatory forces.

My results suggest that the institutional environment influences these processes by determining the patterns of material resources and authority available to actors in their struggles to control the technology strategically, and by constituting the discursive resources or institutional logics on which actors may legitimately draw in their struggles to give meaning to the technology in line with their interests and values. This reasserts that attributes of technology are not the only determinants of diffusion (Munir and Phillips 2005), but that the whole spectrum of interests surrounding diffusion has to be considered (Denis, Hébert et al. 2002; Fitzgerald, Ferlie et al. 2002). This study shows how institutional structures and meanings manifest themselves in the context of specific decisions within an organizational field, and reveals the ways in which governance structures may be contested and realigned when 
they conflict with interests that are legitimized by dominant institutional logics. It was argued that this form of contestation, that I call institution testing, and readjustment at the margins constitute one mechanism by which institutional frameworks are tested, stretched and reproduced or redefined.

In order to understand the dynamic of institutional environment and its impact on diffusion, cultural and structural elements have to be taken into account (Scott 2008). While the former provide interpretive schemas (Ranson, Hinings et al. 1980; Barley 1986), the latter define the position and power of actors in a given organizational field. If I had considered only structural elements, my results would have suggested that only the position of actors in the systems matter and I would have concluded that the adoption by small private clinics, which opened up the diffusion, was idiosyncratic to this case. By considering only cultural elements, I might have wrongly concluded that institutional logics alone are sufficient to explain the dynamics of the diffusion of innovations.

Overall, the study shows that institutional contexts do indeed influence the patterns of diffusion and adoption of technologies through their impact on decision structures and available meanings. However, the underlying pressures for adoption associated with the bandwagon technology remain, giving rise to intense vertical and horizontal struggles whose form and outcomes may change but whose processual dynamics are remarkably similar. 


\section{REFERENCES}

Abrahamson, E. (1991). "Managerial Fads and Fashions: The Diffusion and Rejection of Innovations." Academy of Management Review 16(3): 586-612.

Adams, E. J., C. Almazan, et al. (2006). "Joint project of the International Network of Agencies for Health Technology Assessment - Part 2: Managing the diffusion of positron emission tomography with health technology assessment." International Journal of Technology Assessment in Health Care 22(2): 149-154.

Aldrich, H. and M. Fiol (1994). "Fools rush in? The institutional context of industry creation." Academy of Management Review 19: 645-670.

Alexander, J. A. and T. A. D'Aunno (2003). Alternative perspectives on institutional and market relationships in the U.S. health care sector. Advances in health care organization theory. S. S. Mick, Wyttenbach, M.E. San Francisco, Jossey-Bass: 45-77.

Allison, G. T. (1971). Essence of decision: Explaining the Cuban missile crisis. Boston, Harvard: Harper Collins Publishers.

Arndt, M. (1995). "The Adoption of Corporate Restructuring by Hospitals." Hospital and Health Services Administration 40(3): 332-347.

Barley, S. R. (1986). "Technology as an occasion for structuring: evidence from observations of CT scanners and the social order of radiology departments." Administrative Science Quarterly 31(1): 78-108.

Barley, S. R. and P. S. Tolbert (1997). "Institutionalization and structuration: Studying the links between action and institution." Organization Studies 18(1): 93-117.

Boltanski, L. and L. Thévenot (1999). "The sociology of critical capacity." European Journal of Social Theory 2(3): 359-377.

Boltanski, L. and L. Thévenot (2006). On Justification: Economies of Worth, Princeton University Press.

Callon, M. (1987). The sociology of an Actor-Network: The case of the electric vehicule. Mapping the dynamics of science and technology. M. Callon, J. Law and A. Rip, MacMillan: 19-34. 
Cetindamar, D. (2001). "The role of regulations in the diffusion of environment technologies: Micro and macro issues." European Journal of Innovation Management 4(4): 186-193.

Champagne, F., J.-L. Denis, et al. (1991). "Structural and political models of analysis of the introduction of an innovation in organizations: The care of the change in the method of payment of physicians in long-term care hospitals." Health Services Management Research 4(2): 94-110.

Chou, S.-Y., J.-T. Liu, et al. (2004). "National health insurance and technology adoption: Evidence from Taiwan." Contemporary Economic Policy 22(1): 26-38.

Christensen, C. M., R. Bohmer, et al. (2000). "Will Disruptive Innovations Cure Health Care?" Harvard Business Review: 102-112.

Cleemput, I., C. Camberlin, et al. (2008). "Methodology for calculating a country's need for positron emission tomography scanners." International Journal of Technology Assessment in Health Care 24(1): 20-24.

Cohen, W. M. and R. C. Levin (1989). Empirical studies of innovation and market structure. Handbook of Industrial Organization. R. Schmalensee and R. D. Willig. Amsterdam, Elsevier Science Publishers B.V. II.

Coleman, J. S., E. Katz, et al. (1966). Medical innovation: A diffusion study. New York, Bobbs-Merrill.

Creed, W. E. D., M. A. Scully, et al. (2002). "Clothes make the person? The tailoring of legitimating accounts and the social construction of identity." Organization Science 13(5): 475-496.

Crozier, M. and E. Friedberg (1977). L'acteur et le système. Paris, Editions du Seuil.

Cutler, D. M. and Huckman (2003). "Technological development and medical productivity." Journal of Health economic 22(2): 187.

Cyert, R. and J. G. March (1963). Behavioural theory of the firm. Englewood Cliff, NJ, Prentice-Hall.

Czarniawska, B. and G. Joerges (1996). The travel of ideas. Translating organizational change. B. Czarniawska and G. Sevon. Berlin, de Gruyter: 13-48.

Damanpour, F. (1991). "Organizational innovation: a meta-analysis of effects of determinants and moderators." Academy of Management Journal 34(3): 555-590.

Deephouse, D. L. and M. C. Suchman (2008). Legitimacy in organizational institutionalism. The SAGE Handbook of Organizational Institutionalism. R. Greenwood, C. Oliver, K. Sahlin and R. Suddaby. London, Sage Publications.

Denis, J.-L., L. Lamothe, et al. (2003). Templates and Pilots in the Framing of Public Sector Reform. European Group for Organization Studies, Copenhagen, cc.

Denis, J.-L., A. Langley, et al. (2007). "Strategizing in pluralistic contexts: Rethinking theoretical frames." Human Relations 60(1): 179-215. 
Denis, J. L., Y. Hébert, et al. (2002). "Explaining Diffusion Patterns for Complex Health Care Innovations." Health Care Management Review 27(3): 60-73.

Denis, J. L., L. Lamothe, et al. (2001). "The dynamics of collective leadership and strategic change in pluralistic organizations." Academy of Management Journal 44(4): 809-837.

DiMaggio, P. J. (1988). Interest and agency in institutional theory. Institutional patterns and organizations - Culture and environment. L. G. Zucker. Cambridge, MA, Ballinger Publishing company: 3-22.

DiMaggio, P. J. and W. W. Powell (1983). "The Iron Cage Revisited: Institutional Isomorphism and Collective Rationality in Organizational Field." American Sociological Review 48: 147-160.

Dopson, S., L. FitzGerald, et al. (2002). "No Magic Targets! Changing Clinical Practice To Become More Evidence Based." Health Care Management Review 27(3): 35-47.

Downs, G. W. J. and L. B. Mohr (1976). "Conceptual issues in the study of innovation." Administrative Science Quarterly 21: 700-713.

Dranove, D. and M. A. Satterthwaite (2000). The industrial organization of health care markets. Handbook of Health Economics. A. J. Culyer and J. P. Newhouse. Amsterdam, Elsevier Science B.V. 1: 1093-1139.

Dranove, D., M. Shanley, et al. (1992). "Is hospital competition wasteful?" $\underline{\text { RAND }}$ Journal of Economics 23(2): 247-263.

Eddy, D. M. (2005). "Evidence-Based Medicine: A Unified Approach." Health Affairs 24(1): 9-17.

Eisenhardt, K. M. (1989). "Building Theories from Case Study Research." Academy of Management Review 14(4): 532-550.

Escarce, J. J. (1996). "Externalities in hospitals and physician adoption of a new surgical technology: An exploratory analysis." Journal of health economics 15: 715734.

Escarce, J. J., B. S. Bloom, et al. (1995). "Diffusion of laparoscopic cholecystectomy among general surgeons in the United-States." Medical Care 33(3): 256-271.

European_Observatory (2000). Health Care Systems in Transition - Switzerland, European_Observatory on Health Care Systems.

Evans, R. G. (1984). Strained Mercy: The Economics of Canadian Health Care. Toronto, Butterworths.

Fendrick, A. M. and J. S. Schwartz (1994). Physicians' Decisions Regarding in Acquisition of Technology. Adopting New Medical Technology. A. C. Gelijns and H. V. Dawkins. Washington, National Academy of Sciences: 71-84.

Fennel, M. L. (1984). "Synergy, influence, and information in the adoption of administrative innovations." Academy of Management Journal 27(1): 113-129.

Ferlie, E., L. Fitzgerald, et al. (2005). "The Non Spread of Innovations : The mediating role of professionals." Academy of Management Journal 48(1): 117-134. 
Fitzgerald, L., E. Ferlie, et al. (2002). "Interlocking interactions, the diffusion of innovations in health care." Human Relations 55(12): 1429-1449.

Fligstein, N. (1985). "The spread of the multidivisional form among large firms, 19191979." American Sociological Review 50: 377-391.

Foote, S. B. (1992). Medical Arms Race - Public Policy and Medical Device Innovation. Berkeley, University of California Press.

Fournier, M.-A. (2001). "Les politiques de main d'oeuvre médicale au québec: bilan 1970-2000." Ruptures, Revue transdisciplinaire en santé 7(2): 79-98.

Friedland, R. and R. R. Alford (1991). Bringing society back in: Symbols, practices, and institutional contradictions. The new institutionalism in organizational analysis. W. W. Powell and P. J. DiMaggio. Chicago, University of Chicago Press.

Fuchs, V. R. (1996). "Economics, values, and health care reform." American Economic Review 86(1): 1-24.

Gelijns, A. and N. Rosenberg (1994). "The dynamics of technological change in medicine." Health Affairs 13(3): 28-46.

Gelijns, A. C., L. D. Brown, et al. (2005). "Evidence, politics, and technological change." Health Affairs 24(1): 29-40.

Glouberman, S. and H. Mintzberg (2001). "Managing the Care of Health and the Cure of Disease-Part I: Differentiation." Health Care Management Review 26(1): 56.

Glynn, M. A. and M. Lounsbury (2005). "From the critics' corner: Logic blending, discursive change and authenticity in a cultural production system." Journal of Management Studies 42(5): 1031-1055.

Gouvernement_du_Québec (2008). The Québec Health and Social Services System In Brief, Direction des communications, ministère de la Santé et des Services sociaux.

Granovetter, M. s. (1973). "The strength of weak ties." American Journal of Sociology 78: $1360-1380$.

Greenhalgh, T., G. Robert, et al. (2005). Diffusion of innovations in health service organizations - A systematic literature review. Oxford, Blackwell Publishing.

Greenhalgh, T., G. Robert, et al. (2004). "Diffusion of innovations in service organizations: Systematic review and recommendations." The Milbank Quarterly 82(4): 581-629.

Greenwood, R., R. Suddaby, et al. (2002). "Theorizing change: The role of professional associations in the transformation of institutionalized fields." Academy of Management Journal 45(1): 58-80.

Greer, A. L. (1984). "Medical technology and professional dominance theory." Social Science and Medecine 18(10): 809-817.

Greer, A. L. (1988). "The State of the Art Versus the State of the Science - The Diffusion of New Medical Technologies into Practice." International Journal of Technology Assessment in Health Care 4: 5-26. 
Greer, A. L. (1994). "Scientific Knowledge and Social consensus." Controlled Clinical Trials 15: 431-436.

Gruber, J., J. Kim, et al. (1999). "Physician fees and procedure intensity: the case of cesarean delivery." Journal of Health Economics 18: 473-490.

Gruber, J. and M. Owings (1996). "Physician financial incentives and cesarean section delivery." RAND Journal of Economics 27(1): 99-123.

Hardy, C. and S. R. Clegg (1996). Some dare call it power. Handbook of organization studies. S. R. Clegg, C. Hardy and W. R. Nord. London, Sage Publications.

Hardy, C. and S. Maguire (2008). Institutional Entrepreneurship. The Sage handbook of organizational institutionalism. R. Greenwood, C. Oliver, R. Suddaby and K. Sahlin-Anderson. Thousand Oaks, CA, Sage.

Hargadon, A. B. and Y. Douglas (2001). "When innovations meet institutions: Edison and the design of the electric light." Administrative Science Quarterly 46: 476-501.

Henderson, R. M. and K. B. Clark (1990). "Architectural innovation: The reconfiguration of existing product technologies and the failure of established firms." Administrative Science Quarterly 35(1): 9-30.

Hickson, D. J., R. J. Butler, et al. (1986). Top decisions - Strategic decision-making in organizations. San-Francisco, CA, Jossey-Bass.

Hillman, A. L. and J. S. Schwartz (1985). "The adoption and diffusion of CT and MRI in the United-States - A comparative analysis." Medical Care 23(11): 1283-1294.

Hillman, B. D., C. R. Neu, et al. (1987). "The diffusion of magnetic resonance imaging scanners in a changing U.S. health care environment." International Journal of Technology Assessment in Health Care 3(4): 545-559.

Hutchison, B., J. Abelson, et al. (2001). "Primary Care in Canada: So Much Innovation, So Little Change." Health Affairs 20(3): 116-131.

Intignano, B. M. (2001). Économie de la santé. Paris, Presses Universitaires de France. James, A. E., S. Perry, et al. (1991). "The diffusion of medical technology: free enterprise and regulatory models in the USA." Journal of medical ethics 17: 150-155.

Kitchener, M. (2002). "Mobilizing the logic of managerialism in professional fields: The case of academic health centre mergers." Organization Studies 23(3): 391-420.

Klein, K. J. and J. S. Sorra (1996). "The challenge of innovation implementation." Academy of Management Review 21(4): 1055-1080.

Kraatz, M. S. and E. S. Block (2008). Organizational Implications of Institutional Pluralism. Handbook of Organizational Institutionalism. R. Greenwood, C. Oliver, R. Suddaby and K. Sahlin-Andersson. London, Sage.

Langley, A. (1999). "Strategies for theorizing from process data." Academy of Management Review 24(4): 691-710.

Latour, B. (1989). La Science en action. Paris, La découverte. 
Lawrence, P. R. and J. W. Lorsch (1967). Organization and environment - Managing differentiation and Integration. Boston, Harvard University Press.

Lawrence, T. and R. Suddaby (2006). Institutions and institutional work. Handbook of Organization Studies. S. Clegg, C. Hardy, W. R. Nord and T. Lawrence. Thousand Oaks, CA, Sage.

Leblebici, H., G. R. Salancik, et al. (1991). "Institutional Change and the Transformation of Interorganizational Fields: An Organizational History of the US Radio Broadcasting Industry ASQ." Administrative Science Quarterly 36: 333-363.

Lee, M. L. (1971). "A conspicuous production theory of hospital behavior." $\underline{\text { Southern }}$ Economic Journal 39(1): 48-58.

Lehoux, P. (2006). The problem of health technology. New York: NY, Routledge.

Lehoux, P. and S. Blume (2000). "Technology Assessement and the Sociopolitics of Health Technologies." Journal of Health Politics and Law 25(6).

Lemieux, V., P. Bergeron, et al. (2003). Le système de santé du Québec. Saint-Nicolas (Québec), Les Presses de l'Université de Montréal.

Locock, L., S. Dopson, et al. (2001). "Understanding the role of opinion leaders in improving clinical effectiveness." Social Science and Medicine 53: 745-757.

Lounsbury, M. (2002). "Institutional transformation and status mobility: The professionalization of the field of finance." Academy of Management Journal 45(1): 255-266.

Lounsbury, M. (2007). "A tale of two cities: Competing logics and practice variation in the profesionalizing of mutual funds." Academy of Management Journal 30(2): 280307.

Lowndes, V. and C. Skelcher (1998). "The dynamics of multi-organizational partnerships: An analysis of changing modes of governance." Public Administration 76: 313-333.

Lozeau, D., A. Langley, et al. (2002). "The Corruption of Managerial Techniques by Organizations." Human Relations 55(5): 537-564.

Luft, H. J., J. C. Robinson, et al. (1986). "The role of specialized clinical services in competition among hospitals." Inquiry 23(1): 83-94.

Maguire, S. (2002). "Discourse and Adoption of Innovations: A Study of HIV/AIDS Treatments." Health Care Management Review 27(3): 74-88.

Maguire, S., C. Hardy, et al. (2004). "Institutional entrepreneurship in emerging fields: HIV/AIDS treatment advocacy in Canada." Academy of Management Journal 47(5): 657-679.

McClellan, M. and D. Kessler (2002). Technological Change in Health Care - A Global Analysis of Heart Attack. Ann Arbor, University of Michigan Press.

Merton, R. K. (1957 (1949)). Social Theory and Social Structure. New York, The Free Press. 
Meyer, A. D. and J. B. Goes (1988). "Organizational assimilation of innovations: A multilevel contextual analysis." Academy of Management Journal 31(4): 897-923.

Meyer, J. W. and B. Rowan (1977). "Institutionalized organizations: Formal structure as myth and ceremony." American Journal of Sociology 83(2): 340-363.

Miles, M. B. and A. M. Huberman (1994). Qualitative Data Analysis - An Expanded Sourcebook. Thousand Oaks CA, SAGE.

Munir, K. A. and N. Phillips (2005). "The birth of the 'Kodak Moment': Institutional entrepreneurship and the adoption of new technologies." Organization Studies 26(11): $1665-1687$.

Nelson, R. R., M. Peck, et al. (1967). Technology, Economic Growth, and Public Policy. Washington, The Brookings Institution.

Newhouse, J. P. (1992). "Medical care costs: how much welfare loss?" Journal of Economic Perspectives 6(3): 3-21.

OECD (2006). Reviews of health systems - Switzerland. Paris, Organization for economic co-operation and development: 190.

OECD (2006). "Source data - Statistics and indicators for 30 countries."

Office_fédérale_de_la_statistique (2004). Tableaux des statistiques de santé Statistiques des hôpitaux et des établissements de santé non hospitaliers 2002. Actualités OFS - Complément d'information:Section de la santé.

Oliver, C. (1991). "Strategic responses to institutional processes." Academy of Management Review 16(1): 145-179.

Oliver, C. (1992). "The Antecedents of deinstitutionalization." Organization Studies 13(4): 563-588.

Patton, M. Q. (2002). Qualitative Research \& Evaluation Methods. Thousands Oaks, Sage.

Pfeffer, J. and G. R. Salancik (2003 (1978)). The external control of organizations. Stanford, CA, Stanford University Press.

Phillips, N., T. B. Lawrence, et al. (2004). "Discourse and institutions." Academy of Management Review 29(4): 635-652.

Pinch, T. J. and W. E. Bijker (1987). The social construction of facts and artifacts: Or how the sociology of science and the sociology of technology might benefit each other. The social construction of technological systems. W. E. Bijker, T. P. Hughes and T. J. Pinch. Cambridge, MA, The MIT Press: 17-50.

Ranson, S., C. R. Hinings, et al. (1980). "The structuring of organizational structures." Administrative Science Quarterly 25(1): 1-17.

Rapoport, J. (1978). "Diffusion of technological innovation among nonprofit firms: a case study of radio-isotopes in U.S. hospitals." Journal of Economics and Business 30(2): 108-118. 
Reay, T. and C. R. Hinings (2005). "The recomposition of an organizational field: Health care in Alberta." Organization Studies 26(3): 351-384.

Renshaw, L. R., J. R. Kimberly, et al. (1990). Technological diffusion and ecological analysis: The case of Magnetic Resonance Imaging. Innovations in Health Care Delivery: Insights for organization theory. S. S. Mick, and Associates. San Francisco, Jossey-Bass: 181-206.

Robinson, J. C., D. W. Garnick, et al. (1987). "Market and regulatory influences on the availability of coranary angioplasty and bypass-surgery in United-States hospitals." New England Journal of Medicine 317(2): 85-90.

Rodriguez, C., A. Langley, et al. (2007). "Governance, power, and mandated collaboration in an interorganizational network." Administration \& Society 39(2): 150193.

Rogers, E. M. (2003). Diffusion of Innovations. New York, The Free Press.

Rohren, E. M. and R. E. Coleman (2004). "Clinical applications of PET in oncology." Radiology 231: 305-332.

Rosenau, P. V. (2000). "Managing medical technology: lessons for the United States from Quebec and France." International Journal of Health Services 30(3): 617-639.

Ryan, B. and N. Gross (1943). "The diffusion of hybrid seed corn in two Iowa communities." Rural Sociology 8(1): 15-24.

Sackett, D. L., W. S. Richardson, et al. (1997). Evidence-based medicine. New York, Churchill-Livingstone.

Schenzler, C. (1998). The effect of competition and regulation on the diffusion of major medical technologies in German and United States hospitals. Faculty of the Graduate School of Vanderbilt University. Nashville, Tennessee, Vanderbilt University: 221.

Schumpeter, J. A. (1944). Capitalism, Socialism, and Democracy. London, George Allen \& Unwin LTD.

Scott, W. R. (2001). Institutions and Organizations. Thousand Oaks, CA, Sage.

Scott, W. R. (2004). Competing logics in health care: Professional, State, and Managerial. The sociology of the economy. F. Dobbin. New York, Russell Sage Foundation: 267-287.

Scott, W. R. (2008). Institutions and organizations - Ideas and interests. Thousands Oaks, CA, Sage Publications.

Scott, W. R., M. Ruef, et al. (2000). Institutional change and healthcare organizations From professional dominance to managed care. Chicago, The University of Chicago Press.

Shane, S. (1995). "Uncertainty avoidance and the preference for innovation championing roles." Journal of international business studies 26(1): 47- 68 .

Shaneyfelt, T. M., M. F. Mayo-Smith, et al. (1999). "Are guidelines following guidelines?" Journal of American Medical Association 281(20): 1900-1905. 
Strang, D. and J. W. Meyer (1993). "Institutional conditions for Diffusion." Theory and Society 22: 487-511.

Strang, D. and S. A. Soule (1998). "Diffusion in organizations and social movements: From hybrid corn to poison pills." Annual Review of Sociology 24: 265-309.

Strauss, A. and J. Corbin (1998). Basics of qualitative Research. Thousand Oaks, Sage.

Streeck, W. and W. Schmitter (1985). Private interest government - Beyond market and state. London, Sage Publications.

Suchman, M. C. (1995). "Managing legitimacy: Strategic and institutional approaches." Academy of Management Review 20(3): 571-610.

Suddaby, R. and R. Greenwood (2005). "Rhetorical Strategies of Legitimacy." Administrative Science Quarterly 35: 35-67.

Thornton, P. H. (2002). "The rise of the corporation in a craft industry: Conflict and conformity in institutional logics." Academy of Management Journal 45(1): 81-101.

Thornton, P. H. and W. Ocasio (1999). "Institutional logics and the historical contingency of power in organizations: Executive succession in the higher education publishing industry, 1958-1990." American Journal of Sociology 105(3): 801-843.

Thornton, P. H. and W. Ocasio (2008). Institutional Logics. The SAGE Handbook of Organizational Institutionalism. R. Greenwood, C. Oliver, K. Sahlin and R. Suddaby. London, Sage Publications: 99-129.

Timmermans, S. and A. Mauck (2005). "The promises and pitfalls of evidence-based medicine." Health Aff (Millwood) 24(1): 18-28.

Tolbert, P. S. and L. G. Zucker (1983). "Institutional sources of change in the formal structure of organizations: the diffusion of civil service reform, 1880-1935." Administrative Science Quarterly 30: 22-39.

Tolbert, P. S. and L. G. Zucker (1996). The institutionalization of institutional Theory. The Handbook of Organization Studies. S. Clegg, C. Hardy and W. Nord. Thousand Oaks, CA, Sage: 175-190.

Tuohy (1999). "Dynamics of a changing health sphere: The Unites States, Britain, and Canada." Health Affairs 18(3): 114-134.

Vaara, E., J. Tienari, et al. (2006). "Pulp and paper fiction: on the discursive legitimation of global industrial restructuring." Organization Studies 27(6): 789-810.

Valente, T. W. (1996). "Social network threshold in the diffusion of innovations." Social Networks 18(1): 69-89.

Valente, T. W. and E. M. Rogers (1995). "The origins and development of the diffusion of innovations paradigm as an example of scientific growth." Science Communication 16(3): 242-273.

Vogt, W. B., J. Bhattacharya, et al. (1995). Diagnostic Technology and Competition. Health economics of Japan: patients, doctors, and hospitals under a universal health insurance program. Tokyo, University of Tokyo Press: 171-185. 
Walston, S. L., J. R. Kimberly, et al. (2001). "Institutional and Economic Influences on the Adoption and Extensiveness of Managerial Innovation in Hospitals: The Case of Reengineering." Medical Care Research and Review 58(2): 194-228.

Westphal, J. D., R. Gulati, et al. (1997). "Customization or Conformity? An Institutional and Network Perspective on the Content and Consequences of TQM Adoption." Administrative Science Quarterly 42(2): 366-394.

WHO (2000). The World Health Report 2000 - Health systems: Improving performance. Geneva, World Health Organization.

Williamson, O. E. (1981). "The economics of organization: The transaction cost approach." American Journal of Sociology 87(3): 548-577.

Wolfe, R. A. (1994). "Organizational Innovation: Review, Critique and Suggested Research Directions." Journal of Management Studies 31(3): 405-431.

Yin, R. K. (2003). Case Study Research - Design and Methods. Thousand Oaks CA, SAGE.

Zilber, T. B. (2002). "Institutionalization as an interplay between actions, meanings, and actors: The case of a rape crisis center in Israel." Academy of Management Journal 45(1): 234-254.

Zilber, T. B. (2006). "The work of the symbolic in institutional processes: Translations of rational myths in Israeli high tech." Academy of Management Journal 49(2): 281303.

Zilber, T. B. (2008). The work of meaning in institutional processes and thinking. Sage Handbook of Organizational Institutionalism. R. Greenwood, C. Oliver, K. Sahlin and R. Suddaby. London, U.K., Sage Publications: 151-169. 
APPENDIX A

INTERVIEW GUIDE FOR THE DIFFUSION OF THE PET SCANNER 


\section{Interview Guide for the Diffusion of the PET scanner in Switzerland}

\section{Présentation}

1.1. Cheminement de carrière?

1.2. Responsabilités actuelles / à l'époque de l'adoption du TÉP?

2. L'innovation

2.1. Qu'est-ce que la TÉP?

2.2. Pour quels patients (indications) recommanderiez-vous le TÉP?

3. Réseau

3.1. Quelles connaissances ou expérience aviez-vous de la TÉP avant son adoption par votre organisation?

3.2. Quelles ont été vos sources d'information qui vous ont convaincu ou non d'adopter la TÉP?

3.3. Qui avait les connaissances / l'expérience de la TÉP à qui vous ou votre organisation s'est référées avant l'adoption?

3.4. Que représente cette personne au sein de l'organisation (compétence, charisme...)?

4. Processus d'adoption

4.1. Qu'est-ce qui a stimulé l'intérêt de la TÉP comme nouvelle technologie diagnostique :

4.1.1. en Suisse?

4.1.2. dans la région?

4.1.3. dans votre établissement?

4.1.3.1. Données scientifiques

4.1.3.2. Qualité des soins

4.1.3.3. Diminution des coûts hospitaliers

4.1.3.4. Meilleure efficience

4.1.3.5. Stakeholders

4.1.3.6. Réputation

4.1.3.7. Profits

4.2. La position de votre organisation face à cette innovation?

4.3.

4.3.1. Pourquoi? département?

4.3.2. Depuis quand?

4.4. Pouvez-vous identifier les groupes internes impliqués dans le dossier?

4.5. Votre rôle dans l'adoption de la TÉP au niveau de votre organisation, de la Suisse?

4.6. Décrire comment s'est déroulée l'adoption de la TÉP en Suisse?

4.6.1. Événements clés

4.6.2. Acteurs clés

4.7. Comment en êtes-vous arrivé à adopter la TÉP dans votre établissement?

4.8. Qui sont (ont été) les promoteurs / à l'adoption de la TÉP?

4.9. $\quad$ opposants?

4.9.1. Radiologues, médecins, infirmières

4.9.2. Commune

4.9.3. Canton

4.9.4. Confédération

4.9.5. Groupes de patients

4.10. Quels bénéfices perçoivent ces groupes dans l'adoption de la TÉP?

4.11. risques

4.12. Quel est (sont) l'argument clé qui a convaincu vous ou vos collègues?

4.13. Le ou les éléments qui ont soulevé le plus de enthousiasme / face à l'adoption de la TÉP? 
4.14. Le ou les éléments qui ont soulevé le plus de résistance / face à l'adoption de la TÉP?

4.15. L'adoption de la TÉP se fait-il par des canaux formels ou informels? Comment?

\section{Impact de l'adoption}

5.1. La TÉP a engendré quel type de changement dans la pratique des professionnels (médecins, infirmières, préposés)?

5.1.1. Organisation du travail

5.1.2. Heures de travail

5.1.3. Charge de travail

5.1.4. Relation avec le patient / intervenant

5.1.5. Responsabilité médicale envers patients

5.1.6. Coûts pour le système de santé

5.1.7. Coûts assumés par les patients

5.1.8. Rémunération des professionnels

5.2. En quoi l'adoption de la TÉP change-t-elle les rôles, responsabilités et pouvoir des acteurs (changement organisationnel)?

6. Environnement institutionnel

6.1. Pouvez-vous identifier la position des principaux groupes / organisations institutionnels qui interviennent dans ce dossier?

6.2. Quel a été le rôle [...] dans l'adoption de cette technologie par votre organisation?

6.3. pour les autres organisations?

6.3.1. Confédération Suisse

6.3.2. Cantons / Santé publique

6.3.3. Communes

6.3.4. Politiques de santé

6.3.5. Incitatifs financiers

6.3.6. Incitatifs politiques

6.3.7. Hôpitaux de la région

6.3.8. Association des hôpitaux / professionnelles / de médecine nucléaire (AMN)

6.3.9. Organismes privés

6.3.10. Organismes communautaires

6.3.11. Organisations de patients

6.3.12. Réseau / Agence d'évaluation des technologies

6.3.13. Office fédéral des assurances sociales

6.3.14. Compagnies d'assurance

6.3.15. Institut Suisse des produits pharmaceutiques

6.3.16. Organisme régulant le nucléaire

6.4. La TÉP a engendré quel type de changement pour le système de santé Suisse? 6.4.1. Coûts pour le système de santé

6.4.2. Coûts assumés par les patients

6.5. Quel impact a eu l'adoption du TÉP sur la dynamique régionale?

7. Controverses, bénéfices et désavantages

7.1. Selon vous, existe-t-il suffisamment de preuves scientifiques et/ou cliniques concernant l'efficacité de la TÉP? Pourquoi?

7.2. Quels sont les aspects du TÉP qui sont controversés ou qui pourraient l'être? 7.2.1. Coûts

7.2.2. L'efficacité d'autres méthodes diagnostiques

7.2.3. Relations entre les professionnels / spécialistes

8. $\quad$ Autres

8.1. Qui au Canton, industrie privée, Direction générale

8.2. À quels endroits la TÉP est-elle utilisée? Depuis quand? Autres informateurs? 

APPENDIX B

CONSENT FORM 


\section{CONSENT FORM - PET SCANNER}

Being asked to participate to this research project, please read carefully the following text. Feel free to ask any question you might have to the interviewer before taking your final decision to participate to this research.

Title of the Research: Institutional Environment and the Diffusion of Complex Innovations in Health Care

\section{Identification of the Research Team Members:}

Ann Langley, HEC Montreal, Full Professor; 514-340-7748; ann.langley@,hec.ca

Alberto Holly, HEC Lausanne, Full Professor; +41 (0)21 692 34 82; alberto.holly@unil.ch

Stéphane Guérard, HEC Lausanne, PhD student; +41 (0)21 69233 18;

stephane.guerard@unil.ch

\section{Short Description of the Research Project:}

This research will develop a better understanding of the dynamic of contextual factors intervening in the diffusion pattern of complex innovations in the health care sector. It will strive to appreciate why an apparently desirable complex innovation - the PET scanner diffuses more easily in one jurisdiction over another. To do so, Switzerland and Quebec institutional environments are to be compared. Taking into account the institutional environment, this study will certainly lead to defining more realistic health care policies.

In this context, you are invited to participate to an interview of 60 to 90 minutes which will be recorded. The themes of the interview will be: the mechanic of the PET scanner technology; the adoption and diffusion process of this technology; the impact of the institutional environment; the actors involved in the adoption; its impact on the organization of work; and controversies, benefits and disadvantages of the PET scanner.

\section{The Respect of Ethical Principals:}

You can be sure that all information you provide will stay confidential. All persons who will have access to this information have already signed a confidentiality commitment. These persons are Ann Langley, Alberto Holly, Stéphane Guérard, and the person in charge of transcribing the interview. The files containing data and transcriptions are to be kept in a safe place. Moreover, no information allowing retracing the identity of participants will be divulged at any moment. Considering the themes that will be explored and the measures of confidentiality taken, participating to this research project should be without prejudice to you, and should not provide you with direct benefits.

Finally, in the eventuality that the management of your organization gave its consent for this research to take place, and that your name was suggested for you to participate, you must not, in any case, feel you have to participate to this research. If you refuse to participate, your decision will not be communicated to your employer. Your participation is totally voluntary.

\section{Signature of the Participant:}

Having read and understood the above text, and having had the opportunity to receive supplementary information, I consent to participate to an interview lead by Stéphane Guérard. I know that I can refuse to answer any question. Also, I know that I can put an end to the interview, which will cancel my consent and will forbid the researcher to use the collected data in this interview.

Name and first name of the participant: 
APPENDIX C

EXAMPLES OF DATA ANALYSIS 


\begin{tabular}{|c|c|c|}
\hline $\begin{array}{l}\text { THEORIZATION } \\
\text { COMPONENTS }\end{array}$ & $\begin{array}{c}\text { Stand-alone PET } \\
\text { Access-based logic } \\
\text { Promoters: Regional hospitals, Association of Nuclear Doctors }\end{array}$ & $\begin{array}{c}\text { PET-CT } \\
\text { Quality-based logic } \\
\text { Promoters: Teaching hospitals }\end{array}$ \\
\hline $\begin{array}{l}\text { What to adopt? } \\
\text { Definition of the } \\
\text { innovation }\end{array}$ & $\begin{array}{l}\text { - PET as a proven clinical tool needed by all regardless of location } \\
\text { «La TEP c'est une instrumentation qui est avant tout clinique. » }\end{array}$ & $\begin{array}{l}\text { - PET-CT as a high-performing proven clinical and research tool } \\
\text { "PET-CT is a research and clinical tool" }\end{array}$ \\
\hline Why adopt? & - $\quad$ PET scan for all & - $\quad$ Better quality diagnoses \\
\hline $\begin{array}{l}\text { Moral legitimation } \\
\text { essentially grounded in } \\
\text { equity of access-based } \\
\text { arguments vs. quality- } \\
\text { based arguments }\end{array}$ & $\begin{array}{l}\text { "Chemotherapy is hard as a treatment. That's why with the PET scanner, } \\
\text { we can evaluate whether local radiotherapy or chemotherapy would be } \\
\text { better and protect the child from suffering. [...] Just think if you have a } 12 \\
\text { year-old child who needs radiotherapy and you have to send them to the big } \\
\text { city. It's torture." } \\
\text { "Ça a pas de bon sens prendre des enfants de } 2 \text { ans de l'hôpital F [de la } \\
\text { région A] et les transférer à l'hôpital THB. » } \\
\text { "L'hôpital THB avait une certaine expertise mais là, on est pas pour acheter } \\
\text { une flotte d'autobus pour transférer la province à l'hôpital THB.» } \\
\text { "c'est une question de qualité de médecine. [Ne pas avoir de PET] c'est de } \\
\text { la mauvaise médecine d'un point de vue éthique. » } \\
\text { "Le TEP c'est incontournable» }\end{array}$ & $\begin{array}{l}\text { "A PET scanner will locate the tumor... in the body but not in a specific way. It will say: it } \\
\text { is there. But with the CT, we can take a tomographic image which will locate the tumor in } \\
\text { the tissue so we can see exactly where it is." } \\
\text { "We would pay the extra because there are not only significant medical benefits in getting } \\
\text { PET-CT but there's actually a cost justification for reducing the scan time using CT." } \\
\text { "Il y a quand meme un avantage quand meme un avantage de précision.» } \\
\text { "Avantage clinique, plus grande capacité locale. " } \\
\text { "Mais ils ne comprennent pas qu'il y a encore un gros développement qui est à faire [et } \\
\text { qu'il ne faut pas en mettre partout].» }\end{array}$ \\
\hline $\begin{array}{l}\text { Competing } \\
\text { interpretations of } \\
\text { efficiency-based logic } \\
\text { tied to access-based and } \\
\text { quality-based arguments } \\
\text { respectively }\end{array}$ & $\begin{array}{l}\text { - Low purchase costs and lower travel costs with greater equity } \\
\text { and access } \\
\text { "Oncology is permanent. You have your cancer, you come back, you are re- } \\
\text { evaluated. There's a lot of travelling. So the PET will allow the } \\
\text { regionalization of care, keeping resources, people, and avoiding excessive } \\
\text { travel costs." } \\
\text { "The Association favours the dedicated PET cameras that are twice as } \\
\text { cheap [than PET-CT], but everyone would get one." } \\
\text { "[With PET] we can save } \$ 15,000-\$ 20,000 \text { for people we operate on } \\
\text { unnecessarily." } \\
\text { "Le cout d'acquisition et d'opération est moins dispendieux.» }\end{array}$ & $\begin{array}{l}\text { - Lower cost per examination with higher quality } \\
\text { "So, typically, if you look today at a typical hospital they take may be } 15-20 \text { minutes to do } \\
\text { the attenuation correction a piece [with a standalone PET scanner] versus } 30 \text { seconds [with } \\
\text { a PET-CT]. [...] [Moreover], The FDG cost per patient is significantly less." } \\
\text { "An ordinary PET scanner can do about six or seven patients per day. With the PET-CT, } \\
\text { we can go up to } 12 \text { so we can double the volume. " }\end{array}$ \\
\hline $\begin{array}{l}\text { Asymmetric } \\
\text { naturalization arguments }\end{array}$ & & $\begin{array}{l}\text { - Inevitability of PET-CT } \\
\text { "[In the conference] basically nobody was speaking of standalone PET. Nobody. [...] I } \\
\text { can't think of a single institution that has actively gone to tender for standalone PET." } \\
\text { "...in that meeting were people like professor X from London from United kingdom. He } \\
\text { has been the president of the European association of nuclear medicine, a very large } \\
\text { scientific body of people and they have no doubt that the PET-CT is the way to go." }\end{array}$ \\
\hline
\end{tabular}




\begin{tabular}{|c|c|c|}
\hline $\begin{array}{l}\text { Who should adopt and } \\
\text { how? } \\
\text { Distribution based on } \\
\text { equity (access-based } \\
\text { logic) vs. competence } \\
\text { (quality-based logic). }\end{array}$ & $\begin{array}{l}\text { - PET for all, coherence with prior distribution of oncology centres } \\
\text { "Better give everyone a good Chrysler than giving a Ferrari to } 3 \text { or } 4 \text { people, } \\
\text { that's what we wanted at the Association." } \\
\text { «C'est un examen du noyau dur de l'hôpital. Ça devrait être public, a affirmé } \\
\text { le Dr A. Le TEP devrait être installé partout où il y a de l'oncologie. » } \\
\text { "With the government, we proposed that the } 15,000 \text { exams that were } \\
\text { necessary per year in oncology, that the } 12 \text { first pieces of equipment be } \\
\text { installed in the regional centres for oncology as the government had already } \\
\text { done it." } \\
\text { "Ce qu'on a proposé c'est qu'il y ait un déploiement dans les centres où il y } \\
\text { avait de la radiothérapie pour que l'unité soit en médecine nucléaire. » }\end{array}$ & $\begin{array}{l}\text { - Competence has to be developed first before allowing adoption } \\
\text { "They'll say, «I am a Cessna pilot, I can also pilot a 747.” People will say that, but it makes } \\
\text { no sense! (..) They'll say: “It's not complicated - I'll put it on automatic pilot.” OK, but is } \\
\text { that the function of a } 747 \text { pilot? So you'll place your life in the hands of someone who } \\
\text { doesn't have the expertise necessary to make complex and major adjustments that a } \\
\text { technology like that requires." } \\
\text { "Les gens qui n'ont pas de formation dans le domaine de la TEP, qui ont tout de même } \\
\text { une formation en médecine nucléaire, ils pensent que c'est nécessairement tout facile. Ils } \\
\text { minimisent le travail de mise en œeuvre. Ils voient les belles images, ça a l'air facile et ils } \\
\text { disent je suis capable de faire ça. » } \\
\text { "On a toujours tendance au Québec de vouloir en saupoudrer un peu partout. Le PET } \\
\text { scan ce n'est pas juste un appareil. Il y a tout l'aspect humain qui est autour de ça. L'aspect } \\
\text { humain ça veut dire des médecins qui sont capables de lire, des techniciens qui sont } \\
\text { capables... des physiciens qui sont capables de l'opérer, du personnel technique pour le } \\
\text { faire fonctionner. Ça c'a ne se crée pas en deux temps trois mouvements. Il faut former des } \\
\text { équipes centrales et après décentraliser ça. Idéalement, ça serait de dire oui on prévoit en } \\
\text { avoir } 10 \text { ou } 12 \text { au Québec. Sauf qu'on va faire ça par étape. On va commencer par bien } \\
\text { équiper les gros centres universitaires avec des bonnes équipes qui vont être capable de } \\
\text { former d'autres équipes par la suite et ainsi de suite. La pensée magique de dire on va en } \\
\text { ouvrir } 10 \text { demain matin puis que ça va tout marcher là, ça c'a va tuer la technique. Ça c'est } \\
\text { garantie que ça tue la technique et dans deux ans on en parle plus. Parce qu'il faut que ça } \\
\text { s'implémente, il faut que ce soit progressif. » }\end{array}$ \\
\hline
\end{tabular}




\begin{tabular}{|c|c|c|c|}
\hline \multicolumn{4}{|r|}{ Conditions behind Institutional Testing } \\
\hline Questions & Factors & Dimensions & Citations \\
\hline \multirow[t]{3}{*}{$\begin{array}{l}\text { What caused institutional } \\
\text { testing? }\end{array}$} & $\begin{array}{l}\text { Legitimacy of the } \\
\text { technology }\end{array}$ & $\begin{array}{l}\text { Large diffusion } \\
\text { abroad }\end{array}$ & $\begin{array}{l}\text { "Donc, les évidences.. Mais il y a ... est-ce que y a également.... le fait que.. je sais pas... la clinique Mayo aux États-Unis.... si soudainement y avaient un PET.... est-ce que le } \\
\text { fait...que des grandes ... institutions. Ça fait partie de lévidence. Quand tout le monde dit - On procéde - on achète... on y va..." }\end{array}$ \\
\hline & & $\begin{array}{l}\text { Adequacy of the } \\
\text { technology inside } \\
\text { this organizational }\end{array}$ & 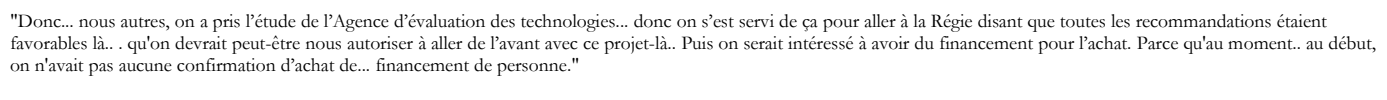 \\
\hline & & $\begin{array}{l}\text { Cancer as a } \\
\text { prioritiy disease }\end{array}$ & 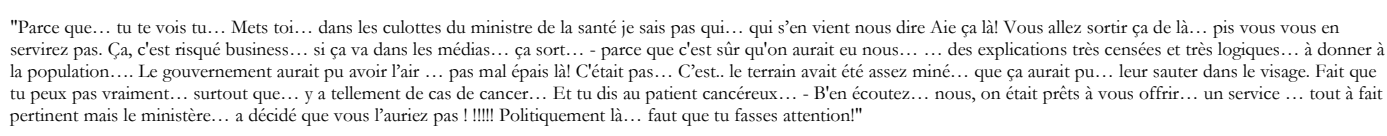 \\
\hline \multirow[t]{6}{*}{$\begin{array}{l}\text { What are the necessary } \\
\text { conditions? }\end{array}$} & $\begin{array}{l}\text { 1. Evolution of the } \\
\text { technology }\end{array}$ & & 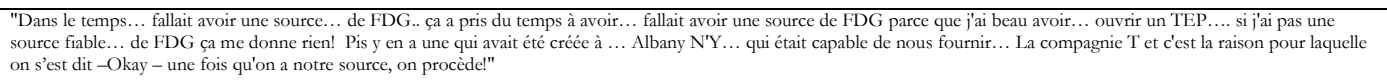 \\
\hline & 2. Financial resources & & $\begin{array}{l}\text { "Si on avait pas eu ce donateur là, dans le processus, c'auraiat été complètement différent - je pourrais pas dire comment... mais c'est clair que c'est ce qui a été l'élément déclencheur } \\
\text { ici..." }\end{array}$ \\
\hline & $\begin{array}{l}\text { 3. No more legitimate } \\
\text { ways available }\end{array}$ & & $\begin{array}{l}\text { "The deployment of PET scanners, I've been hearing about that for four years, and another announcement arrives every 15th of the month. I's the classic running gag. I've stopped } \\
\text { believing in that." }\end{array}$ \\
\hline & $\begin{array}{l}\text { 4. No regulative or } \\
\text { normative sanctions }\end{array}$ & & 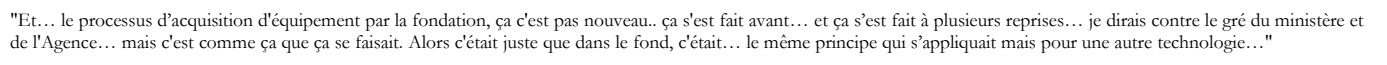 \\
\hline & & & $\begin{array}{l}\text { "Alors.. on avait. la nette impression qu'on portait préiudice à personne.... puisque la caméra était sous utilisée et que... on faisait un certain nombre de cas pour le privé. Et... et } \\
\text { donc, on pouvait exécuter plus de cas... et on réussissait à fonctionner un pue.. pis à a... offrii un service." }\end{array}$ \\
\hline & $\begin{array}{l}\text { 5. Alignment with } \\
\text { mission of the } \\
\text { organization }\end{array}$ & & $\begin{array}{l}\text { "Mais c'est notrer tôle d'être en avant... Cest nous autres qui forment lesé étudiants ... pas de ce temps-ci... mais en général... Alors.. y a des médecins... autant les clinicieiens que des } \\
\text { nucléistes... qui disaient - faudrait qu'on ait cette technologie là au teaching hospital THA1." }\end{array}$ \\
\hline $\begin{array}{l}\text { What are the facilitating } \\
\text { factors? }\end{array}$ & $\begin{array}{l}\text { Competence inside the } \\
\text { organization }\end{array}$ & & Et c'est évident que quand taas des médecins spécialilisés en tes murs pour... cette technologie là.. eux autres en veulent une caméra $\ldots$ sont formés pour ça! \\
\hline \multirow[t]{2}{*}{ Why did it spread? } & Mimetic isomorphism & & GHA, Y ont fait exactement la même chose que nous autres. Y ont répliqué le même modèle. \\
\hline & $\begin{array}{l}\text { Competition between } \\
\text { organizations }\end{array}$ & & 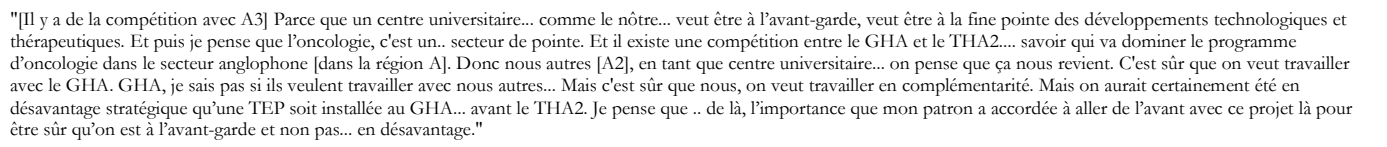 \\
\hline $\begin{array}{l}\text { Why was it a successful } \\
\text { strategy (consequences)? }\end{array}$ & $\begin{array}{l}\text { Speed up adoption } \\
\text { process }\end{array}$ & & Adopting without the consent of the government is a strategy to get a PET. Otherwise, we would nave not get one or wait a long time before getting one. \\
\hline
\end{tabular}


